Portland State University

PDXScholar

Fall 12-7-2017

\title{
Technology Planning for Aligning Emerging Business Models and Regulatory Structures: the Case of Electric Vehicle Charging and the Smart Grid
}

Kelly R. Cowan

Portland State University

Follow this and additional works at: https://pdxscholar.library.pdx.edu/open_access_etds

Part of the Power and Energy Commons, and the Technology and Innovation Commons Let us know how access to this document benefits you.

Recommended Citation

Cowan, Kelly R., "Technology Planning for Aligning Emerging Business Models and Regulatory Structures: the Case of Electric Vehicle Charging and the Smart Grid" (2017). Dissertations and Theses. Paper 4031. https://doi.org/10.15760/etd.5915

This Dissertation is brought to you for free and open access. It has been accepted for inclusion in Dissertations and Theses by an authorized administrator of PDXScholar. Please contact us if we can make this document more accessible: pdxscholar@pdx.edu. 


\title{
Technology Planning for Aligning Emerging Business Models \\ and Regulatory Structures - The Case of Electric Vehicle Charging \\ and the Smart Grid
}

by

Kelly R. Cowan

\begin{abstract}
A dissertation submitted in partial fulfillment of the
\end{abstract} requirements for the degree of

\author{
Doctor of Philosophy \\ in \\ Technology Management
}

\author{
Dissertation Committee: \\ Tugrul Daim, Chair \\ Alan Yeakley \\ Jisun Kim \\ Steven Walsh
}

Portland State University

2017 
(C) 2017 Kelly R. Cowan 


\begin{abstract}
Smart grid has been described as the Energy Internet: Where Energy Technology meets Information Technology. The incorporation of such technology into vast existing utility infrastructures offers many advantages, including possibilities for new smart appliances, energy management systems, better integration of renewable energy, value added services, and new business models, both for supply- and demand-side management. Smart grid also replaces aging utility technologies that are becoming increasingly unreliable, as the average ages for many critical components in utility systems now exceed their original design lives. However, while smart grid offers the promise of revolutionizing utility delivery systems, many questions remain about how such systems can be rolled out at the state, regional, and national levels. Many unique regulatory and market structure challenges exist, which makes it critical to pick the right technology for the right situation and to employ it in the right manner. Technology Roadmapping may be a valuable approach for helping to understand factors that could affect smart grid technology and product development, as well as key business, policy and regulatory drivers. As emerging smart grid technologies are developed and the fledgling industry matures, a critical issue will be understanding how the combination of industry drivers impact one another, what barriers exist to achieving the benefits of smart grid technologies, and how to prioritize R\&D and acquisition efforts. Since the planning of power grids often relies on regional factors, it will also be important investigate linkages between smart grid deployment and regional planning goals. This can be used to
\end{abstract}


develop strategies for overcoming barriers and achieving the benefits of this promising new technology. This research builds upon existing roadmapping processes by considering an integrated set of factors, including policy issues, which are specifically tuned to the needs of smart grids and have not generally been considered in other types of roadmapping efforts. It will also incorporate expert judgment quantification to prioritize factors, show the pathways for overcoming barriers and achieving benefits, and discussing the most promising strategies for achieving these goals. 


\section{DEDICATION}

I dedicate this work to my parents, Rosemarie Spading Cowan and Daniel William Cowan. You were my first teachers, the ones who showed me how to dream big, encouraged me to learn, and always believed in me. You taught me learn from success and failure. Thank you for everything you have helped me to do in life. 


\section{ACKNOWLEDGMENTS}

I want to acknowledge and give thanks to the many people who helped me to complete this work. To my partner, Kenya, your love and support sustains me and keeps me motivated. To my brother, Aaron, thank you for always being the person I could talk to about anything. To my advisor, Tugrul, you helped me in countless ways, but mainly just kept pushing me to succeed and never stopped believing I could do it. To my longtime mentor and committee member, Steve, your mixture of humor, honesty, and humanity made you someone I could always count on for advice, help, and understanding. To Sul, who passed away this year, you helped set me on my path and I will miss you. To my committee member, Alan, you were always fair and open-minded and showed remarkable dedication in continuing to stay on my committee even after you left PSU. To my committee member, Jisun, you showed the understanding and compassion that can only come from someone who has completed the ETM program and is now willing to help others overcome its challenges. To all the people at PSU and in the ETM program who helped me, there are too many of you to list, but I remember and appreciate you. To Ibrahim, Nima, and Muhammad, you helped me clarify my thinking for my research and motivated me to finish. To Edwin, Joao, and Chih-Jen, you have

always been voices of encouragement and I appreciate it. To Shawn, your humanity and kindness represents the best of our Department. 


\section{TABLE OF CONTENTS}

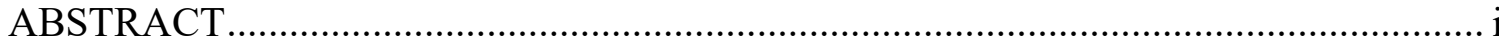

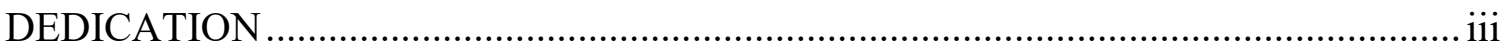

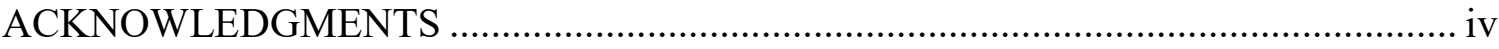

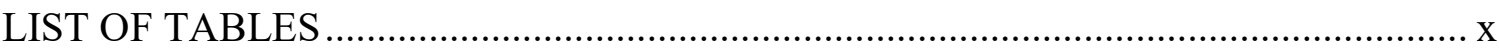

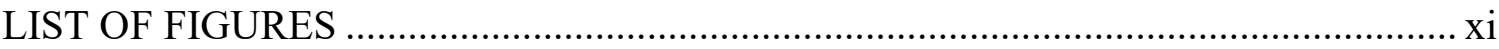

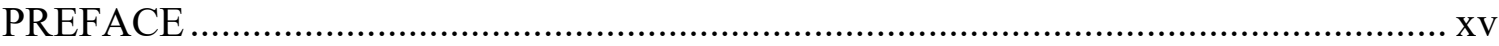

CHAPTER 1: Introduction .............................................................................. 1

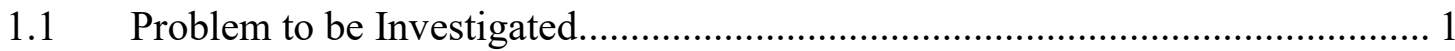

1.1.1 Research Problem Description..................................................... 3

1.1.2 Initial Research Objectives ........................................................... 3

1.1.3 Significance of the Research............................................................ 4

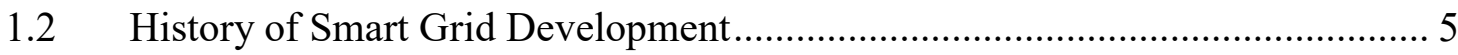

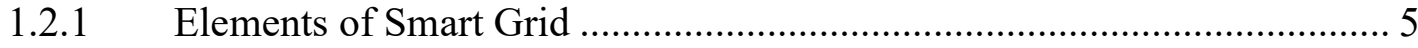

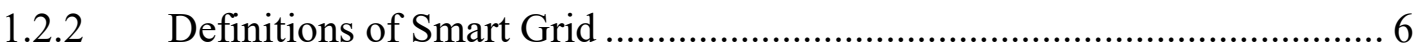

1.2.3 What Technologies are Included in Smart Grid?.................................. 13

1.2.4 An Integrated Approach to Smart Grid Roadmapping .......................... 15

1.2.5 Roadmapping and Key Driving Factors ......................................... 19

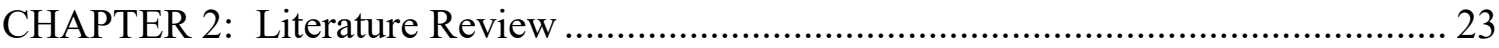

2.1. Smart Grid Roadmapping Literature .................................................. 23

2.2. Influences on the Smart Grid Landscape in Oregon \& the Pacific Northwest. 28 
2.3. Developing Smart Grid Roadmaps for Oregon \& the Pacific Northwest......... 32

2.4. Expert Input: Charrette Process .................................................................... 33

2.5. Future Smart Grid Roadmap Development Process ................................... 36

2.5.1. Preliminary Roadmap for Sub-Industry in Smart Grid Sector................. 37

2.6. Conclusions on Preliminary Smart Grid Roadmap Development ................... 41

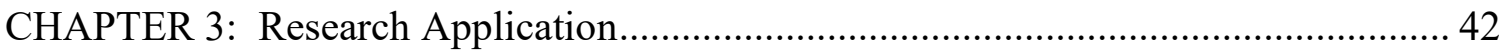

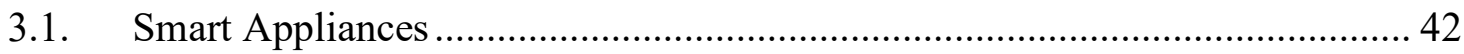

3.2. Electric Vehicles as Smart Appliances ................................................... 44

3.3. Electric Vehicle Smart Charging and Vehicle-to-Grid ................................ 51

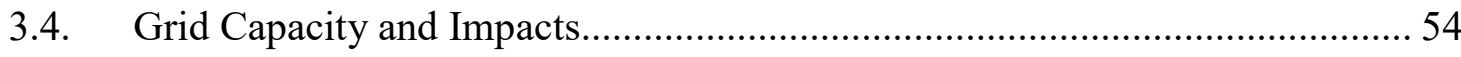

3.5. Smart Grid and Renewable Energy Integration ........................................... 56

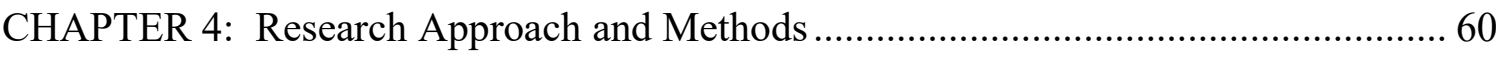

4.1. Technology Roadmapping for Business and Regulatory Integration: The Case

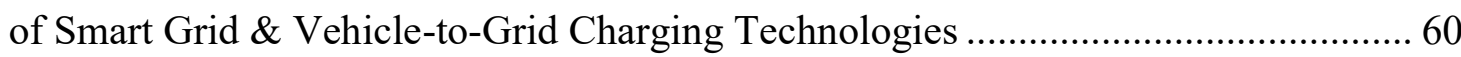

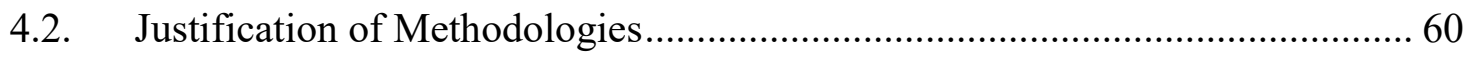

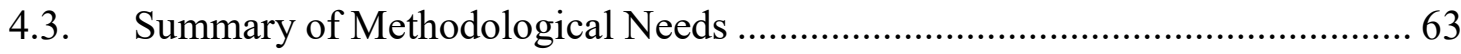

4.3.1. Methodological Needs: Technology Roadmapping Literature ................. 64

4.3.2. Methodological Needs: Smart Grid \& Electric Vehicle Literature .......... 66

4.3.3. Methodological Needs: Resource Planning \& Policy Literature .............. 69

4.3.4. Research Gaps, Goals, and Questions.............................................. 71

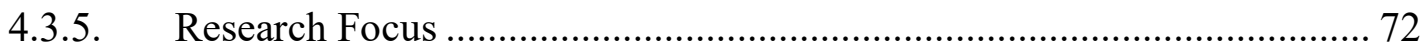

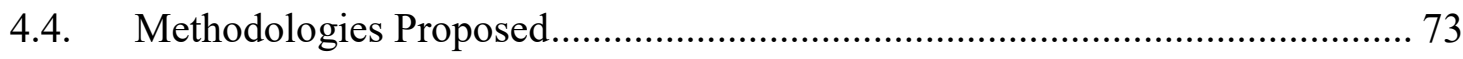

4.4.1. Business Concept Development ....................................................... 73 


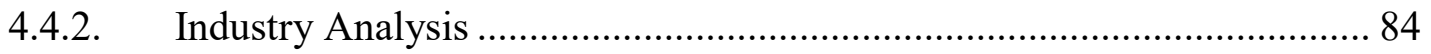

4.4.3. TRM Construction \& Prioritization .......................................................... 99

4.4.4. Conclusions on Methodologies............................................................ 111

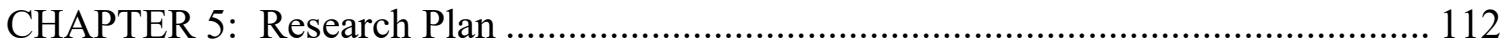

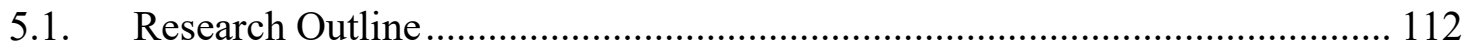

5.2. Preliminary Research Activities .............................................................. 114

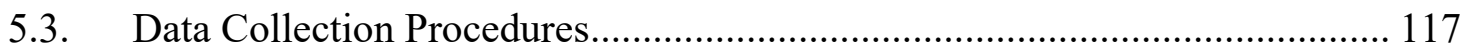

CHAPTER 6: Research Validity and Reliability ........................................................... 123

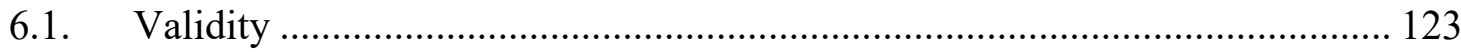

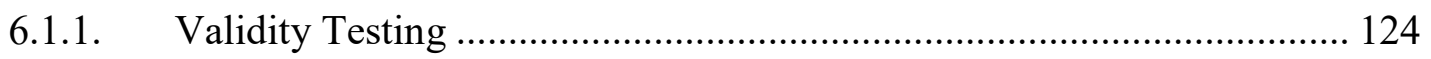

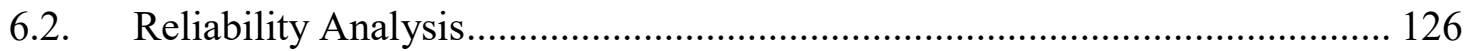

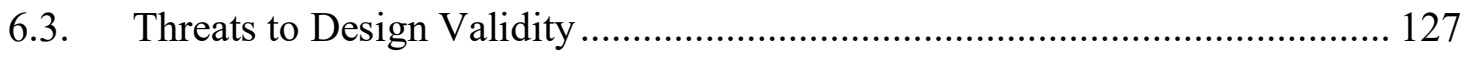

6.4. Validity and Reliability Results ................................................................ 129

6.4.1. Validating Data Collection Instrument and Reliability Results.............. 129

CHAPTER 7: Results for Electric Vehicle Case Study .................................................. 132

7.1. Business Concept Development for Electric Vehicle Case Study .................. 132

7.2. Industry Analysis for Electric Vehicle Case Study........................................ 143

7.3. Roadmap Construction \& Prioritization ...................................................... 157

7.3.1. TRM Needs and Tools for this Study .................................................. 158

7.3.2. Technology Roadmap Model............................................................. 165

7.3.3. Analysis of Alternatives........................................................................ 179

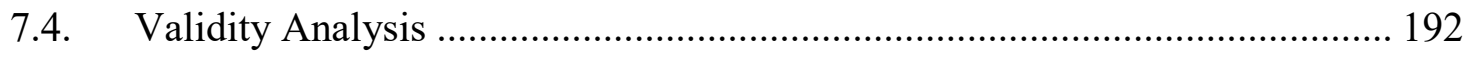

CHAPTER 8: Research Outcomes, Conclusions, and Recommendations ..................... 195 


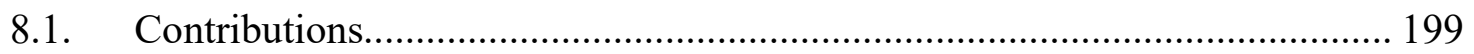

8.2. Assumptions Limitations and Future Work ……………………………...... 202

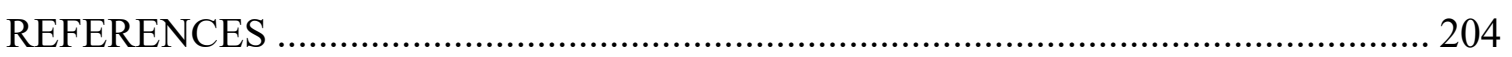

APPENDIX A: US Sales of Leading BEVs and PHEVs from 2010 to 2017 ............... 223

APPENDIX B: Definitions of Smart Grid Technology and Investment Terms ............. 224

APPENDIX C: Human Subjects Waiver Request ........................................................ 237

APPENDIX C1: Human Subjects Waiver Request - Sample Instruments .................... 242

APPENDIX C2: Human Subjects Waiver Request - Consent Form ............................. 252

APPENDIX C3: Human Subjects Waiver Request - Release Form.............................. 254

APPENDIX D: Research Approach ....................................................................... 255

APPENDIX D1: Research Approach - Summary ................................................... 256

APPENDIX D2: Research Approach - Cover Letter ...................................................... 261

APPENDIX D3: Research Approach - Workshop Requirements List .......................... 266

APPENDIX D3-0: Research Approach - Workshop Requirements (Pre-Testing)....... 268

APPENDIX D3-1: Research Approach - Workshop Requirements (Business Concept

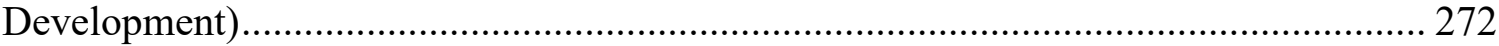

APPENDIX D3-2: Research Approach - Workshop Requirements (Industry Analysis

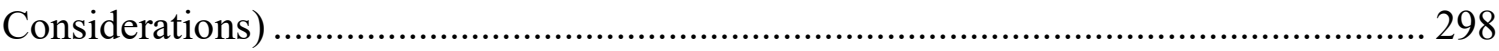

APPENDIX D3-3: Research Approach - Workshop Requirements (Roadmapping \&

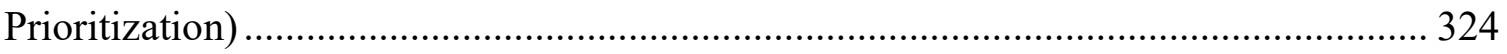

APPENDIX D3-4: Research Approach - Workshop Requirements (Analysis \&

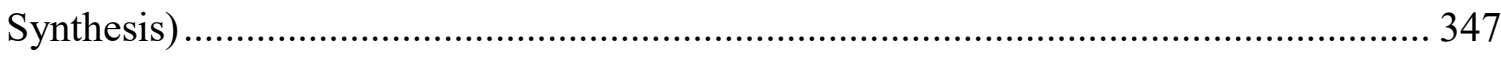

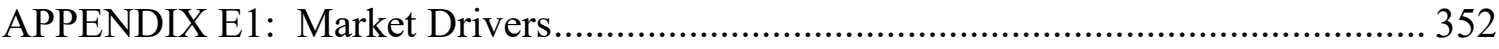




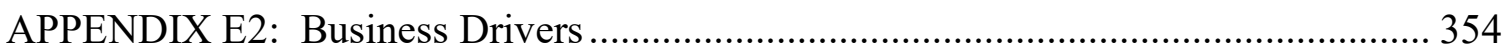

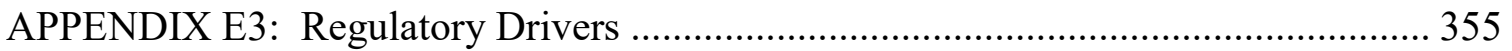

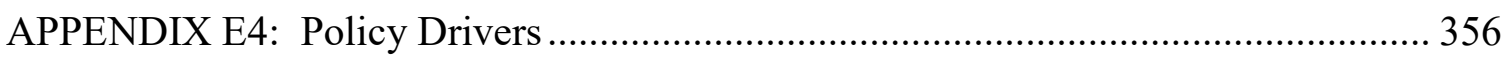

APPENDIX F1: Roadmapping - Problem Characteristics .............................................. 357

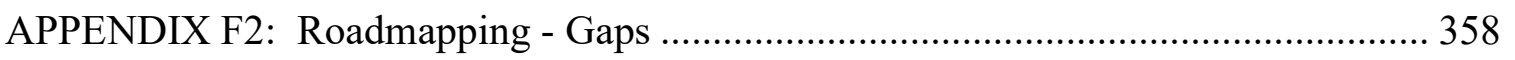

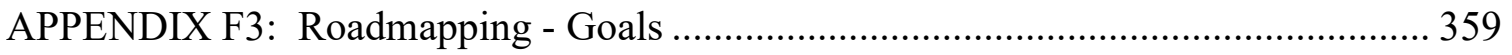

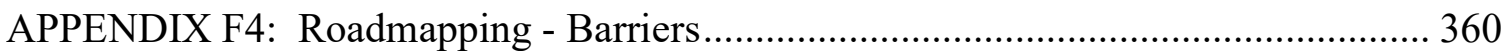

APPENDIX F5: Roadmapping - Business Development............................................. 362

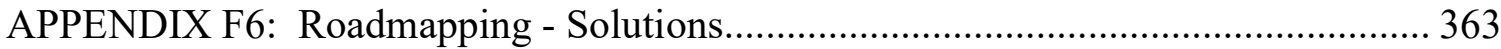

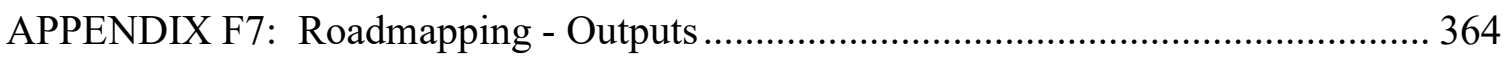

APPENDIX F8: Roadmapping - Market Development.................................................. 365

APPENDIX F9: Roadmapping - Business Development............................................ 366

APPENDIX F10: Roadmapping - Research \& Development ........................................ 367

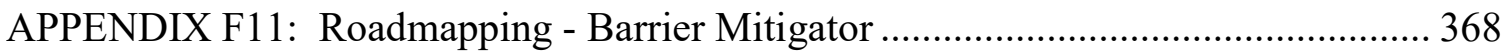

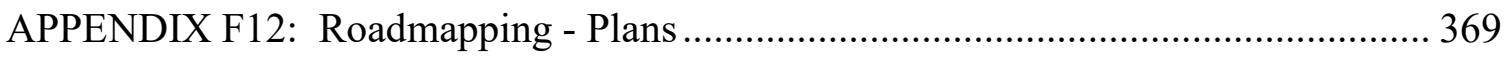

APPENDIX F13: Roadmapping - Technologies …………………………………...... 370

APPENDIX F14: Roadmapping - Barrier Element ...................................................... 371

APPENDIX G1: Investor-Owned Business Structures .................................................. 372

APPENDIX G2: Utility-Owned Business Structures .................................................... 374

APPENDIX G3: Third Party / Aggregator-Owned Structures ........................................ 375 


\section{LIST OF TABLES}

Table 1.1: Estimated Costs and Benefits of U.S. Smart Grid Deployment .................... 11

Table 2.1: Prominent Smart Grid Roadmaps or Studies in the US............................... 24

Table 3.1: Percentages of EVs versus Total Vehicles Sales in 2016............................ 49

Table 3.2: US EV Sales as a Percentage of World Totals (2014 to 2017) ...................... 50

Table 3.3: Characteristics of EV Supply Equipment (EVSE / Chargers) ...................... 51

Table 6.1: Workshop Data Collection Instruments................................................ 125

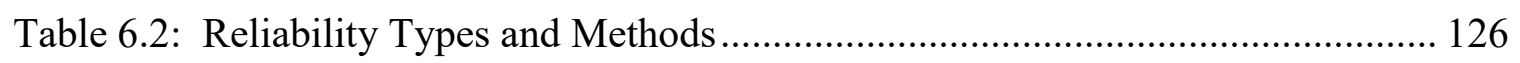

Table 6.3: Reliability and Validity Analysis Plan ............................................... 128

Table 6.4: Instrument Validation - Business Concept Development........................... 129

Table 6.5: Instrument Validation - Industry Analysis.......................................... 130 


\section{LIST OF FIGURES}

Figure 1.1: Traditional Electric Utility Structure - One-way System .............................. 7

Figure 1.2: Smart Grid Electric Structure - Two-way System.......................................... 7

Figure 1.3: Functional Views of Smart Grid Communication Channels............................ 8

Figure 1.4: Investment Required for a Fully Functioning Smart Grid .......................... 12

Figure 1.5: Key Elements and Drivers Contributing to Smart Grid ................................ 14

Figure 1.6: Why an Integrated Approach to Smart Grid Roadmapping is Needed ......... 15

Figure 1.7: Electric Market Restructuring ………………......................................... 17

Figure 1.8: Market Maturation Process …………………......................................... 18

Figure 1.9: Balancing Planning Perspectives in Regulated Industries ........................... 21

Figure 2.1: Smart Grid Influences in Oregon \& the Pacific Northwest............................ 28

Figure 2.2: Expert Input - Benefits vs. Barriers for Smart Grid in the Pacific Northwest 36

Figure 2.3: Preliminary Roadmap Inputs for Demand Response Technology ................ 39

Figure 3.1: Flexibility Supply Curve for Renewable Energy Integration......................... 58

Figure 4.1: Technology Roadmapping Literature Gaps .................................................. 64

Figure 4.2: Smart Grid \& Electric Vehicle Literature Gaps ........................................... 67

Figure 4.3: Resource Planning \& Policy Literature Gaps.................................................. 69

Figure 4.4: Summary of Research Gaps, Goals, and Questions ...................................... 71

Figure 4.5: Focal Area for Research .......................................................................... 73

Figure 4.6: Stakeholder-Objective Matrix for e-Bike Pilot Study ................................... 75 
Figure 4.7: Business Sub Model Matrix for e-Bike Pilot Study .................................. 79

Figure 4.8: Opportunities \& Perspectives in e-Bike Pilot Study ................................ 81

Figure 4.9: Business Structure \& Goals Summary in e-Bike Pilot Study ..................... 82

Figure 4.10: Industry Analysis for e-Bike Pilot Study …....................................... 87

Figure 4.11: Business-Stakeholder Alternatives for e-Bike Pilot Study....................... 89

Figure 4.12: Industry Factor Alternatives for e-Bike Pilot Study............................... 93

Figure 4.13: Static \& Dynamic Business Models for e-Bike Pilot Study...................... 97

Figure 4.14: Grouped Drivers - Market and Business ............................................ 101

Figure 4.15: Grouped Drivers - Regulatory and Policy........................................ 102

Figure 4.16: Market, Business / Regulatory vs. Product \& Goals .............................. 103

Figure 4.17: Products \& Goals vs. Technologies \& Barriers Grid .............................. 104

Figure 4.18: Technologies \& Barriers vs. Research, Development, and Barrier Mitigation 105

Figure 4.19: Sample Regional EVSC Model ....................................................... 106

Figure 4.20: Sample TRM for e-Bike Pilot Study .................................................. 109

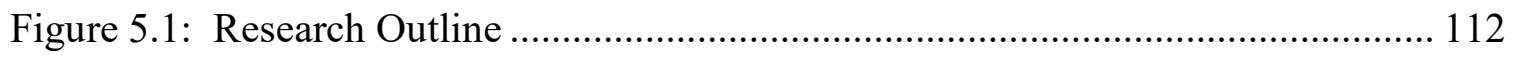

Figure 5.2: Panel 1 - Business Concept Development.............................................. 115

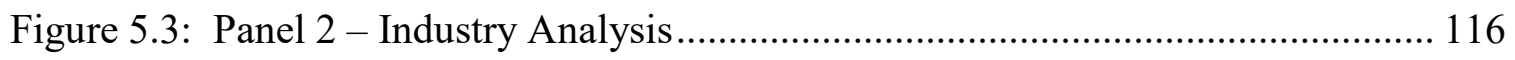

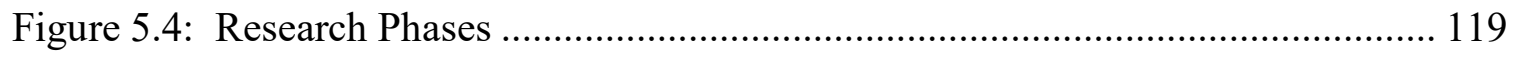

Figure 7.1: Stakeholder-Objective Matrix for EV Study ......................................... 134

Figure 7.2: Business Sub Model Matrix for EV Study ….................................... 138

Figure 7.3: Opportunities \& Perspectives in EV Study ...................................... 140

Figure 7.4: Industry Analysis for EV Study .......................................................... 145 
Figure 7.5: Business-Stakeholder Alternatives for EV Study .................................... 148

Figure 7.6: Industry Factor Alternatives for EV Study.............................................. 152

Figure 7.7: Static \& Dynamic Business Models for EV Study..................................... 155

Figure 7.8: Grouped Drivers - Market and Business .................................................... 159

Figure 7.9: Grouped Drivers - Regulatory and Policy ................................................... 160

Figure 7.10: Market, Business, Regulatory \& Policy vs. Plans and Outputs ................. 161

Figure 7.11: Plans \& Outputs vs. Technologies \& Barriers ........................................... 162

Figure 7.12: Technologies and Barriers vs. R\&D and Barrier Mitigation...................... 163

Figure 7.13: Integrated TRM Model - Electric Vehicle Charging - Part 1................... 168

Figure 7.14: Integrated TRM Model - Electric Vehicle Charging - Part 2.................... 169

Figure 7.15: Integrated TRM Model - Electric Vehicle Charging - Part 3 ……............. 170

Figure 7.16: Integrated TRM Model - Electric Vehicle Charging - Part 1a.................. 173

Figure 7.17: Integrated TRM Model - Electric Vehicle Charging - Part 1b.................. 173

Figure 7.18: Integrated TRM Model - Electric Vehicle Charging - Part 2a.................. 175

Figure 7.19: Integrated TRM Model - Electric Vehicle Charging - Part 2b.................. 176

Figure 7.20: Integrated TRM Model - Electric Vehicle Charging - Part 3a.................. 177

Figure 7.21: Integrated TRM Model - Electric Vehicle Charging - Part 3b.................. 177

Figure 7.22: Business Model Specifications............................................................. 180

Figure 7.23: Business Model vs. TRM Comparison Table - Investor-Owned ............... 181

Figure 7.24: Business Model vs. TRM Comparison Chart - Investor-Owned .............. 185

Figure 7.25: Business Model vs. TRM Comparison Table - Utility-Owned.................. 186

Figure 7.26: Business Model vs. TRM Comparison Chart - Utility-Owned .................. 187

Figure 7.27: Business Model vs. TRM Comparison Table - Aggregator Owned......... 188 
Figure 7.28: Business Model vs. TRM Comparison Chart - Aggregator-Owned ......... 189

Figure 7.29: Business Model vs. TRM Comparison Chart - Overall.......................... 190

Figure 7.30: Business Model vs. TRM Comparison Chart - S1, S2, S3 -Investor-Owned,

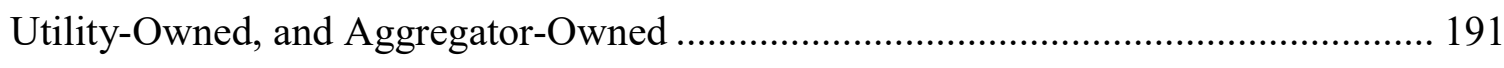

Figure 7.31: Validity - Roadmaps and Business Model Specifications........................ 193 


\section{PREFACE}

The study consists of eight chapters. Chapter 1 contains the introduction section. Chapter 2 includes a literature review about smart grid technologies and the factors affecting the development of roadmaps for its deployment. Chapter 3 presents the research application regarding technology planning for electric vehicle smart charging technologies for meeting of regional energy policy and planning goals. Chapter 4 describes the research approach and methods. Chapter 5 explains the research plan and outline. Chapter 6 discusses research validity and reliability. Chapter 7 sums up expected research outcomes. Finally, Chapter 8 discusses research outcomes, including

conclusions and recommendations, as well as assumptions, limitations, contributions, and future work. 


\section{CHAPTER 1: Introduction}

\subsection{Problem to be Investigated}

Electrical utility systems are part of a large and important industry in the U.S., with nearly $\$ 400$ billion in revenues in $2016[1,2]$. Smart grid technologies offer many promising benefits for the modernization of electrical power delivery systems. The following are just a few of the benefits offered by smart grid: (1) Improvement in operating efficiencies of electricity grids at all levels of the system; (2) Improvement of communications and controls within the power system for all actors, including generators, transmitters, system operators, distributors, and end-users; (3) Opportunities for new value-added services related to control and management of energy; (4) and increased system reliability by replacing obsolete hardware that is nearing the end of its useful service life [3]. With the average age of electrical transformers in the US power grid now at 42 years, out of a maximum design life of 40 years, critical elements of the power system are now at risk, and there is a strong need to modernize aging infrastructure for the power grid [4] [5].

Current power grids, especially in the United States, are being used well past their designed lifetime. Updates to these systems are important to address energy inefficiency, reliability, and security vulnerabilities of the 21 st century. It is possible to use the emerging technology smart grid technology product platform $[66,67]$ on many types of 
utility systems, including gas, water, and electricity delivery systems, but this research will focus only on smart electricity grids.

Power grid modernization offers the opportunity to implement technologies with new capabilities that may have been difficult or impossible in the past. From remotely operated energy management system, self-monitoring and self-healing systems, to smart electric vehicles, smart grid can open a myriad of new opportunities for businesses, consumers, and decision makers $[6,7]$. Therefore, it is critical to examine how smart grid is likely to develop in the future, what its effects may be, and to create a detailed roadmap showing how this vision might occur.

The next section will describe the smart grid industry and related technologies in greater detail. The need for development of roadmaps to guide the deployment of smart grid technologies will then be discussed, including current efforts in Oregon and the US Pacific Northwest. This field is very broad, so only a limited number of technologies and the capabilities they provide will be described, with an emphasis on technologies that are currently being introduced and seen as important in the region. In particular, this research will focus on how smart grid technologies can be used to meet key regional goals, such as enabling the integration of renewable energy, which according to recently enacted legislation, must now provide $25 \%$ of the energy mix in Oregon by $2025[8,9]$. Thus, the following questions will be specifically explored. 
What factors are most significant in motivating the adoption of smart grid technologies? How can important emerging smart technologies, like electric vehicles, be used to integrate renewable energy into the power system? What policies can encourage businesses and individuals to participate in such systems?

\subsubsection{Research Problem Description}

The topic described above raises a number of interesting questions that are important to explore both in the industry practitioner literature and the academic research literature. First, how can a tool such as technology roadmapping be extended to include a policy layer, business services model layer, and an expanded product market needs layer, which includes the ability to consider appropriate technology performance metrics. The research further raises the question of the interaction between technology push versus market pull. It then extends these concepts by considering how they might be affected by policy and business model push-pull dynamics.

\subsubsection{Initial Research Objectives}

1. How can technology roadmapping be used to improve regional smart grid planning? 
2. How can technology roadmapping be extended to better integrate technology planning, business model development, and regulatory and policy considerations for smart grid?

3. What are the best ways to encourage the adoption of emerging smart grid technologies that meet critical regional needs, such as the use of electric vehicles to help with the integration of renewable energy?

\subsubsection{Significance of the Research}

This research can provide insights to help planners understand which factors are most likely to promote diffusion and adoption of smart grid technologies and their use for the integration of renewable energy. It offers valuable extensions to the concept of technology roadmapping by integrating consideration of regulatory and policy issues, business model development, and technology research and development. It explores the interactions between traditional technology push and market pull dynamics by adding consideration of the policy and business model push-pull relationships. It then helps to build an understanding about how these factors inform one another to improve chances of successful deployment of technology. 


\subsection{History of Smart Grid Development}

The alternating current power grid used in the United States evolved primarily from technologies developed in the 1880's by industry pioneers, such as Edison, Tesla, Ansull, and Westinghouse [10]. Many of the core concepts used for developing early local grids, such as centralized unidirectional electric power transmission, are still common today, over 120 years later.

Smart grid differs from the traditional grid in a number of ways. Some of this distinction depends upon the definition of smart grid. At the most fundamental level, smart grid is a term for the application of modern technology components and design architectures to the power grid, mainly in the form of digital information and communication technologies [11].

Recent government policy has begun to recognize the importance of smart grid. According to Title XIII of the Energy Independence and Security Act of 2007, the United States Department of Energy identifies the following as key elements that collectively characterize smart grid [12]:

\subsubsection{Elements of Smart Grid}

1) Increased use of digital information and controls technology to improve reliability, security, and efficiency of the electric grid.

2) Dynamic optimization of grid operations and resources, with full cyber-security. 
3) Deployment and integration of distributed resources and generation, including renewable resources.

4) Development and incorporation of demand response, demand-side resources, and energy-efficiency resources.

5) Deployment of 'smart' technologies (real-time, automated, interactive technologies that optimize the physical operation of appliances and consumer devices) for metering, communications concerning grid operations and status, and distribution automation.

6) Integration of 'smart' appliances and consumer devices.

7) Deployment and integration of advanced electricity storage and peak-shaving technologies, including plug-in electric and hybrid electric vehicles, and thermalstorage air conditioning.

8) Provision to consumers of timely information and control options.

9) Development of standards for communication and interoperability of appliances and equipment connected to the electric grid, including the infrastructure serving the grid.

10) Identification and lowering of unreasonable or unnecessary barriers to adoption of smart grid technologies, practices, and services.

\subsubsection{Definitions of Smart Grid}

While these attributes are useful for describing what smart grid does, there is no commonly agree upon definition of what smart grid is. Many definitions are possible 
from the point of view of different stakeholders who are interested in a different aspect of smart grid systems.

From the point of view of utility companies, a critical distinction between the smart grid and traditional electricity systems is that while the traditional grid is a one-way system between the utility companies and end-users, smart grid allows an interactive twoway communication system. This is shown in the figure below.

Figure 1.1: Traditional Electric Utility Structure - One-way System

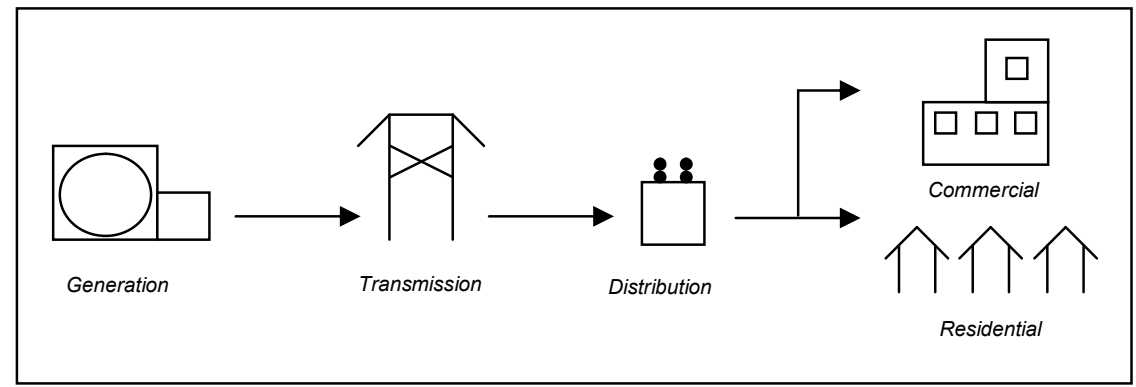

Source: Derived from EPRI [9]

Smart grid provides two-way communication among the components of the utility system. This is shown in the next figure.

Figure 1.2: Smart Grid Electric Structure - Two-way System

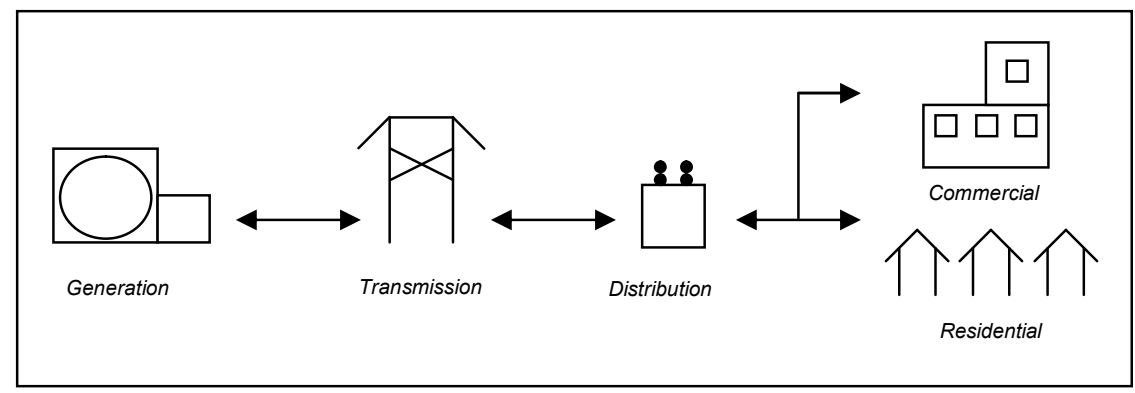

Source: Derived from EPRI [9] 
Two-way communication helps with the three key aspects of electrical utility systems: (1) Power Production (Generation); (2) Power Transport (Transmission); and (3) the Power Delivery to serve loads, or needs of end users (Distribution) [10]. It can also enable end-users to manage their energy use and participate in how the utility system operates. This leads to three different functional views of communication in utility systems, which are shown on the figure below.

Figure 1.3: Functional Views of Smart Grid Communication Channels

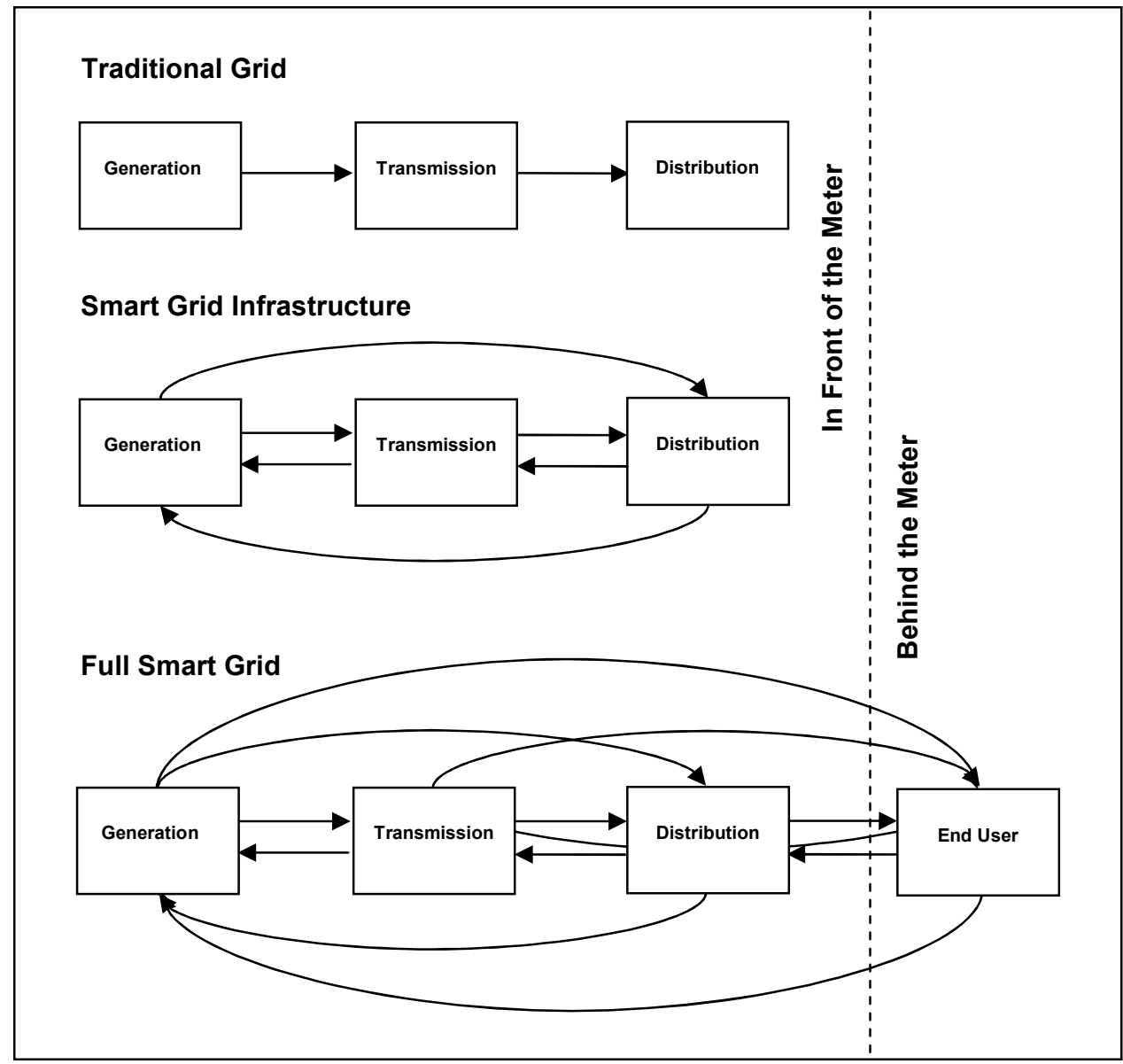

Source: Derived from Shively [10] and Warkentin-Glenn [13] 
The replacement of one-way communication enables a more robust and efficient utility system, or smart grid infrastructure. However, both the traditional grid and the new smart infrastructures enabled by two-way communication have generally focused only on delivery of electricity to the end-user's utility meter [10]. Anything the end-user does with the electricity after it has been delivered by the utility company is considered, in common industry parlance, to be "behind the meter," while utility companies have traditionally seen their role as providing the service "in front of the meter [13]." However, smart grid allows a new paradigm where customer energy management can affect the operations of the utility system as a whole, allowing generation, transmission, and distribution to be adjusted based on real time usage levels. Based on this viewpoint, realization of full smart grid requires an ability to address issues both in front and behind the meter. Thus, several different definitions of smart grid are possible based on the viewpoints of those involved.

Smart grid allows better coordination between the key components of the utility system, enabling better utilization of resources, and lower costs. Thus, it can be seen as a form of system level energy efficiency. System operators provide an additional function of managing the interactions between generation, transmission, and load serving entities in the utility system, as well as coordinating with regional transmission operators in the four major electrical interconnection systems in North America. Traditionally, many utilities have had vertically integrated structures, providing all of the generation, transmission, distribution, and system operation functions within their control areas [14]. Under a smart grid framework, the overall system can be operated by Independent 
System Operators (ISOs) at state or regional levels, as well as through power pools or traditional vertically integrated utilities.

Based on a utility systems viewpoint, the Electric Power Research Institute (EPRI) has offered the following definition of smart grid [15]:

"The overlaying of a unified communications and control system on the existing power delivery infrastructure to provide the right information to the right entity."

However, from the point of view of electricity end-users, smart grid is not all about infrastructure, and it does not stop with the delivery of power to their homes or businesses. It may also involve smart appliances that are part of Home Area Networks, which can manage energy usage based on time-of-use prices and minimize utility costs for consumers [16]. It may also include intelligent dashboards, or monitoring devices, which can keep track of and control energy usage. Some devices can even remotely control or schedule the operations of smart appliances across the Internet, or through mobile devices, like smart phones.

While utility companies can play a role in supporting such systems for consumers, from their point of view, a smart grid can exist regardless of whether end-users attach smart devices to it or not. But, from the end-user point of view, little difference would be seen between a smart grid and a traditional grid unless these end-use devices are present. 
Thus, author Thomas Friedman offers a more general, consumer-oriented definition of the smart grid as: "The Energy Internet: Where IT meets ET." The terms "IT" and "ET" here refer to "Information Technology" and "Energy Technology [17]."

With these two concepts in mind regarding a consumer-oriented smart grid definition, versus an industry-oriented smart grid, what are the key benefits of smart? What are the costs of such a system, and who will bear them? These costs and benefits are summarized on the table below.

Table 1.1: Estimated Costs and Benefits of U.S. Smart Grid Deployment

\begin{tabular}{|l|c|}
\hline & 20 Year Total (billion \$US) \\
\hline Net Investment Required & $338-476$ \\
\hline Net Benefit & $1,294-2,028$ \\
\hline Benefit to Cost Ratio & $2.7-6.0$ \\
\hline
\end{tabular}

Source: Derived from EPRI 2011 [18].

According to the above estimates, the cost to deploy smart grid technology in US utility control centers and connect them to consumers" homes could range between "\$338 billion and $\$ 476$ billion over the next 20 years [18]." However, the study projects " $\$ 1.3$ trillion to $\$ 2$ trillion in benefits over that period." Such benefits will include greater grid reliability, integration of renewable energy, plug-in vehicles, reductions in electricity demand, and stronger cybersecurity. Overall, benefits would be expected to outweigh costs by a factor of 2.7 to 6.0 . 
EPRI expects costs to fall most heavily on utility distribution systems that deliver power to retail customers. The breakdown of these costs is summarized in the figure below. Just over $71 \%$ of the expenses for the higher-cost estimate in this study would go toward upgrades of substations, lines, poles, meters, and retail billing and communication systems. Nearly $19 \%$ of total costs would go to upgrading high-voltage transmission, including installation of sensors to monitor potential failures in the system. Almost $10 \%$ of costs would go toward components that would be installed directly in the homes of residential consumers. The breakdown of these costs is summarized in the figure below.

Figure 1.4: Investment Required for a Fully Functioning Smart Grid

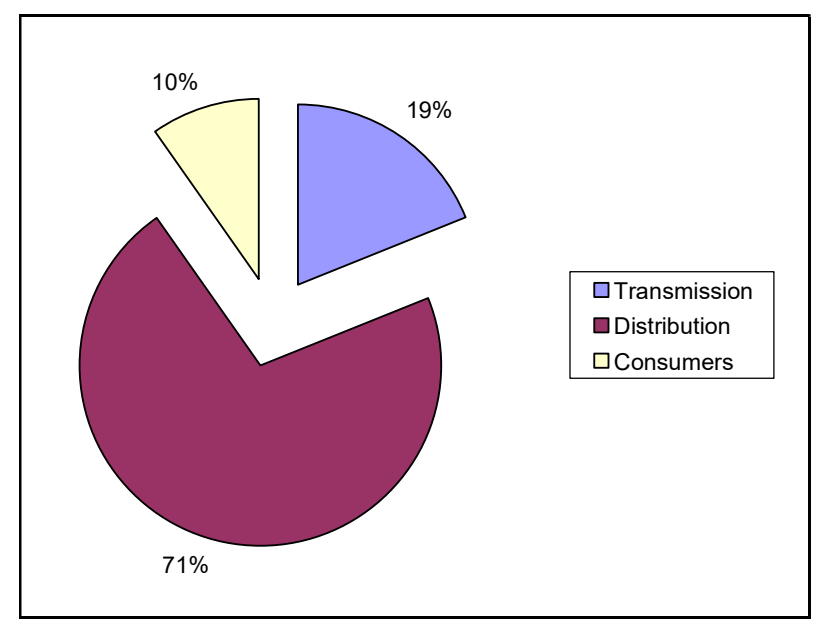

Source: Derived from EPRI 2011 [18]

Given the potential benefits of smart grid, it is important to plan for future deployment of such technology. Smart Grid technologies present enormous opportunities, but also challenges. Thus, section 2 below will explore what has currently been found in the literature regarding smart grid roadmapping efforts. However, first it is 
important to examine what is and is not included in smart grid. Several key types of technologies are briefly introduced in the next section and then further defined in the glossary in Appendix B.

\subsubsection{What Technologies are Included in Smart Grid?}

While the term "smart grid" has been in widespread use since at least 2005, it has not always been consistently used [19]. Smart grid is not a single thing, or an exact end state. It is a process of gaining more and more capabilities to improve upon the features that the electric utility industry has traditionally been able to offer for over a century. The figure below shows some of the key technologies that comprise smart grid, where they fit in the general smart landscape, and the main drivers affecting smart grid. 
Figure 1.5: Key Elements and Drivers Contributing to Smart Grid

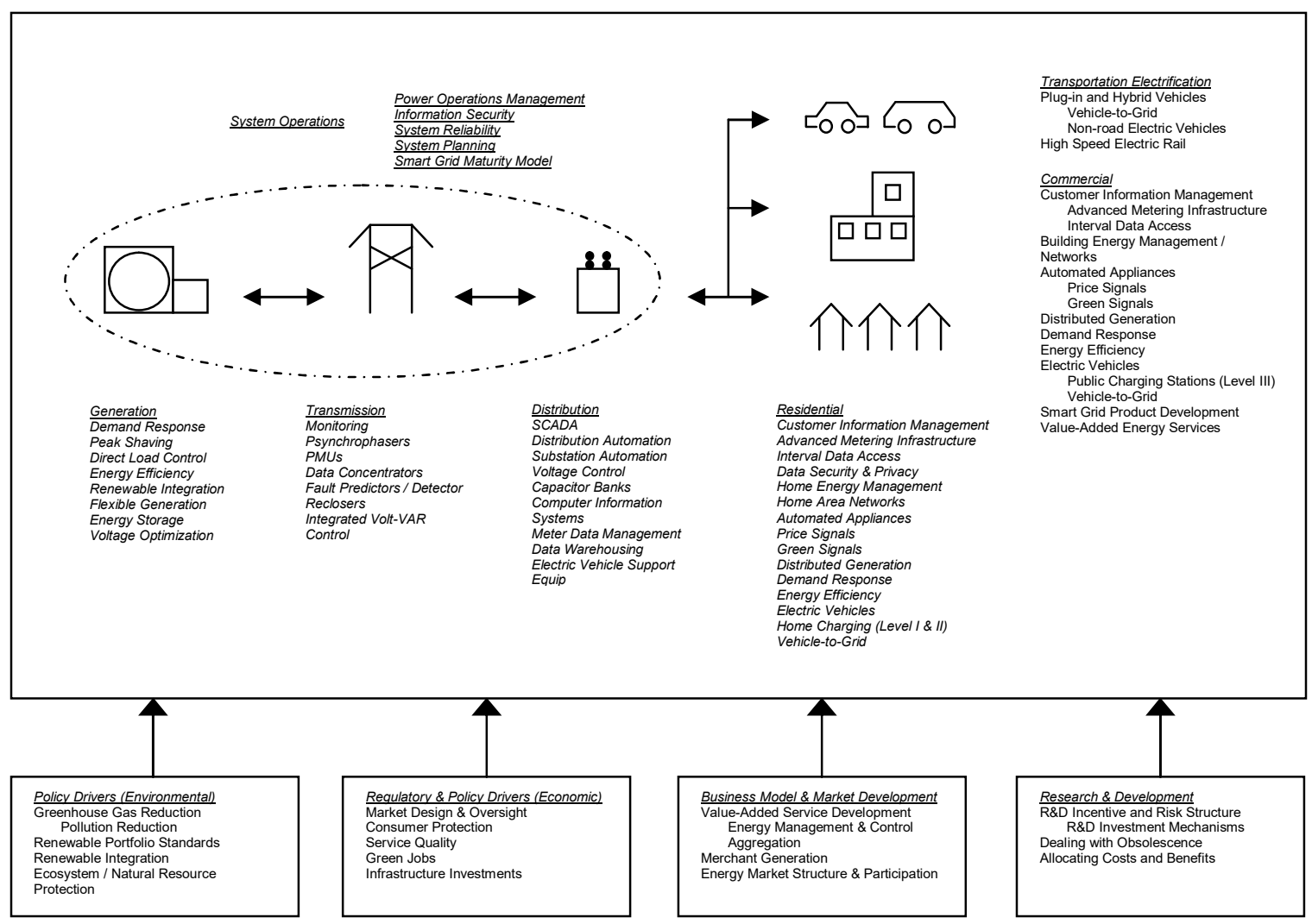

Smart grid technologies cover a wide range of functions, so it would be difficult to describe all the technologies that comprise it in detail. However, its main categories and functional areas are shown in the figure above and selected key terms are further defined in the glossary in Appendix B. The figure also shows key policy, market, business model and technology drivers that are influencing the evolution of the industry. The next section further explores these drivers to help understand why an integrated approach is needed for constructing smart grid roadmaps. 


\subsubsection{An Integrated Approach to Smart Grid Roadmapping}

Having explored the definitions of smart grid, looked at what technology types it includes and what it does, a clearer picture has began to emerge regarding this rapidly evolving industry. Many different elements and drivers for smart grid have been identified, but more explanation is needed regarding the type of integrated approach that will be needed to construct comprehensive smart grid roadmaps. The following figure shows examples of some of the factors to be considered in creating such an integrated approach.

Figure 1.6: Why an Integrated Approach to Smart Grid Roadmapping is Needed

\begin{tabular}{|c|c|}
\hline $\begin{array}{l}\text { Industry Characteristics } \\
\text { Capital Intensity (B) } \\
\text { Economies of Scale (B) } \\
\text { Network Effects (B) } \\
\text { Tendency toward Natural Monopoly (M) }\end{array}$ & $\begin{array}{l}\text { Regulatory \& Policy Structure } \\
\text { Partially or Fully Regulated Monopoly (M) } \\
\text { Regulated Profit or Rate of Return (B)(M) } \\
\text { Protect Customers from Lack of Competition (M) } \\
\text { Provide Investors with Stable Returns (B) }\end{array}$ \\
\hline $\begin{array}{l}\text { Business \& Market Development Process } \\
\text { Develop Value-Added Services }(B) \\
\text { Avoiding Product Commoditization }(B) \\
\text { Need for Standards and Interoperability }(P)(T) \\
\text { Dealing with Built-in Obsolescence }(T)(B) \\
\text { Capturing Rapid Technological Improvements }(T)(B)\end{array}$ & $\begin{array}{l}\text { Provide Key Economic Development Functions }(P) \\
\text { Provide Strategic and National Security Functions }(P) \\
\text { Planning Method: Least Cost Least Risk }(P)(B) \\
\text { Minimize Risks to Customers }(M)(P) \\
\text { Cost Recovery only for Prudently Incurred Risks }(B)\end{array}$ \\
\hline $\begin{array}{l}\text { Retail Competition }(B)(P) \\
\text { Wholesale Competition }(B)(P) \\
\text { Incentivizing Customer Participation }(P)(B) \\
\text { Energy Efficiency }(T)(P)(B) \\
\text { Distributed Generation }(T)(P)(B) \\
\text { Demand Response }(T)(P)(B) \\
\text { Electric Vehicles / Vehicle-to-Grid }(T)(P)(B)\end{array}$ & $\begin{array}{l}\text { Research \& Development Process } \\
\text { Technology Intensive Industry }(T) \\
\text { Low Incentives to Innovate }(P)(M) \\
0.25 \% \text { of Revenues Spent on R\&D (B)(M) } \\
\text { High R\&D Needs }(T) \\
\text { Increase Energy Efficiency }(T)(B) \\
\text { Reduce Operations \& Maintenance Costs }(T)(B) \\
\text { Support Renewable Energy }(T)(P) \\
\text { Support Environmental Policies }(T)(P) \\
\text { Support Economic Development Policies }(T)(P)(B)\end{array}$ \\
\hline
\end{tabular}

Unlike many other technology intensive industries, the electric power industry has been highly regulated, almost since the time that Thomas Edison opened the first commercial power station in lower Manhattan in 1882 [20]. With high barriers to entry, high capital requirements, and generally positive economies of scale in production, the industry has 
many key characteristics of natural monopolies [21]. It benefits from network effects, making it cheaper to serve customers when they are all part of the largest possible network of interconnections [14]. Once the health, safety, environmental, and economic benefits of electrification became widely known, states began establishing regulatory compacts to extend the benefits of electric power to all citizens [14]. This was generally done by creating monopoly services territories with utilities agreeing to an "obligation to serve" under regulated rates. Early industry pioneers, like Samuel Ansull, felt the industry could benefit from the stability and protection of a regulated monopoly structure, thus setting a tone that has remained to the present day [22].

Although the electricity industry has many key characteristics of natural monopolies, there are also some significant disadvantages to the regulated monopoly structure. It can be argued that regulated utilities lack an incentive to innovate. In fact, the percentage of $R \& D$ expenditures in the utility industry is only $0.25 \%$, one of the lowest of all major technology-based industries [23]. Maximum profits are set by regulators and costs can only be recovered for investments carefully described and approved ahead of time. This strongly discourages uncertainty in favor of simple, predictable operating efficiency. Thus, the incentive to take risks and try unproven new ideas can often be neglected. While efforts to "deregulate" or "restructure" the industry offer some potential to realign incentives for more innovation and competition, early failures, like the collapse of Enron in 2001, have caused many to move very cautiously [24]. 
Despite a historical aversion to risk, and methodological biases toward "least cost" and "least risk" planning, the electrical utility industry is being forced to innovate. Intermittent sources of renewable energy, like wind power and solar, are being added to the grid, along with legal requirements to generate power from renewable sources and reduce greenhouse gases; Electric Vehicles and Plug-in Hybrid Electric Vehicles are being developed which have the potential to both improve and exacerbate issues with peak demand. At the same time, businesses and consumers alike are demanding more information and control over the management of their electricity use, as well as protection of their critical financial and personal data. But, these new demands can only be met if the proper regulatory and market structures can be put in place that enable the right technologies and business models to be developed to meet these needs. The figure below shows elements of US electric power industry that are generally considered likely or unlikely to have some form of competitive market restructuring in the near future [25].

Figure 1.7: Electric Market Restructuring

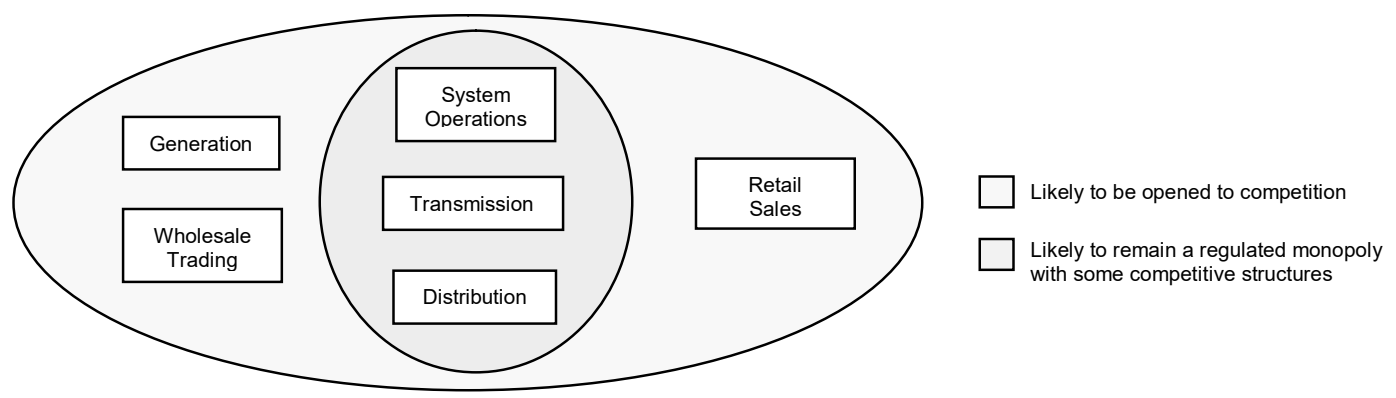

Source: Derived from Shively [10]

Thus, the portions of the electric power industry which have historical worked best as regulated monopolies are likely to continue operating in this manner. However, 
the portions of industry that are most amenable to market development would then begin a restructuring process. This is summed up on the market maturation diagram below.

Figure 1.8: Market Maturation Process

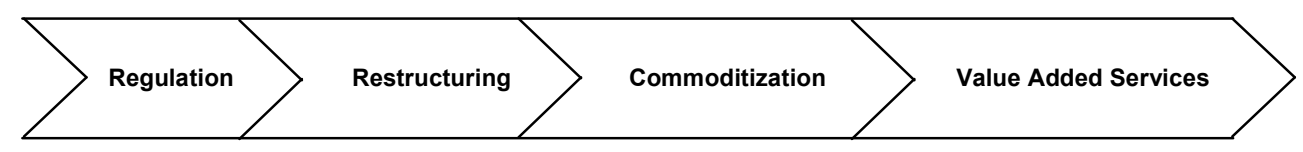

Source: Adapted from Shively [10]

Each of the sectors previously proposed for restructuring is likely to develop at a different pace through the market maturation process. The break up of the AT\&T monopoly in the US telecommunications industry provides an example of this that may be illustrative [26]. Although the break up initially led to only a few more choices for basic services, over the intervening decades, a wide range of new service offerings have emerged. Thus, if proper oversight is exercised, the electric power industry, and the smart grid sector in particular, may be able to benefit from some similar processes that have led to the creation of new value-added services and business models in other industries.

This section has discussed the policy, technology, market, and business development issues associated with smart grid. Taking an integrated approach to addressing these issues can help provide a more complete picture of how to construct comprehensive smart grid roadmaps for state and regional planning purposes. The next section will explain more about what roadmapping is and the factors that affect it. 


\subsubsection{Roadmapping and Key Driving Factors}

Roadmapping is a term used in many industries, but it is not always interpreted in the same way. For the purposes of this research, the technology roadmapping process pioneered by Motorola in the 1980's is the main concept that will be extended [27]. Second generation roadmaps for disruptive technologies were developed by Walsh [28]. The concept was further refined in the 1990's [29] and a standard approach, known as the T-Plan was developed in early 2000 [30, 31]. In addition, a process known as an S-Plan was developed to provide an overview of the strategic landscape for a potential technology product. Such roadmaps are useful for identifying key technologies and gaps that exist in a strategic and technology planning processes [32].

Roadmaps show key possibilities for relationships between technologies and products over time. Most successful roadmaps attempt to integrate the perspectives of "technology push" and the "market pull [33]." In the case of the development of smart grid roadmaps, integration of these perspectives is critical. While the Shumpeterian view that essential change within an industry depends strongly on the type and quality of technology developed in that new industry [34], it also must meet important and well defined market needs, as described by Schmookler [35]. Additionally, the history of strong regulation in the electric utility industry requires an understanding of the policy and regulatory perspectives. As the industry looks at possible regulatory restructuring, the development of new market structures and business models will also be key 
perspectives to incorporate. Several form of analysis are used to examines these perspectives, including interpretative flexibility of policy storylines, which have been applied in the energy sector in relation to the transition of institutional priorities [36]. The figure below provides visual representation of the integrated approached that this research proposes in balancing the various roadmap perspectives.

Regulatory and policy factors can exert both a push and a pull on traditional technology push and market pull perspectives. At times, policy may combine with technology push to create a sort of "policy push," which nudges technology to do more to meet an important policy goal, such as increased fuel efficiency vehicles or zero emission vehicles, for example. It is possible that this may cause technologies to fall out of alignment with market pull demands of consumers, such as with those who prefer larger but less fuel efficient vehicle for other reasons, such as horsepower and cargo capacity. At other times, policy make take the form of a pull, attempting to get technology more aligned with market preferences than it otherwise might be given new technological capabilities that have been developed. An example of this might include privacy and information security requirements for customer data from devices like smart wireless utility meters. While the requirements for protecting this data do present some significant challenges, they provide an important protection to consumer and thus serve a significant policy purpose. This would be an equal and opposite case to the previous policy-push example, so it could be termed a "policy pull." For the purposes of this research, as we consider the possible role of policy in balancing the technology push and market pull perspectives, it is useful to consider a "policy push-pull" dynamic that would be able to 
act back and forth on these other two perspectives. This can be visualized as the Regulatory \& Policy Push / Pull arrow in the following figure on balancing perspectives for planning in the utility industry.

Figure 1.9: Balancing Planning Perspectives in Regulated Industries

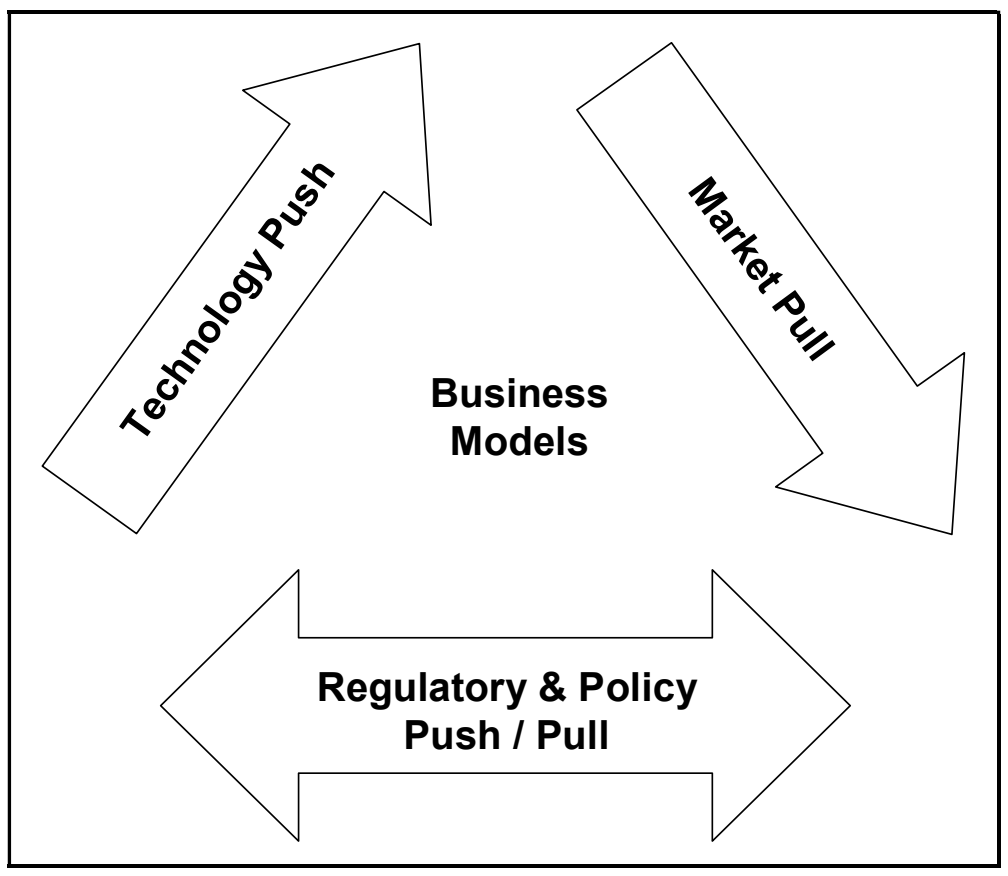

Business models are shown occupying the central space in the above diagram, as they are reliant on technology, market, and policy factors. They can be seen as a means for implementing successful combinations of these factors. The exact combination of factors can be visualized as a shape, if you will, that represents the space made available by the dynamic action of the other three factors. For the purposes of this research, this visual metaphor is essential for understanding the central importance of business models and the essential nature of an integrated approach for understanding successful technological innovation. Furthermore, while these points are likely applicable to a wide 
range of industries, the central role of regulation and policy on the utility industry, and the impact it exerts on shaping business models are seen as a reason why it may be particularly important for this research.

Therefore, research proposed here will develop a roadmapping process that specifically considers business and market needs, regulatory and policy issues, and technology development needs. Additional details are provided in the methodological needs section in chapter 4.3.1 regarding the requirements for creating a methodology to integrate these factors into a cohesive research approach to fit the challenges of this industry. However, it is important to first look at some of the current work that has been done to create roadmaps specifically related to smart grid.

There have been a number of prominent recent efforts to create smart grid roadmaps that address one or more aspects of the above mentioned issues. However, none of these efforts appear to have taken an integrated approach to addressing all of these issues. The next section will examine and discuss these efforts and identify any gaps that need to be filled. 


\section{CHAPTER 2: Literature Review}

\subsection{Smart Grid Roadmapping Literature}

The following section contains a review of the literature on smart grid roadmapping. A more general discussion of the technology roadmapping literature is given in section 4 .

There have been a variety of efforts to create smart grid related roadmaps and plans for the US and a number of countries around the world. Most of these roadmaps have been either fairly general efforts at the state or national levels, or very specific efforts that have been focused at the level of cities and municipal areas. No smart grid roadmaps were identified that focused in detail on regional level issues, such as those of the US Pacific Northwest. Also, while the roadmap efforts in areas outside the US are illustrative for many purposes, issues related to technology standards, policy, market structure, and business models vary greatly among countries. This can make these efforts difficult to compare. Thus, for this research, the primary focus is on efforts and issues relevant to the US. The following is a list of some prominent examples of smart grid roadmaps or studies recently conducted in the US. 
Table 2.1: Prominent Smart Grid Roadmaps or Studies in the US

\begin{tabular}{|c|c|c|c|c|c|c|c|c|}
\hline & \multicolumn{4}{|c|}{ Level } & \multicolumn{4}{|c|}{ Type } \\
\hline & City & State & Regional & National & Technology & Policy & Market & Business \\
\hline $\begin{array}{l}\text { California } \\
\text { Independent } \\
\text { System Operator } \\
{[37-39]}\end{array}$ & & $\mathrm{X}$ & & & $\mathrm{X}$ & $\mathrm{X}$ & & \\
\hline $\begin{array}{l}\text { California } \\
\text { Energy } \\
\text { Commission } \\
{[40-42]}\end{array}$ & & $\mathrm{X}$ & & & $\mathrm{X}$ & $\mathrm{X}$ & $X$ & \\
\hline $\begin{array}{l}\text { Illinois Smart } \\
\text { Grid } \\
\text { Collaborative } \\
{[43-45]}\end{array}$ & & $\mathrm{X}$ & & & $\mathrm{X}$ & $X$ & & \\
\hline $\begin{array}{l}\text { Public Utility } \\
\text { Commission of } \\
\text { Oregon, UM } \\
1460 \text { [46] }\end{array}$ & & $\mathrm{X}$ & & & $X$ & $\mathrm{X}$ & & \\
\hline $\begin{array}{l}\text { Brown \& Satler } \\
\text { Survey of Law } \\
\text { and Regulation } \\
{[47,48]}\end{array}$ & & $X$ & & $\mathrm{X}$ & & $\mathrm{X}$ & & \\
\hline $\begin{array}{l}\text { Galvin } \\
\text { Electricity } \\
\text { Initiative }[9,15, \\
18,49]\end{array}$ & & $\mathrm{X}$ & & $X$ & $\mathrm{X}$ & $\mathrm{X}$ & $\mathrm{X}$ & \\
\hline $\begin{array}{l}\text { National } \\
\text { Institute of } \\
\text { Standards and } \\
\text { Technology [48, } \\
50]\end{array}$ & & & & $\mathrm{X}$ & $\mathrm{X}$ & $\mathrm{X}$ & & \\
\hline $\begin{array}{l}\text { Xcel Energy - } \\
\text { Smart Grid City } \\
\text { (Boulder, CO) } \\
{[51,52]}\end{array}$ & $X$ & & & & $\mathrm{X}$ & $\mathrm{X}$ & & $\mathrm{X}$ \\
\hline $\begin{array}{l}\text { Austin Energy - } \\
\text { Pecan Street } \\
\text { Project (Austin, } \\
\text { TX) [53-55] }\end{array}$ & $\mathrm{X}$ & & & & $\mathrm{X}$ & & & $\mathrm{X}$ \\
\hline
\end{tabular}

The list of roadmap projects described above contains some of the key efforts to understand smart grid deployments at the city, state, and national levels. The work by the California Independent System Operator [37-39] and California Energy Commission [4042] represents some of the leading thinking in the nation about new smart grid plans and roadmaps. They have laid out many of the costs and benefits to the state, with an 
emphasis on specific technologies, but their scope has been fairly limited in exploring these issues on a broader regional level. With the experience of the California Energy Crisis in 2001, the prospects for new market restructuring efforts are also likely to face high uncertainty. Similarly, the Illinois Smart Grid Collaborative examined many key issues regarding smart grid policy, and technology at the state level, but with only limited implications in terms of planning on a regional basis [43-45]. Brown \& Satler examine and discuss smart grid issues in eleven states, mainly at the level of state and national policy considerations $[47,48]$. Overall, at least four states (CA, OR, NY, and TX) have approved policies to move them toward implementation of smart grid, while seven others (CO, DC, DE, IN, NJ, OH, and PA) are in the process of examining such policies [44]. But, while their survey of the smart grid landscape could form a useful basis for the creation of a future roadmap, the study does itself does not actually create a fully formed roadmap. The Oregon Public Utility Commission recently completed the UM 1460 docket, examining key issues regarding smart grid deployment in Oregon and establishing reporting requirements for investor owned utilities regarding their future smart grid plans [46]. However, while this effort lays some important groundwork for the creation of future smart grid plans, much additional work is still needed to create an integrated smart grid roadmap to address state and regional issues.

There are also a number of very detailed studies regarding Austin Energy's Pecan Street Project, which describes far reaching plans for smart grid deployment in the Austin municipal area, along with consideration of some of the business model issues necessary to give these technologies future viability [53-55]. However, despite some important 
success that have already occurred in the Pecan Street demonstration project, they do not appear to have created a formal roadmap for this process. Xcel Energy's Smart Grid City project is another example of a smart grid demonstration project in the metro area of Boulder, CO [51,52]. While Xcel energy originally envisioned the project as providing guidance for how to deploy smart grid in a regional utility system, a number of problems developed in the course of the project, and efforts seem to have only gotten to the level of the city and municipal area.

The Galvin Electricity Initiative has produced many publications addressing key aspects of smart grid deployment, but its focus has primarily been on high level recommendations at the state and national level $[9,15,18,49]$. Likewise, the National Institute of Standards has produced documents discussing many key issues for smart grid deployment at the national level, including an emphasis on the development of smart grid interoperability standards $[48,50]$.

After examining the many prominent smart grid planning efforts in this section, there appears to be a need for a more comprehensive analysis in order to create smart grid roadmaps to address state and regional issues. Also, none of the roadmaps identified took an integrated approach to understanding technology, policy, market structure, and business model issues needed to make future smart grid systems effective. Therefore, there is a need for research to bridge these gaps. 
It should also be noted that some of the current roadmaps make use of proprietary tools or modeling methods. The Smart Grid Maturity Model (SGMM) is one such tools which has gained significant attention [56]. Originally developed by the Global Intelligent Utility Network Consortium, this tool has been further refined and developed to integrate with the methods used in Carnegie Mellon University's well known Capabilities Maturity Model Integration (CMMI) $[57,58]$. The SGMM appears to be a valuable process for a number of utilities to use to engage in certain aspects of planning related to the development of smart grid roadmaps. Due to the proprietary nature of the model, however, those who chose to use it are required to contract with Carnegie Mellon. This research aims to develop a more transparent method of analysis for constructing smart grid roadmaps. It should also be noted that research proposed here is more general than that of the SGMM. Like other CMMI-based methods, the SGMM provides detailed project monitoring and assessment tools. It helps an organization understand how a project can fit with the company's organizational culture, business structure, and communications channels. These are all valuable functions, but the goal of this research is to develop more of a high level vision for regional smart grid roadmaps. Once such an overall roadmap is created for a region, utilities and other organizations that may want the detailed project management and assessment capabilities offered by SGMM could then utilize that tool.

This section has provided an overview of some of the most prominent examples of smart grid roadmap efforts in the US over the past decade. The next section will 
examine some of the challenges to creating a smart grid roadmap for Oregon and the Pacific Northwest, which meets the unique needs of area.

\subsection{Influences on the Smart Grid Landscape in Oregon \& the Pacific Northwest}

A variety of policies, laws, and other influences at the state, federal, and regional levels have shaped the landscape for smart grid in Oregon and the Pacific Northwest. Although many of these policies were enacted at the federal level, their main effects often occurred at the state or even regional levels. Selected examples are summarized in the figure below. While most of these examples could be categorized as policy or regulatory instruments, they also have influences on the other key dimensions discussed in previous sections, such as technology, market structure, and business model development.

Figure 2.1: Smart Grid Influences in Oregon \& the Pacific Northwest

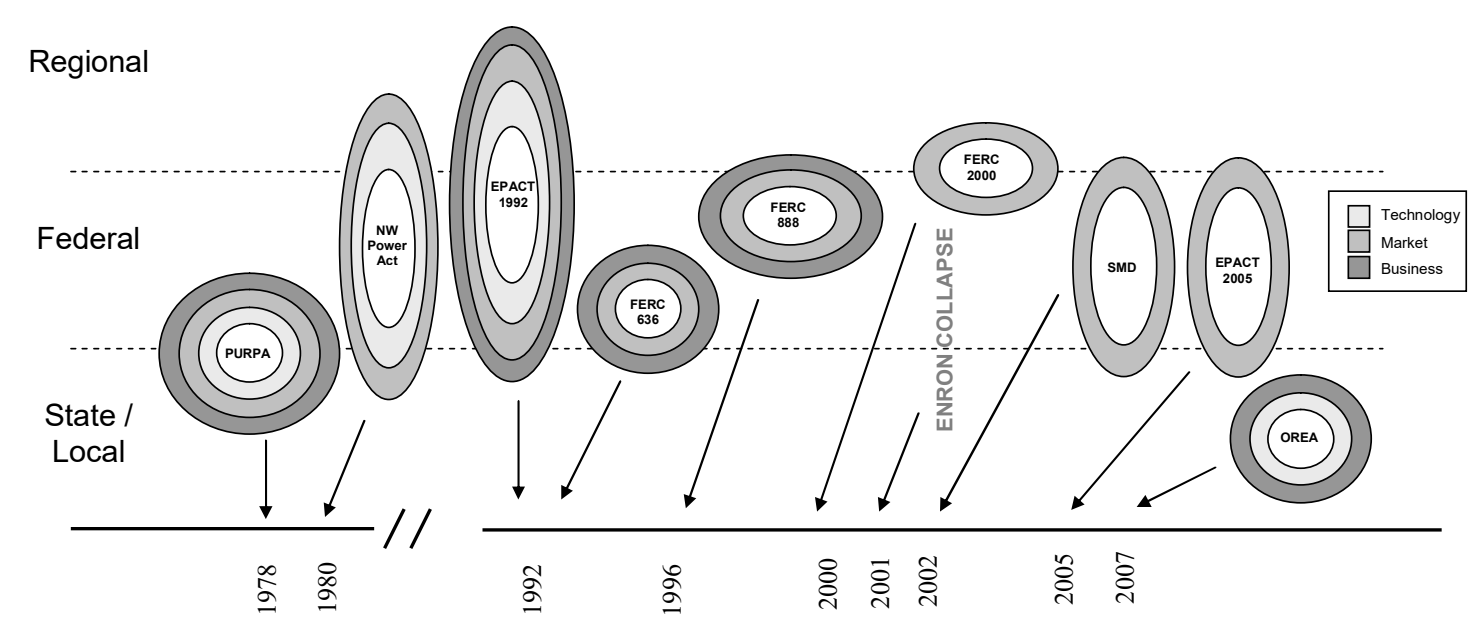


When Congress passed the Public Utilities Regulatory Act (PURPA) of 1978, in the midst of the 1970's Energy Crisis, it introduced a new class of non-utility owned power generation [59]. The act required utilities to consider purchases from independent power producers (IPPs) that provided generation from specific types of qualifying facilities, such as cogeneration or renewable energy, at the avoided cost of new utility construction [6]. Thus, the policy directives of PURPA affected the utility industry nation-wide on a technology, market, and business model level. Shortly thereafter, the Northwest Power Act of 1980 established federal policy guidelines specifically affecting the states of the Pacific Northwest (Oregon, Washington, Idaho, and Montana) [60]. The act has had three main effects: (1) Allowing Northwest states access to low cost power from the federal hydropower system; (2) Establishing the Northwest Power and Planning Council (now called the Northwest Power and Conservation Council), which conducts regional planning on both energy issues and mitigation of fish and wildlife impacts from the federal hydropower system; and (3) a focus on energy conservation, which has met two thirds of the growth in energy demand since 1980 and has proven to be one of the region's lowest-cost, lowest-risk, and lowest-impact resources [61]. While the Northwest Power Act did not deal specifically with business models to drive the deployment of energy conservation technology, it can be seen as a force that helped create a market for such technologies and thus spurred the development of innovation in the industry.

Over the next decade, IPPs continued to expand, but were limited to selling power to incumbent utilities. To address this, Congress passed the Energy Policy Act of 1992 (EPACT), increasing market access for IPPs by forcing utilities to transmit third-party 
power over utility lines ("wheeling"), and requiring utilities to consider purchased power as an alternative to utility-owned construction in their Integrated Resource Plans [62]. The Federal Energy Regulatory Commission (FERC) further restructured the industry with FERC Order 636, requiring utilities to unbundle transmission and energy services [63]. This was followed in 1996 by FERC Order 888, which among other things, established open access transmission, standardized non-discriminatory transmission rates, separated generation, transmission, power control, and distribution functions, and encouraged the development of Independent System Operators (ISOs) [64]. FERC then expanded its efforts to consolidate utility regulation at the federal and regional levels with Order 2000, which required utilities to come up with plans to join or create Regional Transmission Organizations (RTOs) [65]. However, FERC appeared to have underestimated the political strength of opposition from congressional delegations, particularly in the Northwest, Rocky Mountain, and Southeast regions, which feared a loss of control over low cost hydropower. The collapse of Enron in 2001 further strengthened opposition to such restructuring. In 2002 when FERC proposed more forceful measures to create a Standard Market Design (SMD) across the US, its budget was threatened and it was forced to back down [66]. By 2003 it had issued new guidelines favoring less uniformity and more tolerance for regional variation. A new EPACT in 2005 further emphasized that the role of restructuring should focus on wholesale rather than retail competition as national policy [67].

The needs of Oregon and the Pacific Northwest present some additional complications against the backdrop of the state, federal, and regional regulatory history 
described above. The Oregon Renewable Energy Act of 2007 established a Renewable Portfolio Standard (RPS), requiring that the state's largest utilities generate $25 \%$ of their electricity from renewable sources by $2025[8,9]$. The RPS requirements for promoting renewable generation and integrating intermittent supplies of renewable energy, such as wind power, onto the grid have been a strong policy driver on the utility system that is likely to heavily impact planning for a smart grid roadmap as well. Washington and Montana have also passed requirements for renewable energy, making this an important regional issue.

As one of the states that resisted SMD, Oregon has neither an RTO nor a single state-wide ISO. The Bonneville Power Administration (BPA), however, is an agency charged with marketing the power from the federal hydropower system throughout the region. So, in some respects, BPA may be seen as a substitute for a number of the functions of an RTO, and at various times has tried to move toward RTO establishment, including Grid West, Northwest Grid, and ColumbiaGrid [68]. However, since additional RTO-like functions can be important for a number of aspects of grid modernization, there have been several proposals to create entities to perform some of these functions.

Currently, an Energy Imbalance Market (EIM) is being proposed for the 12 US states and portions of Mexico and Canada that are member of the Western Electricity Coordination Council (WEEC) power grid [5]. The EIM would establish a centralized, 5-minute market to enable more efficient use of transmission capacity, but would keep 
day-ahead and hourly scheduling with current balancing authorities. Another proposal called Intra-Hour Transaction Accelerator Platform (I-Tap) could improve the efficiency of hourly, day-ahead markets [69]. Both of these proposals offer interesting functions which may be important for aspects of state and regional smart grid roadmaps, but it is unclear if, when, or how they may be implemented.

Having described the regulatory history and needs for future grid modernization, the next key question is: How can a process be created to construct a smart grid roadmap for Oregon and the Pacific Northwest? Some preliminary steps to answer this question are explored in the next section.

\subsection{Developing Smart Grid Roadmaps for Oregon \& the Pacific Northwest}

Currently, no state or regional smart grid roadmaps have been identified that take an integrated approach to the policy, technology, business model, and market development issues in Oregon and the Pacific Northwest. The only independent organization focusing on the development or the smart grid industry in the state and region is a trade association called Smart Grid Oregon. The trade association is made up of people with diverse backgrounds, including utility industry executives, people with experience in state and federal regulatory and legislative positions, entrepreneurs providing products and services in the smart grid industry, and a range of non-profit organizations and other stakeholders interested in various other effects smart grid might have, including economic, social, and environmental impacts. 
In an effort to better understand the factors and priorities that could affect roadmap development in the four key subject areas identified above, a charrette technique was used to gather expert judgment data from a group of experts at Smart Grid Oregon. The author is also affiliated with Smart Grid Oregon.

\subsection{Expert Input: Charrette Process}

To begin the process of understanding the importance of specific factors related to constructing a smart grid roadmap for Oregon and the Pacific Northwest, a diverse group of smart grid experts was assembled. The group consisted of nine experts from the Smart Grid Oregon Policy Committee. They were drawn from a variety of backgrounds, including: Electricity Industry Executives (2); leaders from major Non-Profit Organizations related to energy and the environment (3); Regulatory and Legislative backgrounds (2); Smart grid technology experts, service professionals, and entrepreneurs (2). Overall, there were a roughly equal number of experts who specialized in areas related to each sector.

The experts began with the start concepts derived from the literature, but they were free to add factors if they felt additional concepts were important or to indicate if they felt any of the factors were inappropriate or not significant. To rapidly gather input from this group of experts, a charrette technique was used to allow them to quickly validate and prioritize variables through the use of a voting process [70]. Each expert 
was allowed to cast a total of five votes, assigning no more than one vote to a single factor. This permitted the experts to identify the set of five factors they considered to be most significant, without worrying about exactly how the factors ranked in terms of relative importance. All votes were then tallied to reveal the consensus regarding the factors that the most experts considered significant.

The experts considered two main questions: The importance of Benefits and Opportunities for smart grid versus Challenges and Barriers. These are summarized on the chart below. The issues identified are also organized according to the key policy, market, business model, and technology development categories discussed in previous sections.

A number of interesting results are evident from the expert judgment data. First, two different questions were addressed. Some very significant issues were identified in the Policy and Regulatory category. Grid stability and reliability were seen as critical benefits that could be promoted, along with reducing pollution, promoting the integration of renewable energy, avoiding future rate increases, and creating jobs. The challenges and barriers in the policy category were not always phrased in equal and/or opposite terms to the potential benefits, but they seemed to be strongly held at a similar level of importance. The barriers focused on problems with rate and regulatory structures, as well as slow regulatory processes. Very different terms were used for describing barriers versus benefits in the Policy / Regulatory category. One interpretation of this difference is that it could indicate very different understandings of the elements that drive value in 
this category, versus those that create costs. However, in the Market and Business Model category, as well as the Technology Development category, there were often very directly related costs and benefits. One example of this is the view by some experts that smart grid would lead to loss of contact with vulnerable customers (i.e. elderly or low-income customers). However, other experts felt that smart grid would actually lead customers to have greater control and ability to participate in the utility system. Likewise, in the case of the Technology Development category, the need to develop interoperability standards was seen as a very significant problem. However, the benefit of developing standards was seen as an issue of even greater positive significance, once the potential of such benefits could be recognized. 
Figure 2.2: Expert Input - Benefits vs. Barriers for Smart Grid in the Pacific Northwest

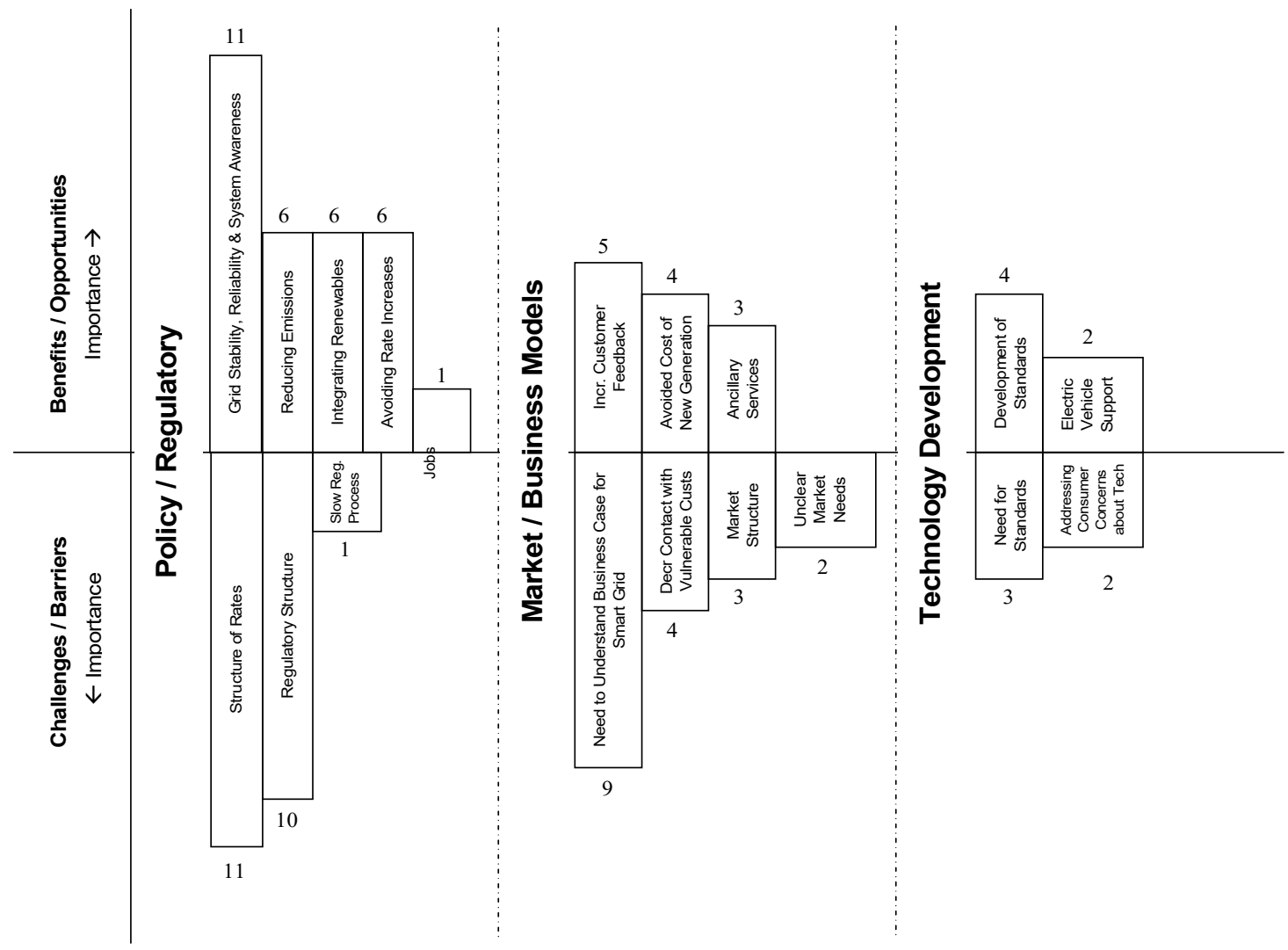

Although the charrette process used here was clearly exploratory, it does provide some useful terms for building on in future studies. The next section will deal with some of the needs and challenges for creating these types of smart grid roadmaps.

\subsection{Future Smart Grid Roadmap Development Process}

This study has examined the benefits of smart grid, described the history of the electric utility system and regulatory processes in the US, reviewed the literature 
regarding leading examples of smart grid demonstration projects, and analyzed the need for further development of smart grid roadmaps. An initial group of experts was then consulted regarding issues specific to creating smart grid roadmaps for Oregon and the Pacific Northwest. So, after the results of this initial research, what would smart grid roadmaps look like for the state and/or the region?

To answer to this question, two basic levels of analysis are needed: Construction of a general roadmap with the overall drivers and roadmap layers necessary to understand broad challenges at the technology, business model, regulatory \& policy levels; and (2) development of one or more sub-roadmaps focusing on details of specific technologies or industrial applications. Constructing a complete roadmap for the entire smart grid industry is a large task, so an intermediate step was undertaken to construct the preliminary inputs for a roadmap for a sub-industry in the smart grid sector. In this case, demand response technologies were chosen.

\subsubsection{Preliminary Roadmap for Sub-Industry in Smart Grid Sector}

The T-Plan roadmap format described in previous sections is a useful starting point to visualize the outlines of a smart grid roadmap [30, 31]. In the current case, the format is adapted from a typical set of layers, such as technology, product, and drivers (business and market), to include drivers with additional layers for policy, business model, and market structure. Expert judgment, such as the data gathered through the charrette process, can be used to help understand the issues affecting these drivers. 
As mentioned in the previous section, it is a big task to create a roadmap for the entire smart grid industry, so the preliminary elements of a sub-roadmap was first constructed regarding a specific type of smart grid technology called Demand Response (DR) [71]. DR includes a large class of smart appliances that are capable of communicating with the grid and determining if increases or decreases in energy use are needed at a particular time. This can help mitigate the occurrence of certain peak demand times, which are very expensive for utility systems to deal with, and can also help to better utilize energy at off-peak times. DR is seen as one technology which may be able to help better integrate intermittent sources of renewable energy, like wind power, into utility systems through this process of matching supply with demand [72]. When matched with appropriate market mechanisms, DR is seen as one of the fastest and lowest cost mechanisms for renewable energy integration [73]. 
Figure 2.3: Preliminary Roadmap Inputs for Demand Response Technology

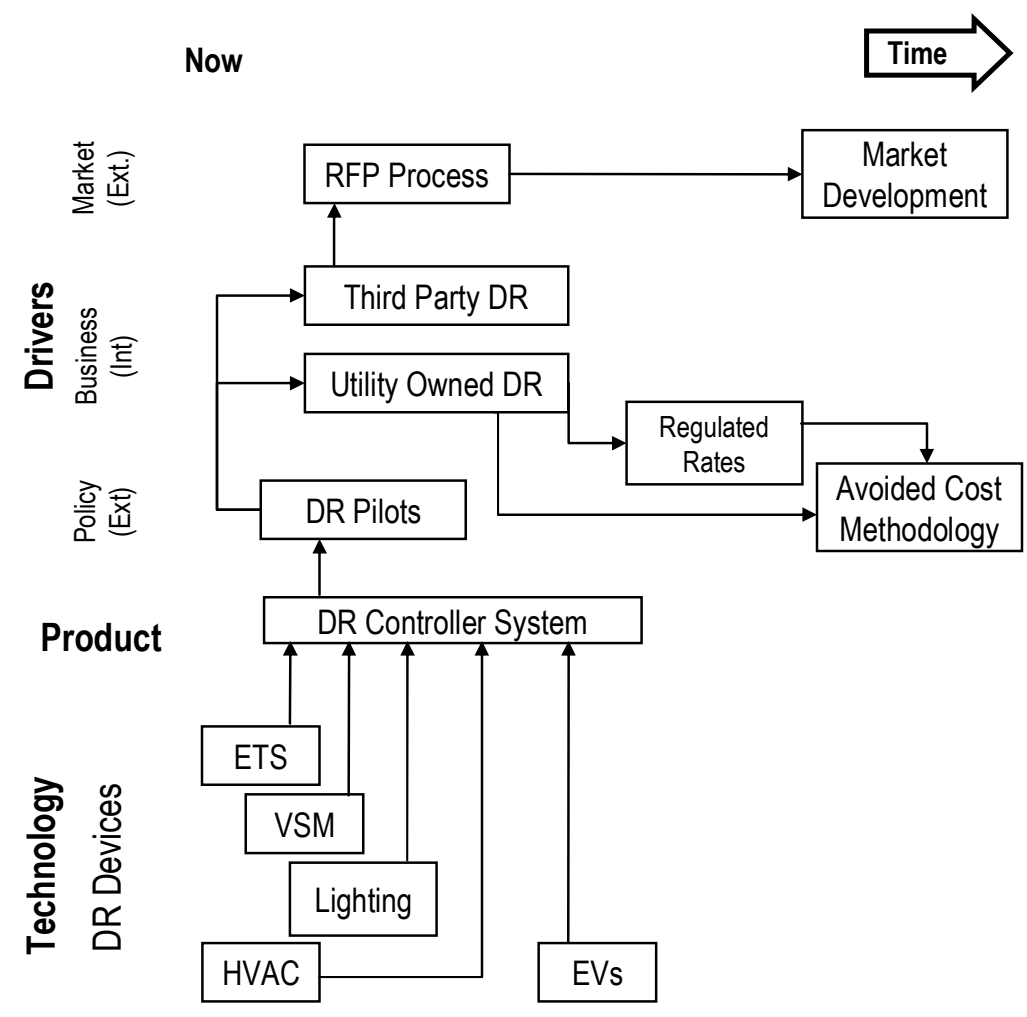

The information about can be used as inputs for a more complete DR Roadmap in the future. It was developed in consultation with utility professionals and people with backgrounds in utility regulation. The goal was simply to provide a general vision for different ways DR could be deployed. While it was not intended to be a detailed analysis, it is illustrative of several key issues. The technologies listed on the roadmap include the following types of demand response enabled devices: Electro-thermal Storage (ETS / Electric Water Heaters); Variable Speed Motors (VSM); Energy Efficient Lighting; Heating, Ventilation \& Air Conditioning (HVAC); and Electric Vehicles (EVs). Taking the example of EVs, if these were connected to a DR Controller product which could interface with a smart grid, this could connect EV owners to two basic types of 
pilot programs. In one case, utility companies would own and operate demand response, which would mean rates paid for program participation would be set by the utility commission, most likely based on the a calculation of the avoided cost of generation. In a second case, third-party demand response would be used, which would require third parties to create requests for proposals regarding the rates for program participation, and with enough participation from demand response providing entities, this could evolve into a robust retail market for demand response with prices that varied in real time.

The initial steps taken toward producing a DR technology roadmap are described in this section. This provides an example of how key smart grid industries, like demand response fit in the larger smart grid field. The next section will offer conclusions about the results of this preliminary study, and the next steps for conducting smart grid roadmap research in Oregon and the Pacific Northwest. A case study will be developed to focus more specifically on a key smart appliances which form the sub-sectors of the emerging smart grid industry. In particular electric vehicles will be discussed as one of the first smart appliances with potential to be mass produced and adopted by millions of consumers. The use of such vehicles in Vehicle-to-Grid (V2G) systems will also be discussed. This concept has the potential to make a particularly strong impact on smart grid development, since it can be used for making the grid more robust, meeting challenges, like the integration of renewable energy, and possibly alleviating strains on the grid that could otherwise occur as a result of large amount of uncoordinated charging of electric vehicles. 


\subsection{Conclusions on Preliminary Smart Grid Roadmap Development}

This research has described the need to take an integrated approach to examining the Technology, Policy, Market, and Business Model development of smart grid roadmaps in Oregon and the Pacific Northwest. It has begun the process of collecting data regarding each of these four areas. Using expert judgment, the basis for a robust roadmap can then be constructed to understand the overall development of smart of smart grid in Oregon and the Pacific Northwest. In addition to a general smart grid roadmap for the state and the region, more specific roadmaps could be developed to deal with important sectors within the regional smart grid industry. An Electric Vehicle Smart Grid Roadmap is one such target for future research, as it could help meet important goals for the integration of renewable energy and reduction of greenhouse gases in the region. Additional methods that may be useful in constructing such roadmaps include the construction of Hierarchical Decision Models that help prioritize drivers and elements related to each layer of the smart grid roadmap. Specific metrics could also be defined for each driver that could then be translated into desirability values for the evaluation of each alternative. Currently no state or regional smart grid roadmaps exist for Oregon or the Pacific Northwest that take an integrated approach to understanding the technology, policy, market, and business model needs for the state and region. Therefore, this research fills an important gap. 


\section{CHAPTER 3: Research Application}

\subsection{Smart Appliances}

Smart grids allow electricity to be delivered efficiently to devices or appliances that can utilize this energy to perform useful functions. Smart appliances are capable of interacting with smart grid systems, using energy when it is cheapest and most abundant, as well as preventing or reducing possible strains on the grid, such as high peak loads. This research will focus on identifying and studying emerging smart appliances that solve critical challenges that are arising for the power grid. Examples of such challenges include dealing with critical peak power usage and the process of balancing or integrating increasing amounts of intermittent renewable energy resources, such as wind power, onto the existing grid.

A renewable portfolio standard is a government mandate that require utility companies to derive specific percentages of their electricity generation from sources of renewable energy, like wind power and solar energy. Since most of the leading types of renewable electricity generation have variable outputs, producing electricity only when the wind is blowing or the sun is shinning, there is an increasing importance to addressing the integration of such resources and doing it at a reasonable cost. Emerging smart grid technologies, such as electric vehicles, have been proposed as possible solutions for meeting some of the challenges of renewable energy integration in a cost effective manner [64]. However, a number of needs, gaps, and barriers must be addressed in order 
to for such systems to be effective. Therefore, this research aims to create a technology roadmap to help understand the issues that must be addressed to create future smart grid systems on state and regional levels, as well as quantifying the priorities of specific elements within these systems.

What are some examples of smart appliances? Some types of smart devices have been mentioned in previous sections on smart grid, which describe technologies designed to improve performance in three main areas: Generation, Transmission, and Distribution.

A variety of smart appliances have been developed, but most are not generally in widespread use. Starting in 2010, the large scale launch of electric vehicles, such as the Nissan Leaf, Chevrolet Volt, and Prius Plug-in, offers the possibility of mass produced vehicles capable of complex grid interactions [65]. Although the adoption rate for electric vehicles or plug in hybrid electric vehicles is uncertain, even modest rates of penetration in the market of 12.8 million passenger vehicles sold annually in the US could mean that thousands or even millions of electric vehicles could be on US roads within a few years [74, 75]. In 2011 the Obama administration announced an ambitious goal of having one million plug-in vehicles on American highways by 2015 [66]. Although this was a stretch goal that was not attained, independent analyses have predicted these levels of adoption in the near future [67]. Since electric vehicles use relatively large amounts of electricity compared to other household appliances, they have the potential to create an impact on the grid. If most electric vehicle charging is done by consumer households at "off-peak" times, or period of low utility system utilization, such 
as late at night, then EVs are not expected to place significant strain on the grid. According to Jim Piro, CEO or Portland General Electric, if $10 \%$ of the vehicle in the Portland metro areas were plug-in vehicle by 2020 , it would only result in a modest 50 MW increase in the utility's needs [68]. Piro further explained that even if all the city's vehicles were electric vehicles, he felt the utility could easily handle this with some modest capacity additions, as long as people did not all try to charge their cars at the same time. Ensuring that charging is not all done at once, and thus overloading grid capacity, will be an important future role for smart grid.

\subsection{Electric Vehicles as Smart Appliances}

Electric vehicles are devices which use electric motors for propulsion. They have a long history, with the first practical devices appearing in the 1830's in the locomotive industry [63]. Today they are used in many areas of the transportation sector, with the most common land transport applications being electric trains, buses, trams, and increasingly, electric and hybrid electric automobiles. Electric automobilies are selfpropelled vehicles that carry their own power sources, such as of electric batteries, hybrid gas-electric systems, or fuel cells. The focus of this research will be on electric vehicles used primarily for light duty passenger automotive applications.

Electric vehicles (EVs) offer a number of potential benefits compared to internal combustion engines (ICEs), the current dominant technology in the light duty passenger 
automotive sector. However, EVs also come with some significant costs and challenges. One of the main advantages for EVs is that they offer significantly greater efficiency regarding the conversion of energy into vehicle propulsion than ICEs. Well-to-Wheel efficiency measures the amount of energy spent from the time oil is extracted from the oil well to the time it is used to power the wheels of a vehicle $[76,77]$. The overall Well-toWheel efficiency for an ICE is estimated at approximately 13\%, while for EVs power by oil fired generation, it is about $25 \%$ [77, 78]. Since less fuel is required to produce the power needed to drive EVs than ICEs, fewer emissions are produced regardless of the energy sources used for producing the electricity. Even if electric power is produced from high polluting sources, such as coal fired generation, the use of EVs still results in better overall environmental impacts than gasoline powered ICEs [79, 80]. The emissions produced in the generation of electricity are also generally better controlled, less toxic, and further away from the street level where they can result in damaging effects to human health $[80,81]$. If lower emission sources of energy are used, such as electricity from an hydroelectric station, the Station-to-Wheel efficiency for EVs increases to about $35 \%$ and the environmental impact is more favorable than when gasoline powered vehicles are compared to EVs charged with electricity produced using the average energy mix in the US [77]. As greener generation sources are added to the grid, this has the potential to further reduce the impact of electric vehicle charging. However, it should be noted that energy mix is a function of power system planning, not a property affected by EV technologies. 
The development and adoption of electric vehicles has occurred in several major waves over the last 150 years. The first significant wave of adoption occurred in the late $19^{\text {th }}$ century, and by the early $20^{\text {th }}$ century, electric trains, buses, and automobiles were in widespread use [82]. In the US, electric vehicles remained the dominant form of automobile transportation until around the second decade of the $20^{\text {th }}$ century, when the development electric starter motors for internal combustion engines finally made gasoline powered vehicles a safe and convenient transportation alternative [83].

While vehicles powered ICEs have continued to dominate the transportation sector up to the present day, significant interest in several types of electric automobiles was revived both in the 1970's and 1990's, due primarily to concerns about rising fuel prices and environmental impacts from automobile emissions. A modest number of Battery Electric Vehicles (BEVs) and Hybrid Electric Vehicles (HEV) were introduced in the 1990s, but these initial products were used mainly for market testing purposes [77, 84]. BEVs were ultimately not put into wide scale production at that time, due to a variety of factors involving battery range, performance, cost, and other issues [85]. HEVs, however, which combined the use of gasoline and electric propulsion systems to improve fuel economy, were further developed and marketed. These vehicles have experienced significant worldwide adoption, with over 10 million HEVs sold by 2015, over half of which are in the US $[86,87]$. While HEVs was less than $3 \%$ of US new car sales in 2012, the HEV and BEV market in the US is expected to surpass $5 \%$ of the market by 2017 and around $10 \%$ by 2020 [88]. 
The success of HEVs and improvements in BEV technology have led to the recent introduction of Plug-in Hybrid Electric Vehicles (PHEV), such as the Chevrolet Volt in December 2010, and the Toyata Prius Plug-in in January of 2012 [89, 90]. PHEVs, like the Volt, offer the fuel efficiency advantages of an HEV, the long range of a gasoline vehicle, and the ability to plug-in to electric power sources which can charge the vehicles battery and allow it to operate for around 40 miles in all-electric mode. According to the US Department of Transportation, $66 \%$ of US drivers travel less than 30 miles per day and 76\% travel less than 40 miles per day, so a PHEV like the Chevrolet Volt would be able to meet the needs of about $3 / 4^{\text {th }}$ of American drivers using only its allelectric driving mode [91, 92]. This allows the vehicle to operate primarily on inexpensive electric power, while producing no direct tail pipe emissions. For longer trips, a PHEV can use its gasoline engine. Combining the mile per gallon efficiency of the Volt's gasoline engine (approximately $37 \mathrm{MPG}$ ) with it performance in electricvehicle mode, it can achieve a mile per gallon equivalent (MPGe) of 93. This results in average emissions per mile equal to $43.4 \mathrm{CO} 2 \mathrm{~g} / \mathrm{mi}(27 \mathrm{CO} 2 \mathrm{~g} / \mathrm{km}$ in all electric mode $)$ [93]. The Nissan Leaf is BEV introduced into the US market in 2011. It has an 99 MPGe rating and produces would produce about $20 \mathrm{CO} 2 \mathrm{~g} / \mathrm{mi}$ using average US energy mix [94]. According to Chevrolet, the Volt should "cost less than 2 cents per mile to drive on electricity, compared with 12 cents a mile on gasoline at a price of $\$ 3.60$ a gallon [95]." 
Sales of leading PHEV and BEV in the US from 2010 to 2017 have been modest, but fast growing. Sales of the most popular models--the Chevrolet Volt, Nissan LEAF, Toyota Prius Plug-in and others - are shown in Appendix A for data obtained by the end of September 2017.

Sales of the industry leading EVs in the US reached over 91,000 by the third quarter of 2017. They are expected to be lower than overall sales of approximately 120,000 in 2016. In 2016 the Prius Prime came out and only 52 of the previous Prius Plug-in Hybrid Vehicles (PHV) were still sold in the US. So, the sales figures of the 52 old model Prius PHVs were added to the figures of the new Prius prime to represent the continuation of this line. Sales of leading EVs in the US in 2015 total stumbled to around 89,000, up just slightly from off of 2013 year sales. Sales of EVs in 2014 reached over 105,000 , exceeding trend projections from the third quarter of the year, where they were on track to only sell about 58,000. 2014 sales represented about a $25 \%$ increase over 2013 sales. 2012 figures were nearly triple the sales from 2011 and cumulative EV sales nearly quadrupled, to almost 64,000 . Sales of the Nissan LEAF began to rebound after being impacted by the Japanese tsunami of 2011, but the end of the year, sales only slightly exceed that of 2011 [102]. In 2013, a number of additional EV models became available from Ford and in 2014, BMW introduced its i3 model, which has been so successful that by quarter 3 of 2015, it sales figures were slightly higher than the Nissan Leaf at that point in the year [97]. Declining gas prices in 2015 may have been one factor that hurt electric vehicle sales, as well as the expiration of a number of tax credits and 
incentives, like carpool lane permits, in a number of areas. In addition to low gas prices, another explanation for the decline is sales is that a number of all new vehicle models were announced for 2016, possibly causing some consumer to wait for those new models.

Future trends for the adoption of BEVs and PHEVs are not yet clear. When some of the first mass produced EVs were sold in 2012, the 41,000 EVs in the US represented only about $0.32 \%$ of the 12.8 million vehicles sold in the previous year. The figure below shows how the percentage of EV sales versus total vehicle sales has changed for the US and worldwide by 2016 .

Table 3.1: Percentages of EVs versus Total Vehicles Sales in 2016

\begin{tabular}{|c|c|c|}
\hline & Total Vehicles & EV Sales \\
\hline US & $17,600,000$ & 159,139 \\
\hline Worldwide & $88,100,000$ & 664,437 \\
\hline
\end{tabular}

Source: Calculated from InsideEVs [99], Money [103], and Business Insider [104]

As the above figures show, EV sales in 2016 accounted for nearly 1\% of total vehicle sales in the US and 3.8\% of vehicles sales worldwide. Nissan CEO Carlos Ghosn projects that by 2020 , nearly $10 \%$ of cars sold globally will be BEVs [105]. The US remains one of the most important markets for EV, but its share of the worldwide EV fleet has changed significantly over time. The percentage of US EV sales versus worldwide EV sales is shown in the figure below. In 2014, US EV sales accounted for nearly 40\% of global EV sales, but by 2016 and 2017, that figure had settled down to only about $25 \%$ of cumulative sales. 
Table 3.2: US EV Sales as a Percentage of World Totals (2014 to 2017)

\begin{tabular}{|l|c|c|c|c|c|}
\cline { 2 - 6 } \multicolumn{1}{c|}{} & Cumulative & $\mathbf{2 0 1 7}(\mathbf{Q 1 - 3})$ & $\mathbf{2 0 1 6}$ & $\mathbf{2 0 1 5}$ & $\mathbf{2 0 1 4}$ \\
\hline USA & 520,287 & 121,502 & 159,139 & 116,597 & 123,049 \\
\hline Worldwide & $2,083,174$ & 547,727 & 664,437 & 550,297 & 320,713 \\
\hline \multicolumn{7}{r}{$\mathbf{2 5 . 0 \%}$} & $\mathbf{2 2 . 2 \%}$ & $\mathbf{2 4 . 0 \%}$ & $\mathbf{2 1 . 2 \%}$ & $\mathbf{3 8 . 4 \%}$
\end{tabular}

Source: Calculated from Green Car Reports [96], and HybridCars [97] and InsideEVs [98-101]

At present, however, very little can be definitively concluded regarding future adoption patterns of EVs. This research will not attempt to address all the current economic issues associated with EV ownership, or the numerous other pros and cons that are just now beginning to be considered about this technology. Instead, it will focus on analyzing the factors involved with the development of smart EV charging systems that connect to the power grid, and understanding the various advantages or disadvantages that such systems could provide. As with other aspects of EVs, this emerging technology offers a complex set of trade-offs. If trade-offs with low operating costs versus high purchase prices are favorable, EVs may be adopted in sufficient numbers that they may become a significant resource for or burden on the power grid. With current high gas prices, government subsidies, and other benefits, like the use of carpool lanes, EVs may begin to pay back their high purchase prices quickly and grow in popularity. If battery prices continue to fall, this trend could accelerate, increasing the need to understand the grid impacts that could occur. If technologies are developed in ways that align smart business models, as well as regulatory, and policy frameworks, this could help solve one more piece of the puzzle of how to make our future transportation system cleaner, greener, and smarter for the key stakeholders. The next section will look in more detail at 
how electric vehicles can be connected to the power grid in ways that help provide value for all those involved.

\subsection{Electric Vehicle Smart Charging and Vehicle-to-Grid}

Electric vehicle charging is the process by which the electrical energy stored in vehicles batteries is replenished after use. Devices which perform this charging function are commonly referred to as EV Supply Equipment, or EVSE. In most cases, EV owners are likely to charge their vehicles in their home garages overnight. Residential EV charging is expected to account for $60-80 \%$ of charging needs $[106,107]$. The table below shows a list of the various types of electric vehicle charging options and the time requirements and performance characteristics of each option.

Table 3.3: Characteristics of EV Supply Equipment (EVSE / Chargers)

\begin{tabular}{|c|c|c|c|c|}
\hline $\begin{array}{c}\text { Charger } \\
\text { Type }\end{array}$ & $\begin{array}{c}\text { Charging } \\
\text { Time }\end{array}$ & $\begin{array}{c}\text { Power } \\
\text { Supply }\end{array}$ & Voltage & $\begin{array}{c}\text { Max } \\
\text { Current }\end{array}$ \\
\hline Level I & $6-10 \mathrm{hrs}$ & $1.5 \mathrm{~kW}$ & $120 \mathrm{VAC}$ & $16 \mathrm{~A}$ \\
\hline Level II & $3-4 \mathrm{hrs}$ & $6.6 \mathrm{~kW}$ & $240 \mathrm{VAC}$ & $32 \mathrm{~A}$ \\
\hline Level III & $20-30 \mathrm{~min}$ & $50 \mathrm{~kW}$ & $400-500 \mathrm{VDC}$ & $100-125 \mathrm{~A}$ \\
\hline
\end{tabular}

Source: AeroVironment [108], ECOtality [109]

As shown in the table above, Level I chargers are generally provided with EV as a default, slow charging option, which can work with voltages that are available from standard US electrical wall outlets. Level II chargers are a faster and more powerful 
option that may be installed for additional cost by a home owner [108]. In the case of long distance trips or other situations where an EV battery becomes depleted and cannot be recharged at home, public charging stations are becoming available to meet this need. Level II charging stations are also becoming available in many commercial locations. Level III chargers, also known as DC quick chargers, are the fastest option, but require specialized equipment and commercial level voltages in the 400-500 volt range [109].

What is vehicle to grid or gridable vehicle technology? The Vehicle-to-Grid (V2G) concept envision a process where electric vehicles or plug-in hybrid electric vehicles are attached to a utility grid where they are capable of both charging and discharging energy from their battery storage systems [110]. The charging and discharging rates will vary as the needs of the vehicle or the power grid charge. In this type of system, vehicles connected to a charging system will communicate with the grid and become either providers user of vehicle charging services [111].

The V2G concept is seen as valuable because the majority of vehicles are parked are parked over $90 \%$ of the time. Thus, there is an opportunity for vehicle batteries to be used at these times to provide services to the grid. From the consumer point of view, the key issue is just making sure that there is sufficient charge in their vehicle batteries when they need to use their cars for transportation purposes. These types of V2G services have been estimated to be worth as much as $\$ 4,000$ per for a single EV [112]. However, this can only occur if a system is set up that uses the right technology and business model, 
and the right frameworks are put in place to meet regulatory and policy requirements. One idea for creating such a framework is a transactive energy model. Transactive energy is a concept that envisions each instance where power is supplied or demanded on the grid as a transaction, which has a market value at that time [113] [114]. Smart appliances connected to the grid would be able to determine the availability and cost of electricity to meet their needs. In cases where the cost of electricity was high and devices did not need to perform a function right away, they might be programmed to wait for a later time, such as evenings, when electricity is usually available at lower "off-peak" rates. In cases where a device like an electric vehicle could either supply or demand electricity, it might be able to achieve optimum profitability by selling at the times that prices were high and buying at the times when prices are low. This assumes, of course, that the device also knows what the user's needs will be and keeps enough energy storage to meet those needs. Otherwise, it is possible that too much energy will be sold and the user will then have to buy additional energy to meet essential needs at potentially high market prices. Transactive energy frameworks are an important emerging concept that is currently being pursued in the utility sector. Such frameworks are expected to have significant impacts on the way electric vehicle charging or V2G systems are implemented in the future.

An early example of V2G research is underway at the University of Delaware, where a demonstration project is investigating economic, and environmental issues related to the technology and exploring market development needs [113]. Additional 
example of such projects include one at the Austin Pecan Street Project, PNNL, NREL, Pacific Gas \& Electric, Xcel Energy, and others [114].

There are a number of technical hurdles to $\mathrm{V} 2 \mathrm{G}$, including the fact that it is often difficult for EV to convert AC and DC currents and put electricity back onto the grid at precise the time it is needed and in exactly the form that is required. One simpler variation on $\mathrm{V} 2 \mathrm{G}$ is called smart charging, where vehicles to not put electricity back onto the grid, but they vary their usage, or charge rates significantly in response to grid needs. This effectively makes the electric vehicles a type of demand response technology, which achieves many of the same goals as $\mathrm{V} 2 \mathrm{G}$, but uses a much simpler process. The following sections explores some additional requirements related grid capacity requirement for EV charging and how using various type of smart charging systems, up to and including $\mathrm{V} 2 \mathrm{G}$ to address these concerns. Once this is done, the process of designing systems to that fit with critical regulatory and policy requirement can also be addressed.

\subsection{Grid Capacity and Impacts}

Portions of the US utility infrastructure are already prepared to accommodate the adoption of significant numbers of electric vehicles. According to a new study by Pacific Northwest National Labs, if all the light duty vehicles in the country were replaced with plug-in electric vehicles, the off-peak generation capacity that often goes unused during 
late night hours would be nearly sufficient to charge all these vehicles [115]. However, there is no doubt that this would have effects on other parts of the utility infrastructure. In some cases, distribution infrastructure, such as transformers and substations may need to be upgraded. However, this could be done gradually, on a case-by-case basis.

In terms of environmental effects, a transition to an all electric fleet of light duty vehicles in the US would result in a $27 \%$ reduction in emissions of carbon dioxide, methane, and nitrous oxide, an increase in particulate matter emissions, no change in sulfur dioxide emission and a virtual elimination of carbon monoxide and volatile organic compound emissions [116]. This assumes that power generation would continue to be performed with the country's current energy mix, which relies on coal fired power plants for nearly half of its electricity production. However, as the energy mix has transitioned toward higher percentages of renewable energy and natural gas fired generation, the overall emissions in the system go down, and the benefit of using electric vehicles increases. It should also be noted that while emissions of many pollutants would not be eliminated, they would be displaced from the "street level," where they have "high human-health implications [115]."

Therefore, if widespread adoption of EVs occurs in the near future in the US, it is both technically feasible for the power grid to handle this and it is environmentally beneficial to do so. From an economic point of view, it also appears that this would not 
involve excessive amounts of new infrastructure investment for power generation and transmission, but may involve some need for distribution system upgrades. However, a number of additional challenges remain to develop a system for smart electric vehicle charging that would meet regional utility and regulatory needs, while doing so with a sound business model. The next section looks at the needs for solving one of the key regional utility planning needs in the Pacific Northwest, being able to integrate increasing amount of intermittent renewable energy in a cost effective manner.

\subsection{Smart Grid and Renewable Energy Integration}

The ability to integrate rapidly growing amounts of intermittent renewable energy onto the power grid is a critical challenge in the Pacific Northwest, as mentioned in opening paragraph in this chapter. The Oregon Renewable Energy Act of 2007 established a Renewable Portfolio Standard (RPS), requiring that the state's largest utilities generate a percentage of their retail electricity from qualified renewable energy sources. The RPS mandates that utilities providing over 3\% of Oregon's load produce $25 \%$ of their power from renewable energy sources by 2025 [9]. Intermediate targets of $5 \%$ by $2011,15 \%$, by 2015 , and $20 \%$ by 2020 were also established [117]. Smaller utilities were given smaller targets.

As a region, the Pacific Northwest (PNW) United States has a large amount of renewable energy and integrating it is now a major challenge. Over 8,000 $\mathrm{MW}$ of 
intermittent renewable energy in PNW at end of 2016 [118]. An additional 3,000 to 4,000 MW by are expected by 2025. The Bonneville Power Administration (BPA), which is charged with managing the Federal Columbia River Power System, has commissioned independent estimates showing that it can integrate approximately 3,500 MW of this renewable energy with existing hydropower facilities [119]. However, the task of integrating additional capacity beyond that will need additional solutions.

In order to make effective use of renewable energy, it must be integrated onto the electricity grid. Many of the leading forms of renewable energy, such as wind power or photovoltaic solar energy, are variable energy resources, meaning their output varies depending on the amount of wind or sunshine available in a local area. In order to match the amount of energy available from variable energy resources to the amount of energy needed on the grid at any one time, a process of "power firming" must occur to integrate renewable energy onto this grid. This means that at times when variable energy resources are not active, energy must be either taken from an energy storage system, or produced from another source. The most cost effective methods of renewable integration are shown on the Flexibility Supply Curve: 
Figure 3.1: Flexibility Supply Curve for Renewable Energy Integration

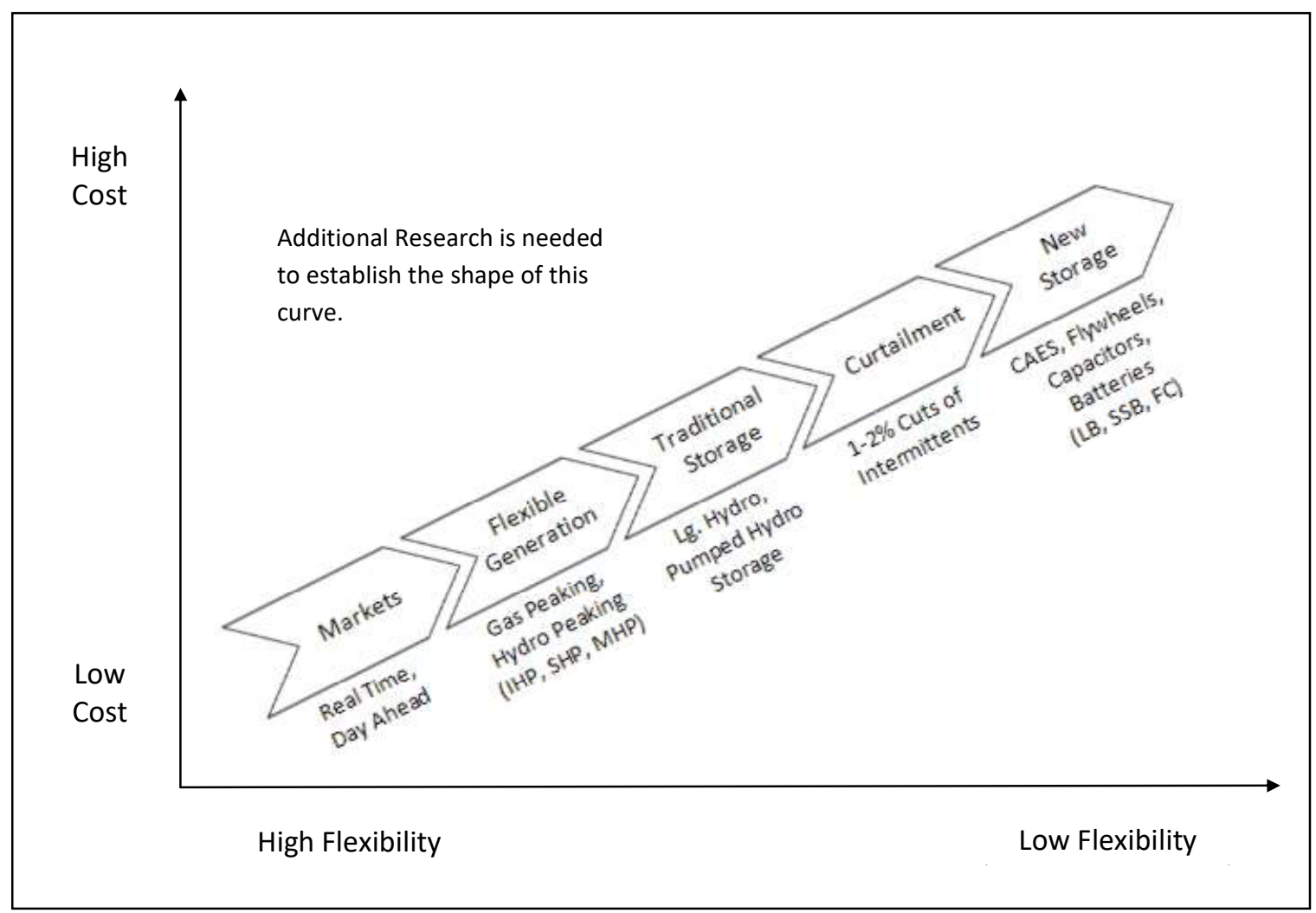

Source: National Energy Efficiency and Renewable Energy Laboratory [71]

The most cost effective and flexible options are located at the base of the supply curve: (1) Markets -- Real-Time, Day Ahead, and Demand Response; (2) Flexible Generation -- Gas Peaking Turbines, and Hydropower Peaking; (3) Large Hydropower and Pumped Storage; (4) Curtailment; and (5) New Storage Technologies--Flywheels, Compressed Air, and other prototypes.

Demand Response, a smart grid technology which allows energy users to manage consumption based on available supply, is a particularly promising technology for 
renewable energy integration. Demand response can be accomplished with a variety of smart appliances that are able to communicate with the grid.

As electric vehicles become more common, emerging vehicle-to-grid technology offers the prospect of allowing electric vehicles to act as a smart appliance when connected to smart grid charging devices. Because of the important policy directives in the Pacific Northwest for reducing carbon emissions and meeting renewable portfolio standard requirements, this research will involve the creation of a roadmap for vehicle to grid technologies that will fit into the general smart grid roadmap for the region that was previously described. The next section looks at the requirements for laying out a technology roadmapping process to address these issues. 


\section{CHAPTER 4: Research Approach and Methods}

\subsection{Technology Roadmapping for Business and Regulatory Integration: The Case of Smart Grid \& Vehicle-to-Grid Charging Technologies}

This section presents a summary of the needs and challenges for constructing a technology roadmap that integrates business, market, regulatory and policy factors to provide a more complete understanding of how emerging technologies can be developed in ways that fit with regulated utility industry structures, energy policy goals, and effective business models. For the case of smart vehicle-to-grid technologies, it is important to be able to tailor this process to the development needs of Oregon and the Pacific Northwest. Each of the methods presented in the research schema will be explained and discussed later in this chapter. First, however, a brief review of specific literature relevant here is presented, along with a justification of why these methods should be used. The diagram for the research schema is shown in Appendix D1.

\subsection{Justification of Methodologies}

What methods are needed to study the development of the emerging vehicle-togrid smart charging industry and understanding the various business and market needs, regulatory and policy requirements, and technology development gaps that must be filled in order to achieve the multiple benefits offered by such technology? To fully answer this, an analysis is required for the entire industry ecosystem, its stakeholders, and value chain. However, Smart Grid, Electric Vehicles, and vehicle charging technologies are still in an emerging state. Likewise, relevant industry structures, regulatory structures, 
and policy structures are at a nascent stage as well. Previous sections have provided additional details regarding each of these areas. However, a clear and comprehensive set of methods is required to study this problem in detail. Therefore, a key goal of this research will be to propose, explain, and implement a set of methodologies that is appropriate for improving understanding in this area. Additional explanations and references to relevant literature will be provided in the next section, which summarizes the methodological needs.

Why may TRM and related methods be useful for studying V2G? Industries and sub-industries are already beginning to coalesce around Smart Grid, Electric Vehicles, and vehicle charging technologies. However, many such efforts lack clear guidance and standards regarding development even within particular sub-industries, much less coordinated planning among related industry clusters and value chains. Technology roadmapping can help provide a vision of where trends are headed.

In situations where clear business opportunities already exist, a technology roadmap makes it easier to identify and understand the nature of such opportunities. However, in many cases, opportunities and strategies for capturing them are just being identified. In some cases, business models have not yet been developed to accommodate evolving regulatory and policy structures. However, as industry and trade associations develop for smart grid, the need is growing to help a wide range of potential Smart Grid users understand how such new grid infrastructures could benefit specific industries or sub-industries. 
Business Concept Development is therefore an important initial step. This provides a way of understanding stakeholder needs, values, and drivers based on regional integrated resource planning goals, policy needs, customer preferences, and opportunities that can be filled by bridging technology gaps. The next critical step is an industry analysis that makes use of tools like Porter's Five Forces to understand the viability of particular business concepts with an industry. However, this tool needs to be modified to focus particular attention on the effect of barriers that exist within regulated industries, such as utilities, which generally have evolved as natural monopolies. While regulated monopoly structures in many cases are unlikely to change for such industries, it is important to understand how changes in technology, policy, and limited market restructuring can create new opportunities. Therefore, the goal of this phase of industry analysis is to understand what factors can mitigate existing barriers and how appropriate business targets can be designed and used to create technology roadmaps. The next phase is then the actual technology roadmap construction, including prioritization of key technology gaps, as well as barriers and mitigators. Finally, an outcome analysis is used to summarize the main paths to desired outcomes and what factor dependencies exist in order to achieve these outcomes.

The types of methods presented in this section are needed in order to deal with the unique nature of smart grid technology and product development for regulated regional utility systems in general and for electric vehicle smart charging systems in particular. Many problems cannot be solved at just a local or state level, but must instead be solved 
at higher levels, such as through the coordinated development of regional power system planning, policies, and technologies. Smart Grid and Electric Vehicle Smart Charging applications are new, and the characteristics of such systems are not well understood yet. Multiple perspectives are needed to understand how regulatory and policy issues, as well as market characteristics, can lead to the creation of new business models that are appropriate for the rapidly evolving smart grid technologies that are now emerging.

\subsection{Summary of Methodological Needs}

Literature from several key literature streams has been reviewed in previous sections of this research. These literature streams were initially discussed in a general manner. However, now the goal in the following sections is to synthesize the lessons learned from reviewing those literature streams and to determine if additional elements are required to develop a comprehensive methodology for achieving the goal given in the title of this research: Technology Planning for Aligning Emerging Business Models and Regulatory Structures - The Case of Electric Vehicle Charging and the Smart Grid. To achieve this, gaps are identified in three main literature areas: Technology Roadmapping, Smart Grid \& Electric Vehicles, and Integrated Resource Planning. More detail about each of these areas is provided in the sections below. 


\subsubsection{Methodological Needs: Technology Roadmapping Literature}

The first key area analyzed was the Technology Roadmapping literature. The initial discussion of this in section 1.2.5 began the process of identifying drivers and performing the first steps for s-plan and t-plan style roadmap analyses for demand response technologies. Also discussed were the current efforts to create smart grid roadmaps, which actually involved a different set of literature than traditional technology roadmapping. The following research gaps are summarized on the table below.

Figure 4.1: Technology Roadmapping Literature Gaps

\begin{tabular}{|c|c|c|}
\hline Research Concept & References & Research Gaps \\
\hline $\begin{array}{l}\text { Various processes developed } \\
\text { for applying TRM in current } \\
\text { and emerging industries }\end{array}$ & [29-33], [120-129], [130-139] & $\begin{array}{l}\text { Method is needed to integrate } \\
\text { business modeling, policy, } \\
\text { and regulatory factors into }\end{array}$ \\
\hline $\begin{array}{l}\text { Several methods integrate } \\
\text { aspects of business modeling } \\
\text { with TRM }\end{array}$ & $\begin{array}{l}{[132,133],[135,136],[140-145],} \\
{[61,62,146-148],[149-162],[163,} \\
164]\end{array}$ & TRM for the utility industry \\
\hline $\begin{array}{l}\text { Few studies consider policy } \\
\text { dimensions of TRM or } \\
\text { regulatory frameworks, } \\
\text { particularly in the utility } \\
\text { industry }\end{array}$ & {$[165,166],[146],[61],[149]$} & $\begin{array}{l}\text { TRM goals must align with } \\
\text { regional-level factors for } \\
\text { utility industry and associated } \\
\text { products }\end{array}$ \\
\hline $\begin{array}{l}\text { TRM generally used at } \\
\text { company-, industry-, and } \\
\text { national-level, rather than } \\
\text { incorporating regional utility } \\
\text { concerns }\end{array}$ & $\begin{array}{l}{[5,66-73][165-170]} \\
{[61,62,145-155],[171-178]}\end{array}$ & $\begin{array}{l}\text { Additional work needed } \\
\text { prioritizing R\&D, acquisition } \\
\text { processes, and barriers in } \\
\text { utility related industries }\end{array}$ \\
\hline $\begin{array}{l}\text { More work also needed } \\
\text { prioritizing } R \& D \text {, acquisition, } \\
\text { and barriers }\end{array}$ & & \\
\hline
\end{tabular}


A number of processes have been developed for applying TRM to current and emerging industries. General methods have been created for examining both the strategic landscape and technology performance characteristics of new technology product development [29-33]. In section 1.2.5 and an initial study was begun to apply such processes to a particular smart grid sub-industry involving demand response products. Application of such processes to disruptive technologies is highly relevant for smart grid and has been well examined in the literature [120-129]. The process has also been applied to emerging technologies in the renewable and sustainable energy industry, which have strong overlaps with and similarities to the smart grid industry [130-139].

However, the customization of such processes to meet the needs of specific industries, business models, and emerging technology products is an important need that must be addressed. A variety of methods have been developed for integrating aspects of business modeling with technology roadmapping [132, 133], [135, 136], [140-145]. The application of roadmapping to smart grid related industries also need to consider regional implications associated with region spanning utility systems [61, 62, 146-148] and development of business models to address strategic, regulatory, and policy landscapes [149-164].

However, few studies have done detailed analysis of the policy dimensions of TRM or regulatory frameworks, particularly with regard to the utility industry $[165,166]$, [146], [61], [149],. TRM has generally been done at company-, industry-, and nationallevel, rather than incorporating regional utility concerns [5, 66-73] [165-170]. More 
work is also needed to understand how to prioritize R\&D needs, acquisition efforts [171178] as well as to understand barriers what may affect implementation. It then may be possible to determine how such barriers could be mitigated with practices involving appropriate business models, market, and regulatory elements [61, 62, 145-155].

Therefore, a method is needed to integrate business modeling, policy, and regulatory factors into TRM for the utility industry. This method is particularly important for the utility industry, due to it unique characteristics and the need for regional scale solutions. Additional research is also needed regarding prioritization of $\mathrm{R} \& \mathrm{D}$ acquisition processes, and barriers in utility related industries. An improved methodology could provide a more complete and better integrated smart grid roadmap to improve planning in the industry. Without such a method, technology planning for regional scale utility systems is likely to be slower, more difficult, and less integrated.

\subsubsection{Methodological Needs: Smart Grid \& Electric Vehicle Literature}

The second key area discussed was the Smart Grid and Electric Vehicle literature. The initial discussion of this included only general literature. The following research gaps are summarized on the table below. 
Figure 4.2: Smart Grid \& Electric Vehicle Literature Gaps

\begin{tabular}{|c|c|c|}
\hline Research Concept & References & Research Gaps \\
\hline $\begin{array}{l}\text { Smart grid roadmap } \\
\text { literature typically focuses } \\
\text { on operational plans for } \\
\text { utilities as opposed to } \\
\text { regional energy planning } \\
\text { Generally do not consider } \\
\text { regional goals and } \\
\text { structural barriers to } \\
\text { business and market } \\
\text { adoption } \\
\text { No current SG roadmaps } \\
\text { for Oregon or the Pacific } \\
\text { Northwest. }\end{array}$ & $\begin{array}{l}\text { [3], [6], [14-19], [40, 41], [37-39, } \\
56-59],[179] \\
\text { [42-51], [52-55], [180, 181], [182- } \\
\text { 189], [167, 168], [190-193] } \\
\text { [43, 44, 46, 47] } \\
\text { [71-73], [110], [123-129], [140], } \\
\text { [194-197] }\end{array}$ & $\begin{array}{l}\text { Smart grid planning } \\
\text { literature could benefit } \\
\text { from better alignment } \\
\text { with technology } \\
\text { roadmapping literature } \\
\text { Process needed to create } \\
\text { roadmaps for smart grid } \\
\text { technologies that integrate } \\
\text { business modeling with } \\
\text { regulatory factors and } \\
\text { policy factors to meet } \\
\text { regional energy planning } \\
\text { objectives and overcome } \\
\text { structural barriers } \\
\text { Customization needed to } \\
\text { develop technology } \\
\text { roadmapping processes } \\
\text { for EV smart charging } \\
\text { systems }\end{array}$ \\
\hline
\end{tabular}

Smart grid roadmap literature typically focuses on operational plans [3], [6], [14], [15-19], for utilities as opposed to regional energy planning [37-39, 56-59]. Some studies examined limited aspects of wider regional planning and generally indicated advantages over more narrow operational plans [40, 41], [179].

However, most current studies examined to date generally have not emphasized regional level considerations [42-55]. Research on important elements of regional level smart grid planning has been initiated [180-189]. But, these results have not generally been integrated into models that systematically consider and assess regional goals $[167$, 168, 190-193]. Process needed to create roadmaps for smart grid technologies that 
integrate business modeling with regulatory factors and policy factors to meet regional energy planning objectives and overcome structural barriers.

Although some initial state-level studies have been conducted, no current smart grid roadmaps have been created for Oregon or the Pacific Northwest on a regional basis $[43,44,46,47]$. Supporting important goals like the Renewable Portfolio Standard in Oregon and most other Northwestern states has been discussed in chapter 3, along with smart appliances, such as electric vehicles. Electric Vehicle Smart Charging technologies appear to offer significant potential to support key state and regional goals for meeting the portfolio standard and enhancing to robustness of the power system. However, significant planning efforts [71-73] are needed to created roadmaps related to these emerging technologies [110], [123-129], [140] and adapt them to the needs business and market, policy and regulatory, and technology needs that have been discussed for such a system [194-197].

Processes are needed to create roadmaps for smart grid technologies that integrate business modeling with regulatory factors and policy factors to meet regional energy planning objectives and overcome structural barriers. Smart grid planning literature could benefit from better alignment with technology roadmapping literature. But, significant customization is needed to develop roadmapping processes for EV Smart Charging Systems. 


\subsubsection{Methodological Needs: Resource Planning \& Policy Literature}

The third key area discussed was the Resource Planning literature. The initial discussion of this included only general literature. The following research gaps are summarized on the table below.

Figure 4.3: Resource Planning \& Policy Literature Gaps

\begin{tabular}{|c|c|c|}
\hline Research Concept & References & Research Gaps \\
\hline $\begin{array}{l}\text { Strategic alignment of } \\
\text { business model and policy } \\
\text { frameworks particularly } \\
\text { important for regulated } \\
\text { industries like electric } \\
\text { utilities }\end{array}$ & $\begin{array}{l}{[4],[8],[10],[20-26],[40-45],} \\
{[49],[39,56],[182-186],[190],} \\
{[198,199]}\end{array}$ & $\begin{array}{l}\text { Need to incorporate an } \\
\text { understanding of utility } \\
\text { regulation and planning } \\
\text { processes to create } \\
\text { strategic alignment } \\
\text { between business models } \\
\text { and policy frameworks }\end{array}$ \\
\hline $\begin{array}{l}\text { Unique regional energy } \\
\text { policy planning issues in } \\
\text { Pacific Northwest due to } \\
\text { regulatory frameworks }\end{array}$ & $\begin{array}{l}{[46-48,50],[59],[180,181],[5,} \\
69,187],[61,146,147],[192]\end{array}$ & $\begin{array}{l}\text { TRM methods need to be } \\
\text { adapted to unique } \\
\text { regulatory frameworks for } \\
\text { regional utility industries }\end{array}$ \\
\hline $\begin{array}{l}\text { Multiple perspectives view } \\
\text { is critical for creating robust } \\
\text { planning models in the } \\
\text { utility industry }\end{array}$ & $\begin{array}{l}{[29-31],[71-73],[172-177],[200,} \\
201]\end{array}$ & $\begin{array}{l}\text { Strong need for multiple } \\
\text { perspective planning } \\
\text { models in utility industry } \\
\text { that create strategic } \\
\text { alignment between } \\
\text { business models, policy, } \\
\text { and regulatory } \\
\text { requirements }\end{array}$ \\
\hline
\end{tabular}

Strategic alignment of business model and policy frameworks is particularly important for regulated industries like electric utilities [4], [8], [10], [20-22]. As discussed in chapter 1, utilities generally have large capital costs, high barriers to entry, and increasing efficiencies of scale. This gives them many characteristics of natural monopolies. Traditional structures present a number of advantages and disadvantages. But, with rapid technology advances in the utility sector, one key issue is the need to 
overcome chronically low levels of R\&D investment in the industry, estimated at around $0.25 \%$ of revenues [23]. There is also a need to understand that many aspects of utility regulatory structures have been useful and durable [24-26]. Thus, it is necessary to incorporate an understanding of utility regulation and planning processes [40-45] to create alignment [182-186] between business models and policy frameworks [190], [198, 199], and technology development [49], [39, 56],.

In particular, unique energy policy planning issues exist in Pacific Northwest due to multiple regulatory frameworks at the state $[46-48,50]$, federal $[59,180,181]$, and regional [5, 69, 187] levels. Implementing improved smart grid roadmaps will take considerable amounts of discipline spanning knowledge [61, 146, 147], [192]. A multiple perspectives view [172-177] is critical for creating robust planning models in the utility industry [71-73], [200, 201] and incorporate these inputs into a roadmapping process that an understanding of utility regulation and planning processes to create strategic alignment between business models and policy frameworks. TRM methods need to be adapted to unique regulatory frameworks for regional utility industries [2931]. Overall, there is a strong need for robust, multiple perspective planning models in the utility industry that create strategic alignment between business models, policy, and regulatory requirements 


\subsubsection{Research Gaps, Goals, and Questions}

The following sections summarizes the Research Gaps, Research Goals and Research Questions determined after performing all the analysis up to this point in this study.

Figure 4.4: Summary of Research Gaps, Goals, and Questions

\section{Research Gaps}

\section{Research Goal}

\section{Research Questions}

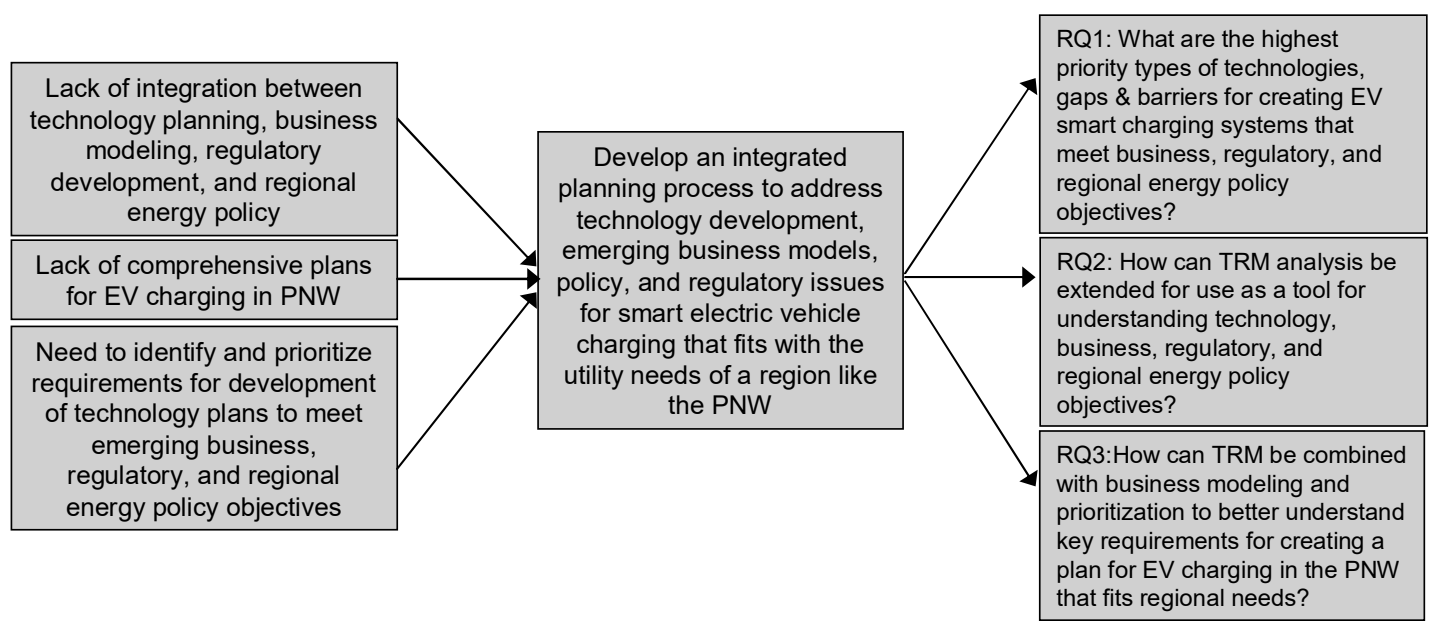

The gaps identified in sections 4.3.1, 4.3.2, and 4.3.3 are consolidated here and used to synthesize a Research Objective. The Research Objective is to develop an integrated planning process to address technology, business models, regulatory, and policy issues for electric vehicle smart charging systems to meet utility needs in regions like the Pacific Northwest. Based on these objectives, three main research questions are created to guide this study. The first research question is: What are the highest priority 
technologies, gaps \& barriers for creating EVSC systems that meet business, regulatory, and regional energy policy objectives? The second research question is: Is TRM an appropriate tool for understanding technology, business, regulatory, and regional energy policy objectives? The third research question is: RQ3:Can TRM be combined with business modeling and prioritization to better understand key requirements for creating a plan for EVSC in the PNW that meets business, regulatory, and regional energy policy objectives? The next section then explains the industry focus for this study.

\subsubsection{Research Focus}

This section explains the industry focus for this study. Although many areas of focus are possible given the topic smart grid roadmapping and regional utility policy, the key policy area that this research focuses on is the need for balancing and ancillary services to achieve integration of intermittent renewable energy resources. This has been identified as a major challenge for the region, as explained in section 3.3. In order to achieve this, the technology application area that will be the focus of this study will be on vehicle-to-grid technologies, such as electric vehicle smart charging systems. A variety of different vehicle charging infrastructures were also explained in section 3.3. These include Level 1 and Level 2 charging, which are primarily used for residential applications and Level 3 charging, which is primarily used in commercial applications, where very rapid charging is required. The diagram below illustrates this area of focus and further breaks down the types of smart charging systems. The next section then discusses the proposed methodology for the overall research design of this research proposal. 
Figure 4.5: Focal Area for Research

Develop Plan for V2G systems to prioritize requirements for meeting technology, business model, regulatory, and regional energy policy objectives

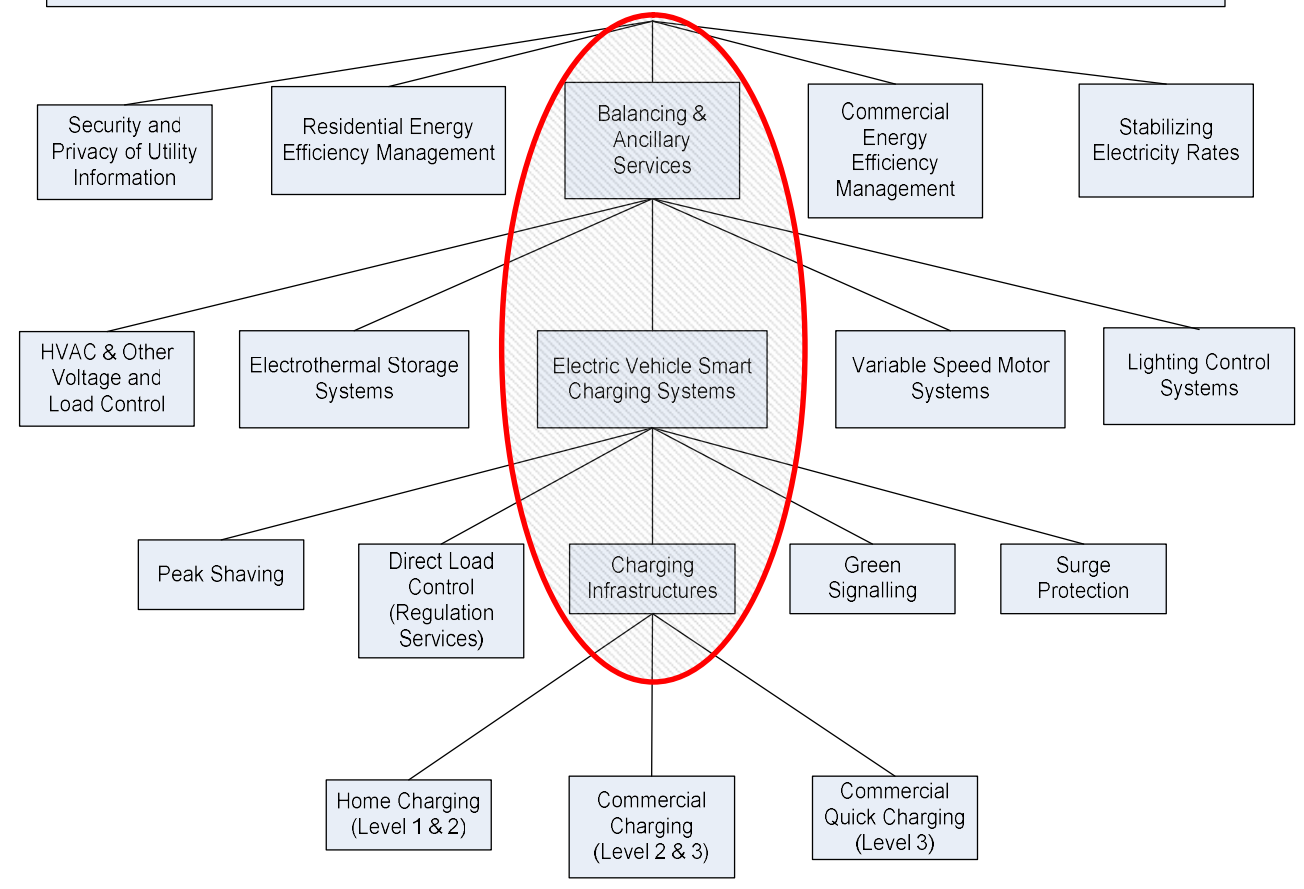

\subsection{Methodologies Proposed}

\subsubsection{Business Concept Development}

An important step in understanding the technology, business, regulatory, and policy landscapes for emerging smart grid appliances, like electric vehicle smart charging systems, is to examine key opportunities that are arising in this area and see if these 
opportunities can be developed into viable business concepts and business plans. A number of steps are necessary in order to identify and analyze such opportunities.

It is important to thoroughly define a complete set of stakeholders who may support or oppose a particular business opportunity. In the analysis matrix for the business sub-model, stakeholders are listed, but the details about them are defined on the stakeholder-objective matrix. Unlike many traditional business opportunities that have been studied outside the utility industry, the unique regulatory structures that exist for companies in Oregon and the Pacific Northwest mean that there are many significant stakeholders who are not direct customers for the product under consideration [202]. For analyzing stakeholders and their values, common tools are outcome matrices, and stakeholder-objective matrices [203, 204]. An example is shown below

The stakeholder-objective matrix provided here shows the key stakeholders and the main objectives they both support and oppose. This matrix specially addresses issues related to renewable energy integration and demand response. As the data is collected for this research, additional information could be added regarding the stakeholder issues for of electric vehicles and vehicle-to-grid system specifically.

To deal with the potential for expert disagreement, the Delphi Method can also be used. Delphi is a structured communication method using an expert panel [172]. Questions are asked over a series of two or more rounds, or iterative sessions. Experts have the opportunity to revise their answers in each round as a result of the information 
they observe from other experts. The goal is to get the experts opinions to converge on a general consensus, which is deemed to be more accurate than individual opinions.

To illustrate how a stakeholder-objective matrix could be applied to small, manageable business case, a pilot study was performed examining the concept of introducing electric bicycle rentals and/or charging on the Portland State University campus. The following diagram illustrates the stakeholder-objective matrix that was derived.

Figure 4.6: Stakeholder-Objective Matrix for e-Bike Pilot Study

\begin{tabular}{|c|c|c|}
\hline $\begin{array}{c}\text { Stakeholder (S) / } \\
\text { Customer (C) / } \\
\text { Provider (P) }\end{array}$ & What they Support & What they Resist \\
\hline UNIVERSITY $(S)(C)(P)$ & $\begin{array}{l}\text { Reducing campus parking. } \\
\text { Reducing campus traffic. } \\
\text { Reducing emissions. The } \\
\text { university is potentially a } \\
\text { stakeholder, customer, and/or } \\
\text { provider of goods and services } \\
\text { related to e-bikes. }\end{array}$ & $\begin{array}{l}\text { Large initial investments. } \\
\text { Uncertain technology. Locked in } \\
\text { obsolescence. Unless } \\
\text { partnerships could be } \\
\text { negotiated, access to e-bikes } \\
\text { would probably be limited to } \\
\text { students, faculty, and staff to } \\
\text { avoid shortages of bikes or other } \\
\text { resources. }\end{array}$ \\
\hline $\begin{array}{l}\text { GOVERNMENT - City, } \\
\text { County, State }(S)(C)\end{array}$ & $\begin{array}{l}\text { Reducing city traffic. Reducing } \\
\text { street parking. Reducing } \\
\text { emissions. City could potentially } \\
\text { participate as a stakeholder or } \\
\text { customer. They support clear } \\
\text { regulations and standards for } \\
\text { charging, operating, and parking. } \\
\text { City government and its } \\
\text { employees may consider } \\
\text { sponsoring or becoming } \\
\text { customers of an e-bike system. } \\
\text { Tax credits or other incentives } \\
\text { (mainly at the city, county, or } \\
\text { state level, but possibly also } \\
\text { federal) to encourage a campus } \\
\text { e-bike system could be important } \\
\text { to make the initial system } \\
\text { feasible to establish. } \\
\text { Governments are more likely to }\end{array}$ & $\begin{array}{l}\text { Unclear regulations for parking } \\
\text { or operating e-bikes on city } \\
\text { streets around campus. They } \\
\text { may initially loose some parking } \\
\text { revenue if street parking drops, } \\
\text { but it is likely to be compensated } \\
\text { for by additional customer } \\
\text { parking tor businesses. } \\
\text { Concerns about bike safety } \\
\text { would have to be addressed. } \\
\text { City government would probably } \\
\text { resist becoming a partner or } \\
\text { customer in such a project } \\
\text { unless technology and business } \\
\text { risk could be sufficient reduced } \\
\text { to make long-term success } \\
\text { probably and avoid a politically } \\
\text { embarrassing failure. } \\
\text { Governments would be reluctant }\end{array}$ \\
\hline
\end{tabular}




\section{Stakeholder (S) I \\ Customer (C) I \\ Provider (P)}

What they Support

support systems that are accessible to the wider community and not just those affiliated with the university.
What they Resist

to establish substantial incentives, credits, or other financial support, especially during the recent economic downturn, unless clear benefits and performance goals could be met and the risk of business or technology failure could be shown to be low.

Civic groups may be concerned about enforcing bike safety requirements and concern about bike vs. car traffic issues. Environmental groups would resist initiates without clear benefits in terms of emissions reduction, green power use, and recycling of toxic battery components.
COMMUNITY GROUPS (S) / COMMUNITY MEMBERS (S)(C)
Civic organizations are concerned with reducing traffic, parking, pollution, noise, as well groups support reduced emissions, use of green power for bike charging. Individuals community members might consider participating in an ebike system, especially if it spread beyond the university campus and into the surround community.

\begin{tabular}{|c|c|c|}
\hline STUDENTS (C) & $\begin{array}{l}\text { Reducing fuel costs, reducing } \\
\text { parking costs, increased } \\
\text { convenience, reducing } \\
\text { emissions. }\end{array}$ & $\begin{array}{l}\text { High upfront fees, long-term } \\
\text { commitments, inconvenience, } \\
\text { steep learning curves, lack of } \\
\text { reductions of emissions or other } \\
\text { pollutants, lack of use of } \\
\text { renewable energy. }\end{array}$ \\
\hline FACULTY (C) & $\begin{array}{l}\text { Reducing fuel costs, reducing } \\
\text { parking costs, increased } \\
\text { convenience, reducing } \\
\text { emissions. Faculty are like to } \\
\text { want increased cargo capacity } \\
\text { and convenience compared to } \\
\text { students. }\end{array}$ & $\begin{array}{l}\text { Difficult financing, long-term } \\
\text { commitments, steep learning } \\
\text { curves, inconvenience, steep } \\
\text { learning curves, lack of } \\
\text { reductions of emissions or other } \\
\text { pollutants, lack of use of } \\
\text { renewable energy. }\end{array}$ \\
\hline STAFF (C) & $\begin{array}{l}\text { Reducing fuel costs, reducing } \\
\text { parking costs, increased } \\
\text { convenience, reducing } \\
\text { emissions. }\end{array}$ & $\begin{array}{l}\text { High upfront fees, long-term } \\
\text { commitments, inconvenience, } \\
\text { steep learning curves, lack of } \\
\text { reductions of emissions or other } \\
\text { pollutants, lack of use of } \\
\text { renewable energy. }\end{array}$ \\
\hline \multirow{2}{*}{$\begin{array}{l}\text { UTILITY COMPANIES } \\
(\mathrm{P})\end{array}$} & $\begin{array}{l}\text { Cost recovery, fair rate of return, } \\
\text { stable long-term market, clear } \\
\text { regulations, pricing. }\end{array}$ & $\begin{array}{l}\text { Lack of standards, locking in } \\
\text { technological obsolescence }\end{array}$ \\
\hline & $\begin{array}{l}\text { ROI, market share development, } \\
\text { intellectual property } \\
\text { development, business model } \\
\text { scalability. }\end{array}$ & $\begin{array}{l}\text { Unprofitable,or marginally } \\
\text { profitable markets, lack of } \\
\text { standards, lack of clear } \\
\text { regulation, unproven technology. }\end{array}$ \\
\hline
\end{tabular}


Source: Adapted from [203, 204]

The stakeholder-objective matrix for this pilot study summarizes a number of important points. The main participants envisioned in the electric bicycle enterprise for this pilot study can be divided into Stakeholders (S), Customers (C), and Providers (P). Several participants fall into more than one categories. These participants include: University $(\mathrm{S})(\mathrm{C})(\mathrm{P})$; Government $(\mathrm{S})(\mathrm{C})$; Community Groups (S) and Community Members (S)(C); Students (C); Faculty (C); Staff (C); Utility Companies (P); and Third Party Vendors (P). Each participant has specific issues labeled "what they support" and "what they oppose," which are summarized on the above chart. This information can then be used as an input to determine how stakeholder objectives can be translated into drivers of value production for products and services on a technology roadmap. This information will then be fed into the next stage of the research process, which is to conduct an industry analysis to design and obtain a business target, define business model alternatives, establish content to construct a technology roadmap, and understand key barriers and mitigators to development.

After an opportunity is recognized, such as through literature, consultation with experts, or other means, a business modeling process can be performed to further define and assess the potential opportunity. A model is then defined describing the opportunity 
both in it current state, the "as is" model, and what is desired in the future, the "to be" model $[132,163,164]$. However, prior to creating this model, a preliminary sub-model is created to assess initial ideas. A series of basic questions are answered as shown below to begin defining an opportunity that may later be developed into a complete business model. The questions have been modified to make them relevant for creating an integrated smart grid roadmap, which may have a number of stakeholders who are not necessarily direct customers.

To illustrate how this type of business sub-model matrix could be applied, a pilot study was performed examining the case of electric bicycle rental and/or charging on the Portland State University campus. The following diagram illustrates the business submodels that were derived. 
Figure 4.7: Business Sub Model Matrix for e-Bike Pilot Study

\begin{tabular}{|c|c|}
\hline Sub Model & Sub Model Features \\
\hline $\begin{array}{l}\text { Who? } \\
\text { Stakeholders? UNIVERSITY, GOVERNMENT, COMMUNITY } \\
\text { What do they support / oppose (See stakeholder matrix) } \\
\text { Customers? STUDENTS, FACULTY, STAFF, LOCAL GOVT, } \\
\text { COMMUNITY } \\
\text { Markets? UNIVERSITY-AFFILIATED, COMMUNITY- } \\
\text { AFFILIATED, COMBINATION } \\
\text { Segments? SHORT-, MED-, LONG-DISTANCE COMMUTERS }\end{array}$ & $\begin{array}{l}\text { Structure of Market? UNIVERSITY-OWNED, UTILITY } \\
\text { OWNED, } 3^{\text {RD PARTY }} \\
\text { Target Customers? STUDENTS, FACULTY, STAFF, OTHERS } \\
\text { AS OPPORTUNITY ARISES }\end{array}$ \\
\hline $\begin{array}{l}\text { What? } \\
\text { Value Proposition? INEXPENSIVE, CONVENIENT, GREEN } \\
\text { TRANSPORTATION } \\
\text { What do stakeholders have now? FOSSIL FUEL VEHICLES, } \\
\text { NON-ELECTRIC BIKES } \\
\text { What do stakeholders want? LOWER FEUL COSTS, LOWER } \\
\text { PARKINGING COSTS, EASIER BIKE COMMUTING FROM } \\
\text { LONG DISTANCES, LOWER EMISSIONS }\end{array}$ & $\begin{array}{l}\text { Products? ELECTRIC BICYCLES, CHARGING SYSTEMS } \\
\text { Customer Utilities? CONVENIENCE, REDUCED COSTS, } \\
\text { LOWER POLLUTION } \\
\text { Competitiveness? LOW E-BIKE OPERATING COSTS. } \\
\text { OVERCOMING INITIAL SKEPTICISM ABOUT HIGH } \\
\text { PURCHASE COSTS AND UNCERTAINTY ABOUT E-BIKES IS } \\
\text { A CRITICAL CHALLENGE TO BE ADDRESSED. }\end{array}$ \\
\hline $\begin{array}{l}\text { How? } \\
\text { Value Delivery? BIKE RENTAL, BIKE LEASING, BIKE SALES, } \\
\text { BIKE CHARGING, MEMBERSHIP / SUBSCRIPTION }\end{array}$ & $\begin{array}{l}\text { Finance Acquisition? PRIVATE, BANK, VC, CROWD SOURCE, } \\
\text { MICROFINANCE } \\
\text { Manufacturing? N/A } \\
\text { Distribution Channel? B2C, B2G, B2C2G COMBO }\end{array}$ \\
\hline $\begin{array}{l}\text { Profit \& Revenues? } \\
\text { Customers? STUDENTS, FACULTY, STAFF, LOCAL GOVT, } \\
\text { COMMUNITY } \\
\text { Markets? UNIVERSITY-AFFILIATED, COMMUNITY- } \\
\text { AFFILIATED, COMBINATION } \\
\text { Segments? SHORT-, MED-, LONG-DISTANCE COMMUTERS }\end{array}$ & $\begin{array}{l}\text { Profit Model? FOR-PROFIT, NON-PROFIT, } \\
\text { Ownership Structure? PRIVATE, PUBLIC, PUB-PRIV } \\
\text { PARTNERSHIP }\end{array}$ \\
\hline
\end{tabular}

Source: Adapted from [132, 163, 164]

Several key pieces of information can be seen from the above figure. Key stakeholders include university faculty, staff, and students, as well as businesses or organizations in the local area, and local government. Decisions must be made regarding whether to focus first on specific user segments among these stakeholders or on a combination of segments. Further decisions must be made regarding the possibility of university, utility, or third-party ownership of an electric bicycle venture and if the primary profit mechanism will be rentals, battery charging, leasing, or some combinations thereof. Options for financing and distribution can then be determined that 
are appropriate for each of these cases. The next step in this process explains more details about defining a business model.

A number of additional steps are required in order to define a business model. However, before proceeding, it is important to define what is meant by a business model. In creating the framework for this research, we referred mainly to Hamel [157], Slywotzky [158, 159], and Chesbrough [160]. Slywotzky's definition is perhaps most clear and succinct. A business model is described as:

"The totality of how a company selects its customers, defines and differentiates its offerings, defines the tasks it will perform itself and those it will outsource, configures its resources, goes to market, creates utility for customers, and captures profit. It is the entire system for delivering utility to customers and earning a profit from that activity."

Understanding appropriate business models for emerging technologies, such as electric vehicle-to-grid smart charging appliances, is critically important, since much of the new technology is in a nascent state and the direction of development can depend strongly upon perceived business opportunities. This can likewise be affected by perspectives regarding the market, regulatory and policy goals, and the rate at which technical capabilities are developing. It should be noted, however, that the business models identified for this research do not constitute fully developed business plans. They focus instead on attempting to summarized and categorize the key types of factors that could drive value creation and revenue generation. The next step in this process is to examine each of these key perspectives mentioned above and to have experts determine 
what that they consider to be the highest priority issues in these areas during the following time periods: 1 year; 2 to 4 years; and 5 to 10 years.

As was done in the previous section a pilot study involving electric bicycle use at Portland State University has been used to illustrate how this type of business concept development can be applied. The following diagram illustrates the business concept development information that was obtained from this process.

Figure 4.8: Opportunities \& Perspectives in e-Bike Pilot Study

Opportunity Recognition (Worksheet 1): What is the basic opportunity and why is it valuable?

(IRP, Policy Analysis, ISRM)
A. Ask: What?
Value Proposition
Products? ELECTRIC BICYCLES
Capabilities? SIMPLE, INEXPENSIVE, GREEN TRANSPORTATION
Competitive Advantage? LOW COST, CONVENIENT
B. Ask: Where? PORTLAND STATE UNIVERSITY CAMPUS, MICROGRID, ECODISTRICT...
C. Ask: Why? Why is this important? (See Perspectives in next section for more detail)

Perspectives Recognition (Worksheet 2): Priority Issues in next 1 to 10 years (Based on S-Plan elements)
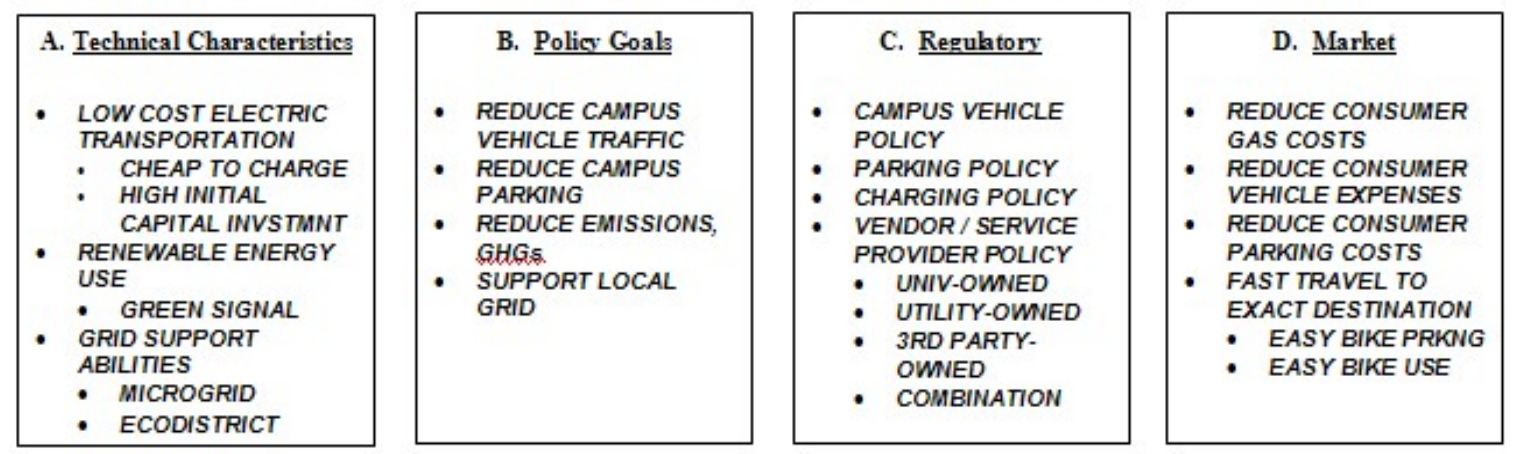

Source: Derived from [30, 145, 203, 204]

The pilot study resulted in a number of interesting insights into these questions. It helped define the basic opportunity and value proposition (summarized on Worksheet 1 
above): To provide low cost, convenient, environmentally friendly transportation with electric bicycles that are easy to use. It defined where the electric bicycles would be used: On and around the Portland State University campus, and any associated campus microgrid, or ecodistrict. It then examined why this opportunity would be important by analyzing perspectives on the technical characteristics and policy goals, as well as regulatory and market considerations (summarized on Worksheet 2 above).

The next step in this process is to provide more details about the necessary business structure and goals. This information is summarized in the figure below.

Figure 4.9: Business Structure \& Goals Summary in e-Bike Pilot Study

Business Structure \& Goals (My Vision \& My Will, ISRM Tools, Stakeholder-Objective Matrix)

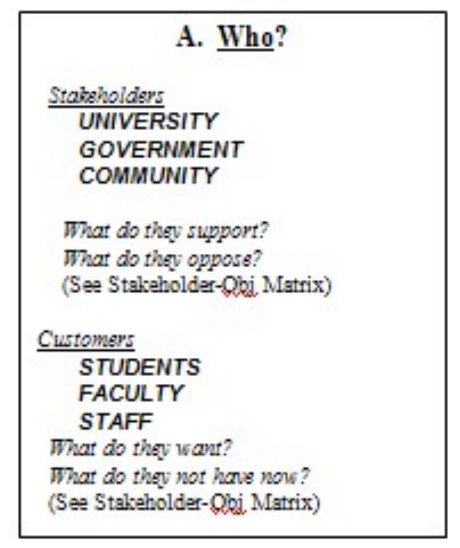

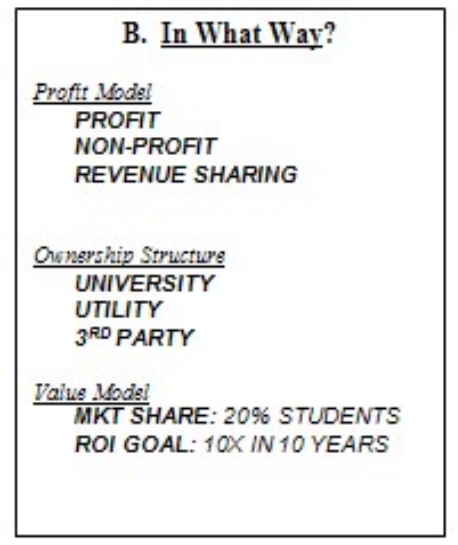

\begin{tabular}{|c|}
\hline C. How? \\
Valus Deliver Msthod \\
\hline BIKE RENTAL \\
BIKE SALES \\
BIKE CHARGING SERVICE \\
\\
Distribution Chavvel \\
B2C \\
B2G, B2G2C \\
B2UNIV \\
Finance Msthod \\
\hline UNIV SEL F FINANCING \\
BANKS \\
PRIVATE, VENTURE CAP \\
CROWD / MICRO FINANCE \\
\hline
\end{tabular}

Synthesis: By answering the above questions, it should be possible to determine (at least tentatively)

- What is the "as is" situation or opportunity to be explored? FROM: USE OF NON-ELECTRIC BICYCLES ON CAMPUS AS A TRANSPORATION ALTERNATIVE PRIMARILY FOR SHORTRANGE COMMUTERS

- What is the "to be" vision? TO: USE OFELECTRIC BICYCLES ON CAMPUS AS PART OF AN INTEGRATED CAMPUS COMMUTER SYSTEM AIMED AT REDUCING CAR USE FOR INTERMEDIATE-AND LONG-RANGE COMMUTERS.

- What are the business goals over time (i.e. $10 \mathrm{X}$ growth in 10 years...)

- What are the key gap areas or needs?

Source: Adapted from [132, 163, 164, 205] 
By answering the types of questions presented above, it should be possible to determine the following (at least tentatively):

- What is the "as is" situation or opportunity to be explored?

- What is the "to be" vision?

- What are the business goals over time (i.e. 10X growth in 10 years...)

- What are the key gap areas or needs?

A brief example of how this tool would be used is to estimate potential sales of a specific product, like residential electric vehicle chargers in Oregon over the next 10 years. A company engaged in a similar type of electronic equipment business might consider getting into this business through one or more of the potential distribution channels, but only if it could expand sales in a current business area by some goal (commonly $10 \mathrm{X}$ over 10 years). The estimated sales are the "to be" number and the current product sales are the "as is" number. If the number for the goal of increasing sales by $10 \mathrm{X}$ is greater than the "to be" number, this means there is a gap in what the new industry is estimated to achieve versus the business's goal of increasing its current sales. After determining if such as gap exists and how large it is, various alternatives can be examined for achieving the business goal through one or more business models. This helps understand key decisions that are likely to make regarding business entrant to an industry therefore this research proposes to use this as an input into an integrated roadmapping process.

Based on the pilot study, the "as is" situation is: Use of non-electric bicycles on campus as a transport alternative primarily for short-range commuters. The "to be" situation is: Use of electric bicycles on campus as part of an integrated campus 
commuter system aimed at reducing car use for intermediate- and long-range commuters. The initial business goal can be stated in several ways. In terms of return on investment, a goal of achieving a $10 \mathrm{X}$ or ten-fold return on investment within 10 years is envisioned. In terms of market share, the goal is to achieve participation equal to $20 \%$ of the student population. At this point in the analysis of this pilot study, such goals can be considered "stretch goals." However, they are useful in defining some possibly metrics of success that were considered reasonably attainable, based on the data gathered for this study. Key gaps or needs that would be necessary to address in order to achieve these goals would be to make decisions regarding the choice of specific value delivery methods, distribution channels, and finance methods. To better understand the possibilities that exist for each of those alternatives, an industry analysis is helpful. Therefore, an industry analysis is performed in the next section, and a more detailed analysis of results for each of these alternatives is provided there.

\subsubsection{Industry Analysis}

Industry analysis is a critical step in this research process. It makes use of well known tools, like Porter's Five Forces, to understand the viability of particular business concepts with an industry. However, this tool needs to be modified to focus particular attention on the effect of barriers that exist within regulated industries, such as utilities, which generally have been structured as regulated monopolies. While, in most cases, regulated monopoly structures are not expected to be fundamentally changed in these industries, it is important to understand how changes in technology, policy, and limited 
market restructuring may lead to the creation of new opportunities. Therefore, the goal of this phase of industry analysis is to understand what factors can mitigate existing barriers and how appropriate business targets can be designed and incorporated into roadmaps.

A widely used tool for analyzing industry conditions is Porter's Five Forces [161, 162]. The tool identifies five forces based on industrial organization economics that indicate the overall attractiveness or profitability of an industry based on its intensity of competition. The tool is valuable for most industries with competitive structures. The forces examined include the internal market issues of: (1) bargaining power of buyers; bargaining power of suppliers; (3), the viability of substitutes for the product or service in question (4), and the external market issue of new entrants to market.

In the case of pure monopolies, there would be almost no threat of new entrants, so Porter's Five Forces would be of limited value. However, many utility systems function as regulated monopolies in limited service territories. In these cases, the five forces model is relevant and can produce some valuable insights. This is especially true, as many utility systems have considered various types of restructuring, creating deregulated or partially de-regulated systems that have increased the competitive elements within the industry.

However, when using the five forces model, it makes sense to modify portions of it in a number of ways to fit the general nature of the utility industry. Typically, barriers to entry are still extremely high for utilities, even in the absence of traditional monopoly 
structures, since the investments for utility infrastructure are very capital intensive. So, a starting assumption for analysis in this industry is that is very important to understand the size and types of barriers that exist. Barriers can be further sub-divided into both the typical business \& market barriers (1) and regulatory \& policy barriers (2). So, the industry analysis portion of this research makes use of this modified structure for the five forces model.

Another area that is examined is business \& market targets, as well as regulatory \& policy targets for overcoming barriers in those areas. Finally, mitigation programs are examined, such as business \& market programs, as well as regulatory \& policy programs that could potentially be used for overcoming these barriers. The following diagram shows the modified framework. Information from electric bicycle pilot study mentioned in previous sections is provided here. 
Figure 4.10: Industry Analysis for e-Bike Pilot Study

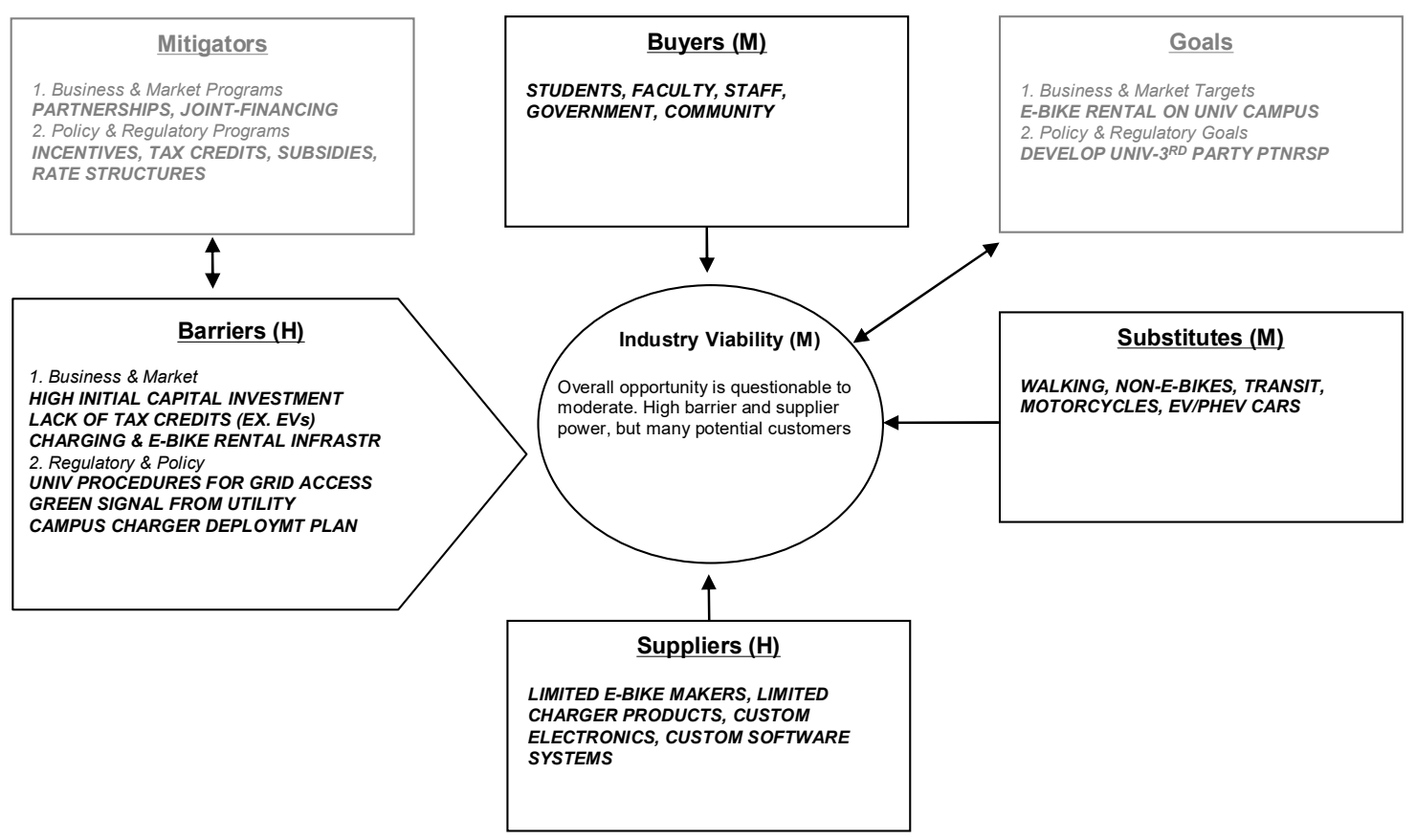

Source: Modified from [161, 162]

Based on the results of the pilot study, a number of key points can be observed. Industry Viability was rated as questionable to moderate. This was primarily due to high perceived barriers and high supplier power. Substitutes for electric bicycles were considered low to moderate. A number of mitigators were identified for addressing barriers, such as joint financing, and special rate structures or incentives that could be used to make the goal of a university-third-party partnership more attainable. The overall opportunity was considered somewhat attractive, as many potential buyers, are believe to exist for this type of system.

The industry analysis produces three main outcomes: (1) Designing and Obtaining a business target; (2) Establishing content to construct a technology roadmap integrating 
the business / market and regulatory / policy issues identified in the industry analysis; and (3) to understand the key barriers that exist and how they can be mitigated. This information will becomes an input for the next phase of the research, which constructs a roadmap based on these elements and begins the process of prioritizing them.

In situations where clear business opportunities already exist, a technology roadmap makes it easier to identify and understand the nature of such opportunities. However, in many cases, opportunities and strategies for capturing them are just being identified. In some cases, business models have not yet been developed to accommodate evolving regulatory and policy structures.

To better analyze and define the basis for various business models that are possible in the emerging smart grid industry, a technique will be used called My Vision \& My Will is used in the next section [132, 163, 164]. As previously mentioned, a business opportunity can be examined in terms of both "as is" and "to be" conditions. By looking at gaps between these two conditions, different scenarios or alternative approaches can be envisioned for achieving the desired objective. In cases where a set of industry roadmaps already exist, this can be used as an input for considering alternatives to reach the "to be" condition. However, because the type of integrated roadmaps desired in this research do not currently exist, it will be necessary to come up with scenario alternatives through a process of expert judgment. The following matrix is one tool that is helpful in determining the type of business to customer relationship that is envisioned. 
To illustrate how this type of business-stakeholder alternatives analysis could be applied a pilot study was performed examining the case of electric bicycle rental and/or charging on the Portland State University campus. The following diagram illustrates the business-stakeholder alternatives information that resulted from the study.

A number of key pieces of information are summarized on the figure below. The main business alternatives examined were Business-to-Consumer (B2C), Business-toGovernment (B2G) with an additional Business-to-Business (B2B) option, and Businessto-Community-to-Government (B2C2G2B).

Figure 4.11: Business-Stakeholder Alternatives for e-Bike Pilot Study

\begin{tabular}{|c|c|c|c|}
\hline & B2C & B2G(2B) & B2C2GB \\
\hline Customer / Stakeholder & $\begin{array}{l}\text { STUDENTS, FACULTY, STAFF } \\
\text { COMMUNITY MEMBERS }\end{array}$ & $\begin{array}{l}\text { UNIVERSITY, GOVERNMENT, } \\
\text { COMMUNITY ASSNS. }\end{array}$ & $\begin{array}{l}\text { STUDENTS, FACULTY, STAFF } \\
\text { COMMUNITY MEMBERS, } \\
\text { UNIVERSITY, GOVERNMENT, } \\
\text { COMMUNITY ASSNS. }\end{array}$ \\
\hline Product / Services & $\begin{array}{l}\text { E-BIKE RENTALS, INDIV } \\
\text { MEMBERSHIP, CHARGING } \\
\text { FEE, }{ }^{\star} E-B I K E \text { LEASE, }{ }^{\star} E-B I K E \\
\text { PURCHASE }\end{array}$ & $\begin{array}{l}\text { E-BIKE LEASE, GROUP } \\
\text { MEMBERSHIP, E-BIKE } \\
\text { RENTAL, CHARGING FEED- } \\
\text { IN, E-BIKE PURCHASES }\end{array}$ & $\begin{array}{l}{ }^{*} \text { EE-BIKE LEASE INCENTIVES, } \\
{ }^{*} E-B I K E \text { PURCHASE } \\
\text { INCENTIVES }\end{array}$ \\
\hline Operations System & $\begin{array}{l}\text { PERSONAL BUYS, RENTALS } \\
\text { SOFTWARE / WEB ENABLED, } \\
\text { POINT OF SALE }\end{array}$ & $\begin{array}{l}\text { GROUP BUYS \&RENTALS } \\
\text { SOFTWARE / WEB ENABLED }\end{array}$ & $\begin{array}{l}\text { INDIVIGROUP BUYS \& } \\
\text { RENTALS, INCENTIVES, } \\
\text { COMBINATION SYSTEMS } \\
\text { SOFTWARE / WEB ENABLED, } \\
\text { POINT OF SALE }\end{array}$ \\
\hline Profit Model & $\begin{array}{l}\text { INDIV: RENTALS, } \\
\text { MEMBERSHIP, CHARGING } \\
\text { LEASE, PURCHASE }\end{array}$ & $\begin{array}{l}\text { GROUP: RENTALS, } \\
\text { MEMBERSHIP, CHARGING } \\
\text { LEASE, PURCHASE }\end{array}$ & $\begin{array}{l}\text { INDIV/GROUP LEASE } \\
\text { INCENTIVES, PURCHASE } \\
\text { INCENTIVES, CHARGING } \\
\text { FEED-IN }\end{array}$ \\
\hline $\begin{array}{l}\text { Growth Model } \\
2013 \text { (now) } \\
2018 \text { (5 year) } \\
2023 \text { (10 year) }\end{array}$ & $\begin{array}{l}500 \text { customers ( } 2 \% \text { campus }) \\
2000(10 \%) \\
4000(20 \%)\end{array}$ & $\begin{array}{l}850 \text { (cam, gov, biz) } \\
4000(10 \%, 10 \%, 5 \%) \\
8000(20 \%, 15 \%, 10 \%)\end{array}$ & $\begin{array}{l}1000 \text { (cam, gov, biz, com) } \\
4500(10 \%, 10 \%, 5 \%, 2 \%) \\
9500(20 \%, 15 \%, 10 \%, 5 \%)\end{array}$ \\
\hline
\end{tabular}

Source: Derived from $[132,163,164]$ 
In the first case, $\mathrm{B} 2 \mathrm{C}$, the electric bicycle program is conducted directly to the end-consumers: The students, faculty, and staff at the university utilizing the program. Various products or services are available under this model, such as e-bike rentals, individual memberships, charging programs, e-bike leases, and e-bike purchases. Profit models are created based on each of these product service types. A number of operations systems are also available for enabling delivery of these products and services, such as software or web-enabled transactions, point of sales transactions at kiosks, or individual transactions between buyers and sellers. The growth model associated with B2C-oriented strategies is estimated based on an initial start-up in the first year, and then estimating growth over 5 years and growth over 10 years. Estimates for these time period are that an initial group of 500 customers ( $2 \%$ of the campus population) could be established in the first year of operations. After 5 years, the goal would be to grow this figure to 2,000 ( $10 \%$ of campus population), and after 10 years, the figure would be increased to 4,000 ( $20 \%$ of campus population). Such a strategy has the advantage of being focused on a single population in a well defined area. A number of the other strategies differ primarily in the fact that they reach out to a broader population in the area surround the campus and the community. So, they potentially can reach a greater population. However, they also have the disadvantage of being less focused on a narrow group with similar needs. Therefore, other techniques and strategies are expected to be required to serve these populations. 
In the second case, $\mathrm{B} 2 \mathrm{G}$, the idea is that rather serving only the consumers on campus, the initial focus will be on faculty and staff at the university, as well as local government agencies, such as city and county employees in the immediate vicinity of campus. This group would act as a set of lead-users, testing the system. It is likely that rather than individually selling to consumers, agreements would be negotiated that would allow package deals for all employees or groups of employees at Portland State University, Portland City Government, Multnomah County Government, the Portland Development Commission, City Police, Firefighters, Public Safety workers, and others. This is expected to be a fairly large group, which often has a history of working with and frequently even sharing building space on the Portland State University campus. Due to the likelihood of group deals, a relatively large group of customers could probably be acquired quickly. The decision could also be made to expand the focus of this strategy to a B2G2B model, which would do the same as above, except that in addition to government employees, it would also add employees of businesses in the areas surrounding the Portland State University campus. This would allow for an even larger group of customers, but would carry the risk of being less focused, and potentially requiring a more diverse set of requirements to meet customer needs than would be the case with a more narrowly defined group. In the case of the later strategies, estimates are that the initial customer base in the start-up year would be approximately 850 ( $2 \%$ of campus employees, $2 \%$ government employees, and $1 \%$ of local business employees). After 5 years, the figure would be projected to grow to 4,000 (10\% campus, $10 \%$ government, and 5\% business). In 10 years the goal would be to increase this figure to 8,000 ( $20 \%$ campus, $15 \%$ government, and $10 \%$ business). 
In the third case, B2C2G2B, this is essentially an all-of-the-above strategy. In additional reaching out directly to the end-consumers on the Portland State University campus (students, faculty, and staff), the customer base would also include local government employees, local business employees, and other community members in the surrounding area. This approach would have the advantage of a very large potential customer base, but would also have the disadvantage of being less focused than the other more narrowly defined approaches, and therefore having to meet a much more diverse set of customer needs. In this case estimates are that the initial customer base in the start-up year would be approximately 1,000 (2\% of campus employees, $2 \%$ government employees, $1 \%$ of local business employees, and $1 \%$ of other community members). After 5 years, the figure would be projected to grow to 4,500 (10\% campus, $10 \%$ government, $5 \%$ business, and 2\% community). In 10 years the goal would be to increase this figure to $9,500(20 \%$ campus, $15 \%$ government, $10 \%$ business, $5 \%$ community).

The goal of this analysis is to consider a variety of different business approaches with potential customer groups that would require different techniques for serving them and would ultimately result in very different sizes of initial customer bases, as well as the eventual size of the customer based after 10 years. The objective is not to provide forecasts to determine precisely how many customers will make a purchase in a given year. The objective is merely to begin quantifying general expectations regarding some 
of the different business approaches and to be considering the different techniques for reaching customers with a variety of different types of needs.

Another business modeling tool is then used to consider how various factors may be able to change the basis of competition over time. The following matrix provides a way of analyzing this. This offers a useful tool for examining potential factors that may impact an industry with respect to emerging dimensions of competition and overall industry viability.

Figure 4.12: Industry Factor Alternatives for e-Bike Pilot Study

\begin{tabular}{|c|c|c|c|c|}
\hline & & 2015 & 2020 & 2025 \\
\hline \multirow[t]{2}{*}{ Regulatory / Policy } & $\begin{array}{l}\text { New Policy / } \\
\text { Existing Regulatory } \\
\text { Structure }\end{array}$ & $\begin{array}{l}\text { CAMPUS E-BIKE POLICY, } \\
\text { CHARGING POLICY, } \\
\text { VENDOR POLICYI } \\
\text { PRTNRSHPS }\end{array}$ & $\begin{array}{l}\text { COMPREHENSIVE } \\
\text { CAMPUS VEHICLE USE } \\
\text { POLICY, STANDARIZED } \\
\text { PARTNERSHIP STRUCS }\end{array}$ & $\begin{array}{l}\text { TRANSACTIVE ENERGY } \\
\text { POLICY, SMART } \\
\text { APPLIANCE STDs, } \\
\text { STRATEGIC } \\
\text { PARTNERSHIP PLANS }\end{array}$ \\
\hline & $\begin{array}{l}\text { New Regulatory } \\
\text { Structure / } \\
\text { Existing Policy }\end{array}$ & $\begin{array}{l}\text { E-BIKE AGREEMNT, } \\
\text { CHARGING RATES, FEED- } \\
\text { IN, VENDOR } \\
\text { FRAMEWORK }\end{array}$ & $\begin{array}{l}\text { VEHICLE USE FEES, } \\
\text { STUDENT BIKE ORE-BIKE } \\
\text { FEES OR CREDITS, } \\
\text { STANDARIZED } \\
\text { PARTNERSHIPS }\end{array}$ & $\begin{array}{l}\text { TRANSACTIVE VALUE } \\
\text { SIGNAL, SMART } \\
\text { APPLIANCE INCENTIVES, } \\
\text { STRATEGIC PARTNERS }\end{array}$ \\
\hline \multirow[t]{2}{*}{ Market / Product } & $\begin{array}{l}\text { New Product / } \\
\text { Existing Market }\end{array}$ & $\begin{array}{l}\text { BIKE \& E-BIKE RENTAL } \\
\text { SOFTWARE, CHARGING } \\
\text { SYSTEM / MEMBERSHIP, } \\
\text { PARTNER MEMBER } \\
\text { SYSTEM, VENDOR } \\
\text { SERVICE SYS }\end{array}$ & $\begin{array}{l}\text { E-BIKE RENTAL, LEASING } \\
\text { \& PURCH, SMART } \\
\text { CHARGING SYSTEM, } \\
\text { GOVT / COMM } \\
\text { MEMBERSHIP PRGM, } \\
\text { VENDOR SERVICE SYS }\end{array}$ & $\begin{array}{l}\text { E-BIKE SMART } \\
\text { TRANSPORT SYSTEM, } \\
\text { SMART CHARGING } \\
\text { SYSTEM, GOVT / COMM } \\
\text { MEMBERSHIP PRGM, } \\
\text { VENDOR SERVICE SYS }\end{array}$ \\
\hline & $\begin{array}{l}\text { New Market / } \\
\text { Existing Product }\end{array}$ & $\begin{array}{l}\text { MED \& LONG-DISTANCE } \\
\text { BIKE / E-BIKE COMMUTER } \\
\text { SYSTEM, GOVT/ } \\
\text { COMMUNITY } \\
\text { PARTNERSHIPS }\end{array}$ & $\begin{array}{l}\text { LONG-DISTANCE E-BIKE } \\
\text { COMMUTER SYSTEM, } \\
\text { GOVT / COMMUNITY } \\
\text { PARTNER SYSTEM }\end{array}$ & $\begin{array}{l}\text { E-BIKE / SMART VEHICLE } \\
\text { ALTERNATIVE SYSTEM, } \\
\text { GOVT / COMMUNITY } \\
\text { PARTNER SYS, BUS } \\
\text { PARTNER SYS }\end{array}$ \\
\hline \multirow[t]{2}{*}{ Technology / Function } & Technological Factor & $\begin{array}{l}\text { POINT OF USE RENTAL, } \\
\text { MOBILE RENTAL, } \\
\text { CHARGING TRACKER, } \\
\text { EMISSIONS TRACKER, } \\
\text { VENDOR REVENUE SYS }\end{array}$ & $\begin{array}{l}\text { MOBILE \& POU RENTAL, } \\
\text { LEASE / PURC FULLFMT, } \\
\text { CHARGING TRACKER, } \\
\text { EMISSIONS TRACKER, } \\
\text { VENDOR REVENUE SYS }\end{array}$ & $\begin{array}{l}\text { SMART VEHICLE } \\
\text { ALTERNATIVE SYSTEM,, } \\
\text { SMART CHARGING \& } \\
\text { EMISSIONS SYSTEMS, } \\
\text { PARTNER MGT SYS }\end{array}$ \\
\hline & Functional Factor & $\begin{array}{l}\text { FAST, CONVENIENT } \\
\text { RENTAL, TRAINING / } \\
\text { EASE OF USE, } \\
\text { ACCURATE TRACKING OF } \\
\text { CHARGING, EMISSIONS } \\
\text { PERF AND VENDOR } \\
\text { REVENUES }\end{array}$ & $\begin{array}{l}\text { EFFICIENT MOBILE \& POU } \\
\text { RENTAL, INTUITIVE EASE } \\
\text { OF USE OPS, ACCURATE } \\
\text { TRACKING OF } \\
\text { CHARGING, EMISSIONS } \\
\text { PERF AND VENDOR } \\
\text { REVENUES }\end{array}$ & $\begin{array}{l}\text { SMART "SCHEDULE } \\
\text { AWARE" VEHICLE } \\
\text { SYSTEM, INTUITIVE EASE } \\
\text { OF USE, ACCURATE } \\
\text { TRACKING OF } \\
\text { CHARGING, EMISSIONS } \\
\text { PERF AND VENDOR } \\
\text { REVENUES }\end{array}$ \\
\hline
\end{tabular}

Source: Derived from [132, 163, 164] 
Several categories of industry factor alternatives were considered for the electric bicycle pilot study at Portland State University. These factors were divided into Regulatory / Policy; Market / Product, and Technology / Function. The first two categories were further subdivided into new versus existing structures or conditions in those areas, and the analysis then considers changes that are envisioned based on those initial conditions over the next 10 years. The third category simply examined changes to technological and functional factors over this time period.

Several categories of industry factor alternatives were considered for the electric bicycle pilot study at Portland State University. These factors were divided into the following: Regulatory / Policy; Market / Product; and Technology / Function. The first category further subdivided into New Policy / Existing Regulatory versus New Regulatory / Existing Policy structures. The second category was divided between New Product / Existing Market versus New Market / Existing Product. The third category simply examined changes to Technological Factors versus Functional Factors. The analysis then considered changes over the next 10 years that are envisioned based on initial structures and conditions in each category.

For the Regulatory / Policy category, the main issues involved moving from a period in which few campus policies exist now regarding electric bicycles, electric charging stations, and policies regarding related vendors and/or partnerships to a period in 5 to 7 years when these policies would be expected to mature into comprehensive, standardized structures. Then, within 10 years, advanced options, such as transactive 
energy policy and smart appliance standards could be developed and strategic partnerships could be planned. At the same time that new policies were evolving, appropriate regulatory structures, rates, frameworks, and instruments would be developed that would make the new systems practical to implement.

For the Product / Market category, the main issues involved moving from a period in which new products are being developed related to electric bicycles and charging stations, but these products would have to be tested with a variety of currently envisioned market groups to determine the best products that would lead to the adoption of smart electric bicycle systems within the next 10 years. At the same time, new target market could be tested and to see if evolving electric bicycle products could be made to appeal to new groups of end-users and delivered in ways that better meet their needs.

For the Technology / Product category, the main issues involved moving from point of use systems to more mobile systems in the next 5 to 7 years, and finally to smart and "schedule aware" systems in the next 10 years that would be capable of anticipating how to meet customer needs by using information that is already known about the customer's location and schedule. As technologies evolved these new capabilities, product development would also occur that would address concerns about things like emissions performance, cost effectiveness, and ease of use. Like the trends envisioned for the technology development, the product development would be expected to move more from point of use to mobile platforms in the next 5 to 7 years and within 10 years 
have products that easily and intuitively incorporate schedule aware and location aware functions.

A final method used for understanding business modeling that will provide input into the roadmapping process is the Static vs. Dynamic Business Model Matrix. An example of this matrix is provided below. The matrix examines core business areas and which, if any, have the potential to grow or shrink given current conditions and practices, or which areas have the potential to sustain long-term growth.

To illustrate how this type of static and dynamic business model matrix could be applied a pilot study was performed examining the case of electric bicycle rental and/or charging on the Portland State University campus. The following diagram illustrates the models that were derived. 
Figure 4.13: Static \& Dynamic Business Models for e-Bike Pilot Study

\begin{tabular}{|c|c|c|c|c|c|}
\hline \multirow[b]{2}{*}{ Biz Model } & \multirow{2}{*}{\multicolumn{2}{|c|}{ Product / Service }} & \multicolumn{3}{|c|}{ Basic Business } \\
\hline & & & Govt / Comm (B2G2B) & Direct E-bikes (B2C) & $\begin{array}{c}\text { Combined Model } \\
\text { (B2C2G2B) }\end{array}$ \\
\hline \multirow{4}{*}{$\begin{array}{l}\frac{\infty}{D} \\
\frac{\pi}{2}\end{array}$} & \multirow{2}{*}{ 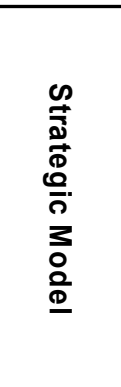 } & 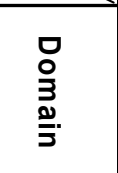 & $\begin{array}{l}\text { Existing Prod / Existing Market: } \\
\text { Focus on improving e-bike charging } \\
\text { options for univ faculty/staff, govt, and } \\
\text { bus partners in community (initial } \\
\text { rollout). Acquire limited number of e- } \\
\text { bikes for sales and rental test }\end{array}$ & $\begin{array}{l}\text { New \& Existing Prod / New \& } \\
\text { Existing Mkt: E-bike charging for } \\
\text { current owners in univ students, fac/st } \\
\text { comm. E-bike sales and rentals for } \\
\text { new users. }\end{array}$ & $\begin{array}{l}\text { New \& Existing Product / New \& } \\
\text { Expanded Market: E-bike charging, } \\
\text { rental, leasing, and sales to univ } \\
\text { students, fac/st, govt \& bus partners. }\end{array}$ \\
\hline & & 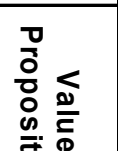 & $\begin{array}{l}\text { Affordable convenient, green, and } \\
\text { healthy bicycle transportation for } \\
\text { university community and partner } \\
\text { organizations: Reduce fuel cost, } \\
\text { reduce parking costs, }\end{array}$ & $\begin{array}{l}\text { Cheap, convenient, green, and } \\
\text { healthy bicycle transportation for } \\
\text { university student and employees: } \\
\text { Reduce fuel cost, reduce parking } \\
\text { costs, }\end{array}$ & $\begin{array}{l}\text { Affordable convenient, green, and } \\
\text { healthy bicycle transportation for } \\
\text { university community and partner } \\
\text { organizations: Reduce fuel cost, } \\
\text { reduce parking costs, }\end{array}$ \\
\hline & \multicolumn{2}{|c|}{ Supply Method } & $\begin{array}{l}\text { E-bike charging, mainly through } \\
\text { membership for existing owners, test } \\
\text { e-bike sales and rental programs. }\end{array}$ & $\begin{array}{l}\text { Direct E-bikes rentals, charging, } \\
\text { and/or membership options }\end{array}$ & $\begin{array}{l}\text { Direct E-bikes rentals, leasing, sales, } \\
\text { charging, mainly through } \\
\text { membership. }\end{array}$ \\
\hline & \multicolumn{2}{|c|}{ Profit Model } & $\begin{array}{l}\text { E-bike charging, equipment, } \\
\text { equipment sales, multi-level } \\
\text { membership program with partner } \\
\text { associations, and test rental } \\
\text { programs. }\end{array}$ & Rentals, bike charging, membership & $\begin{array}{l}\text { Rentals, bike charging, equipment } \\
\text { leasing, equipment sales, multi-level } \\
\text { membership program with partner } \\
\text { associations }\end{array}$ \\
\hline 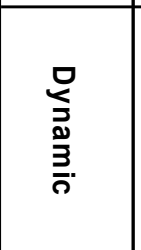 & 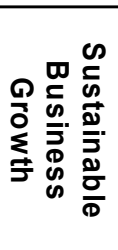 & 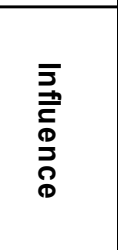 & $\begin{array}{l}\text { Focus on extended campus market of } \\
\text { faculty, and staff, as well as local } \\
\text { government and community } \\
\text { associations: } 300 \text { customers }(2 \% \\
\text { fac/st, } 1 \% \text { gov, } 1 \% \text { bus by } 2015 \text {; } \\
1200 \text { customers ( } 5 \% \text { fac/st, } \% \text { gov } \\
5 \% \text { bus by } 2018 \text {. }\end{array}$ & $\begin{array}{l}\text { Focus on direct campus markets } \\
\text { campus markets: } 750 \text { customers } \\
\text { (3\% campus) by } 2015 ; 2500 \\
\text { customers ( } 10 \% \text { campus) by } 2020 \text {; } \\
5000 \text { customers ( } 20 \% \text { campus) by } \\
2025 \text {. }\end{array}$ & $\begin{array}{l}\text { Serve extended campus, government, } \\
\text { local business partners, and the } \\
\text { community: } 1,000 \text { customers }(2 \% \\
\text { campus, } 1 \% \text { gov, } 1 \% \text { orgs, } 1 \% \\
\text { community) by } 2015 ; 4500 \text { customers } \\
\text { (10\% campus, } 10 \% \text { gov } 5 \% \text { bus, } 2 \% \\
\text { com) by } 2020 ; 9,500 \text { customers ( } 20 \% \\
\text { campus, } 15 \% \text { gov, } 10 \% \text { bus, } 5 \% \\
\text { com). }\end{array}$ \\
\hline
\end{tabular}

Source: Derived from $[132,163,164]$

Much of the information on the Static \& Dynamic Business Model Matrix is just a summary of information presented on previous matrices, but it is then categorized according to the areas that contribute to long-term stable growth versus more variable growth. A variety of pros and cons related to each of the basic business models have already been discussed, but this tool allows a final comparison of similarities and differences, as well as a few new insights about risks and rewards associated with each. The basic value propositions between the main business models, B2G2B, B2C, and $\mathrm{B} 2 \mathrm{C} 2 \mathrm{G} 2 \mathrm{~B}$, are all pretty much the same: Inexpensive, convenient, environmentally friendly transportation that reduces the impact of vehicle use and parking requirements in 
the campus community. Each of the models is aimed at a progressively larger potential market in the order listed above, from left to right. However, they also involve some progressively increasing risks, as the models move from markets in which the products are currently expected to have an appeal to new markets where the expectations are less certain. B2G2B can be described as a more focused and less risky strategic model, with a small domain of initial target users, simple supply method and fairly robust set of profit model alternatives. However, it has a more limited dynamic growth capability, focusing instead on slow, sustainable business growth and limited overall influence in the broader potential market. At the other end of the spectrum, $\mathrm{B} 2 \mathrm{C} 2 \mathrm{G} 2 \mathrm{~B}$ is truly an all of the above approach, but takes on some significant additional risks in exchange for the potential for higher dynamic growth potential. The B2C approach could be described as somewhere in between the other two approaches.

The information from each of business modeling tools discussed in this section will becomes an input for the next phase of the research, which constructs a roadmap based on these elements and begins the process of prioritizing them. This will be important, as the industry is undergoing rapid growth and development. A wide range of potential smart grid users will need to understand how such new grid infrastructures could be used with new business models for specific industries or sub-industries. 


\subsubsection{TRM Construction \& Prioritization}

The following section shows the elements of the proposed roadmapping process. Information from the Business Concept Development and Industry Analysis processes mentioned in previous sections is also incorporated at this stage. Information from the stakeholder-objectives matrix provides inputs for roadmap drivers and construction of the various layers. The process of Industry Analysis, which was also mentioned previously, is then performed to identify product and service gaps. This information is also used in understanding the prioritization of the roadmap elements. Additional details about each of the workshops used in these processes are described below.

In the first workshop, the stakeholder information was translated into drivers of value production for products and services for a technology roadmap. Product and service performance factors necessary to satisfy these drivers will then be identified. Current products and services that meet existing performance requirements will be identified, along with any gaps or deficiencies in being able to meet these requirements.

The second workshop analyzed emerging technologies and compared them to required technology characteristics that are expected to be important for those technologies. Potential solutions were examined to see how they may meet required characteristics. This information will then be used to determine if gaps exist in technology requirements and the present state of development for these technologies. If

gaps are identified, then descriptions of R\&D programs necessary to fill these gaps will be created. 
In the third workshop, the current market environment and policy environment with respect to EVSC was examined. If any market or policy elements negatively impacted product or service performance in the first workshop, items on the Solutions layer show possible ways to address such market or policy barriers. Specific mitigation strategies, such as policy changes or market incentives may then be considered to overcome these barriers.

The output of the second and third workshops were then analyzed in order to determine which technology-product gaps are the most significant to address and which market and policy barriers are the important as well. The end result of this is an EVSC roadmap which will help stakeholders understand the most critical elements that are necessary to achieve goals. Potential outcomes can then be analyzed, along with prioritization scores to determine the main factors necessary for key stakeholders to achieve desired outcomes and the factor dependencies required. More detail on the prioritization process will be described in the next section, along with the information needed to construct the technology roadmap.

\subsubsection{Methodological Needs: Resource Planning \& Policy Literature}

The following section provides a set of tools designed to assist with the roadmap development and prioritization process. A series of data collection instruments, matrixes, 
and prioritization tools are presented to perform various stages of roadmap construction and assessment of the various input factors.

The first tool, shown below, provides a means of grouping data related to market and business drivers. Expert are also asked to rate the general priority level of each of these drivers based on their views of it overall future impact on the market. An example is shown below using data from the PSU electric bicycle pilot study that has been mentioned in previous sections.

Figure 4.14: Grouped Drivers - Market and Business

\begin{tabular}{|c|c|c|c|}
\hline \# & Grouped Market Drivers & Priority & Notes and Constituent Drivers \\
\hline 1 & Car transportation costs & $\sqrt{ } \sqrt{ } \sqrt{ }$ & Fuel Costs, Vehicle Costs \\
\hline 2 & Car parking requirements & $\sqrt{ } \sqrt{ } \mathrm{V}$ & Parking Permits Costs, Availability of parking, Distance of parking \\
\hline 3 & Car traffic issues (campus \& surrounding area) & $\checkmark v$ & Time of travel \\
\hline 4 & E-bike transportation costs & $\sqrt{ } \downarrow \downarrow$ & E-bike purchase or rental costs, E-bike charging costs \\
\hline 5 & E-bike parking requirement & $\sqrt{ } V$ & Parking Permits Costs, Availability of parking, Distance of parking \\
\hline 6 & E-bike traffic & $\checkmark$ & Time of travel \\
\hline & & & \\
\hline & & & \\
\hline & & & \\
\hline & & & \\
\hline
\end{tabular}

\begin{tabular}{|c|c|c|c|}
\hline \# & Grouped Business Drivers & Priority & Notes and Constituent Drivers \\
\hline 1 & Business structure / partnership & 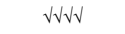 & University-owned, third-party, utility-owned, etc. \\
\hline 2 & Charging infrastructure requirements & $\downarrow \sqrt{ } \downarrow$ & Campus grid upgrades/interface, charging system installation \\
\hline 3 & E-bike charging system & $\sqrt{ } \downarrow \downarrow$ & Hardware \& software deployment/customization \\
\hline 4 & E-bike capital investment & $\sqrt{ } \downarrow \checkmark V$ & Vendor selection, purchase, financing \\
\hline 5 & E-bike sales and/or rental infrastructure & $\sqrt{ } \downarrow \downarrow$ & Hardware \& software deployment/customization \\
\hline 6 & E-bike usage system & $\sqrt{ } \downarrow$ & $\begin{array}{l}\text { Short-term rental, long-term rental, membership, business } \\
\text { partnerships }\end{array}$ \\
\hline & & & \\
\hline & & & \\
\hline & & & \\
\hline
\end{tabular}

Source: $[30,145,150]$

The second tool, shown below, is another basic data gathering form used for collecting and grouping information related to regulatory and policy drivers. Expert are 
also asked to rate the general priority level of each of these drivers based on their views of it overall future impact of specific regulatory structure or policy initiatives regarding the development of an industry and related technology products. An example is shown below using data from the PSU electric bicycle pilot study that has been mentioned in previous sections.

Figure 4.15: Grouped Drivers - Regulatory and Policy

\begin{tabular}{|c|c|c|c|}
\hline \# & Grouped Regulatory Drivers & Priority & Notes and Constituent Drivers \\
\hline 1 & Campus Grid Management Rules \& Procedures & $\sqrt{ } \sqrt{ } \downarrow \checkmark$ & Requirements for interconnections, grid management system \\
\hline 2 & Utility regulations & $\downarrow \downarrow \checkmark$ & Requirements for municipal grid connection \\
\hline 3 & Campus Vehicle Use Incentives / Penalties & $\downarrow \downarrow$ & Vision for vehicle use on campus, vision for parking on campus \\
\hline 4 & Campus Emission Incentives / Penalties & $W \downarrow$ & Goals for emissions reduction, energy efficiency, vehicle use \\
\hline 5 & University Business Partnership Practices & $\checkmark \mathrm{V}$ & \\
\hline 6 & University Facilities / Infrastructure Investment Practices & $\sqrt{ }$ & \\
\hline & & & \\
\hline & & & \\
\hline & & & \\
\hline & & & \\
\hline
\end{tabular}

\begin{tabular}{|c|l|c|l|}
\hline$\#$ & \multicolumn{1}{|c|}{ Grouped Policy Drivers } & Priority & Notes and Constituent Drivers \\
\hline 1 & City, County, State Energy Policies and Codes & $\sqrt{ } \downarrow$ & Fit with energy \& sustainability plans, meet codes \& reqs \\
\hline 2 & Utility Integrated Resource Plan & $\sqrt{ } \downarrow$ & Consistency with utility infrastructure planning \& upgrade needs \\
\hline 3 & Campus Vehicle Plan / Goals & $\sqrt{ } \downarrow$ & Vision for vehicle use on campus, vision for parking on campus \\
\hline 4 & Campus Emission Plan / Goals & $\sqrt{ } \downarrow$ & Goals for emissions reduction, energy efficiency, vehicle use \\
\hline 5 & University Business Partnership Guidelines & $\sqrt{ }$ & \\
\hline 6 & University Facilities / Infrastructure Investment Guidelines & $\checkmark \downarrow$ & \\
\hline & & & \\
\hline & & & \\
\hline & & & \\
\hline & & & \\
\hline
\end{tabular}

Source: $[30,145,150]$

The third tool used in this process takes the information gathered from the previous sets of grouped drivers and then attempts to match business and market, as well as regulatory and policy drivers to specific product features and performance goals desired by customers and other potential stakeholders for a particular product. For each 
row, or feature, on the matrix a score is determined as follows: 1 to 3 check marks are used $(1$ check $=$ low, 2 checks $=$ medium, 3 checks $=$ high $)$, or one to three "X's" can be assigned ( $1 \mathrm{X}=-1$ impact, $2 \mathrm{X}^{\prime} \mathrm{s}=-2$ impact, $3 \mathrm{X}^{\prime} \mathrm{s}=-3$ impact). For each column, a driver priority score of 1 to 10 is used, with 1 being a low high priority and 10 being a very high priority. Overall scores are then determined by multiplying each set of row and column scores and then adding up these scores for each category of drivers, such as the business and market, or regulatory and policy drivers shown below, and then normalizing the scores out of 10. These scores are then shown on the right hand side of the matrix under the heading "Prioritization." Additional score columns can be added if needed.

Figure 4.16: Market, Business / Regulatory vs. Product \& Goals

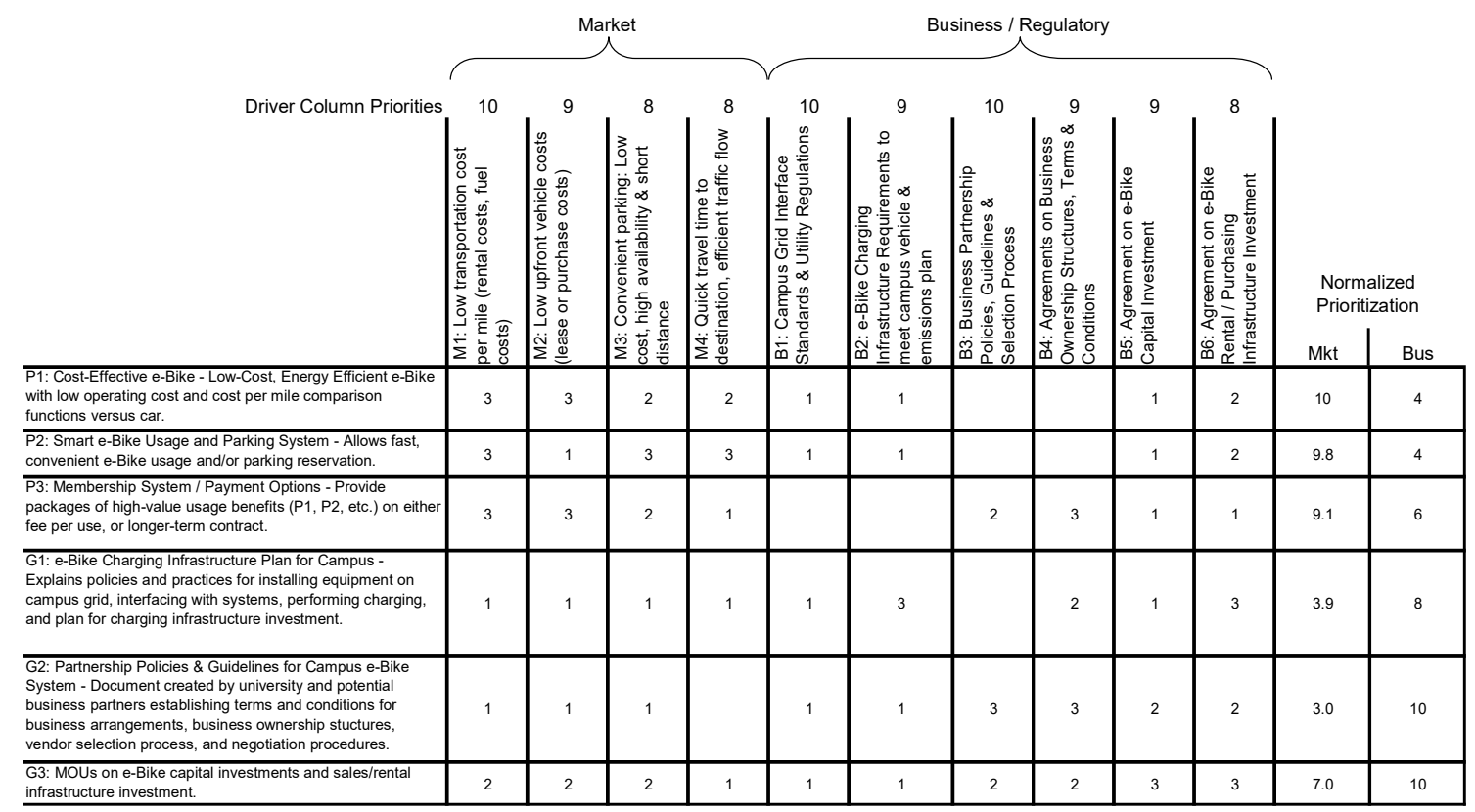

Source: $[30,145,150]$

A similar process to the method above is followed in the next section. Technology product features and stakeholder goals are compared against potential 
barriers that may exist. Also examined are mitigators which may help reduce such barriers. Finally, a third process like the previous two above is performed. Technology barrier and mitigators are compared against $R \& D$ barriers and potential mitigators. Scores are determined using the prioritization process previously described.

Figure 4.17: Products \& Goals vs. Technologies \& Barriers Grid

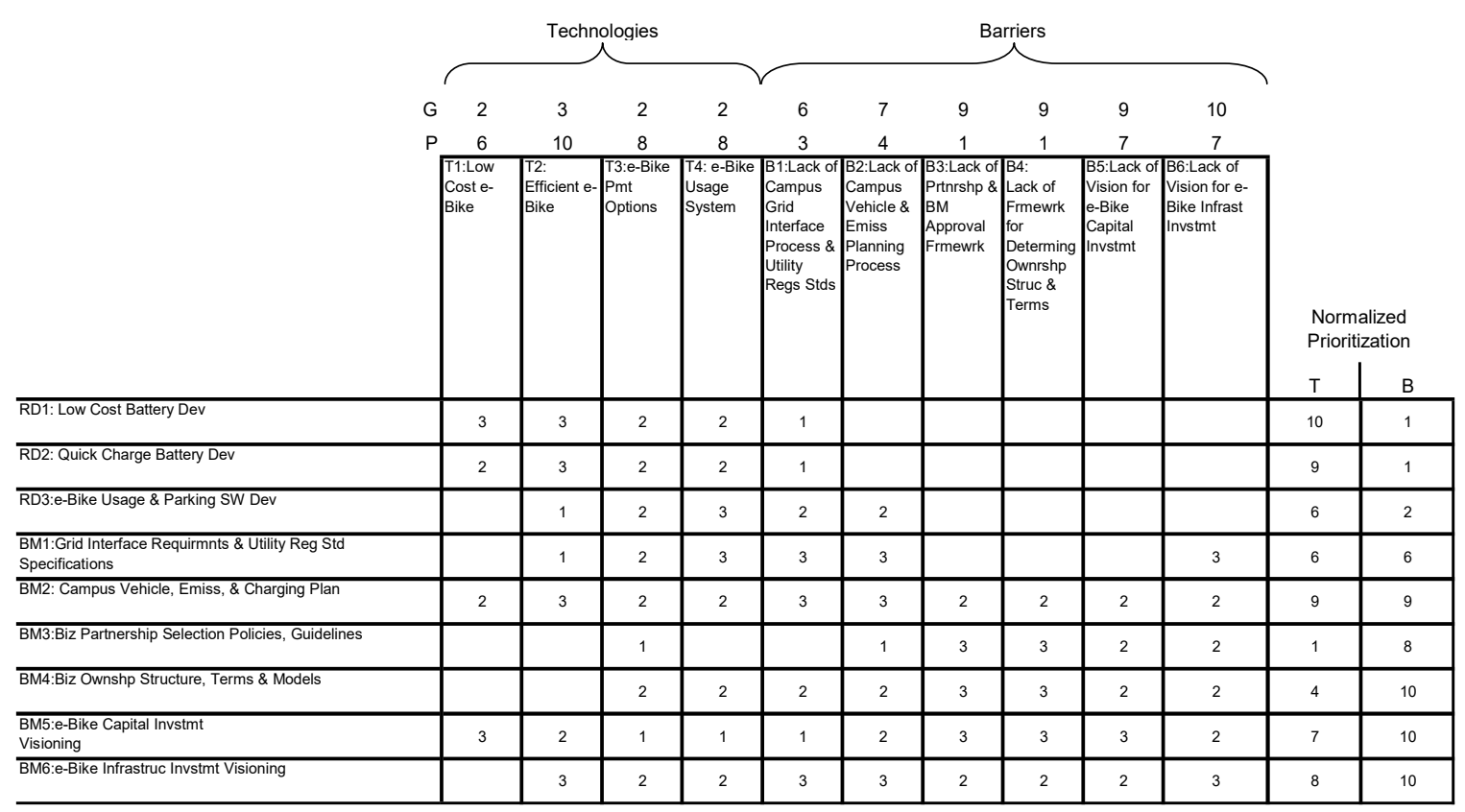

Source: $[30,145,150]$

Once these processes are complete, the data is gathered, analyzed and used as an input for the next stage of the research, which involves construction of the visual roadmap model with appropriate time scales and prioritization data. A sample of the proposed design for such a model is provided in the next section. 
Figure 4.18: Technologies \& Barriers vs. Research, Development, and Barrier Mitigation

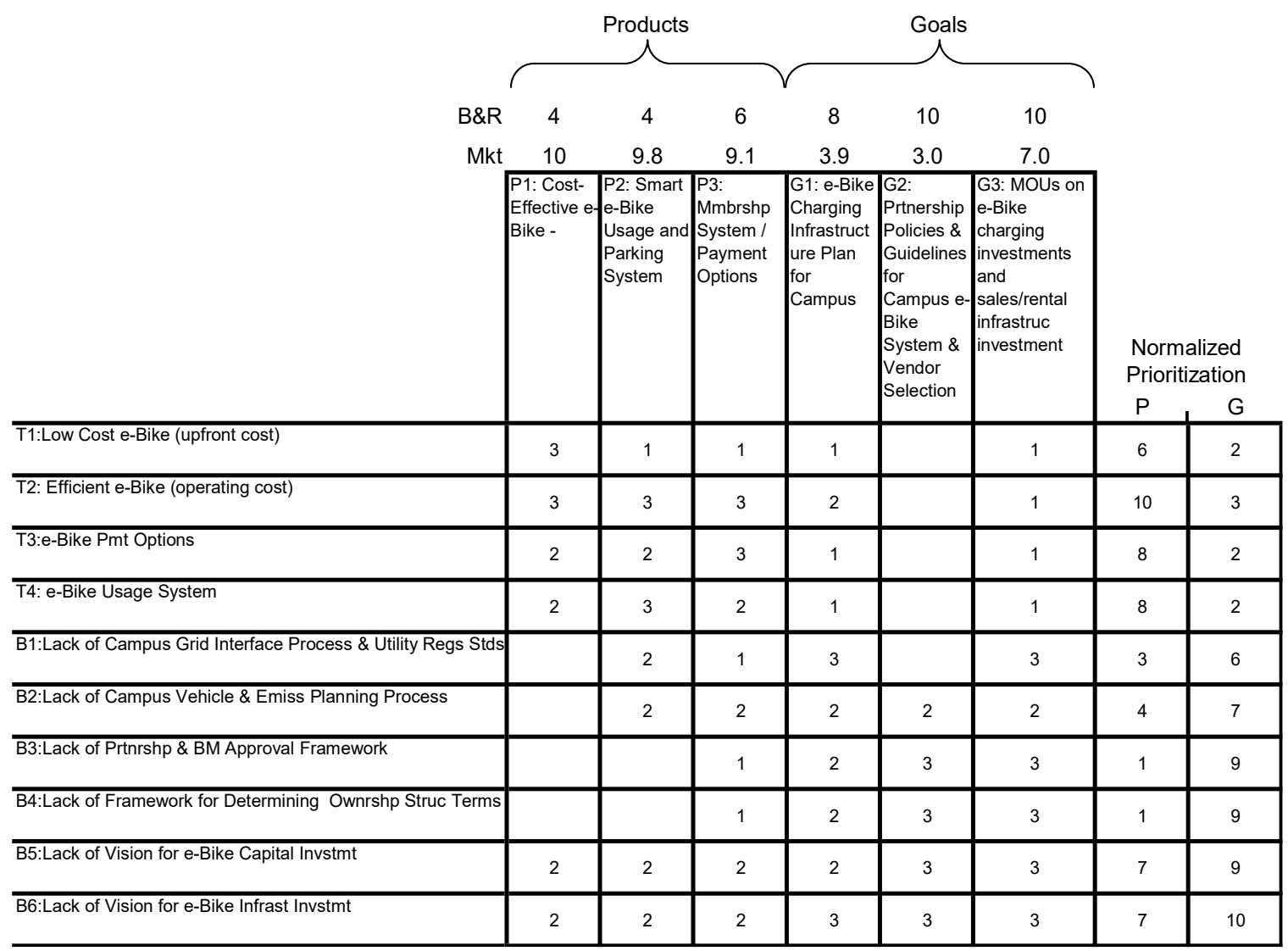

\subsubsection{TRM Model Design}

After finishing the initial data gathering and prioritization processes, a roadmap model incorporating all the data that has been collected can be constructed. A sample of the proposed design for this model is shown below. 
Figure 4.19: Sample Regional EVSC Model
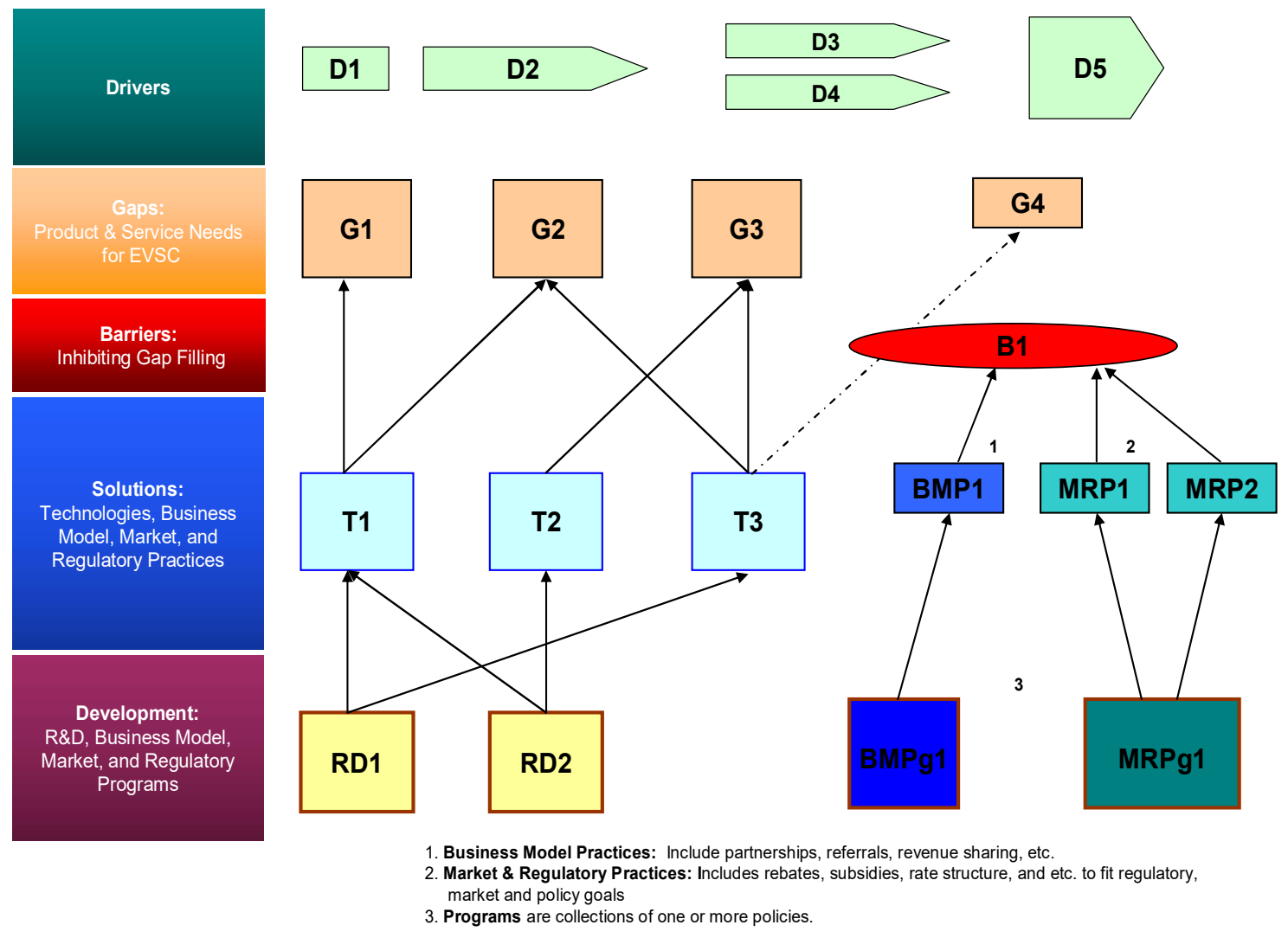

The proposed design for the technology roadmap model to be used in this research has a number of features which can be seen above. It includes elements at the development level that consider both the needs for R\&D development (RD1, RD2), as well as development of programs related to business model (BMPg1) development and programs involving market structure and regulatory considerations (MRPg1). R\&D development programs can be matched to technology solutions (T1, T2, T3) that ultimately fill a gap or help accomplish a goal by satisfying product and service needs determined through analysis of drivers. Business Model and Market / Regulatory programs consist of a collection of practices that are used to accomplish a specific 
purpose, such as the mitigation of barrier. Examples of Business Model Practices might include the use of multi-level business referrals systems, review sharing, or various types of partnerships to capture a new business opportunity or achieve a goal. Examples of Market and Regulatory Practices might include the development systems with government, manufacturers, non-profits or other entities to promote market development for new products through mechanisms like subsidies, rebates, preferential rate structure, and etc. Such systems would be designed to fit stakeholder goals for regulatory, market or policy outcomes. Depending on the priority, or relative strength of impact, that each of these programs and practices may have, they could contribute toward the mitigation of a barrier. An example of a barrier in this sample model may be the absence of a transactive energy market structure for buying and selling electric used to charge vehicles or fed back into the grid (similar to a feed-in tariff for residential solar panel systems). To promote the development of such a system regulators might establish specific rates and policy structures, while utility companies and third-party service providers would offer equipment and service with specific incentives designed to entice customers to use their systems. This could ultimately result in the lowering of the transactive energy system barrier (B1). The lowering of this barrier may allow an existing technology (T3) to pass through the barrier and accomplish a specific goal (G4). In this case, an example of such a technology might be existing energy efficiency aggregation systems which would then be able to accomplish key energy efficiency goals as outlined by the Northwest Power and Conservation Council. 
While the model proposed here is just an example, it offers a number of interesting advantages over current roadmapping models. Technology development often occurs to meet multiple market and stakeholder needs and often must function in complex policy and regulatory landscapes. This is especially true in the case of technologies used by in public utility industries. It is difficult to visualize which technologies need to be developed to meet key stakeholder needs, because barriers often exist that would prevent those technologies from perform an intended function. By putting barriers directly on a roadmap, it becomes easier to visualize whether technology development is needed to meet specific goals, or if it could already meet those goals in the absence of barriers. Furthermore, in emerging industries, market structures and business models are often not well defined in the initial stages. By analyzing the need for business model and market development, significant insight may be gained regarding future progress in an industry. In addition, examining how such business model and market development may affect industry barriers could provide suggestions about the type and direction of technology development that needs to occur. Therefore, this roadmap design aims to integrate technology, business, regulatory, and policy issues into a single process that gives a powerful visual representation of the development priorities and pathways. A final stage of outcome analysis is then performed to examine the key learnings from the roadmapping in more detail and make a step-by-step action plan.

To illustrate how this type of business sub-model matrix could be applied a pilot study was performed examining the case of electric bicycle rental and/or charging on the 
Portland State University campus. The following diagram illustrates the business submodels that were derived.

Figure 4.20: Sample TRM for e-Bike Pilot Study
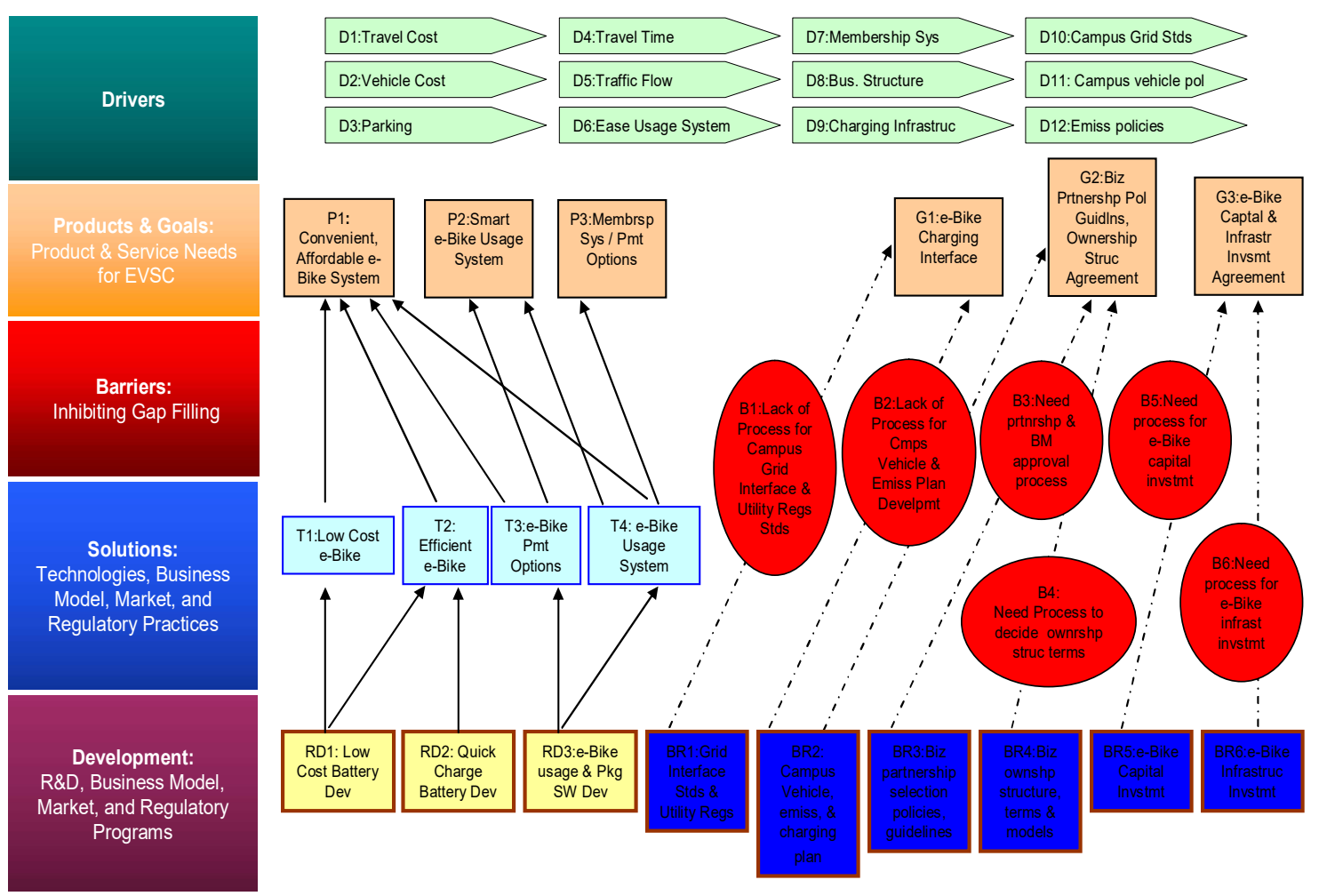

Several key pieces of information can be seen from the above figure. Key stakeholders include university faculty, staff, and students, as well as businesses or organizations in the local area, and local government. Decisions must be made regarding whether to focus first on specific user segments among these stakeholders or on a combinations of segments. Further decisions must be made regarding the possibility of university, utility, or third-party ownership of an electric bicycle venture and if the primary profit mechanism will be rentals, battery charging, leasing, or some 
combinations thereof. Options for financing and distribution can then be determined that are appropriate for each of these cases. The next step in this process explains more details about defining a business model.

\subsubsection{Prioritized Action Paths \& Critical Analysis of Results}

Using prioritized TRM, the main paths and dependencies for desired outcomes can be identified. Finally, an outcome analysis is used to summarize the main paths to desired outcomes and what factor dependencies exist in order to achieve these outcomes.

When three main research phases are completed, results will be analyzed and summarized. The main paths to desired outcomes will be identified and the factor dependencies exist in order to achieve these outcomes. Using prioritized Technology Roadmap, deliverables will be identified, along and main paths and dependencies for desired outcomes.

Several types of validity tests [206] will be conducted, which will be described in greated detail in Chapter 6. Content validity will be established by testing research instruments, which will be reviewed by expert advisory group to minimize ambiguity and confusion in the data collection process. Construct validity will be established using an expert panel that will rate the relevance, importance and ease of responding to each instrument. Criteria validity will be established after the study by asking experts to rate how well they feel the final results match roadmapping needs and expectations they have. 
Consistency will be established primarily by using the Delphi Method used for resolving inconsistencies in expert judgments during study [172].

After consensus is achieved on roadmap in prior research phase, this phase will be conducted by the research asynchronously. Experts will be consulted to clarify remaining issues. Deliverables include prioritized requirements to meet desired outcomes. Paths and dependencies are action steps over time with prioritized requirements. Final analysis and conclusions will then be done drawing upon a variety of qualitative research techniques [207] [208] [209], including case study analysis [210]. Then final results, limitations, and contributions will be determined.

\subsubsection{Conclusions on Methodologies}

The types of methods presented in this section are needed in order to deal with the unique nature of smart grid technology and product development for the regulated regional utility systems in general and for electric vehicle smart charging systems in particular. Many problems cannot be solved on just a local or state level, but must instead be solved at higher levels, such as coordination within regional power systems and policies. Smart Grid and Electric Vehicle Smart Charging application are new and the characteristics of such systems are not well understood yet. Multiple perspectives are needed to understand how regulatory and policy issues, and market characteristics can lead to the creation of new business models that are appropriate for the rapidly evolving smart grid technologies that are now emerging. 


\section{CHAPTER 5: Research Plan}

\subsection{Research Outline}

The following diagram outlines the key steps needed to conduct the research described in the paper up to this point. Additional detail about each of the steps is then provided in the next sections.

Figure 5.1: Research Outline

\begin{tabular}{|c|c|c|c|c|c|}
\hline & & Phase 1 & Phase 2 & Phase 3 & Phase 4 \\
\hline Documents & \begin{tabular}{|c|} 
Technology \\
Planning for \\
Business, \\
Regulatory \& \\
Policy Integration
\end{tabular} & $\begin{array}{c}\text { Start-up Business } \\
\text { Model } \\
\text { Development }\end{array}$ & Industry Analysis & $\begin{array}{l}\text { Prioritization \& } \\
\text { Verification }\end{array}$ & $\begin{array}{l}\text { Analysis \& } \\
\text { Synthesis }\end{array}$ \\
\hline Methods & $\begin{array}{c}\text { Research Design } \\
\text { Diagram }\end{array}$ & $\begin{array}{l}\text { Business Concept } \\
\text { Development }\end{array}$ & $\begin{array}{c}\text { Modified 5 Forces } \\
\text { (Reg Indus), Profit } \\
\text { Modeling }\end{array}$ & $\begin{array}{l}\text { TRM Constrcution } \\
\text { \& Prioritization }\end{array}$ & $\begin{array}{c}\text { Integrated TRM \& } \\
\text { Analysis }\end{array}$ \\
\hline Processes & $\begin{array}{c}\text { Literature, Experts } \\
(6-8)\end{array}$ & $\begin{array}{c}\text { Literature, Email } \\
\text { Virtual Panel (6-8) }\end{array}$ & \begin{tabular}{|c} 
Literature, Email \\
Virtual Panel (6-8)
\end{tabular} & Workshop (12-16) & $\begin{array}{c}\text { Research } \\
\text { Synthesis, Expert } \\
\text { Feedback (12-18) }\end{array}$ \\
\hline Description & \begin{tabular}{|c|} 
Utility Experts, Pol \\
Anlyts, EV/V2G \\
Bus \& Tech \\
Experts \\
\end{tabular} & $\begin{array}{l}\text { Utility Execs, Pol } \\
\text { Anlyts, EV/V2G } \\
\text { Bus Experts }\end{array}$ & $\begin{array}{l}\text { Utility Execs, Pol } \\
\text { Anlyts, EV/V2G } \\
\text { Bus Experts }\end{array}$ & $\begin{array}{c}\text { Utility Experts, Pol } \\
\text { Anlyts, EV/V2G } \\
\text { Bus \& Tech } \\
\text { Experts }\end{array}$ & $\begin{array}{l}\text { Data Analysis, } \\
\text { Validation \& } \\
\text { Conclusions }\end{array}$ \\
\hline Validation & $\begin{array}{c}\text { Content \& Face } \\
\text { Validity Tools }\end{array}$ & $\begin{array}{c}\text { Content Validity } \\
\text { Tools }\end{array}$ & $\begin{array}{l}\text { Content Validity } \\
\text { Tools }\end{array}$ & $\begin{array}{c}\text { Criteria Validity } \\
\text { Tools }\end{array}$ & $\begin{array}{c}\text { Criteria Validity } \\
\text { Tools }\end{array}$ \\
\hline Examples & $\begin{array}{l}\text { Complete B\&R } \\
\text { Model and } \\
\text { Complete } \\
\text { Prioritized TRM }\end{array}$ & $\begin{array}{c}\text { Stakeholder- } \\
\text { Objective Matrix, } \\
\text { Business Sub- } \\
\text { Models, Business } \\
\text { Summary, } \\
\text { Stakeholder } \\
\text { Perspectives, and } \\
\text { Business Model } \\
\text { Overview }\end{array}$ & \begin{tabular}{|c|} 
Modified 5 Forces \\
Model, Business- \\
Stakeholder \\
Alternatives \\
Matrix, Industry \\
Factor Alternatives \\
Matrix, Statics \& \\
Dynamic Business \\
Models
\end{tabular} & $\begin{array}{l}\text { Grouped Drivers, } \\
\text { Impact Matrices, } \\
\text { Initial TRM and } \\
\text { Prioritization }\end{array}$ & $\begin{array}{c}\text { Final Integrated } \\
\text { TRM, Analysis or } \\
\text { Alternatives and } \\
\text { Priorities }\end{array}$ \\
\hline
\end{tabular}


The overall goal of this research is to conduct technology planning for business, regulatory and policy integration. This is shown in the second column of the research outline above. Conducting this research requires a comprehensive review of the literature streams, an expert panel of utility and policy experts, as well as a panel of technology and business experts. Expert judgment is used to assess factors required to create business models and consider other relevant business and regulatory factors. Data gathered for the research will have to be verified and validated or consistency and reliability. It is then used to construct a technology roadmap, and prioritize the items on that roadmap. All this information is then analyzed to create an integrated and prioritized roadmap that considers business, regulatory, and technology factors. Further analysis will identify key conclusions.

The research process used for this study will consist of four phases: (1) Start-up Business Model Development; (2) Industry Analysis; (3) Prioritization \& Verification; and (4) Analysis and Synthesis. Methods, Processes, Descriptions, Validation Techniques, and Examples of specific deliverables are also summarized in the Research Outline table.

At this stage in the research, the following steps have already been performed to prepare for the research process. A literature review has been completed and a pilot technology roadmap process has been tested. Initial expert recruitment has been started and a preliminary schedule of research activities was planned. The next section describes next steps required to perform data collection. 


\subsection{Preliminary Research Activities}

Preliminary design of this research consisted of literature review and pilot studies that have been previously described in this study. Initial research instruments and forms were developed in the pilot study to guide each panel through step-by-step processes to accomplish the tasks outlined in the Research Outline. These have been described in the methodology section.

The next step was then to establish two expert panels that were required to conduct the initial research. The following criteria were used for the recruitment and selection of experts to provide judgment data for this study. Experts were all management-level professionals with at least five to ten years of experience and a degree in a relevant discipline to the research topic being discussed. The members of each panel were selected to provide balance and to represent a range of viewpoints. The goal of the panel was to span multiple industries and disciplines to achieve a cross section designed to eliminate bias. Additional detailed descriptions of selection criteria are listed, along with an initial list of recruitment candidates for the expert panels.

Two expert panels were assembled to conduct this research. Each panel is described below and data on each panel is then presented on a summary table. 
Expert Panel 1 was tasked with identify drivers, gaps / goals, and barriers for the development of electric vehicle smart charging and vehicle-to-grid systems in the PNW. The panel included managers, executives, and decision makers in the utility industry, as well as energy policy analysts familiar with issues in the region. They identified product and service gaps and help assess what technologies and programs need to be developed to overcome key barriers and meet customer and stakeholder needs. The following is a description of each of the experts recruited for each of the panels. As previously mentioned, participants were all senior-level managers or experts, with a minimum of 510 years experience in their fields.

Figure 5.2: Panel 1 - Business Concept Development

\begin{tabular}{|c|l|l|}
\hline Se ctor & \multicolumn{1}{|c|}{ Industry } & \multicolumn{1}{c|}{ Title } \\
\hline \multirow{2}{*}{ Electrical Utilities } & Investor Owned Utilty & $\begin{array}{l}\text { Business Model \& Program Development } \\
\text { Director }\end{array}$ \\
\cline { 2 - 3 } & Municipal Utily & General Manager \\
\hline \multirow{2}{*}{$\begin{array}{c}\text { Government / NGO / } \\
\text { Policy Analys ts }\end{array}$} & Trade Association / Analyst & Vice-Chair \\
\cline { 2 - 3 } & Government & Program Director \\
\hline \multirow{2}{*}{\begin{tabular}{c} 
Business \& T echnology \\
\cline { 2 - 3 }
\end{tabular}} & $\begin{array}{l}\text { Smart Grid Software \& } \\
\text { Standards }\end{array}$ & Founder, CEO \\
\cline { 2 - 3 } & $\begin{array}{l}\text { Electric Vehicles and } \\
\text { Charging }\end{array}$ & Founder, President \\
\hline
\end{tabular}

Expert Panel 2 identified required characteristics of smart vehicle-to-grid charging systems. They analyzed the industry and identified gaps in technologies and business models to satisfy customer and stakeholder needs. They identified potential solutions to problems and programs to reach these solutions. The panel consisted of executives, business people, and experts from the electric vehicle and charging industry. 
The following is a description of each of the experts recruited for each of the panels. As previously mentioned, they were all senior-level managers or experts, with a minimum of 5-10 years experience in their fields.

Figure 5.3: Panel 2 - Industry Analysis

\begin{tabular}{|c|l|l|}
\hline Se ctor & \multicolumn{1}{|c|}{ Industry } & \multicolumn{1}{c|}{ Title } \\
\hline \multirow{2}{*}{$\begin{array}{c}\text { Electrical Utilities \& } \\
\text { Related Organizations }\end{array}$} & Investor Owned Utility & Program Manager \\
\cline { 2 - 3 } & Utility \& Regulatory Analysis & Program Director / Analyst \\
\hline $\begin{array}{c}\text { Government / NGO / } \\
\text { Regulator y and Policy } \\
\text { Analysts }\end{array}$ & Advocacy Organization & Executive Director \\
\cline { 2 - 3 } & Regulatory and Policy Analyst & Analyst/ Fmr. Utility Commissioner \\
\hline \multirow{2}{*}{$\begin{array}{c}\text { Business / Ec onomic } \\
\text { Development }\end{array}$} & $\begin{array}{l}\text { Electric Vehicles and Smart } \\
\text { Device Products and Senvices }\end{array}$ & Vice President \\
\cline { 2 - 3 } & Building Energy Management & President \\
\cline { 2 - 3 } & $\begin{array}{l}\text { Oregon Economic } \\
\text { Development }\end{array}$ & Program Manager \\
\hline
\end{tabular}

Panel 1 and Panel 2 each participated in a workshop to gather data from the panel experts. After a workshop was conducted with each panel, a third workshop was performed to analyze the results of the answers from the first 2 workshops. The third workshop was then used for constructing the final roadmap for this study and prioritizing the most important elements. The next section describes detailed data collection procedures that were used for collecting data during all of these workshops. 


\subsection{Data Collection Procedures}

The research approach and methodological needs were discussed in the previous chapter. This chapter then described an overall research plan and outline. The following section will now discuss specific data collection procedures that will be used. Additional detail, definitions, and references of each aspect of this, including workshop agendas and background information is provided in Appendix D. This section summarizes the overall structure of data collection procedures used in this research.

Data Collection is conducted in a series of 5 phases: Phases 1 through 4, as well as a Phase 0 for instrument testing. These phases are listed on the table below and then described in further detail in this section.

Prior to beginning formal data collection, each instrument will be pre-tested by an informal advisory group, as mentioned in the Phase 0 agenda for pre-testing. Then, preselected experts were sent a cover letter and consent form to secure their participation in the study.

Experts were asked to participate in up to three workshops, which will had durations of about two hours for the first two workshops, and lasted about four hours for the final workshop. The first two workshops were online forums with five experts in business, technology, or policy aspects of the field. All data collection forms were emailed to experts ahead of time and the time in the workshop time was spent clarifying 
the results of the responses and determining if consensus can be achieved regarding these results. The third workshop was an in-person forum involving the 10 experts from both of the previous workshops. Workshop participants included Utility Industry Executives, Policy Analysts, Electric Vehicle Technology Experts, Business Owners and Managers in the Electric Vehicle and Vehicle Charging industries, and experts in the emerging field of Vehicle-to-Grid. The workshops focused on the following topics: (1) Business Concept Development, including future technology and business model development; (2) Industry Analysis, including regulatory, policy, and business development; and (3) Technology Roadmap Development, including prioritization and desirability rating of objectives and barriers. 
Figure 5.4: Research Phases

0. (PHASE 0): Instrument Pre-Testing

1. PHASE 1: Business Concept Development
a. Stakeholder-Objective Matrix
b. Business Sub-Models
c. Business Summary,
d. Stakeholder Perspectives
e. Business Model Overview

2. PHASE 2: Industry Analysis
a. Modified 5-Forces Model
b. Business Stakeholder Alternatives Matrix
c. Industry Factor Alternatives Matrix
d. Static \& Dynamic Business Models

3. PHASE 3: Roadmap Construction \& Prioritization
a. Grouped Drivers
b. Impact Matrices
c. TRM and Prioritization

\section{PHASE 4: Analysis \& Synthesis}
a. Integrated TRM
b. Analysis of Alternatives and Priorities

The data collection guidebook in Appendix D contains a full set of directions for returning data for the online forums used in workshop 1 and workshop 2, including introductory contact messages, invitations, and proposed agendas. Each of the 
workshops consisted of online forum conducted using WebEx conference software, which enabled participants to engage in an internet-based audio conference, as well as to see shared documents on their computers. Prior to beginning the online forums, the data collection forms for each workshop were posted to the WebEx meeting space. All participants were contacted by email with an invitation to the web-based meeting and a password for accessing the meeting space. If they did not have WebEx accounts, they were also prompted to create free accounts at that time. Participants could log in and access the shared data collection and background documents for panel workshop 1 and 2 (see Appendix D). Those were also attached by email and sent to participants 2 weeks prior to the workshop. They could either log in and edit documents, creating a modified version of the documents that allowed all people to see their suggested inputs, or they could return the completed form by email to the researcher leading this study, so they could be posted to the online forum. This gave participants the opportunity to see the data collection forms which would be discussed at the online forum, provide input, and even see the responses of others, prior to participating in the online forum. The ability to participate ahead of time facilitated faster and easier discussion for the online panels. All but one expert in each panel returned all the requested data prior to the joining the online forums. However, even the experts who were not able to return all the data ahead of time were still able to catch up and participate because they had read the background materials prior to the workshop and were prepared for the process.

For workshop 1, which dealt with Business Concept Development, 5 out of 6 experts who participated in that panel returned data answering at least one third or more 
of the questions prior to joining the online forum. For workshop 2, which dealt with Industry Analysis, 5 out of the 7 experts who participated in that panel returned data answering at least one third or more of the questions prior to joining the online forum. This allowed the time during both online forums to be spent more effectively to discuss the similarities and differences in expert answers during the forum and to achieve a consensus regarding answers. Both workshops were very successful in gathering all the needed data within two hours and achieving consensus. There were a number of areas of disagreement after each workshop, mainly over the wording of specific items. The Delphi technique was used to resolve differences. This was conducted by the researcher by making phone calls to follow up with experts until the differences were resolved. For panel 1, two rounds of calls were needed with three experts. For panel 2, one round of calls was needed with two experts. The data from workshop 1 and 2 can be seen in the Results section in Chapter 7.

For workshop 1, which dealt with Business Concept Development, 5 out of 6 experts who participated in that panel returned data answering at least one third or more of the questions prior to joining the online forum. For workshop 2, which dealt with Industry Analysis, 5 out of 7 experts who participated in that panel returned data answering at least one third or more of the questions prior to joining the online forum. For workshop 3, which was an in-person workshop that used the data from the first two workshops to construct the roadmap and prioritize roadmap elements. It combining experts from the previous two panels. A total of 9 out of 10 of the experts who participated in the first two workshops participated in final workshop. Experts were also 
asked to agree on definitions of the set of business models relevant for each of key ownership structure to the industry. Comparison matrices were then constructed to show which roadmap elements corresponded with each business model. Follow-up with experts was done to validate the results.

When the first three workshops were completed, the results were then analyzed and tested for validity and consistency. The results of that analysis are show in the next chapter and that information is then used to synthesize the final results, which include prioritized sets of requirements needed to overcome key barriers and meet the outcomes that experts consider most desirable. A prioritized set of action steps needed over time to achieve these results is then discussed and final conclusions are made regarding the current research and any next steps.

The next chapter discusses requirements and methods for verification and validation of the data gathered in this study. 


\section{CHAPTER 6: Research Validity and Reliability}

\subsection{Validity}

Many type of validity are discussed in research literature. The two main forms are internal and external validity. Internal validity evaluates the extent to which a research instrument truly measures what is purports to, while external validity refers to the generalizability of research findings among different people, settings, and times [206]. External validity is primarily a logical process of how extrapolations are made from data. For the purpose of research design, the more important question to initially address is generally internal validity. The 3 main types of internal validity are Content, Construct, and Criterion Validity.

Content validity is a measure of the extent to which an instrument contains a representative sample of all relevant items of interest for a subject of study. In this study, one of the most practical methods for confirming content validity is likely to be consultation with the expert panel. The purpose of the data collection instruments used in the research will be explained and they will be asked to rate each question or content area of the instrument and provide comments. Workshop data collection instruments which will be used to collect responses are described in the next section. Ratings and the comments should provide a valuable means of assessing needs and making changes based upon this feedback. 
Construct validity addresses the issue of the variance that exists within a measure. The underlying constructs being measured are identified to determine how well the measurement instrument accounts for them. The expert panel will also be used to test construct validity, such as by rating the relevance of questions and providing comments. Factor analysis is also mentioned in the literature as a way of testing construct validity [206]. Factor analysis can be used to identify underlying constructs and thus determine validity based on the measurement of these constructs.

Criterion validity evaluates how successfully a measure predicts or estimates outcomes related to a criterion. As an example, one might examine how well the score received on a job skills test predicts an employee's actual on-the-job performance quality. If high test scores were correlated with high job performance and vice versa, then the job skills test score appears to be a criterion that is a valid predictor of performance. It would be difficult to test for criterion validity before all the data collection instruments are deployed. The most likely method of testing criterion validity will be to wait until the data is collected and then use expert judgments.

\subsubsection{Validity Testing}

For the proposed research, validity will be addressed through a variety of procedures, including, but not limited to the following. A focus group will be recruited for a pilot study group. The people selected for the pilot group will preferably have experience in the energy sector, or will have knowledge from similar work or research in 
related areas. The pilot group will be asked to fill out the initial draft data collection instruments and provide feedback to help refine it. It will then be sent to a panel of experts from the electrical utility industry for further modification. The goal of this testing process is to ensure relevance, verify logic and flow structure, and eliminate as many ambiguities as possible.

Following a suggestion from Daim's study of the electronics manufacturing sector [211], a data collection instrument test tool will be used to help experts review the data collection instruments and assess relevance, as well as ease of use in answering questions [206, 212]. A 5-point Likert scale will be used to rate relevance and ease of answering question, with a 1 indicating low values and a 5 indicating high values. The overall goal is to verify content and construct validity.

Table 6.1: Workshop Data Collection Instruments

\begin{tabular}{|l|l|l|l|}
\hline \multicolumn{1}{|c|}{ Intention of Question } & Relevance & $\begin{array}{c}\text { Ease of } \\
\text { Answering } \\
\text { Question }\end{array}$ & Comments \\
\hline $\begin{array}{l}\text { 1. <Question Text> The importance } \\
\text { of this question is... }\end{array}$ & $\begin{array}{l}\text { Rate on a } \\
\text { scale of } 1 \text { to 5, } \\
\text { with 5 being } \\
\text { high } \\
\text { <uestion is intended to get } \\
\text { information on... }\end{array}$ & $\begin{array}{l}\text { Rate on a scale } \\
\text { of 1 to 5, with 5 } \\
\text { being high }\end{array}$ & \\
\hline
\end{tabular}




\subsection{Reliability Analysis}

Reliability is a measure of the extent to which an instrument provides results that are consistent. Instruments that are reliable produce stable measurements under a variety of conditions. A number of theories of reliability can be used for determining levels of consistency in measurement instruments. The following table shows some of the best known techniques for estimating reliability, and summarizes how they work [206, 212].

Table 6.2: Reliability Types and Methods

\begin{tabular}{|l|l|l|l|}
\hline \multicolumn{1}{|c|}{ Type } & \multicolumn{1}{|c|}{ Coefficient } & \multicolumn{1}{c|}{ What is Measured } & \multicolumn{1}{c|}{ Methods } \\
\hline Test-Retest & Stability & $\begin{array}{l}\text { Test reliability inferred from } \\
\text { respondent scores. Same test } \\
\text { administered twice to same } \\
\text { subjects after interval of less } \\
\text { than six months. }\end{array}$ & Correlation \\
\hline Parallel Forms & Equivalence & $\begin{array}{l}\text { Extent to which similar forms } \\
\text { of the same measure produce } \\
\text { same or similar results. } \\
\text { Administered simultaneously } \\
\text { or with a delay. } \\
\text { Interrater estimates of judges' } \\
\text { scores. }\end{array}$ & Correlation \\
\hline Internal Consistency & $\begin{array}{l}\text { Cronbach's alpha } \\
\text { Split-half } \\
\text { KR20 }\end{array}$ & $\begin{array}{l}\text { Extent to which instrument } \\
\text { items are homogeneous and } \\
\text { reflect the same underlying } \\
\text { construct/s. }\end{array}$ & $\begin{array}{l}\text { Correlation } \\
\text { (Specialized) }\end{array}$ \\
\hline
\end{tabular}

Stability is a perspective on reliability that means being able to produce consistent results with repeated measurements by the same person with the same instrument. It is often difficult with many data collection instruments to measure 
stability, as there is seldom an opportunity to retest the same points again and again [213].

Equivalence is another perspective on reliability that is considered more practical for situations such as workshops. It can be tested by comparing the scoring of the same event by different observers. Interrater reliability can then be determined by examining the correlation between the scores of different judges.

Internal consistency is a third perspective on reliability that requires the administration of only one test instrument to determine consistency or homogeneity among items. Cronbach's alpha coefficient is frequently used for measuring internal consistency, particularly for multi-item scales at an interval level of measurement. The coefficient ranges from 0 to 1.0 , with increasing values corresponding to higher reliability. A value 0.7 is a typical reliability threshold.

\subsection{Threats to Design Validity}

For each threat that is present in this research design, a report will be provided to address the following:

1. How it would be manifested in this study?

2. What it would look like in the data?

3. How it would be accounted for in the data analysis? 
The table below presents a summary of how reliability and validity can be addressed for this study. Reliability is measured using internal consistency. Validity is determined using all three measures of internal validity.

Table 6.3: Reliability and Validity Analysis Plan

\begin{tabular}{|l|l|c|c|}
\hline Validity Type & $\begin{array}{c}\text { Validity } \\
\text { Approach }\end{array}$ & Testing Method & When Tested \\
\hline Reliability & $\begin{array}{l}\text { Internal } \\
\text { Consistency }\end{array}$ & Cronbach's alpha & After study \\
\hline \multirow{3}{*}{ Validity } & Content & Expert Judgment & Before study \\
\cline { 2 - 4 } & Construct & Expert Judgment & Before study \\
\cline { 2 - 4 } & Criterion & Expert Judgment & After study \\
\hline
\end{tabular}

Validity analysis will be performed using a variety of mechanisms. After the study, experts will rate how well final results match roadmapping needs and expectations. K-means clustering will also be used for determining most significant barriers, a welltested cluster analysis method in social research.

Reliability analysis will also be performed using a number of techniques. During study, inconsistencies among expert judgments will be resolved using Delphi Method. 


\subsection{Validity and Reliability Results}

\subsubsection{Validating Data Collection Instrument and Reliability Results}

In order to begin this study with a set of data collection instruments considered valid by experts, a number of test were conducted. These tests followed the guidelines mentioned in previous sections of this chapter. Experts were contacted to review the instruments used for the Business Concept Development workshop and Industry analysis workshops. The results of these validity tests are show on the tables below.

The first set of instruments tested was for the Business Concept Development workshop. The following table summarizes validity results for this set of instruments.

Table 6.4: Instrument Validation - Business Concept Development

\begin{tabular}{|c|c|c|c|c|c|c|}
\hline Instrument & Area & Title & $\begin{array}{c}\text { Experience } \\
\text { (yrs) }\end{array}$ & $\begin{array}{c}\text { Ease (1- } \\
5)\end{array}$ & $\begin{array}{c}\text { Relev ance } \\
\quad(1-5)\end{array}$ & Comments \\
\hline \multirow{4}{*}{$\begin{array}{c}\text { Stakeholder } \\
\text { Objectives Matrix }\end{array}$} & Acad, Util & Project Manager & $4-5$ & 5 & 5 & \multirow{4}{*}{$\begin{array}{l}\text { Better organiz ation of back ground and } \\
\text { directions would he lp, as well as } \\
\text { clarification on what is requ ired to do } \\
\text { the survey and what is just addition al } \\
\text { background. Need exam ples. Fix } \\
\text { several typos. }\end{array}$} \\
\hline & Gov, Util & Project Mgt Officer & $10+$ & 3 & 4 & \\
\hline & Gov, Indus & Chairm an & 35 & 4 & 5 & \\
\hline & & & & 4.00 & 4.67 & \\
\hline \multirow{3}{*}{$\begin{array}{l}\text { Business Sub- } \\
\text { Models Matrix }\end{array}$} & Indus & CEO & 25 & 4 & 5 & \multirow{3}{*}{ Fix typos. Examples needed. } \\
\hline & Gov, Indus & Chairm an & 35 & 4 & 4 & \\
\hline & & & & 4.00 & 4.50 & \\
\hline \multirow{3}{*}{$\begin{array}{l}\text { Business Models } \\
\text { and Visions } \\
\text { Overview }\end{array}$} & Indus & Vice President & 10 & 5 & 5 & \multirow{3}{*}{$\begin{array}{l}\text { Examples need ed, long descriptions, } \\
\text { clarify requ irements for background } \\
\text { information vs. directions. }\end{array}$} \\
\hline & Indus & CEO & 25 & 4 & 4 & \\
\hline & & & & 4.50 & 4.50 & \\
\hline \multirow{3}{*}{$\begin{array}{l}\text { Opportunities and } \\
\text { Perspectives } \\
\text { Summary }\end{array}$} & Indus & Vice Presid ent & 10 & 4 & 4 & \multirow{3}{*}{$\begin{array}{l}\text { Footnote add ed on "wher e," } \\
\text { Examples need ed. }\end{array}$} \\
\hline & Gov, Indus & Chairm an & 35 & 4 & 4 & \\
\hline & & & & 4.00 & 4.00 & \\
\hline
\end{tabular}


Expert from relevant disciplines were asked to provide input on the Relevance and Ease of Use of the instruments. The general background areas for these experts included: Utility Executives, Policy Analysts, and Business and Technology Experts in the electric vehicle and vehicle charging industry. Further descriptions of the experts' disciplinary area, title, and experience are provided in the summary table. The scored each of the instruments on a 1 to 5 scale, with 1 indicating a poor score and 5 indicating a very good score. All the instruments in the table above received average scores of at least 4 out of 5 for both Relevance and Ease of Use. They were also invited to provide open-ended comments. These comments were considered and used to make modifications to the instruments prior to use in the workshops.

The second set of instruments tested was for the Industry Analysis workshop. The following table summarizes validity results for this set of instruments.

Table 6.5: Instrument Validation - Industry Analysis

\begin{tabular}{|c|c|c|c|c|c|c|}
\hline Instrument & Area & Title & $\begin{array}{c}\text { Experience } \\
\text { (yrs) }\end{array}$ & $\begin{array}{c}\text { Ease (1- } \\
5)\end{array}$ & $\begin{array}{c}\text { Relev ance } \\
(1-5)\end{array}$ & Comments \\
\hline \multirow{3}{*}{$\begin{array}{c}\text { Industry Forces, } \\
\text { Barries, and } \\
\text { Mitigators }\end{array}$} & Indus & President & 25 & 4 & 4 & \multirow{3}{*}{$\begin{array}{l}\text { Fix typos, provide exam ples, clar ify } \\
\text { directions vs. backgrou nd. }\end{array}$} \\
\hline & Indus & President & 25 & 4 & 4 & \\
\hline & & & & 4.00 & 4.00 & \\
\hline \multirow{3}{*}{$\begin{array}{l}\text { Business } \\
\text { Stakeholder } \\
\text { Alternatives }\end{array}$} & Util & Program Manager & 20 & 4 & 4 & \multirow{3}{*}{$\begin{array}{l}\text { Add note explain ing that the three } \\
\text { main column he adings are just a few } \\
\text { possible alter natives. Experts can } \\
\text { modify this. Typos need to be fixed. } \\
\text { Examples needed. }\end{array}$} \\
\hline & Gov, Indus & Exec. Director & 25 & 5 & 5 & \\
\hline & & & & 4.50 & 4.50 & \\
\hline \multirow{2}{*}{$\begin{array}{l}\text { Industry Factor } \\
\text { Alternatives }\end{array}$} & Gov, Indus & Program Manager & 15 & 4 & 4 & \multirow{2}{*}{ Examples needed. } \\
\hline & & & & 4.00 & 4.00 & \\
\hline \multirow{3}{*}{$\begin{array}{c}\text { Static and } \\
\text { Dynamic Business } \\
\text { Models }\end{array}$} & Indus & President & 25 & 5 & 4 & \multirow{3}{*}{ Examples needed. Fix Typos. } \\
\hline & Indus & President & 25 & 5 & 4 & \\
\hline & & & & 5.00 & 4.00 & \\
\hline
\end{tabular}


Expert from relevant disciplines were asked to provide input on the Relevance and Ease of Use of the instruments. The general background areas for these experts included: Utility Analysts, Regulatory and Policy Experts, and Business Experts in the electric vehicle and vehicle charging industry. Further descriptions of the experts' disciplinary area, title, and experience are provided in the summary table. The scored each of the instruments on a 1 to 5 scale, with 1 indicating a poor score and 5 indicating a very good score. All the instruments in the table above received average scores of at least 4 out of 5 for both Relevance and Ease of Use. They were also invited to provided open-ended comments. These comments were considered and used to make modifications to the instruments prior to use in the workshops. 


\section{CHAPTER 7: Results for Electric Vehicle Case Study}

\subsection{Business Concept Development for Electric Vehicle Case Study}

An important step in understanding the technology, business, regulatory, and policy landscapes for emerging smart grid appliances, like electric vehicle smart charging systems, is to examine key opportunities that are arising in this area and see if these opportunities can be developed into viable business concepts and business plans. A number of steps are necessary in order to identify and analyze such opportunities.

It is important to thoroughly define a complete set of stakeholders who may support or oppose a particular business opportunity. In the analysis matrix for the business sub-model, stakeholders are listed, but the details about them are defined on the stakeholder-objective matrix. Unlike many traditional business opportunities that have been studied outside the utility industry, the unique regulatory structures that exist for companies in Oregon and the Pacific Northwest mean that there are many significant stakeholders who are not direct customers for the product under consideration [202]. For analyzing stakeholders and their values, some important and widely used tools are outcome matrices, and stakeholder-objective matrices [203, 204]. These are shown in the tables in this chapter.

The stakeholder-objective matrix provided here shows the key stakeholders and the main objectives they both support and oppose. This matrix specially addresses issues related to renewable energy integration and demand response. As the data was collected 
for this research, additional information was added regarding the stakeholder issues for of electric vehicles and vehicle-to-grid system specifically.

To deal with the potential for expert disagreement, the Delphi Method is used. Delphi is a structured communication method using an expert panel [172]. Questions are asked over a series of two or more rounds, or iterative sessions. Experts have the opportunity to revise their answers in each round as a result of the information they observe from other experts. The goal is to get the experts opinions to converge on a general consensus, which is deemed to be more accurate than individual opinions.

To illustrate how a stakeholder-objective matrix could be applied to small, manageable business case, a case study was performed examining the concept of introducing electric bicycle rentals and/or charging in the Pacific Northwest. The following diagram illustrates the stakeholder-objective matrix that was derived. 


\section{Figure 7.1: Stakeholder-Objective Matrix for EV Study}

\section{Stakeholder (S) / \\ Customer (C) / \\ Provider (P) / \\ Govt \& Reg (G)}

\section{What they Resist}

\begin{tabular}{|c|c|c|}
\hline $\begin{array}{l}\text { PUBLIC UTILITY } \\
\text { COMPANIES (P) }\end{array}$ & $\begin{array}{l}\text { Cost recovery, capital efficiency, staying } \\
\text { within capacity limits, reducing critical } \\
\text { peaks, EE, RPS goals. }\end{array}$ & $\begin{array}{l}\text { Stranded costs, lack of standards, } \\
\text { technological obsolescence, } \\
\text { technological lock-in, } \\
\text { unrecoverable costs, imprudent } \\
\text { risk. }\end{array}$ \\
\hline $\begin{array}{l}\text { PRIVATE UTILITY } \\
\text { COMPANIES (P) }\end{array}$ & $\begin{array}{l}\text { Meeting customer needs, stable long-term } \\
\text { market, clear regulations, pricing. }\end{array}$ & $\begin{array}{l}\text { Stranded costs, lack of standards, } \\
\text { technological obsolescence, } \\
\text { technological lock-in, } \\
\text { unrecoverable costs, imprudent } \\
\text { risk. }\end{array}$ \\
\hline $\begin{array}{l}\text { METERING } \\
\text { EQUIPMENT / } \\
\text { SERVICE } \\
\text { PROVIDERS (P) } \\
\end{array}$ & $\begin{array}{l}\text { ROI, market share development, } \\
\text { intellectual property development, } \\
\text { business model scalability. }\end{array}$ & $\begin{array}{l}\text { Unprofitable,or marginally } \\
\text { profitable markets, lack of } \\
\text { standards, lack of clear regulation, } \\
\text { unproven technology. }\end{array}$ \\
\hline $\begin{array}{l}\text { CHARGING } \\
\text { EQUIPMENT } \\
\text { PROVIDERS (P) }\end{array}$ & $\begin{array}{l}\text { Reducing city traffic. Reducing street } \\
\text { parking. Reducing emissions. City could } \\
\text { potentially participate as a stakeholder or } \\
\text { customer. They support clear regulations } \\
\text { and standards for charging, operating, and } \\
\text { parking. }\end{array}$ & $\begin{array}{l}\text { Stranded costs, lack of standards, } \\
\text { technological obsolescence, } \\
\text { technological lock-in, } \\
\text { unrecoverable costs, imprudent } \\
\text { risk. }\end{array}$ \\
\hline $\begin{array}{l}\text { SOFTWARE / } \\
\text { CHARGING MGT } \\
\text { (P) }\end{array}$ & $\begin{array}{l}\text { Reducing city traffic. Reducing street } \\
\text { parking. Reducing emissions. City could } \\
\text { potentially participate as a stakeholder or } \\
\text { customer. They support clear regulations } \\
\text { and standards for charging, operating, and } \\
\text { parking. }\end{array}$ & $\begin{array}{l}\text { Unprofitable,or marginally } \\
\text { profitable markets, lack of } \\
\text { standards, lack of clear regulation, } \\
\text { unproven technology. }\end{array}$ \\
\hline $\begin{array}{l}\text { EV VENDORS / } \\
\text { SUPPLIERS (P) }\end{array}$ & $\begin{array}{l}\text { Reducing city traffic. Reducing street } \\
\text { parking. Reducing emissions. City could } \\
\text { potentially participate as a stakeholder or } \\
\text { customer. They support clear regulations } \\
\text { and standards for charging, operating, and } \\
\text { parking. }\end{array}$ & $\begin{array}{l}\text { Stranded costs, lack of standards, } \\
\text { technological obsolescence, } \\
\text { technological lock-in, } \\
\text { unrecoverable costs, imprudent } \\
\text { risk. }\end{array}$ \\
\hline $\begin{array}{l}\text { INDUSTRY / } \\
\text { TRADE } \\
\text { ASSOCIATIONS (S) } \\
\text { (C) (P) }\end{array}$ & $\begin{array}{l}\text { Reducing city traffic. Reducing street } \\
\text { parking. Reducing emissions. City could } \\
\text { potentially participate as a stakeholder or } \\
\text { customer. They support clear regulations } \\
\text { and standards for charging, operating, and } \\
\text { parking. }\end{array}$ & $\begin{array}{l}\text { Unprofitable, or marginally } \\
\text { profitable markets, lack of } \\
\text { standards, lack of clear regulation, } \\
\text { unproven technology. }\end{array}$ \\
\hline OPUC (G) & $\begin{array}{l}\text { Reducing city traffic. Reducing street } \\
\text { parking. Reducing emissions. City could } \\
\text { potentially participate as a stakeholder or } \\
\text { customer. They support clear regulations } \\
\text { and standards for charging, operating, and } \\
\text { parking. }\end{array}$ & $\begin{array}{l}\text { OPUC may be concerned about } \\
\text { enforcing bike safety requirements } \\
\text { and concern about bike vs. car } \\
\text { traffic issues. Environmental } \\
\text { groups would resist initiates } \\
\text { without clear benefits in terms of }\end{array}$ \\
\hline
\end{tabular}




\section{Stakeholder (S) / \\ Customer (C) / \\ Provider (P) / \\ Govt \& Reg (G)}

\begin{tabular}{|c|c|c|}
\hline & & $\begin{array}{l}\text { emissions reduction, green power } \\
\text { use, and recycling of toxic battery } \\
\text { components. }\end{array}$ \\
\hline ODOE (G) & $\begin{array}{l}\text { Reducing city traffic. Reducing street } \\
\text { parking. Reducing emissions. City could } \\
\text { potentially participate as a stakeholder or } \\
\text { customer. They support clear regulations } \\
\text { and standards for charging, operating, and } \\
\text { parking. }\end{array}$ & $\begin{array}{l}\text { ODOE may be concerned about } \\
\text { enforcing bike safety requirements } \\
\text { and concern about bike vs. car } \\
\text { traffic issues. Environmental } \\
\text { groups would resist initiates } \\
\text { without clear benefits in terms of } \\
\text { emissions reduction, green power } \\
\text { use, and recycling of toxic battery } \\
\text { components. }\end{array}$ \\
\hline $\operatorname{BPA}(\mathrm{G})$ & $\begin{array}{l}\text { Reducing emissions. City could } \\
\text { potentially participate as a stakeholder or } \\
\text { customer. They support clear regulations } \\
\text { and standards for charging, operating, and } \\
\text { parking. }\end{array}$ & $\begin{array}{l}\text { BPA groups may be concerned } \\
\text { about enforcing bike safety } \\
\text { requirements and concern about } \\
\text { bike vs. car traffic issues. } \\
\text { Environmental groups would resist } \\
\text { initiates without clear benefits in } \\
\text { terms of emissions reduction, green } \\
\text { power use, and recycling of toxic } \\
\text { battery components. }\end{array}$ \\
\hline $\begin{array}{l}\text { EE / RE } \\
\text { ADVOCATES (S) } \\
(\mathrm{G})\end{array}$ & Includes ETO, NEA, OREP & $\begin{array}{l}\text { EE / RE groups may be concerned } \\
\text { about enforcing bike safety } \\
\text { requirements and concern about } \\
\text { bike vs. car traffic issues. } \\
\text { Environmental groups would resist } \\
\text { initiates without clear benefits in } \\
\text { terms of emissions reduction, green } \\
\text { power use, and recycling of toxic } \\
\text { battery components. }\end{array}$ \\
\hline \multirow[t]{2}{*}{$\begin{array}{l}\text { CONSUMER } \\
\text { ADVOCATES }\end{array}$} & $\begin{array}{l}\text { Reducing city traffic. Reducing street } \\
\text { parking. Reducing emissions. City could } \\
\text { potentially participate as a stakeholder or } \\
\text { customer. They support clear regulations } \\
\text { and standards for charging, operating, and } \\
\text { parking. }\end{array}$ & $\begin{array}{l}\text { Consumer groups may be } \\
\text { concerned about enforcing bike } \\
\text { safety requirements and concern } \\
\text { about bike vs. car traffic issues. } \\
\text { Environmental groups would resist } \\
\text { initiates without clear benefits in } \\
\text { terms of emissions reduction, green } \\
\text { power use, and recycling of toxic } \\
\text { battery components. }\end{array}$ \\
\hline & $\begin{array}{l}\text { Reducing city traffic. Reducing street } \\
\text { parking. Reducing emissions. City could } \\
\text { potentially participate as a stakeholder or } \\
\text { customer. They support clear regulations } \\
\text { and standards for charging, operating, and } \\
\text { parking. }\end{array}$ & \\
\hline $\begin{array}{l}\text { GOVERNMENT - } \\
\text { City, County, State }\end{array}$ & $\begin{array}{l}\text { Reducing city traffic. Reducing street } \\
\text { parking. Reducing emissions. City could } \\
\text { potentially participate as a stakeholder or }\end{array}$ & $\begin{array}{l}\text { Unclear regulations for parking or } \\
\text { operating e-bikes on city streets } \\
\text { around campus. They may initially }\end{array}$ \\
\hline
\end{tabular}


Stakeholder (S) /

Customer (C) /

Provider (P) /

What they Support

What they Resist

Govt \& Reg (G)

\begin{tabular}{|c|c|c|}
\hline$(\mathrm{S})(\mathrm{C})$ & $\begin{array}{l}\text { customer. They support clear regulations } \\
\text { and standards for charging, operating, and } \\
\text { parking. City government and its } \\
\text { employees may consider sponsoring or } \\
\text { becoming customers of an e-bike system. } \\
\text { Tax credits or other incentives (mainly at } \\
\text { the city, county, or state level, but } \\
\text { possibly also federal) to encourage a } \\
\text { campus e-bike system could be important } \\
\text { to make the initial system feasible to } \\
\text { establish. Governments are more likely to } \\
\text { support systems that are accessible to the } \\
\text { wider community and not just those } \\
\text { affiliated with the university. }\end{array}$ & $\begin{array}{l}\text { loose some parking revenue if street } \\
\text { parking drops, but it is likely to be } \\
\text { compensated for by additional } \\
\text { customer parking tor businesses. } \\
\text { Concerns about bike safety would } \\
\text { have to be addressed. City } \\
\text { government would probably resist } \\
\text { becoming a partner or customer in } \\
\text { such a project unless technology } \\
\text { and business risk could be } \\
\text { sufficient reduced to make long- } \\
\text { term success probably and avoid a } \\
\text { politically embarrassing failure. } \\
\text { Governments would be reluctant to } \\
\text { establish substantial incentives, } \\
\text { credits, or other financial support, } \\
\text { especially during the recent } \\
\text { economic downturn, unless clear } \\
\text { benefits and performance goals } \\
\text { could be met and the risk of } \\
\text { business or technology failure } \\
\text { could be shown to be low. }\end{array}$ \\
\hline $\begin{array}{l}\text { COMMUNITY } \\
\text { GROUPS (S) / } \\
\text { COMMUNITY } \\
\text { MEMBERS (S)(C) }\end{array}$ & $\begin{array}{l}\text { Civic organizations are concerned with } \\
\text { reducing traffic, parking, pollution, noise, } \\
\text { as well as bike safety. Envrionmental } \\
\text { groups support reduced emissions, use of } \\
\text { green power for bike charging. } \\
\text { Individuals community members might } \\
\text { consider participating in an e-bike } \\
\text { system, especially if it spread beyond the } \\
\text { university campus and into the surround } \\
\text { community. }\end{array}$ & $\begin{array}{l}\text { Civic groups may be concerned } \\
\text { about enforcing bike safety } \\
\text { requirements and concern about } \\
\text { bike vs. car traffic issues. } \\
\text { Environmental groups would resist } \\
\text { initiates without clear benefits in } \\
\text { terms of emissions reduction, green } \\
\text { power use, and recycling of toxic } \\
\text { battery components. }\end{array}$ \\
\hline $\begin{array}{l}\text { PUBLIC UTILITY } \\
\text { COMPANIES (P) }\end{array}$ & $\begin{array}{l}\text { Cost recovery, fair rate of return, stable } \\
\text { long-term market, clear regulations, } \\
\text { pricing. }\end{array}$ & $\begin{array}{l}\text { Lack of standards, locking in } \\
\text { technological obsolescence }\end{array}$ \\
\hline
\end{tabular}

Source: Adapted from [203, 204]

The stakeholder-objective matrix for this case study summarizes a number of important points. The main participants envisioned in the EV enterprise for this case study can be divided into Stakeholders (S), Customers (C), and Providers (P). Several 
participants fall into more than one categories. These participants include: University $(\mathrm{S})(\mathrm{C})(\mathrm{P})$; Government $(\mathrm{S})(\mathrm{C})$; Community Groups $(\mathrm{S})$ and Community Members $(\mathrm{S})(\mathrm{C})$; Students (C); Faculty (C); Staff (C); Utility Companies (P); and Third Party Vendors (P). Each participant has specific issues labeled "what they support" and "what they oppose," which are summarized on the above chart. This information can then be used as an input to determine how stakeholder objectives can be translated into drivers of value production for products and services on a technology roadmap. This information will then be fed into the next stage of the research process, which is to conduct an industry analysis to design and obtain a business target, define business model alternatives, establish content to construct a technology roadmap, and understand key barriers and mitigators to development.

After an opportunity is recognized, such as through literature, consultation with experts, or other means, a business modeling process is performed to further define and assess the potential opportunity. An outcome model is then defined describing the opportunity both in it current state, the "as is" model, and what is desired in the future, the "to be" model $[132,163,164]$. However, prior to creating this model, a preliminary sub-model is created to assess initial ideas. A series of basic questions are answered as shown below to begin defining an opportunity that may later be developed into a complete business model. The questions have been modified to make them relevant for creating an integrated smart grid roadmap, which may have a number of stakeholders who are not necessarily direct customers. 
To illustrate how this type of business sub-model matrix could be applied, a case study was performed examining the case of EV rental and/or charging in the Pacific Northwest. The following diagram illustrates the business sub-models that were derived.

Figure 7.2: Business Sub Model Matrix for EV Study

\begin{tabular}{|c|c|}
\hline Sub Model & Sub Model Features \\
\hline $\begin{array}{l}\text { Who? } \\
\text { Stabeholders? GOVERNMENT, UTILITY COMPANIES, UTILITY } \\
\text { REGULATORS, VENDORS (CHARGING), EV MANUFACTURERS } \\
\text { ENVIR GROUPS \& NGOs } \\
\text { What do they support/ oppose (See stakeholder matix) } \\
\text { Customers? GREEN DRIVERS, ELECTRICITY USERS, GREEN } \\
\text { CONSUMERS } \\
\text { Markets? GREEN AUTOMOBILES, GREEN ENERGY } \\
\text { Segment. GREEN DRIVERS, GREN ENERGY USERS, SHORT-, MED. } \\
\text { RANGE COMMUTERS }\end{array}$ & $\begin{array}{l}\text { Structure of Market? PRIVATE COMPANIES, PUBLIC STOCK COMPANIES, } \\
\text { UTILITIES (PUBLIC / PRIVATE } \\
\text { Target Customers? DRIVERS, GREEN ENERGY USERS (HYBRID \& PV } \\
\text { OWNERSHIP IS A PREDICTOR) }\end{array}$ \\
\hline $\begin{array}{l}\text { What? } \\
\text { Value Proposition? GREEN, EFFICIENT, INEXPENSIVE TRANSPORTATION } \\
\text { (TCO), VEHICLE ENERGY MGT } \\
\text { What do stakeholders have now? FOSSIL FUEL VEHICLES, } \\
\text { What do stakeholders want? GREENER, CHEAPER TRANSPORTATION, } \\
\text { CLEAN \& EFFICIENT ENERGY MGT }\end{array}$ & $\begin{array}{l}\text { Products? EV CHARGING SERVICES } \\
\text { CUstomer Utilities? LOWER POLLUTION, REDUCED COSTS } \\
\text { COMpetitiveness? LOW OPERATION COSTS, RESPONDS TO DEMAND. } \\
\text { OVERCOMING INITIAL SKEPTICISM ABOUT HIGH PURCHASE COSTS } \\
\text { AND UNCERTAINTY ABOUTEVS \& CHARGING OPTIONS IS A } \\
\text { CHALLENGE TO BE ADDRESSED. }\end{array}$ \\
\hline $\begin{array}{l}\text { How? } \\
\text { Value Delivery? TOU / NON-TOU UTILITY, TIME BASED FEES } \\
\text { DEMAND CHARGE, BIZ-CONS PARTNERSHIP, VALIDATION \& VOL } \\
\text { DISCOUNTS }\end{array}$ & $\begin{array}{l}\text { Finance Acquisition? PRIVATE, VENTURE CAP, UTILITY FINANCING } \\
\text { (BONDS), BANKS, CROWD / MICRO FINANCE } \\
\text { Manufacturing? PRIMARILY SW, HW ASSEMBLY \& INSTALL } \\
\text { Distribution Channel? B2C, B2B, B2C2B }\end{array}$ \\
\hline $\begin{array}{l}\text { Profit \& Revenues? } \\
\text { Customers? GREEN DRIVERS, ELECTRICITY USERS, GREEN CONSUMERS } \\
\text { Markets? GREEN AUTOMOBILES, GREEN ENERGY } \\
\text { Segments? GREEN DRIVERS, GREEN ENERGY USERS, SHORT-, MED- } \\
\text { RANGE COMMUTERS }\end{array}$ & $\begin{array}{l}\text { Profit Model? CHARGING SERVICE PROVIDERS: INVESTOR OWNED, } \\
\text { UTILITY OWNED, AGGREGATOR OWNED } \\
\text { Ownership Structure? PRIVATE COMPANIES, PUBLIC STOCK COMPANIES, } \\
\text { UTILITIES (PUBLIC / PRIVATE) }\end{array}$ \\
\hline
\end{tabular}

Source: Adapted from [132, 163, 164]

Several key pieces of information can be seen from the above figure. Key stakeholders include university faculty, staff, and students, as well as businesses or organizations in the local area, and local government. Decisions must be made regarding whether to focus first on specific user segments among these stakeholders or on a combination of segments. Further decisions must be made regarding the possibility of university, utility, or third-party ownership of an EV venture and if the primary profit mechanism will be rentals, battery charging, leasing, or some combinations thereof. 
Options for financing and distribution can then be determined that are appropriate for each of these cases. The next step in this process explains more details about defining a business model.

A number of additional steps are required in order to define a business model. As previously mentioned, the we use the business model elements as referred to by Hamel [157], Slywotzky [158, 159], and Chesbrough [160] in our pilot study.

Understanding appropriate business models for emerging technologies, such as electric vehicle-to-grid smart charging appliances, is critically important, since much of the new technology is in a nascent state and the direction of development can depend strongly upon perceived business opportunities. This can likewise be affected by perspectives regarding the market, regulatory and policy goals, and the rate at which technical capabilities are developing. Therefore, the next step in this process is to examine each of these key perspectives and to have experts determine what that they consider to be the highest priority issues in these areas during the following time periods: 1 year; 2 to 4 years; and 5 to 10 years.

As was done in the previous section, a case study involving EV use in the Pacific Northwest has been used to illustrate how this type of business concept development can be applied. The following diagram illustrates the business concept development information that was obtained from this process. 
Figure 7.3: Opportunities \& Perspectives in EV Study
A. Ask: What?
Value Proposition
Products? ELECTRIC VEHICLE CHARGING
Capabilities? GREEN, EFFICIENT, INEXPENSIVE TRANSPORTATION (TCO)
Competitive Advantage? LOW OPERATION COSTS, RESPONDS TO DEMAND
B. Ask: Where? HOME AND PUBLIC EV CHARGING FOR BUSINESS \& CONSUMER USE
C. Ask: Why? Why is this important? (See Perspectives in next section for more detail)

\begin{abstract}
4. Perspectives Recognition (Worksheet 2): Priority Issues in next 1 to 10 years (Based on S-Plan elements)
\end{abstract}
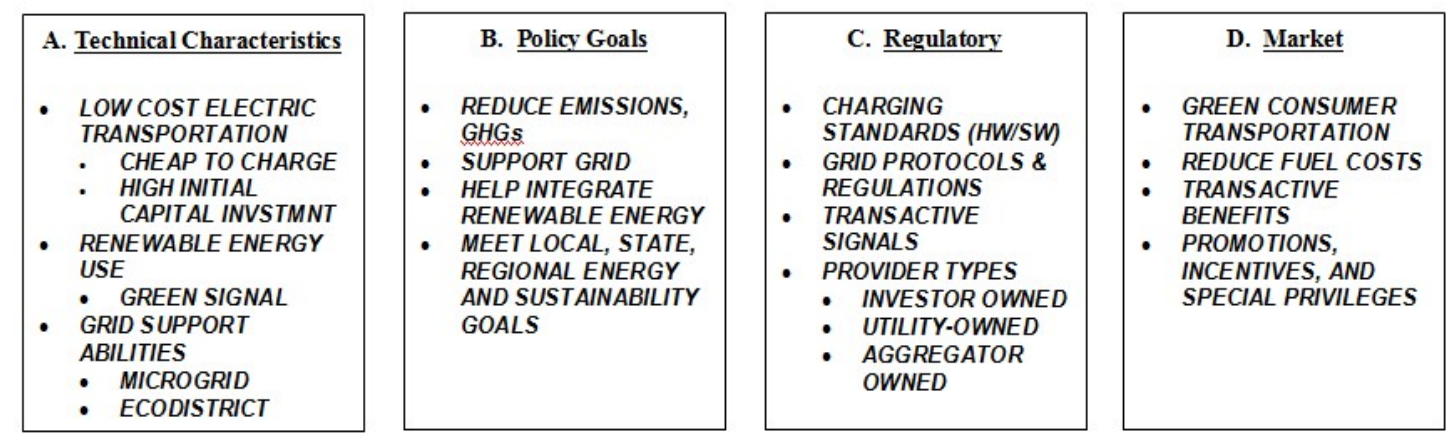

Source: Derived from [30, 145, 203, 204]

The case study resulted in a number of interesting insights into these questions. It helped define the basic opportunity and value proposition (summarized on Worksheet 1 above): To provide low cost, convenient, environmentally friendly transportation with EVs that are easy to use. It defined where the EVs would be used: In the Pacific Northwest, local microgrids, or ecodistricts. It then examined why this opportunity would be important by analyzing perspectives on the technical characteristics and policy goals, as well as regulatory and market considerations (summarized on Worksheet 2 above). 
The next step in this process is to provide more details about the necessary business structure and goals. This information is summarized in the figure below.

Figure 7.1.4: Business Structure \& Goals Summary in EV Study

\begin{tabular}{|c|}
\hline A. Who? \\
Stakeholders \\
\hline GOVERNMENT \\
UTILITIES \\
UTILITY REGULATORS \\
VENDORS (CHARGING) \\
EV MANUFACTURERS \\
ENVIR GROUPS \& NGOs \\
What do they support/oppose? \\
(See Stakeholder-Obj Matrix) \\
Customers \\
DRIVERS \\
ELECTRICITY USERS \\
GREEN CONSUMERS \\
What do they want / not have now? \\
(See Stakeholder-Obj Matrix) \\
\hline
\end{tabular}

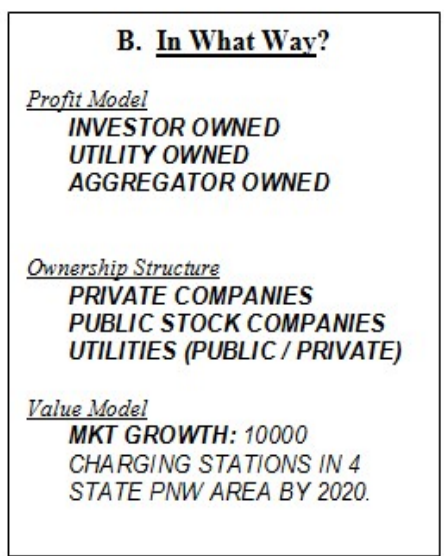

\begin{tabular}{|c|}
\hline C. How? \\
Value Deliver Method \\
\hline TOU / NON-TOU UTILITY \\
TIME BASED FEES \\
DEMAND CHARGE \\
BIZ-CONS PARTNERSHIP \\
VALIDATION \& VOL \\
DISCOUNTS \\
Distribution Channel \\
B2C \\
B2B \\
B2C2B \\
Finance Method \\
\hline PRIVATE, VENTURE CAP \\
UTILITY FINANCING (BONDS) \\
BANKS \\
CROWD / MICRO FINANCE \\
\hline
\end{tabular}

7. Synthesis: By answering the above questions, it should be possible to determine (at least tentatively)

- What is the "as is" situation or opportunity to be explored? FROM: USE OF FOSSIL FUEL VEHICLES AS A TRANSPORTATION ALTERNATIVE MAINLY FOR SHORT-AND MEDIUM RANGE-PASSENGER VEHICLES

- What is the "to be" vision? IO: USE OF ELECTRIC PASSENGER VEHICLES FOR SHORT-AND MEDIUM-RANGE TRANSPORTATION AND CHARGING SYSTEMS THAT FIT WITH AN INTERGRATED REGIONAL ENERGY PLAN TO MEET GOALS FOR INTEGRATING RENEWABLE ENERGY AND SUPPORTING THE POWER GRID.

- What are the business goals over time (i.e. $10 \mathrm{X}$ growth in 10 years...)

- What are the key gap areas or needs?

Source: Adapted from [132, 163, 164, 205]

By answering the types of questions presented above, it should be possible to

determine the following (at least tentatively):

- What is the "as is" situation or opportunity to be explored?

- What is the "to be" vision?

- What are the business goals over time (i.e. 10X growth in 10 years...)

- What are the key gap areas or needs?

A brief example of how this tool would be used is to estimate potential sales of a specific product, like residential electric vehicle chargers in Oregon over the next 10 years. A company engaged in a similar type of electronic equipment business might 
consider getting into this business through one or more of the potential distribution channels, but only if it could expand sales in a current business area by some goal (commonly 10X over 10 years). The estimated sales are the "to be" number and the current product sales are the "as is" number. If the number for the goal of increasing sales by $10 \mathrm{X}$ is greater than the "to be" number, this means there is a gap in what the new industry is estimated to achieve versus the business's goal of increasing its current sales. After determining if such as gap exists and how large it is, various alternatives can be examined for achieving the business goal through one or more business models. This helps understand key decisions that are likely to make regarding business entrant to an industry therefore this research proposes to use this as an input into an integrated roadmapping process.

Based on the case study, the "as is" situation is: Use of non-EVs in the Pacific Northwest as a transport alternative primarily for short-range commuters. The "to be" situation is: Use of EVs in the Pacific Northwest as part of an integrated campus commuter system aimed at reducing car use for intermediate- and long-range commuters. The initial business goal can be stated in several ways. In terms of return on investment, a goal of achieving a $10 \mathrm{X}$ or ten-fold return on investment within 10 years is envisioned. In terms of market share, the goal is to achieve participation equal to $20 \%$ of the student population. At this point in the analysis of this case study, such goals can be considered "stretch goals." However, they are useful in defining some possibly metrics of success that were considered reasonably attainable, based on the data gathered for this study. Key gaps or needs that would be necessary to address in order to achieve these goals 
would be to make decisions regarding the choice of specific value delivery methods, distribution channels, and finance methods. To better understand the possibilities that exist for each of those alternatives, an industry analysis is helpful. Therefore, an industry analysis is performed in the next section, and a more detailed analysis of results for each of these alternatives is provided there.

\subsection{Industry Analysis for Electric Vehicle Case Study}

Industry analysis is a critical step in this research process. It makes use of well known tools, like Porter's Five Forces, to understand the viability of particular business concepts with an industry. However, this tool needs to be modified to focus particular attention on the effect of barriers that exist within regulated industries, such as utilities, which generally have been structured as regulated monopolies. While, in most cases, regulated monopoly structures are not expected to be fundamentally changed in these industries, it is important to understand how changes in technology, policy, and limited market restructuring may lead to the creation of new opportunities. Therefore, the goal of this phase of industry analysis is to understand what factors can mitigate existing barriers and how appropriate business targets can be designed and incorporated into roadmaps.

A widely used tool for analyzing industry conditions is Porter's Five Forces [161, 162]. The tool identifies five forces based on industrial organization economics that indicate the overall attractiveness or profitability of an industry based on its intensity of competition. The tool is valuable for most industries with competitive structures. The 
forces examined include the internal market issues of: (1) bargaining power of buyers; bargaining power of suppliers; (3), the viability of substitutes for the product or service in question (4), and the external market issue of new entrants to market.

In the case of pure monopolies, there would be almost no threat of new entrants, so Porter's Five Forces would be of limited value. However, many utility systems function as regulated monopolies in limited service territories. In these cases, the five forces model is relevant and can produce some valuable insights. This is especially true, as many utility systems have considered various types of restructuring, creating deregulated or partially de-regulated systems that have increased the competitive elements within the industry.

However, when using the five forces model, it makes sense to modify portions of it in a number of ways to fit the general nature of the utility industry. Typically, barriers to entry are still extremely high for utilities, even in the absence of traditional monopoly structures, since the investments for utility infrastructure are very capital intensive. So, a starting assumption for analysis in this industry is that is very important to understand the size and types of barriers that exist. Barriers can be further sub-divided into both the typical business \& market barriers (1) and regulatory \& policy barriers (2). So, the industry analysis portion of this research makes use of this modified structure for the five forces model. 
Another area that is examined is business \& market targets, as well as regulatory $\&$ policy targets for overcoming barriers in those areas. Finally, mitigation programs are examined, such as business \& market programs, as well as regulatory \& policy programs that could potentially be used for overcoming these barriers. The following diagram shows the modified framework. Information from EV case study mentioned in previous sections is provided here.

Figure 7.4: Industry Analysis for EV Study

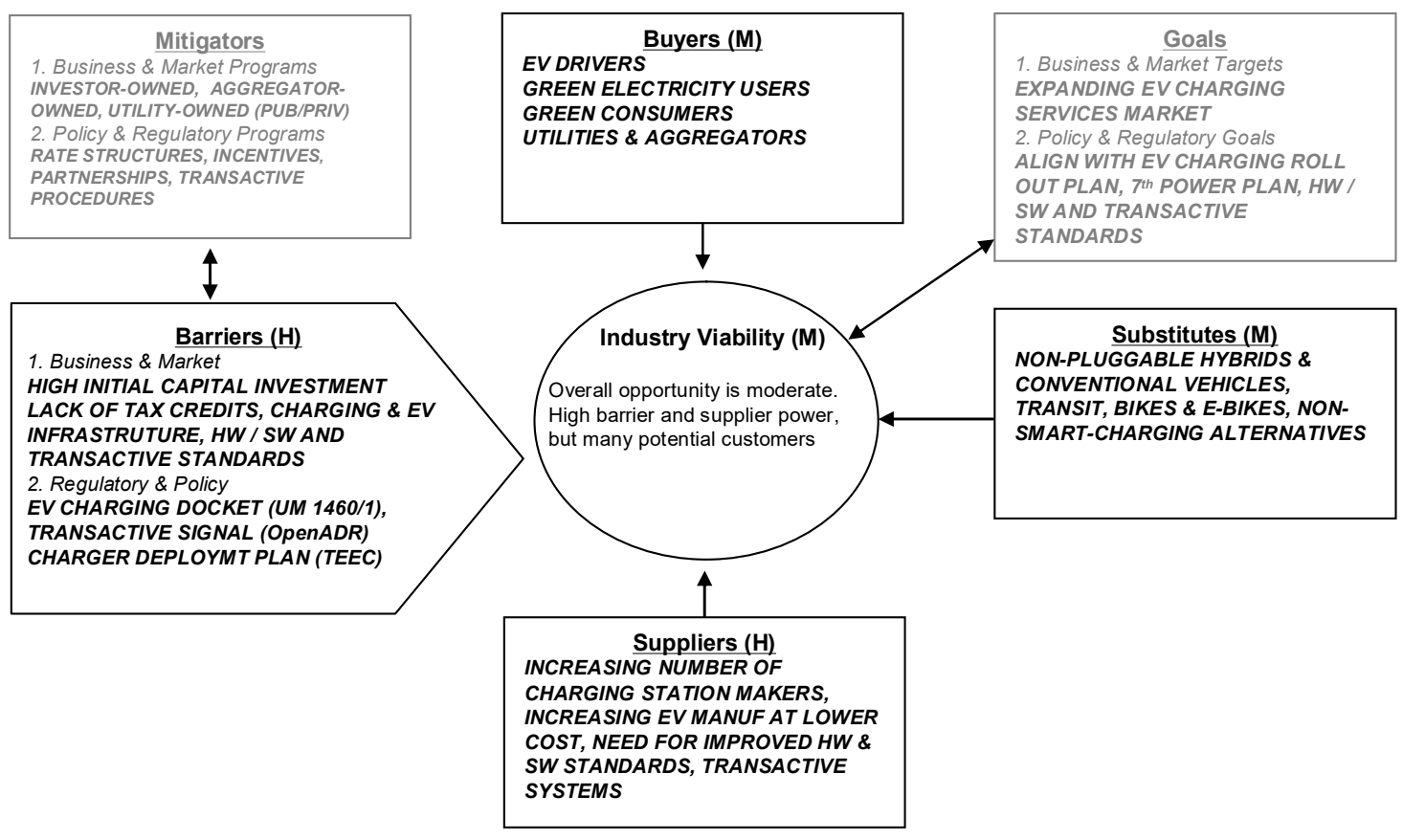

Source: Modified from [161, 162]

Based on the results of the case study, a number of key points can be observed. Industry Viability was rated as questionable to moderate. This was primarily due to high perceived barriers and high supplier power. Substitutes for EVs were considered low to 
moderate. A number of mitigators were identified for addressing barriers, such as joint financing, and special rate structures or incentives that could be used to make the goal of a university-third-party partnership more attainable. The overall opportunity was considered somewhat attractive, as many potential buyers, are believe to exist for this type of system.

The industry analysis produces three main outcomes: (1) Designing and Obtaining a business target; (2) Establishing content to construct a technology roadmap integrating the business / market and regulatory / policy issues identified in the industry analysis; and (3) to understand the key barriers that exist and how they can be mitigated. This information will becomes an input for the next phase of the research, which constructs a roadmap based on these elements and begins the process of prioritizing them.

In situations where clear business opportunities already exist, a technology roadmap makes it easier to identify and understand the nature of such opportunities. However, in many cases, opportunities and strategies for capturing them are just being identified. In some cases, business models have not yet been developed to accommodate evolving regulatory and policy structures.

To better analyze and define the basis for various business models that are possible in the emerging smart grid industry, a technique will be used called My Vision \& My Will is used in the next section [132, 163, 164]. As previously mentioned, a business opportunity can be examined in terms of both "as is" and "to be" conditions. By 
looking at gaps between these two conditions, different scenarios or alternative approaches can be envisioned for achieving the desired objective. In cases where a set of industry roadmaps already exist, this can be used as an input for considering alternatives to reach the "to be" condition. However, because the type of integrated roadmaps desired in this research do not currently exist, it will be necessary to come up with scenario alternatives through a process of expert judgment. The following matrix is one tool that is helpful in determining the type of business to customer relationship that is envisioned.

To illustrate how this type of business-stakeholder alternatives analysis could be applied a case study was performed examining the case of EV rental and/or charging in the Pacific Northwest. The following diagram illustrates the business-stakeholder alternatives information that resulted from the study.

A number of key pieces of information are summarized on the figure below. The main business alternatives examined were Business-to-Consumer (B2C), Business-toGovernment (B2G) with an additional Business-to-Business (B2B) option, and Businessto-Community-to-Government (B2C2G2B). 
Figure 7.4: Business-Stakeholder Alternatives for EV Study

\begin{tabular}{|c|c|c|c|}
\hline & B 2C & B 2C2B & B 2B \\
\hline Customer / Sta keholder & $\begin{array}{l}\text { INVESTOR-OWNED CHARGING } \\
\text { VENDORS, EV DRIVERS }\end{array}$ & $\begin{array}{l}\text { UTILITY-OWNED CHARGING } \\
\text { VENDORS, EV DRIVERS, } \\
\text { ANCILLARY SERVICES } \\
\text { PURCHASERS }\end{array}$ & $\begin{array}{l}\text { INVESTOR-OWNED CHARGING } \\
\text { VENDORS, UTILITY-OWNED } \\
\text { CHARGING VENDORS, } \\
\text { AGGREGATOR-OWNED } \\
\text { CHARGING VENDORS, EV } \\
\text { DRIVERS, ANCILLARY } \\
\text { SERVICE CUSTOMERS }\end{array}$ \\
\hline Product / Services & $\begin{array}{l}\text { CHARGING FEE, PARKING } \\
\text { FEES, MEMBERSHIP FEES, } \\
\text { DEMAND CHARGES, OTHER } \\
\text { PREMIUM SERVICES }\end{array}$ & $\begin{array}{l}\text { TOU \& NON-TOU RATES, } \\
\text { CHARGING FEE, PARKING } \\
\text { FEES, OVERALU USAGE } \\
\text { PLANS, FREE AND } \\
\text { DISCOUNTED USAGE TIMES, } \\
\text { DEMAND CHA RGES, OTHER } \\
\text { PREMIUM SERVICES }\end{array}$ & $\begin{array}{l}\text { CHARGING FEE, PARKING } \\
\text { FEES, MEMBERSHIP FEES, } \\
\text { DEMAND CHARGES, OTHER } \\
\text { PREMIUM SERVICES, } \\
\text { BUSINESS-ORIENTED PLANS }\end{array}$ \\
\hline Operations System & $\begin{array}{l}\text { INDIVIDUAL POINT OF SALE } \\
\text { CONSUMER TRANSACTION } \\
\text { CHARGING HARDWARE, } \\
\text { INTERFACE SOFTWARE }\end{array}$ & $\begin{array}{l}\text { INDIVIDUAL POINT OF SALE } \\
\text { CONSUMER TRANSACTION, } \\
\text { USAGE PLANS (B2C/C2B) } \\
\text { CHARGING HARDWARE, } \\
\text { INTERFACE SOFTWARE }\end{array}$ & $\begin{array}{l}\text { BUSINESS TRANSACTIONS } \\
\text { (CHARGING VENDORS, } \\
\text { ENERGY MGT AGGREGTRS, } \\
\text { ANCILLARY SRV CUSTOMERS) } \\
\text { CHARGING HW \& SW, } \\
\text { AGGREGATION HW \&SW }\end{array}$ \\
\hline Profit Model & $\begin{array}{l}\text { CONSUMER: CHARGING } \\
\text { SERVICES, PARKING FEES, } \\
\text { MEMBERSHIP FEES, DEMAND } \\
\text { CHARGES, OTHER PREMIUM } \\
\text { SERVICES }\end{array}$ & $\begin{array}{l}\text { CONSUMER: CHARGING } \\
\text { SERVICES, PARKING FEES, } \\
\text { TOU PLANS, USAGE PLANS } \\
\text { (B2C/C2B), DEMAND CHARGES, } \\
\text { OTHER PREMIUM SERVICES, }\end{array}$ & $\begin{array}{l}\text { BUSINESS: CHARGING } \\
\text { PROVIDER SERVICES, } \\
\text { AGGREGATION SERVICES }\end{array}$ \\
\hline $\begin{array}{l}\text { Growth Model } \\
2013 \text { (now) } \\
2018 \text { ( } 3 \text { year }) \\
2020 \text { ( } 5 \text { year })\end{array}$ & $\begin{array}{l}1,500 \text { EV customers } \\
7,500 \text { EV customers } \\
10,000\end{array}$ & $\begin{array}{l}1,500 \text { EV customers } \\
7,500 \text { EV customers } \\
10,000\end{array}$ & $\begin{array}{l}1,500 \text { EV customers } \\
7,500 \text { EV customers } \\
10,000\end{array}$ \\
\hline
\end{tabular}

Source: Derived from $[132,163,164]$

In the first case, B2C, the EV program is conducted directly to the endconsumers: The students, faculty, and staff at the university utilizing the program. Various products or services are available under this model, such as EV rentals, individual memberships, charging programs, EV leases, and EV purchases. Profit models are created based on each of these product service types. A number of operations systems are also available for enabling delivery of these products and services, such as software or web-enabled transactions, point of sales transactions at kiosks, or individual transactions between buyers and sellers. The growth model associated with B2C-oriented strategies is estimated based on an initial start-up in the first year, and then estimating 
growth over 5 years and growth over 10 years. Estimates for these time period are that an initial group of 500 customers ( $2 \%$ of the target population) could be established in the first year of operations. After 5 years, the goal would be to grow this figure to 2,000 ( $10 \%$ of target population), and after 10 years, the figure would be increased to 4,000 (20\% of target population). Such a strategy has the advantage of being focused on a single population in a well defined area. A number of the other strategies differ primarily in the fact that they reach out to a broader population in the area surround the campus and the community. So, they potentially can reach a greater population. However, they also have the disadvantage of being less focused on a narrow group with similar needs. Therefore, other techniques and strategies are expected to be required to serve these populations.

In the second case, $\mathrm{B} 2 \mathrm{G}$, the idea is that rather serving only the consumers in the Pacific Northwest, the initial focus will be on faculty and staff at the university, as well as local government agencies, such as city and county employees in the immediate vicinity of campus. This group would act as a set of lead-users, testing the system. It is likely that rather than individually selling to consumers, agreements would be negotiated that would allow package deals for all employees or groups of employees in the Pacific Northwest, Portland City Government, Multnomah County Government, the Portland Development Commission, City Police, Firefighters, Public Safety workers, and others. This is expected to be a fairly large group, which often has a history of working with and frequently even sharing building space in the Pacific Northwest. Due to the likelihood of group deals, a relatively large group of customers could probably be acquired quickly. 
The decision could also be made to expand the focus of this strategy to a B2G2B model, which would do the same as above, except that in addition to government employees, it would also add employees of businesses in the extended area of the Pacific Northwest. This would allow for an even larger group of customers, but would carry the risk of being less focused, and potentially requiring a more diverse set of requirements to meet customer needs than would be the case with a more narrowly defined group. In the case of the later strategies, estimates are that the initial customer base in the start-up year would be approximately 850 (2\% partners, $2 \%$ government employees, and $1 \%$ of local business employees). After 5 years, the figure would be projected to grow to 4,000 (10\% partners, $10 \%$ government, and $5 \%$ business). In 10 years the goal would be to increase this figure to 8,000 (20\% partners, $15 \%$ government, and $10 \%$ business).

In the third case, B2C2G2B, this is essentially an all-of-the-above strategy. In additional reaching out directly to the end-consumers in the Pacific Northwest (utilities, investor / third-party, and government), the customer base would also include local government employees, local business employees, and other community members in the surrounding area. This approach would have the advantage of a very large potential customer base, but would also have the disadvantage of being less focused than the other more narrowly defined approaches, and therefore having to meet a much more diverse set of customer needs. In this case estimates are that the initial customer base in the start-up year would be approximately 1,000 ( $2 \%$ of partners, $2 \%$ government employees, $1 \%$ of local business employees, and $1 \%$ of other community members). After 5 years, the figure would be projected to grow to 4,500 (10\% partners, $10 \%$ government, $5 \%$ 
business, and $2 \%$ community). In 10 years the goal would be to increase this figure to 9,500 (20\% partners, $15 \%$ government, $10 \%$ business, $5 \%$ community).

The goal of this analysis is to consider a variety of different business approaches with potential customer groups that would require different techniques for serving them and would ultimately result in very different sizes of initial customer bases, as well as the eventual size of the customer based after 10 years. The objective is not to provide forecasts to determine precisely how many customers will make a purchase in a given year. The objective is merely to begin quantifying general expectations regarding some of the different business approaches and to be considering the different techniques for reaching customers with a variety of different types of needs.

Another business modeling tool is then used to consider how various factors may be able to change the basis of competition over time. The following matrix provides a way of analyzing this. This offers a useful tool for examining potential factors that may impact an industry with respect to emerging dimensions of competition and overall industry viability. 
Figure 7.5: Industry Factor Alternatives for EV Study

\begin{tabular}{|c|c|c|c|c|}
\hline & & 2015 & 2020 & 2025 \\
\hline \multirow[t]{2}{*}{ Regulatory / Policy } & $\begin{array}{l}\text { New Policy / } \\
\text { Existing Regulatory } \\
\text { Structure }\end{array}$ & $\begin{array}{l}\text { PUBL IC CHARG ING R ATES, } \\
\text { PAR KING AGR EEMENTS \& } \\
\text { RATES, MEMBER SHIP } \\
\text { RATES \& STRUC, } \\
\text { PARTN ERSHIP STRUC, } \\
\text { OTHER PREMIUM SERVICES } \\
\text { AGREEMNTS }\end{array}$ & $\begin{array}{l}\text { PUBL IC \& HOMECH ARGING } \\
\text { RATES AND PROCEDURES, } \\
\text { CUSTOMER RATES \& } \\
\text { GSREEMENTS FEES, OTH ER } \\
\text { PREMIUM SERVICES } \\
\text { AGREEMNTS }\end{array}$ & $\begin{array}{l}\text { PUBL IC CHARG ING R ATES } \\
\text { AND PROC EDURES, } \\
\text { CUTOMER AGREEM ENTS, } \\
\text { B2B AGR EEMEN TS }\end{array}$ \\
\hline & $\begin{array}{l}\text { New Regulatory } \\
\text { Structure / } \\
\text { Existing Policy }\end{array}$ & $\begin{array}{l}\text { PUBL IC CHARG ING } \\
\text { STAND ARDS AND } \\
\text { PROCEDURES, CUSTO MER } \\
\text { AGREEMENT STRUC, } \\
\text { PARTN ER AGREEMENTS }\end{array}$ & $\begin{array}{l}\text { PUBL IC \& HOMECH ARGING } \\
\text { STAND ARDS AND } \\
\text { PROCEDURES, CUSTO MER } \\
\text { AGREEMENT STRUC, } \\
\text { PARTN ER AGREEMENTS }\end{array}$ & $\begin{array}{l}\text { PUBL IC CHARG ING } \\
\text { STAND ARDS AND } \\
\text { PROCEDURES, CUSTO MER } \\
\text { AGREEM ENT STRUC, B2 B } \\
\text { AGREEM ENTS }\end{array}$ \\
\hline \multirow[t]{2}{*}{ Market / Product } & $\begin{array}{l}\text { New Product / } \\
\text { Existing Mar ket }\end{array}$ & $\begin{array}{l}\text { CHARGING SYSTEM, } \\
\text { MEMBERSHIP MGT } \\
\text { PROGRAM, PARTNER } \\
\text { MEMBER PROGRAM, } \\
\text { PREMIUM SERVICES } \\
\text { PROGRAMS }\end{array}$ & $\begin{array}{l}\text { CHARGING SYSTEM, } \\
\text { CUSTOMER ACCOUNTMG T } \\
\text { PROGRAM }\end{array}$ & $\begin{array}{l}\text { CHARGING SYSTEM, } \\
\text { CHARGING VENDOR MGT } \\
\text { SYSTEM, AGGREGATION } \\
\text { MGT PROGR AM }\end{array}$ \\
\hline & $\begin{array}{l}\text { New Market / } \\
\text { Existing Product }\end{array}$ & $\begin{array}{l}\text { CHARGING SER VIC ES FOR } \\
\text { SHORT, MED \&LONG- } \\
\text { DISTANCE COMMUTERS, } \\
\text { PREMIUM SERVICE OFFERS }\end{array}$ & $\begin{array}{l}\text { CHARGING SER VICES FOR } \\
\text { SHORT, MED \&LONG- } \\
\text { DISTANE COMMUTERS, } \\
\text { PREMIUM SERVICE OFFERS }\end{array}$ & $\begin{array}{l}\text { CHARGING SER VIC ES FOR } \\
\text { SMALL AND MED CHARG ING } \\
\text { VENDORS, AGGREG ATION } \\
\text { SRVC FOR SMALL AND MED } \\
\text { CHARGING VENDOR S } \\
\end{array}$ \\
\hline \multirow[t]{2}{*}{ Technology / Function } & Technological Factor & $\begin{array}{l}\text { POINT OF USECH ARGING, } \\
\text { ACCTMGT SYSTEM, } \\
\text { PARTN ERSH PMGTS SYS }\end{array}$ & $\begin{array}{l}\text { INTEGR ATED POINT OF USE } \\
\text { CHARGING AND HAN } \\
\text { ENERG Y MAN AGEMENT, } \\
\text { ACCTMGT SYS }\end{array}$ & $\begin{array}{l}\text { POINT OF USECH ARGING, } \\
\text { B2B AG GREG AT ION } \\
\text { MANA GEMENT SYS }\end{array}$ \\
\hline & Functional Factor & $\begin{array}{l}\text { FAST CON VEN IENT } \\
\text { CHARGING, EA SE OF USE, } \\
\text { PARTN ERSHIP } \\
\text { MANAGEMENT }\end{array}$ & $\begin{array}{l}\text { FASTCON VEN IENT } \\
\text { CHARGING, EASE OF USE, } \\
\text { EASY \& ACCURATE } \\
\text { ACCOUNTM ANAG EMENT }\end{array}$ & $\begin{array}{l}\text { POINT OF USECH ARGING, } \\
\text { B2B AG GREGATION } \\
\text { MANA GEMENT SYS }\end{array}$ \\
\hline
\end{tabular}

Source: Derived from $[132,163,164]$

Several categories of industry factor alternatives were considered for the EV case study in the Pacific Northwest. These factors were divided into Regulatory / Policy; Market / Product, and Technology / Function. The first two categories were further subdivided into new versus existing structures or conditions in those areas, and the analysis then considers changes that are envisioned based on those initial conditions over the next 10 years. The third category simply examined changes to technological and functional factors over this time period.

Several categories of industry factor alternatives were considered for the EV case study in the Pacific Northwest. These factors were divided into the following: 
Regulatory / Policy; Market / Product; and Technology / Function. The first category further subdivided into New Policy / Existing Regulatory versus New Regulatory / Existing Policy structures. The second category was divided between New Product / Existing Market versus New Market / Existing Product. The third category simply examined changes to Technological Factors versus Functional Factors. The analysis then considered changes over the next 10 years that are envisioned based on initial structures and conditions in each category.

For the Regulatory / Policy category, the main issues involved moving from a period in which few campus policies exist now regarding EVs, electric charging stations, and policies regarding related vendors and/or partnerships to a period in 5 to 7 years when these policies would be expected to mature into comprehensive, standardized structures. Then, within 10 years, advanced options, such as transactive energy policy and smart appliance standards could be developed and strategic partnerships could be planned. At the same time that new policies were evolving, appropriate regulatory structures, rates, frameworks, and instruments would be developed that would make the new systems practical to implement.

For the Product / Market category, the main issues involved moving from a period in which new products are being developed related to EVs and charging stations, but these products would have to be tested with a variety of currently envisioned market groups to determine the best products that would lead to the adoption of smart EV systems within the next 10 years. At the same time, new target market could be tested 
and to see if evolving EV products could be made to appeal to new groups of end-users and delivered in ways that better meet their needs.

For the Technology / Product category, the main issues involved moving from point of use systems to more mobile systems in the next 5 to 7 years, and finally to smart and "schedule aware" systems in the next 10 years that would be capable of anticipating how to meet customer needs by using information that is already known about the customer's location and schedule. As technologies evolved these new capabilities, product development would also occur that would address concerns about things like emissions performance, cost effectiveness, and ease of use. Like the trends envisioned for the technology development, the product development would be expected to move more from point of use to mobile platforms in the next 5 to 7 years and within 10 years have products that easily and intuitively incorporate schedule aware and location aware functions.

A final method used for understanding business modeling that will provide input into the roadmapping process is the Static vs. Dynamic Business Model Matrix. An example of this matrix is provided below. The matrix examines core business areas and which, if any, have the potential to grow or shrink given current conditions and practices, or which areas have the potential to sustain long-term growth.

To illustrate how this type of static and dynamic business model matrix could be applied a case study was performed examining the case of EV rental and/or charging on 
the Portland State University campus. The following diagram illustrates the models that were derived.

Figure 7.6: Static \& Dynamic Business Models for EV Study

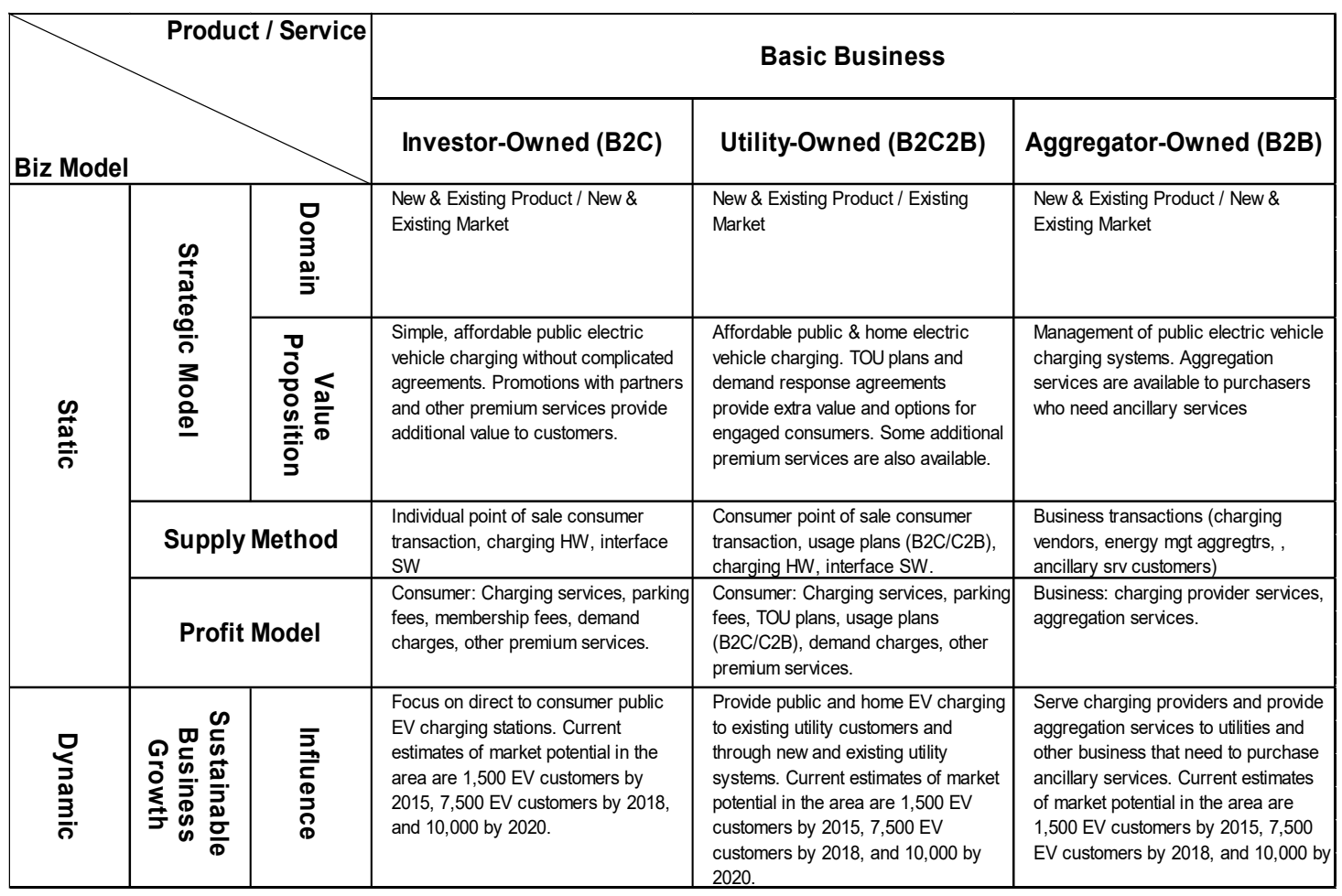

Source: Derived from $[132,163,164]$

Much of the information on the Static \& Dynamic Business Model Matrix is just a summary of information presented on previous matrices, but it is then categorized according to the areas that contribute to long-term stable growth versus more variable growth. A variety of pros and cons related to each of the basic business models have already been discussed, but this tool allows a final comparison of similarities and differences, as well as a few new insights about risks and rewards associated with each. The basic value propositions between the main business models, B2G2B, B2C, and 
$\mathrm{B} 2 \mathrm{C} 2 \mathrm{G} 2 \mathrm{~B}$, are all pretty much the same: Inexpensive, convenient, environmentally friendly transportation that reduces the impact of vehicle use and parking requirements in the campus community. Each of the models is aimed at a progressively larger potential market in the order listed above, from left to right. However, they also involve some progressively increasing risks, as the models move from markets in which the products are currently expected to have an appeal to new markets where the expectations are less certain. B2G2B can be described as a more focused and less risky strategic model, with a small domain of initial target users, simple supply method and fairly robust set of profit model alternatives. However, it has a more limited dynamic growth capability, focusing instead on slow, sustainable business growth and limited overall influence in the broader potential market. At the other end of the spectrum, $\mathrm{B} 2 \mathrm{C} 2 \mathrm{G} 2 \mathrm{~B}$ is truly an all of the above approach, but takes on some significant additional risks in exchange for the potential for higher dynamic growth potential. The B2C approach could be described as somewhere in between the other two approaches.

The information from each of business modeling tools discussed in this section will becomes an input for the next phase of the research, which constructs a roadmap based on these elements and begins the process of prioritizing them. This will be important, as the industry is undergoing rapid growth and development. A wide range of potential smart grid users will need to understand how such new grid infrastructures could be used with new business models for specific industries or sub-industries. 


\subsection{Roadmap Construction \& Prioritization}

The following section shows the components of the roadmapping process. As in the previously mentioned pilot study, information from the Business Concept Development and Industry Analysis processes is also incorporated at this stage. Information from the stakeholder-objectives matrix provides inputs for roadmap drivers and construction of the various layers. The process of Industry Analysis is then performed to identify product and service gaps. This information is also used in understanding the prioritization of the roadmap elements. Additional details about each of the workshops used in these processes are described below.

In the first workshop, the stakeholder information was translated into drivers of value production for products and services for a technology roadmap. Product and service performance factors necessary to satisfy these drivers will then be identified. Current products and services that meet existing performance requirements will be identified, along with any gaps or deficiencies in being able to meet these requirements.

The second workshop analyzed emerging technologies and compared them to required technology characteristics that are expected to be important for those technologies. Potential solutions were examined to see how they may meet required characteristics. This information will then be used to determine if gaps exist in technology requirements and the present state of development for these technologies. If gaps are identified, then descriptions of R\&D programs necessary to fill these gaps will be created. 
In the third workshop, the current market environment and policy environment with respect to EVSC was examined. If any market or policy elements negatively impacted product or service performance in the first workshop, items on the Solutions layer show possible ways to address such market or policy barriers. Specific mitigation strategies, such as policy changes or market incentives may then be considered to overcome these barriers.

The output of the second and third workshops were then analyzed in order to determine which technology-product gaps are the most significant to address and which market and policy barriers are the important as well. The end result of this is an EVSC roadmap which will help stakeholders understand the most critical elements that are necessary to achieve goals. Potential outcomes can then be analyzed, along with prioritization scores to determine the main factors necessary for key stakeholders to achieve desired outcomes and the factor dependencies required. More detail on the prioritization process will be described in the next section, along with the information needed to construct the technology roadmap.

\subsubsection{TRM Needs and Tools for this Study}

The following section provides a set of tools designed to assist with the roadmap development and prioritization process. A series of data collection instruments, matrixes, 
and prioritization tools are presented to perform various stages of roadmap construction and assessment of the various input factors.

The first tool shown below provides a means of grouping data related to market and business drivers. Expert are also asked to rate the general priority level of each of these drivers based on their views of its overall future impact on the market. Each driver is assigned a unique code and described in Appendix E, along with each other roadmap element. This is shown below.

Figure 7.7: Grouped Drivers - Market and Business

\begin{tabular}{|c|l|c|l|}
\hline$\#$ & \multicolumn{1}{|c|}{ Grouped Market Drivers } & Priority & \multicolumn{1}{|c|}{ Notes and Constituent Drivers } \\
\hline DM1 & Energy Management / Emissions \& Sustainability & $\checkmark \checkmark \checkmark$ & Green consumers, carbon footprint, managing fuel costs. Linked to DM3 \\
\hline DM2 & Improved EV Battery Performance & $\checkmark \checkmark \checkmark V$ & Low battery costs, high capacity / range, fast charge, long life \\
\hline DM3 & Reduced Vehicle Costs & $\checkmark \checkmark \checkmark V$ & Linked to DM2 \\
\hline DM4 & Consumer EV / Charging Incentives & $\checkmark \checkmark \checkmark V$ & Subsidies, benefits, financing \\
\hline
\end{tabular}

\begin{tabular}{|c|c|c|c|}
\hline \# & Grouped Business Drivers & Priority & Notes and Constituent Drivers \\
\hline DB1 & $\begin{array}{l}\text { Transactive Energy Business Standards } \\
\text { Development }\end{array}$ & $\sqrt{ } \downarrow \checkmark$ & Linked to G08, PC2, S2-6, B5 \\
\hline DB2 & Charging Infrastructure Requirements & $\sqrt{ } \mathrm{V}$ & Linked to GP5, Go1, Go6-9, Gp3-4 \\
\hline DB3 & Business Partnerships and Policies & $\sqrt{ } W$ & Linked to DB1, PC2-3, Go2, S5-6 \\
\hline DB4 & Need for grid support services, enhanced stability & $\sqrt{ } \sqrt{ }$ & Linked to DB1, DB3, DR5 \\
\hline DB5 & Business Ownership Structures and Financing & $\sqrt{ } \backslash \sqrt{ } \downarrow$ & Linked to DP7 \\
\hline
\end{tabular}

Source: $[30,145,150]$

The second tool, shown below, is another basic data gathering form used for collecting and grouping information related to regulatory and policy drivers. Expert are also asked to rate the general priority level of each of these drivers based on their views of it overall future impact of specific regulatory structure or policy initiatives regarding the development of the industry and related technology products. This is shown below. 
Figure 7.8: Grouped Drivers - Regulatory and Policy

\begin{tabular}{|c|c|c|c|}
\hline \# & Grouped Policy Drivers & Priority & Notes and Constituent Drivers \\
\hline DP1 & Reducing Vehicle Emissions & 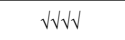 & Linked to DP3-6, DP8 \\
\hline DP2 & Vehicle Fuel Economy / Energy Efficiency & 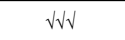 & Linked to DP3-5 \\
\hline $\mathrm{DP} 3$ & State / Regional Energy Planning Goals & $\sqrt{ } \downarrow \sqrt{ }$ & Linked to DP1-2, DP4-6, DP8 \\
\hline DP4 & State / Regional Emissions Policies, Plans & $\checkmark V$ & Linked to DP1-3, DP4-6 \\
\hline DP5 & Electric Vehicle Adoption Goals, plans & $\sqrt{ }$ & Linked to DP1-4, DP6-9, DR1-5 \\
\hline DP6 & RPS and need for Renewable Energy Integration & $\sqrt{ } \sqrt{ }$ & Linked to DP1-5, DP7-9,DR 3, DR5 \\
\hline DP7 & Business EV / Charging Incentives & $\sqrt{ } \backslash \sqrt{ } \downarrow$ & Linked to DR2-5, DB5 \\
\hline DP8 & Renewable Energy Integration Needs & $\sqrt{ } \sqrt{ } \backslash$ & Linked to DP6, DP9 \\
\hline DP9 & Charging Infrastructure Upgrades and Investment Needs & $\sqrt{ } \downarrow \downarrow \downarrow$ & Linked toDP6-8, DP3-5, DR4-5 \\
\hline
\end{tabular}

\begin{tabular}{|c|c|c|c|}
\hline \# & Grouped Regulatory Drivers & Priority & Notes and Constituent Drivers \\
\hline DR1 & Zero Emissions Vehicle Sales Mandate (ZEV / PZEV) & $\downarrow \downarrow \downarrow$ & $\begin{array}{l}\text { ZEV sales requirement in CA and other states. Linked to DP1, DP4, } \\
\text { DP5 }\end{array}$ \\
\hline DR2 & Regulation \& Legislation on EV charging rates and processes & $\sqrt{W W}$ & Linked to DP5,DP7,DR4-5 \\
\hline DR3 & Transactive Energy Standards Development & $\sqrt{ } \sqrt{ } \sqrt{ }$ & Linked to DP6-9, DR4-5 \\
\hline DR4 & Charging Hardware / Software Standardization & $\checkmark \downarrow W \downarrow$ & Linked to DP5, DP8, DP9 \\
\hline DR5 & Plans for Grid Modernization and Stability & 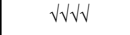 & Linked to DP-56, DP8-9 \\
\hline
\end{tabular}

Source: $[30,145,150]$

The third tool used in this process takes the information gathered from the previous sets of grouped drivers and then attempts to match business and market drivers, as well as regulatory and policy drivers to specific product features and performance goals desired by customers and other potential stakeholders for a particular purpose. For each row, or element, on the matrix a score is determined as follows: 1 to 3 check marks are used $(1$ check $=$ low, 2 checks $=$ medium, 3 checks $=$ high $)$, or one to three " $\mathrm{X}$ 's" can be assigned ( $1 \mathrm{X}=-1$ impact, $2 X^{\prime} \mathrm{s}=-2$ impact, $3 X^{\prime} s=-3$ impact). For each column, a driver priority score of 1 to 10 is used, with 1 being a low high priority and 10 being a very high priority. Overall scores are then determined by multiplying each set of row and column scores and then adding up these scores for each category of drivers, such as the 
business and market, or regulatory and policy drivers shown below. The scores are then normalized out of 10 . These scores are shown on the right hand side of the matrix under the heading "Prioritization." Additional score columns can be added if needed.

Figure 7.9: Market, Business, Regulatory \& Policy vs. Plans and Outputs

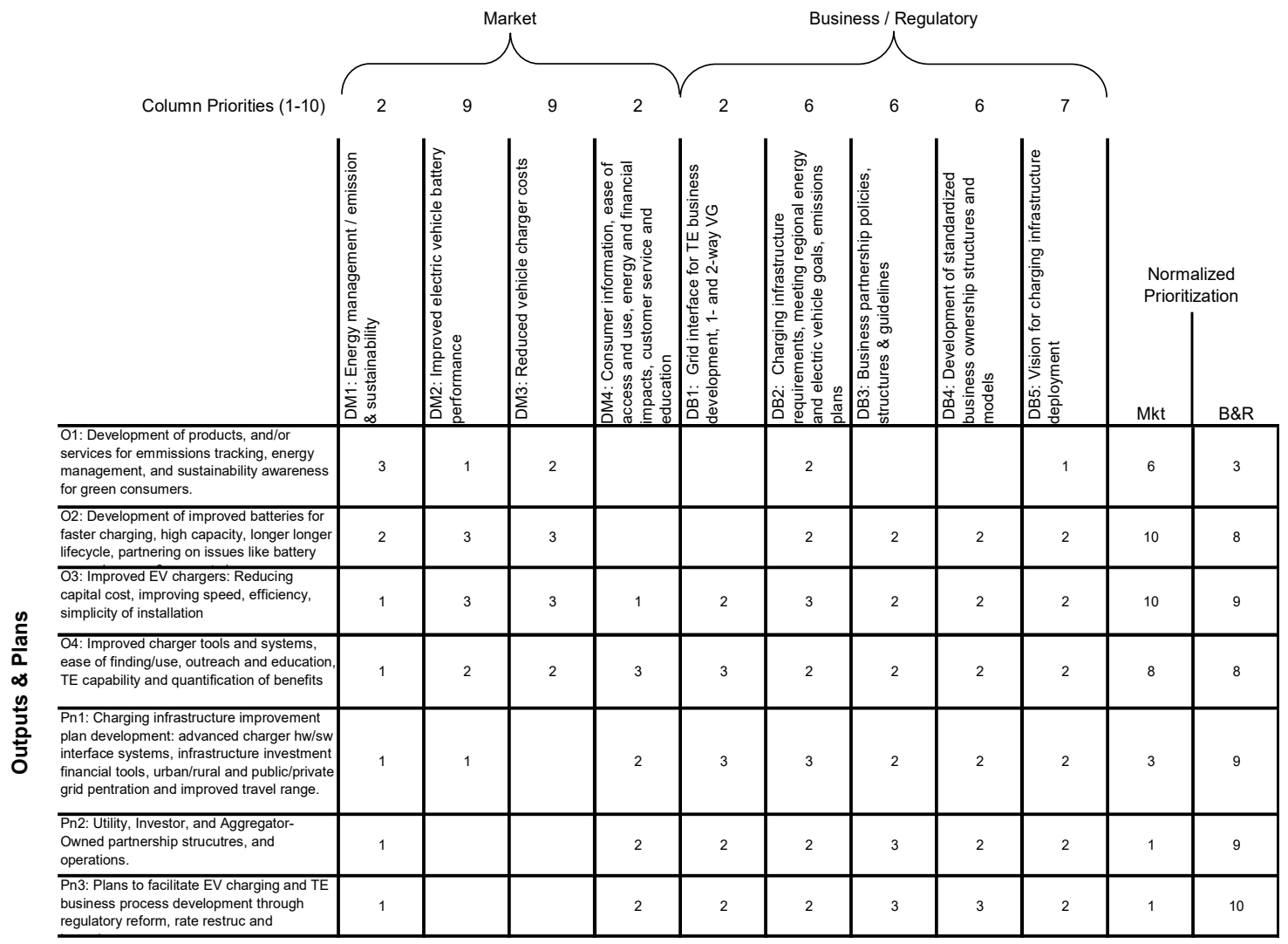

Source: $[30,145,150]$

A similar process to the method above is followed in the next section. Technology product features and stakeholder goals are compared against potential barriers that may exist. Mitigators that may help reduce such barriers are also examined. Finally, a third process like the previous two above is performed. Technology barriers 
and mitigators are compared against $R \& D$ barriers and mitigators. Scores are determined using the prioritization process previously described.

Figure 7.10: Plans \& Outputs vs. Technologies \& Barriers

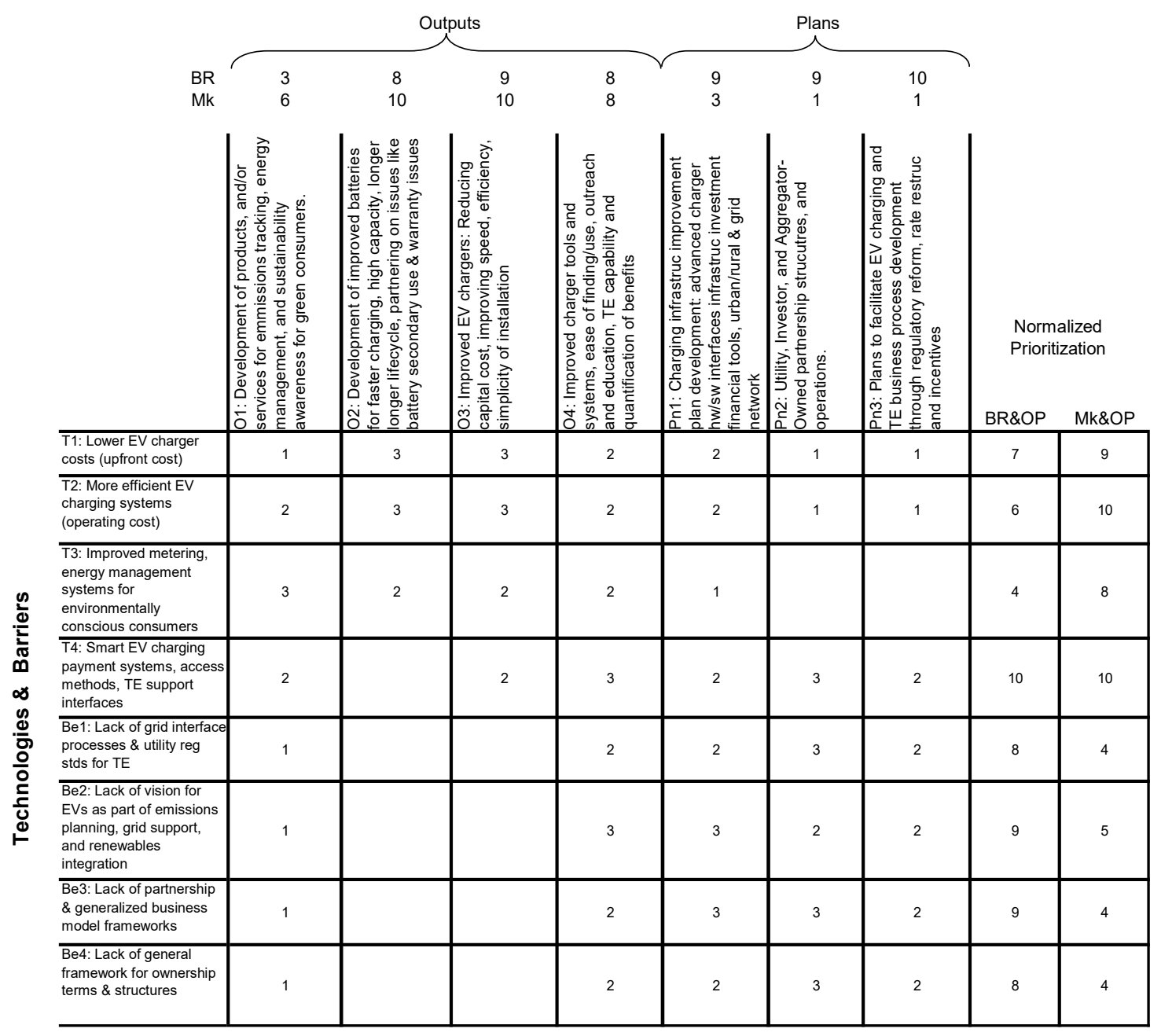

Source: $[30,145,150]$

Once these processes are complete, the data is gathered, analyzed and used as an input for the next stage of the research, which involves construction of the visual 
roadmap model with appropriate time scales and prioritization data. This model is provided in the next section.

Figure 7.11: Technologies and Barriers vs. R\&D and Barrier Mitigation

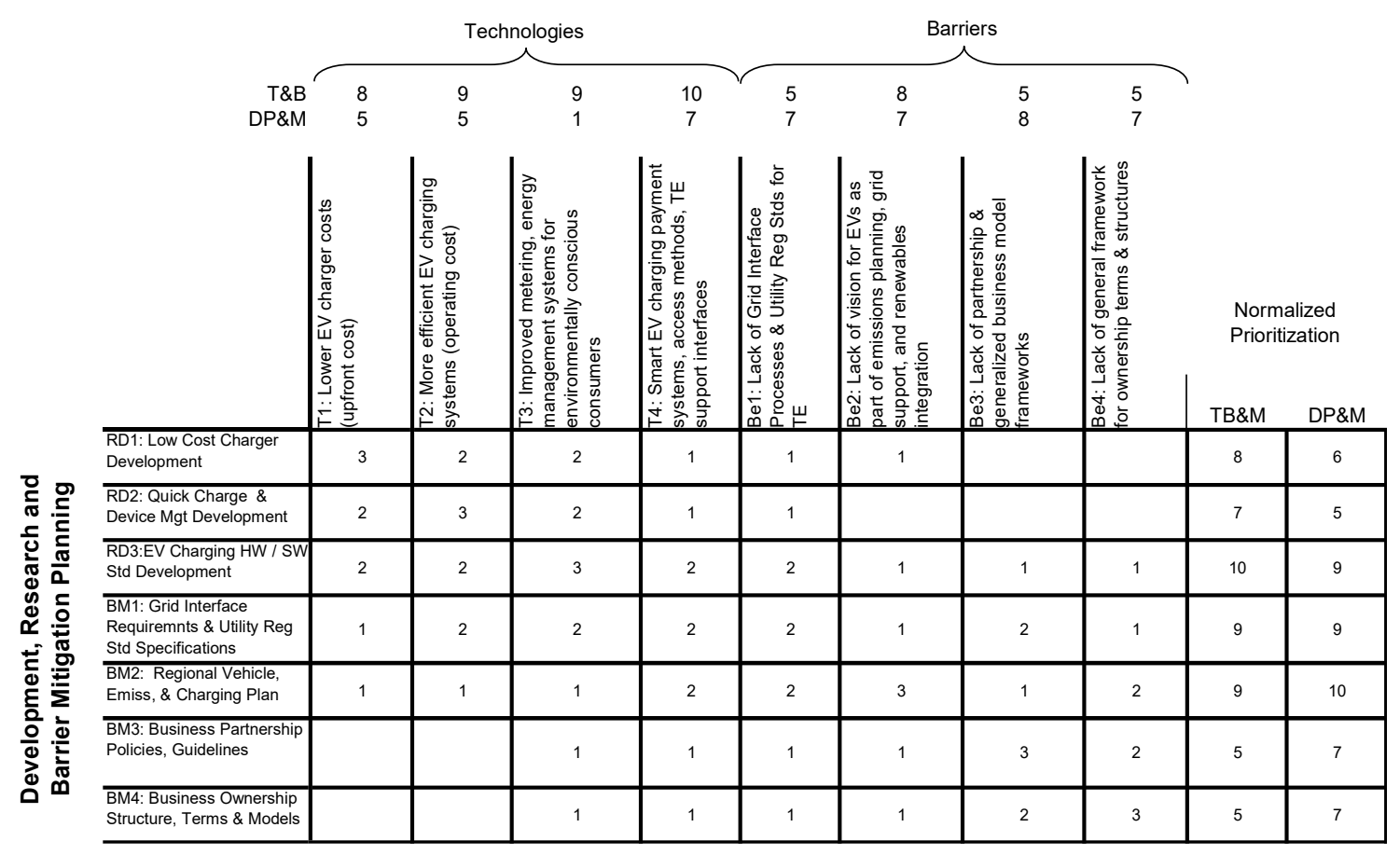

Source: $[30,145,150]$

The scores obtained from matrices used in this section provide a number of interesting results. First there appears to be agreement that development of EV charging hardware and software standards (RD3) was extremely important from technology, business, and regulatory perspectives. Improved DC quick chargers (O3) were also important from a technology perspective, and development of clear, consistent standards would help enable these efforts, removing a key barrier to more wide-spread deployment. Creation of support systems and warranty services for advanced batteries $(\mathrm{O} 2)$ was very 
important from technology, business, and market perspectives. There was consensus that regional planning visions on charger deployment should be developed that could help integrate with existing plans to reach environmental goals and emissions targets. There was a divergence of views on the development of partnership structures (Pn2) as well as incentives and financing for electric vehicle charging (Pn3). These were seen as important from the Business and Regulatory perspective, but less so from the Market perspective. From a Technology perspective, payments systems / transactive energy interfaces (T4) were seen as extremely important and also considered quite significant from the point of view of potential Barriers. Other important issues from this perspective included barriers caused by the lack of a clear vision for the role of electric vehicles in regional renewable energy integration plans, and the lack of standardized business model frameworks. This were seen as important from a business and regulatory point of view, but less so from a market-oriented point of view. A number of other observations can be made by interpreting different aspects of the data, but the points mentioned above seemed to be the key points that fit the clearest patterns. Using the key points presented here, the next section provides a synthesis of the consensus, divergence, and conclusions on next steps, based on this data.

There was consensus that improved DC quick chargers (O3) and development of support systems and warranty services for advanced batteries (O2) was very important from market and business / regulatory perspectives. There was also agreement from EV charging hardware and software standards development (RD3) would be extremely important and it could certainly help enable these efforts. Additionally, there was fairly 
strong consensus that regional planning visions on charger deployment (BM2) should be developed that could help integrate with existing plans to reach environmental goals and emissions targets. Development of partnership structures (Pn2) as well as incentives and financing for electric vehicle charging $(\mathrm{Pn} 3)$ were important from business / regulatory perspective, but less so from a market perspective. Therefore, the recommendations for next steps based on this data would be to focus on hardware/software standards (RD3), support systems and battery warranties $(\mathrm{O} 2)$, quick charger development $(\mathrm{O} 3)$, and deployment plans (BM2). Once these standards are developed and deployment plans are implemented, partnerships (Pn2) and incentives (Pn3) would then make sense to explore. The next section now looks a series of technology roadmaps that incorporate all of these factors over an approximately 10 year planning horizon and look at specific alternatives, such as various business model options, which could be used to address specific challenges at different points in that timeline.

\subsubsection{Technology Roadmap Model}

After finishing the initial data gathering and prioritization processes, a series of roadmap models were constructed incorporating the data. These roadmaps followed requirements discussed in previous sections on TRM Model Design in Chapter 4. Several types of roadmaps were created to examine different aspects of this research. First, an overall roadmap was created that showed the combined effect of business, government, consumer, and market factors over the entire 10-year time span of the roadmap. This roadmap is consists of three parts, representing different set of layers on 
the roadmap. Part 1 is composed of three layers: (1) Drivers; (2) Gaps and Goals; and (3) Problem Characteristics and Barriers. Part 2 contains two layers: (1) a continuation of Problem Characteristics and Barriers; and (2) Solutions, which involve Technology, Business Model, Market, Regulatory, and Barrier Mitigation. Part 3 has 1 layer, which is a continuation of the Solutions layer started in Part 2. Parts 1, 2, and 3 or the overall roadmap are shown in the figures below.

First, however, the following definitions provide a general description of each of the three layers used in the technology roadmapping process. Additional details related to the each of the component elements which appear on these roadmap layers are provided in Appendix F. Layer 1 consists of drivers. Drivers are underlying factors in the environment, such as business and regulatory forces and trends which motive some type or action or response. One example is a Zero Emission Vehicle (ZEV) mandate, which requires a certain percentage of vehicles sold after a specified deadline to be vehicles which produce no tailpipe emissions. This driver is a regulatory factor which motivates an action on the part of industry participants, such as manufacturers of electric vehicles and providers of electric vehicle charging stations to make those products available by the given deadline. Layer 2 consists of Gaps and Goals. Gaps represent the lack of something that a stakeholder feels is needed. For instance, if only $1 \%$ of vehicle currently sold are ZEVs and the eventual requirement is $10 \%$, there is a gap of $9 \%$. Similarly, a goal represents some type of outcome that is desired by particular stakeholders, but has not yet been reached. For example, one factor which may be related to the future deployment of more electric vehicle charging stations is rate and process 
restructuring concerning the prices and methods under which regulated utilities are currently allowed to sell electricity. So, the need for achieving that type of regulatory restructuring would be an important goal. This is similar to the concept of a Gap, but while Gaps often involve things that can be easily measured, such a $1 \%$ versus $10 \%$ vehicle sales, goals are generally more abstract, such a the need for a certain type of outcome. Layer 3 consists of Problem Characteristics and Barriers. Problem Characteristics are the factors involved a particular challenge, such factors that contribute to a certain Gap that currently exists. For example, there may be a need for significantly greater deployment of electric vehicle charging stations and infrastructure. However, until all the requirements are defined for these types of equipment and infrastructure, planning is difficult to perform. So, defining these types of requirements is an essential Problem Characteristic associated with this need. Similarly, Barriers consist of factors which are currently inhibiting the achievement of a specific outcome, such as a Gap or Goal. For example, there may be a need for reducing charging station cost, but the currently low level of adoption of charging stations means that economies of scale have not yet been achieve which can drive down costs. If this barrier is lifted and a solution can be found to deploy larger numbers of charging stations, then this can help meet the goal being blocked by the barrier, which is reduction of costs. On the roadmap, the Gap or Goal being blocked by a barrier is represented an arrow with a dashed line. Once the barrier is lifted, this Gap or Goal can be addressed. But, in order to lift that barrier, a solution is needed. Layer 4 addresses the issue of Solutions. Solutions address the challenges that underlie specific Problem Characteristics and Barriers. Solutions can consist of a variety of elements, including Business Development Processes, as well as 
Market, Regulatory, and Barrier Mitigation factors. For example, the reason economies of scale have not been achieved to drive down charging station cost may be related to factors such as lack of a public investment vision or plan of action for consistent deployment. So, Solutions that provide an investment vision for public charging stations, or Business Development Processes, such as the development of business-industry partnerships, can provide answers needed to address Problem Characteristics and lift Barriers. Each of these elements is shown in parts 1, 2, and 3 of the overall roadmap below.

Figure 7.12: Integrated TRM Model - Electric Vehicle Charging - Part 1
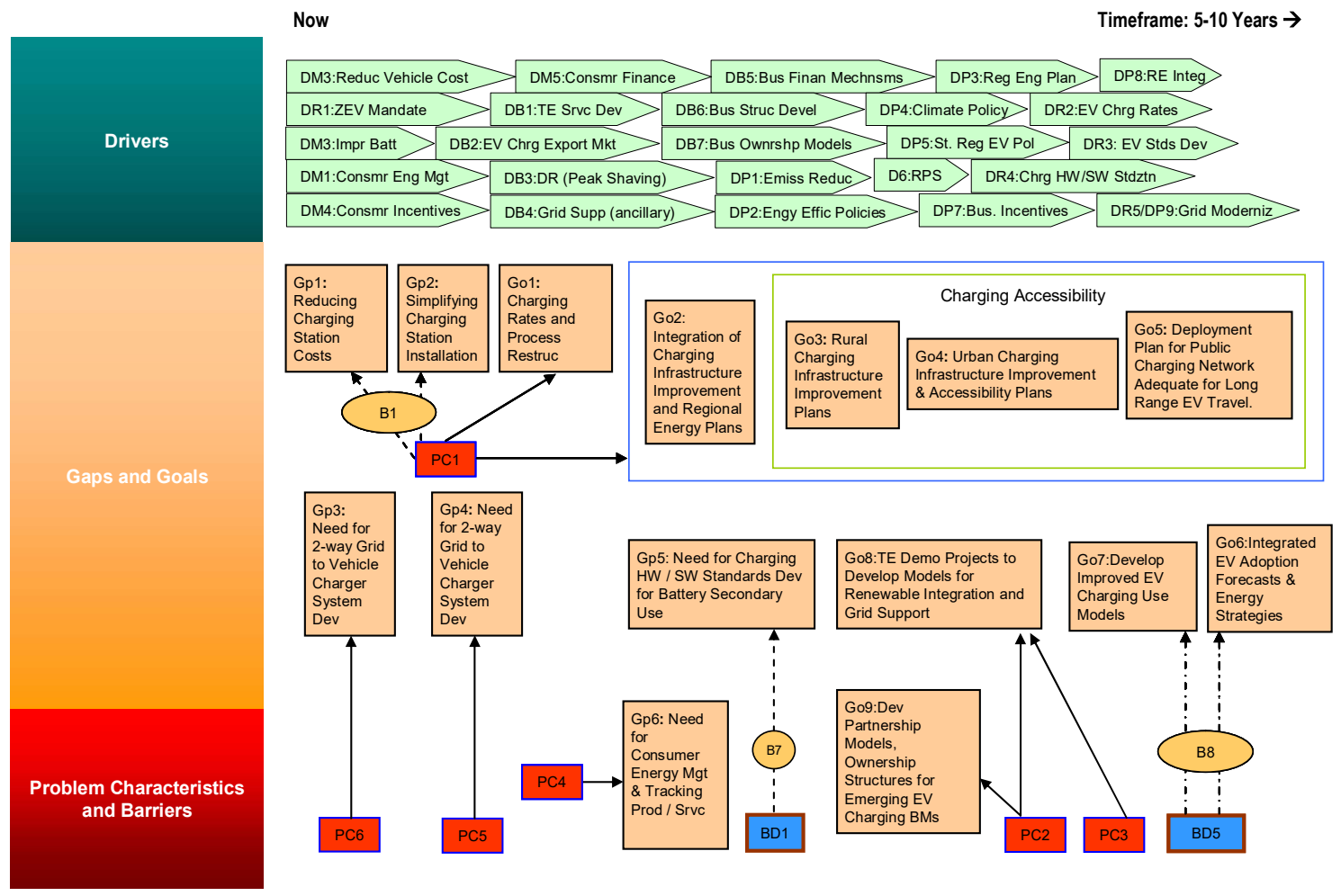
As previously mentioned, Part 1 of the overall roadmap represents the top 3 layers, which consists of Drivers, Gaps and Goals, as well as Problem Characteristics and Barriers. Part 2 of the roadmap then shows the next 2 layers, starting with a continuation of Problem Characteristics and Barriers, and then the initial portion of the Solutions layer. Part 2 is shown below.

Figure 7.13: Integrated TRM Model - Electric Vehicle Charging - Part 2

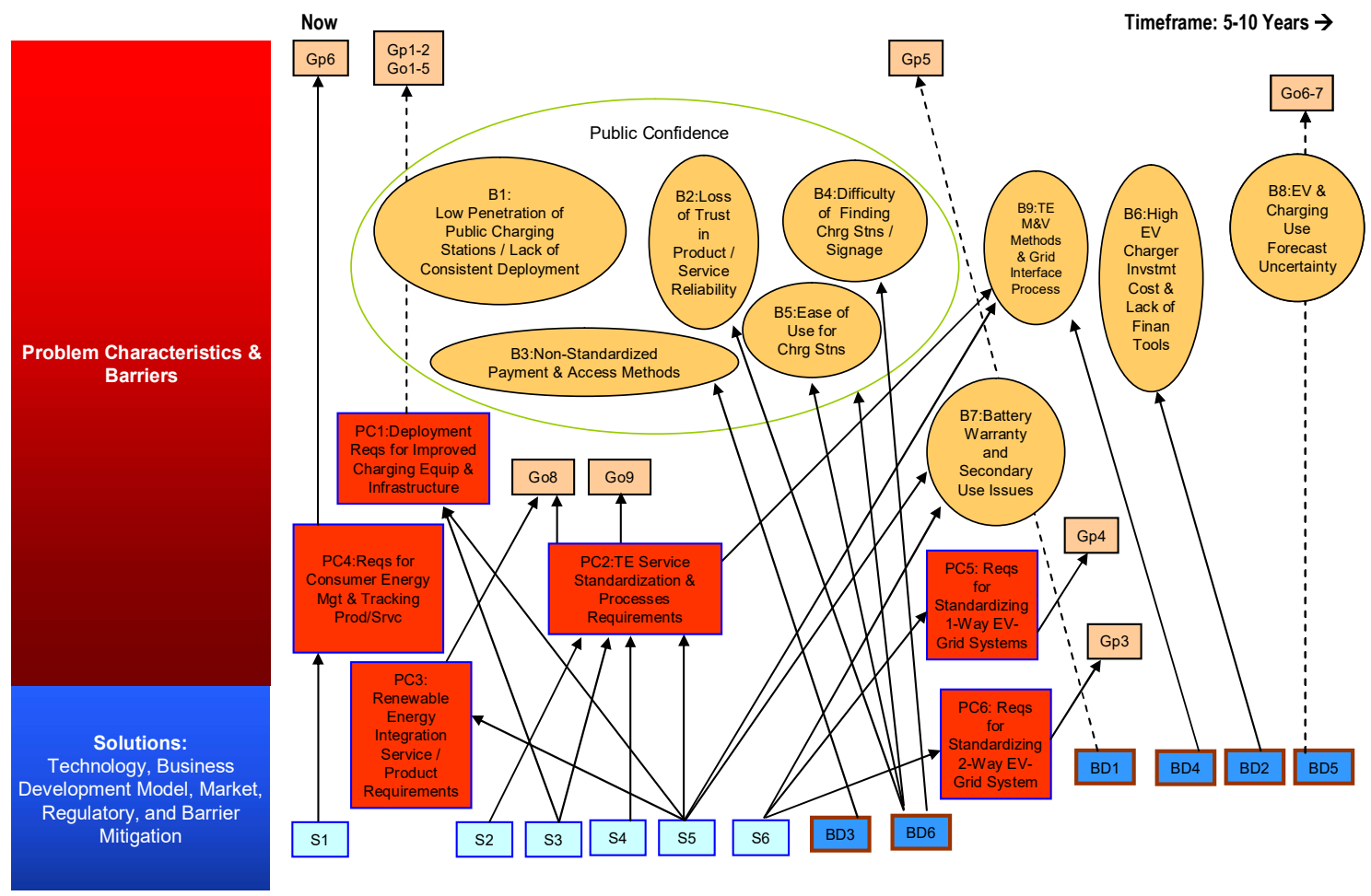

Part 2 of the general roadmap consists of the third and fourth layers, which starts with a continuation of the Problem Characteristics and Barriers layer and then begins the initial portion of the Solutions layer. Part 3 is then shown below. 
Figure 7.14: Integrated TRM Model - Electric Vehicle Charging - Part 3

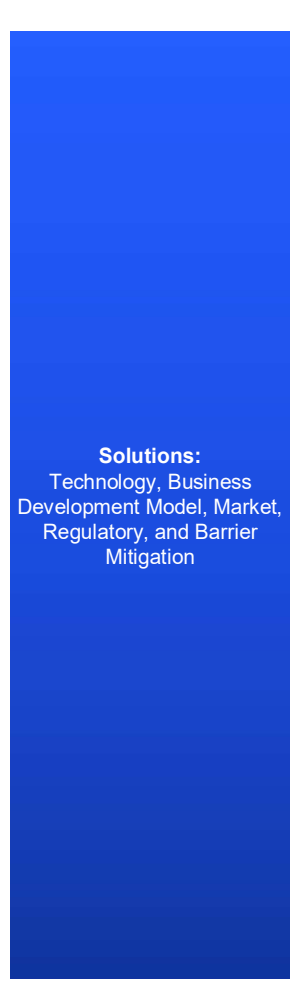

Now

Timeframe: 5-10 Years $\rightarrow$

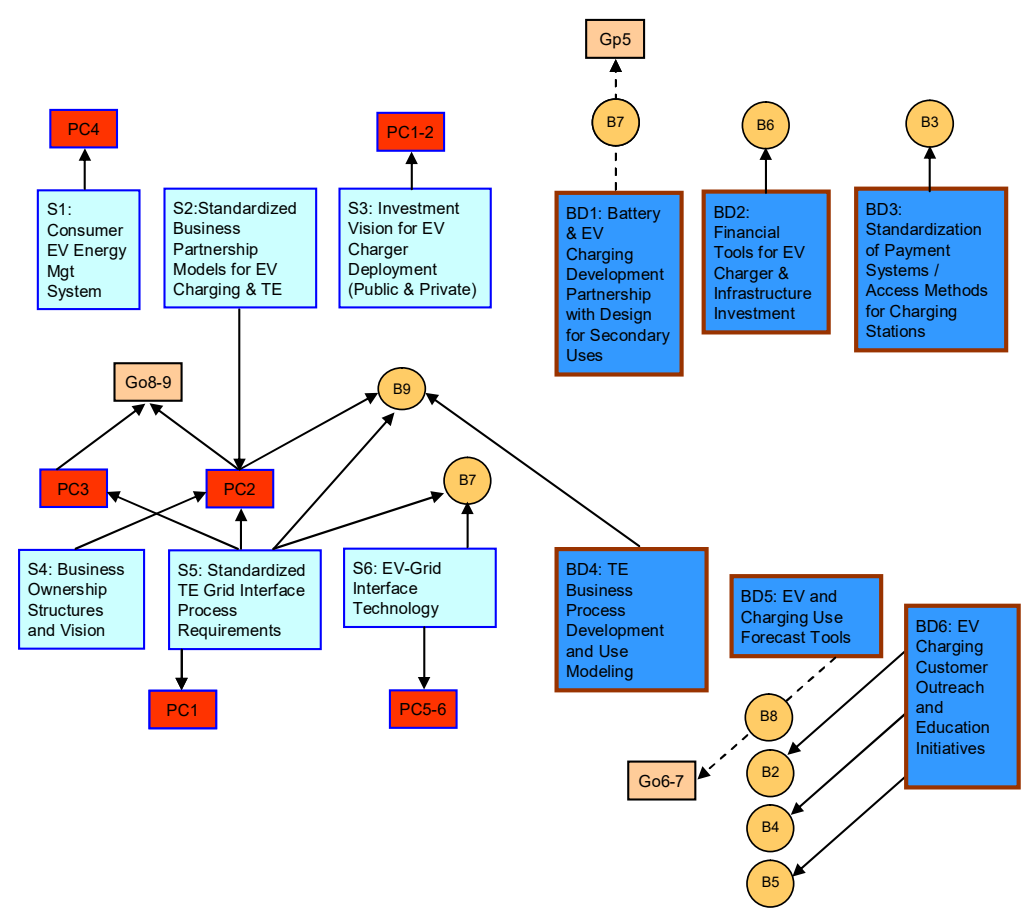

Part 3 of the general roadmap consists of the fourth layer, which began in Part 2. After showing each of these three parts, a number of important facts about the overall roadmap are discussed below, as well as some ways to improve the organization of the roadmap. To make it easier to focus on specific aspects of the roadmap over shorter time horizons, the roadmap is further broken into version A and version B for each of the of the 3 parts. Version A reorganizes the roadmap with a Business and Regulatory Organizational Focus, while version B reorganizes the roadmap with a Consumer and Market focus. Additional details about the organization of the roadmap are provided in the next section. 
Several key pieces of information can be seen from the above figures. Key stakeholders include consumers, businesses, government organizations (GO), and nongovernment organization (NGO), and regulatory agencies. Decisions can then be made regarding whether to focus first on specific user segments among these stakeholders or on a combination of segments. Further decisions can be made regarding different options for ownership structure and primary profit mechanisms. Ownership structures include the possibility of consumers, utilities, or third-parties, such as energy service aggregators owning and/or operating EV charging equipment and services. Key profit mechanisms include the following: (1) Direct fees for vehicle charging and/or parking fees; (2) membership fees and fees for other bundled and premium services, such as internet access or auxiliary vehicle power hook-up fees; advertiser fees or fees for consumers to opt-out of advertisements; ancillary service fees, which provide essential services to utilities, such as voltage and frequency regulation; or energy efficiency optimization contracts and energy aggregation contracts, which allow a network operator to manage and optimize energy use over a grid or micro-grid. Other profit mechanism or combinations of mechanisms are also possible, but these were the main mechanisms identified through conversations with experts who participated in data gathering workshops for this study. Options for financing and distribution methods related to each business model were also considered that were appropriate for each of these cases. Methods for financing EV charging equipment purchase include rebates and tax credits for consumers, on-bill financing through utility companies, and third-party owned equipment with a service lease, or charging as a service models. Additional details about each of these points discussed above are provided in section 7.3.3, under the discussion 
of business models and in Appendix F, where each of the business model specifications is described.

The overall roadmap shown in Parts 1, 2, and 3 summarizes a great deal of information about the technology, business, and regulatory landscape facing the electric vehicle charging industry. However, because it summarizes so many factors in one place, this can make the roadmap look cluttered and difficult to read. Therefore, to make it easier to focus on specific aspects of the roadmap, the follow sections breaks each of the 3 parts into 2 sections. Section A shows a Business and Regulatory focused version of the roadmap. Section B shows Consumer and Market focused version of the roadmap. Each of these are show below as parts 1 through 3, sections A and B. 
Figure 7.15: Integrated TRM Model - Electric Vehicle Charging - Part 1a

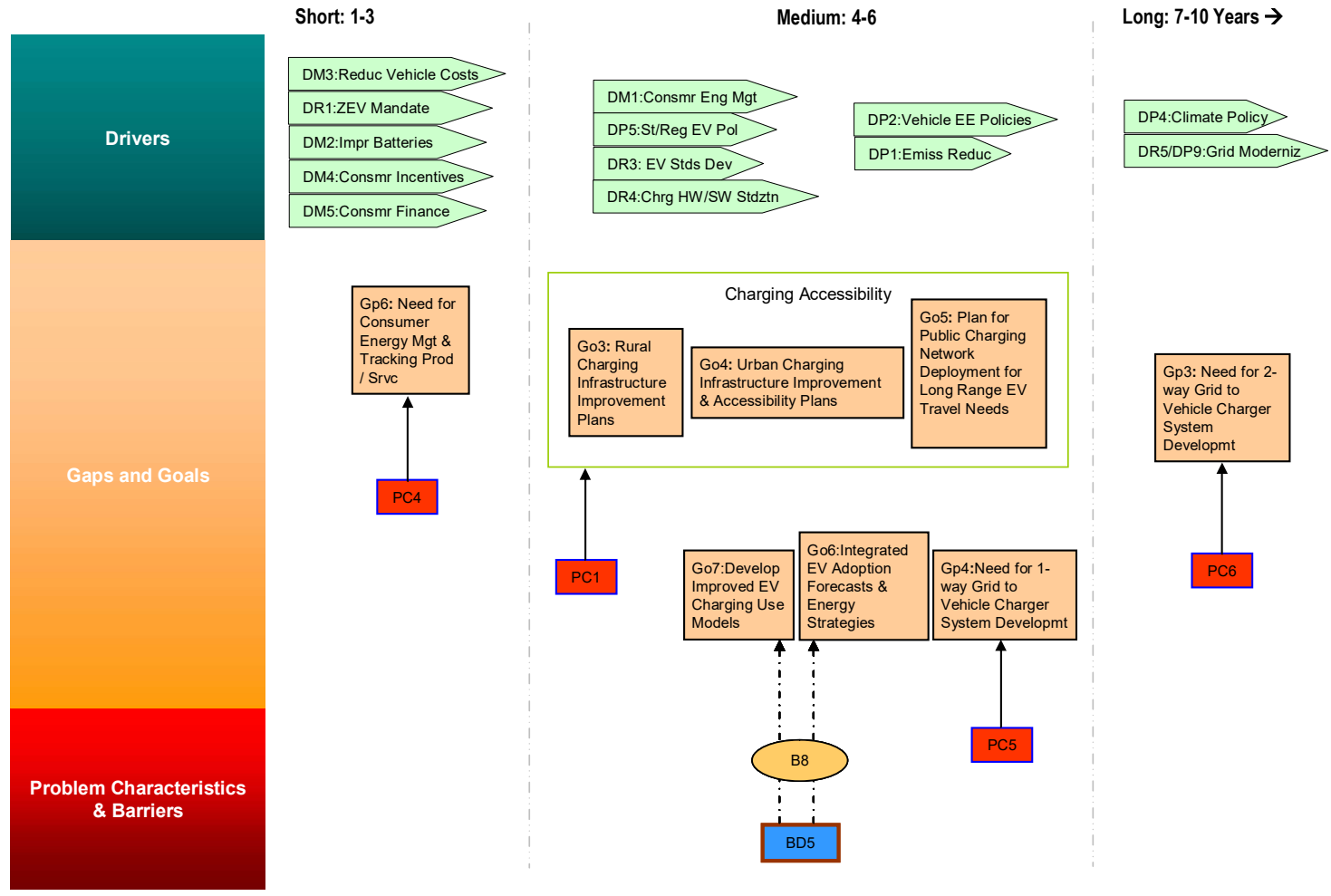

Part 1a of the general roadmap consists of the third and fourth layers, which starts with a continuation of the Problem Characteristics and Barriers layer and then begins the initial portion of the Solutions layer. Part $1 \mathrm{~b}$ is then shown below. 
Figure 7.17: Integrated TRM Model - Electric Vehicle Charging - Part 1b

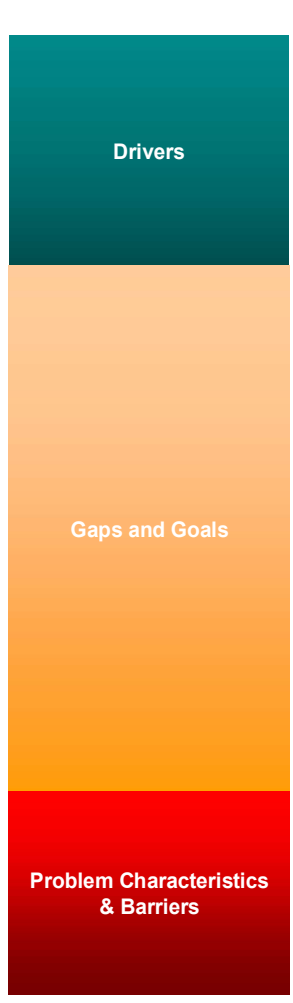

Short: 1-3

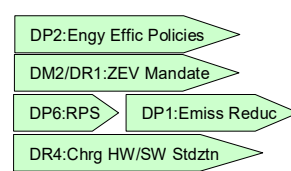

DR4:Chrg HW/SW Stdztn
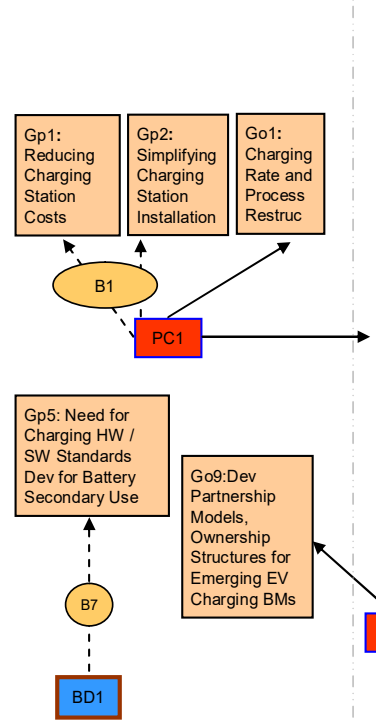

Medium: 4-6

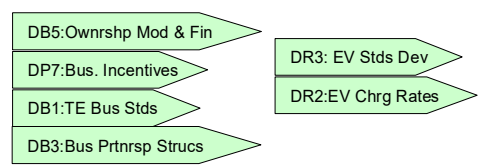

Long: 7-10 Years $\rightarrow$
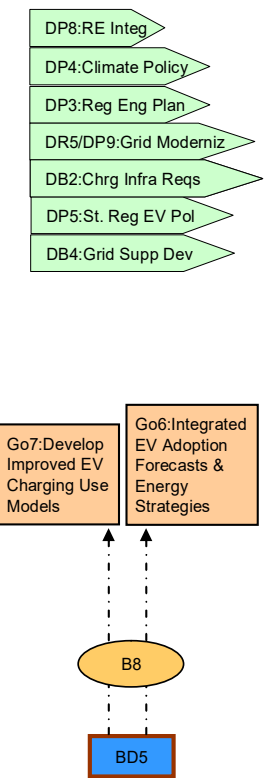

Part $1 \mathrm{~b}$ of the general roadmap consists of the third and fourth layers, which starts with a continuation of the Problem Characteristics and Barriers layer and then begins the initial portion of the Solutions layer. Part $2 \mathrm{a}$ is then shown below. 
Figure 7.18: Integrated TRM Model - Electric Vehicle Charging - Part 2a

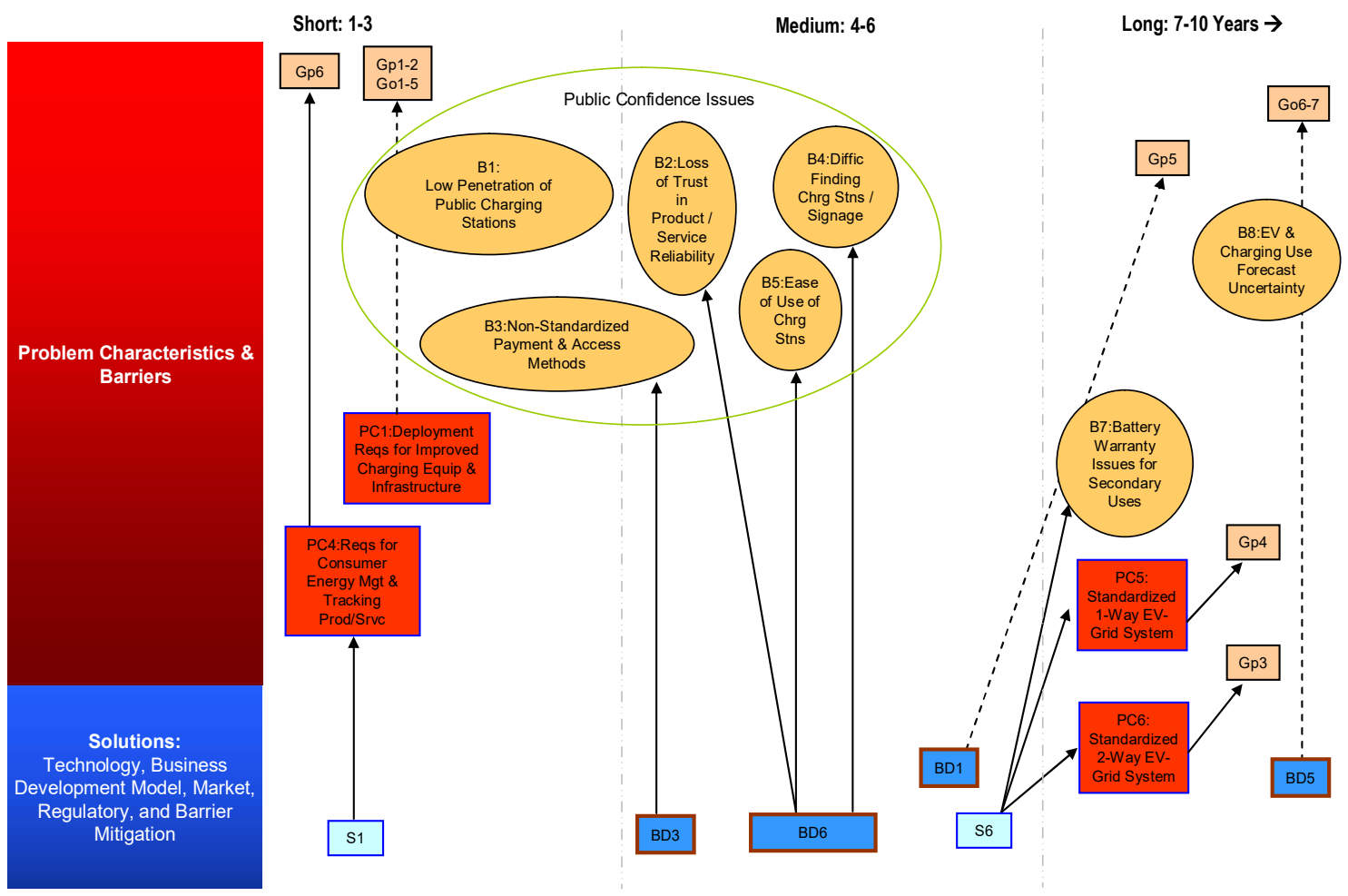

Part $2 \mathrm{a}$ of the general roadmap consists of the third and fourth layers, which starts with a continuation of the Problem Characteristics and Barriers layer and then begins the initial portion of the Solutions layer. Part $2 \mathrm{~b}$ is then shown below. 
Figure 7.19: Integrated TRM Model - Electric Vehicle Charging - Part 2b
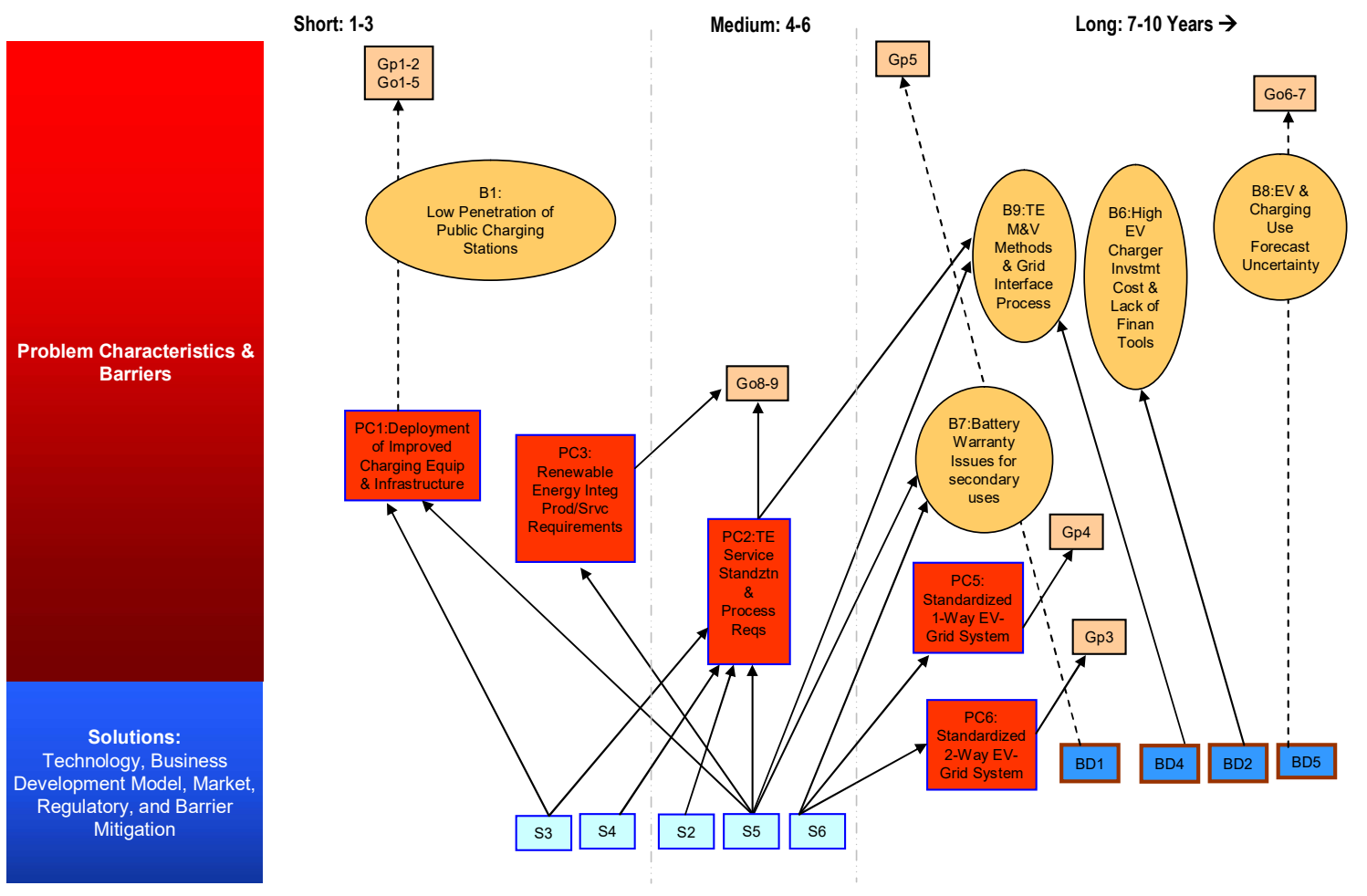

Part $2 \mathrm{~b}$ of the general roadmap consists of the third and fourth layers, which starts with a continuation of the Problem Characteristics and Barriers layer and then begins the initial portion of the Solutions layer. Part 3a is then shown below. 
Figure 7.20: Integrated TRM Model - Electric Vehicle Charging - Part 3a
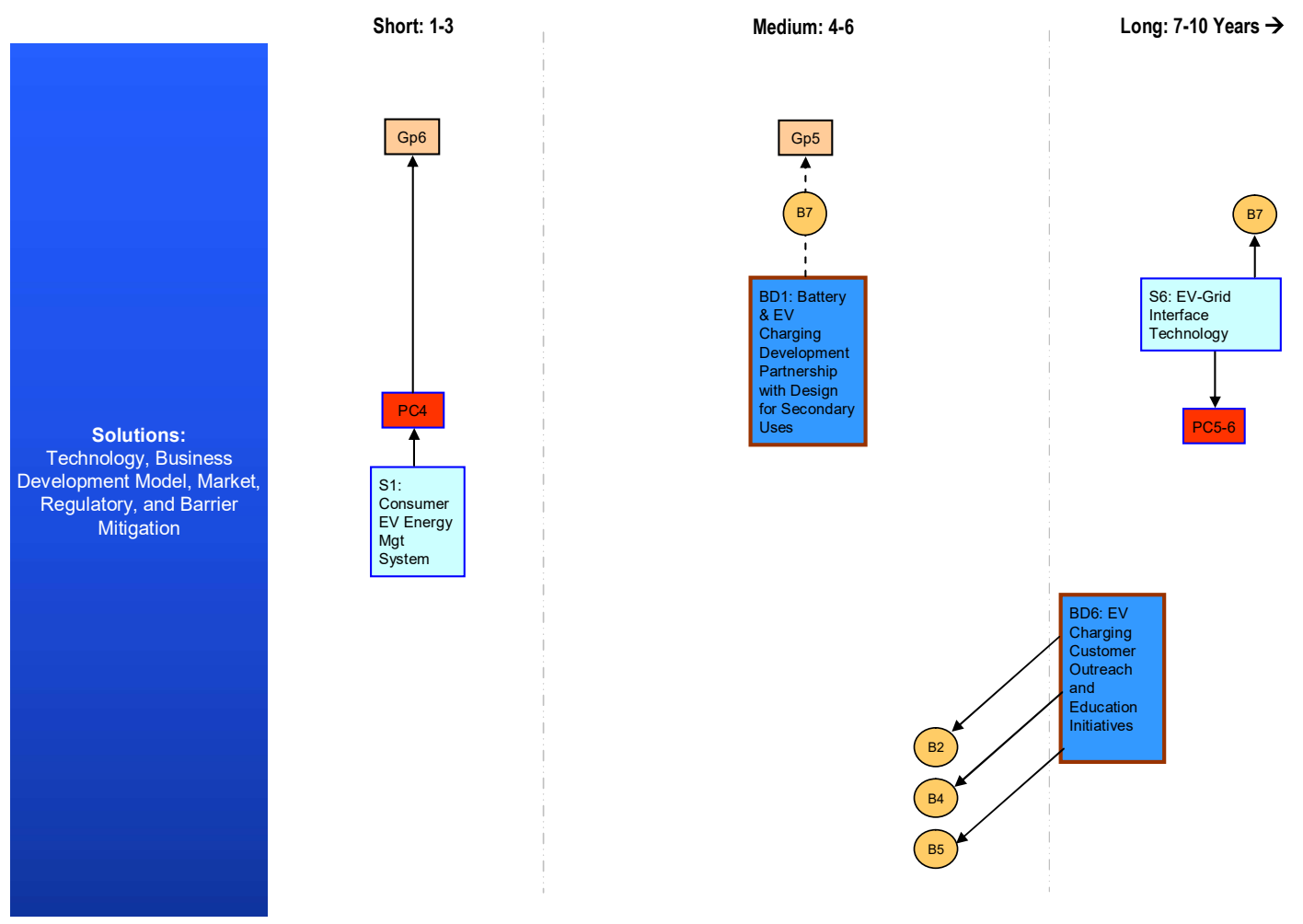

Part $3 \mathrm{a}$ of the general roadmap consists of the third and fourth layers, which starts with a continuation of the Problem Characteristics and Barriers layer and then begins the initial portion of the Solutions layer. Part $3 \mathrm{~b}$ is then shown below. 
Figure 7.21: Integrated TRM Model - Electric Vehicle Charging - Part 3b

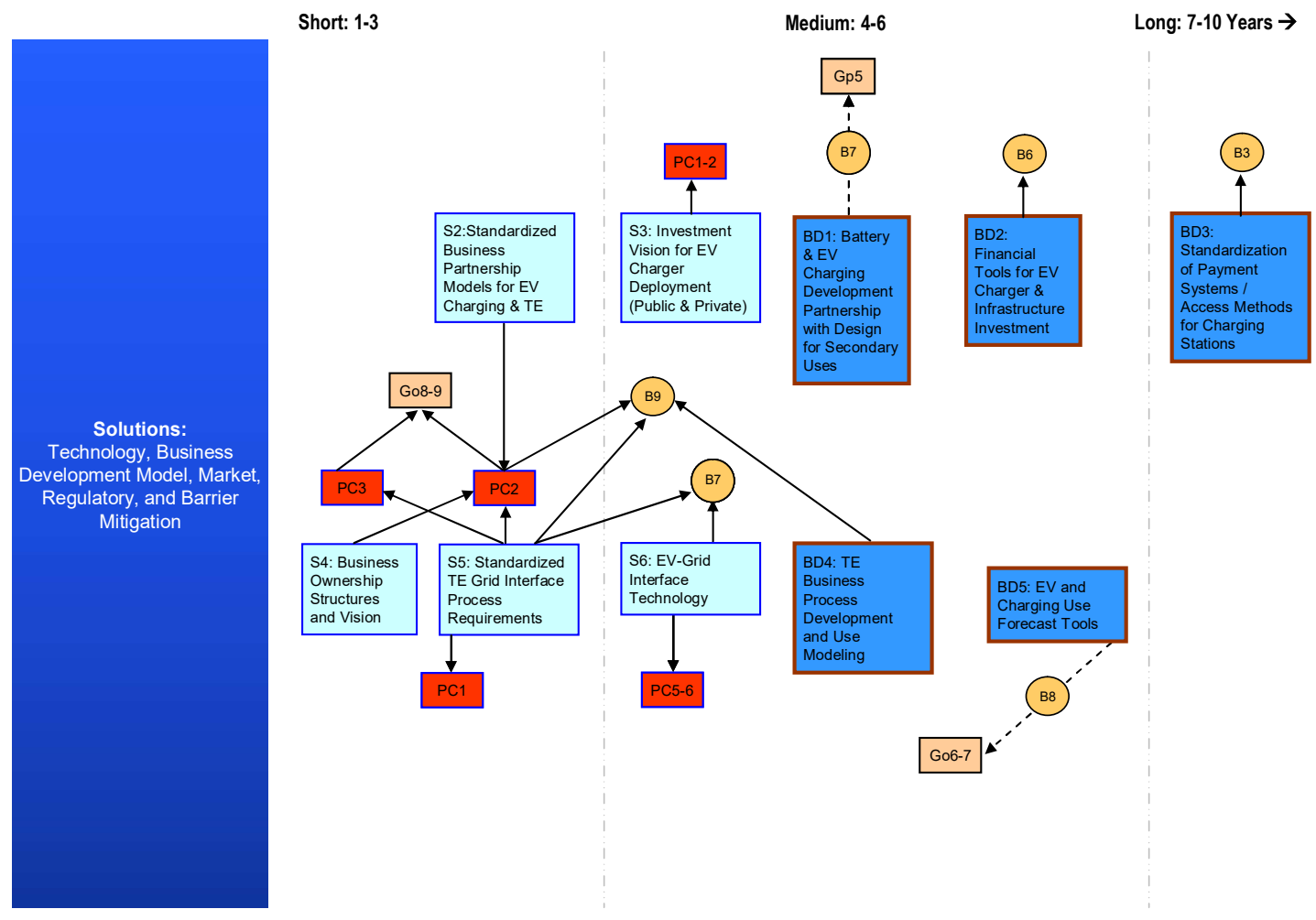

Part $3 \mathrm{~b}$ of the general roadmap consists of the third and fourth layers, which starts with a continuation of the Problem Characteristics and Barriers layer and then begins the initial portion of the Solutions layer.

After constructing the many different roadmaps described in this chapter, analyzing their various parts, and organizing them into different topical areas, a key question that arises is how to best use these data and apply them to the industry environment. An important consideration for this is an analysis of what business models may be used to implement various aspects of the roadmaps that have been developed. To summarize the main business model challenges, expert input was gathered to create a 
taxonomy of business models appropriate for the issues discussed in the roadmap construction process. The models were divided into three main categories, based on the main business ownership structures: Investor-Owned structures (S1); Utility-Owned structures (S2); and Aggregator-Owned structures (S3). A series of business models variants were identified under each of these structures. A total of 31 business models were identified and assigned unique codes. These models are described in the next section, along with an analysis of their significance, and some final conclusions about the process.

\subsubsection{Analysis of Alternatives}

To better understand how the data from this study can be used, several types of analysis were performed. As described in the previous section, a taxonomy of business

models was constructed to summarize the main challenges related to implementation of various aspects of the roadmaps that were produced during the research. The business model taxonomy is show below. 
Figure 7.22: Business Model Specifications

\begin{tabular}{|c|c|c|}
\hline Investor-Owned (S1) & Utility-Owned (S2) & $\begin{array}{c}\text { Third Party / Aggregator- } \\
\text { Owned (S3) }\end{array}$ \\
\hline $\begin{array}{l}\text { Pay per kWh / Level } \\
\text { 1. BMS1A-1: Level } 1 \text { Charging } \\
\text { 2. BMS1A-2: Level } 2 \text { Charging } \\
\text { 3. BMS1A-3: Level } 3 \text { Charging } \\
\text { Flat rate per hour } \\
\text { 4. BMS1B-1: Flat hourly rate } \\
\text { 5. BMS1B-2: Flat monthly rate } \\
\text { Pay for Parking } \\
\text { 6. BMS1C-1: Pay parking only, not } \\
\text { charging } \\
\text { Membership } \\
\text { 7. BMS1D-1: Flat Rate Charging } \\
\text { 8. BMS1D-2: Unlimited Charging } \\
\text { 9. BMS1D-3: Membership Bundle } \\
\text { Premium Services } \\
\text { 10. BMS1E-1: Advertising } \\
\text { 11. BMS1E-2: Internet Access } \\
\text { 12. BMS1E-3 Electrical hookup fee } \\
\text { (trucks) } \\
\text { Transactive } \\
\text { 13. BMS1F-1: Buy/Sell Ancillaries }\end{array}$ & $\begin{array}{l}\text { Pay per kWh (Standardized Rates) } \\
\text { 14. BMS2A-1: Standard Elec Rates } \\
\text { 15. BMS2A-2: TOU Rates (opt-in) } \\
\text { 16. BMS2A-3: TOU Rates (opt-out) } \\
\text { 17. BMS2A-4: Inclined Block Rates } \\
\text { 18. BMS2A-5: EV-specific Rates } \\
\text { 19. BMS2A-6: Demand Charges } \\
\text { Premium Services } \\
\text { 20. BMS2B-1: Advertising } \\
\text { 21. BMS2B-2: Internet Access } \\
\text { 22. BMS2B-3 Electrical hookup fee } \\
\text { (trucks) } \\
\text { Transactive } \\
\text { 23. BMS1F-1: Buy/Sell Ancillaries }\end{array}$ & $\begin{array}{l}\text { Agreements with EVSC owners } \\
\text { 24. BMS3A-1: Level } 1 \text { Charging } \\
\text { 25. BMS3A-2: Level } 2 \text { Charging } \\
\text { 26. BMS3A-3: Level } 3 \text { Charging } \\
\text { Agreements with Utilities } \\
\text { 27. BMS3B-1: Utility Contract } \\
\text { Energy Optimization Contracts } \\
\text { 28. BMS3C-1: Energy Contract } \\
\text { Transactive } \\
\text { 29. BMS3D-1: V2G } \\
\text { 30. BMS3D-2: V2B } \\
\text { 31. BMS3D-3: V2H }\end{array}$ \\
\hline
\end{tabular}

Three main categories of business models were identified based on the main business ownership structures: Structure 1 - Investor-Owned models; Structure 2 Utility-Owned models; and Structure 3 - Aggregator-Owned models (S3). A total of 31 business models variants were identified for each of these structures. These models are described in the next section, along with an analysis of their significance, and some final conclusions about the process. For more details, a description of each of these models is provided in Appendix G.

However, to see a comparison of how each model relates to the elements of the roadmap, a series of comparison charts were created. For more details regarding 
roadmap elements, a description of each is provided in Appendix F. The comparison matrix below further shows which roadmap elements are most important during short-, medium-, and long-term times horizons. The matrix below compares Investor-Owned business models. Each chart summaries of a vast amount of information related to each element. Several examples are given to describe the general way in which these charts can be used for quickly visualizing comparisons among the elements related to each business model.

Figure 7.23: Business Model vs. TRM Comparison Table - Investor-Owned

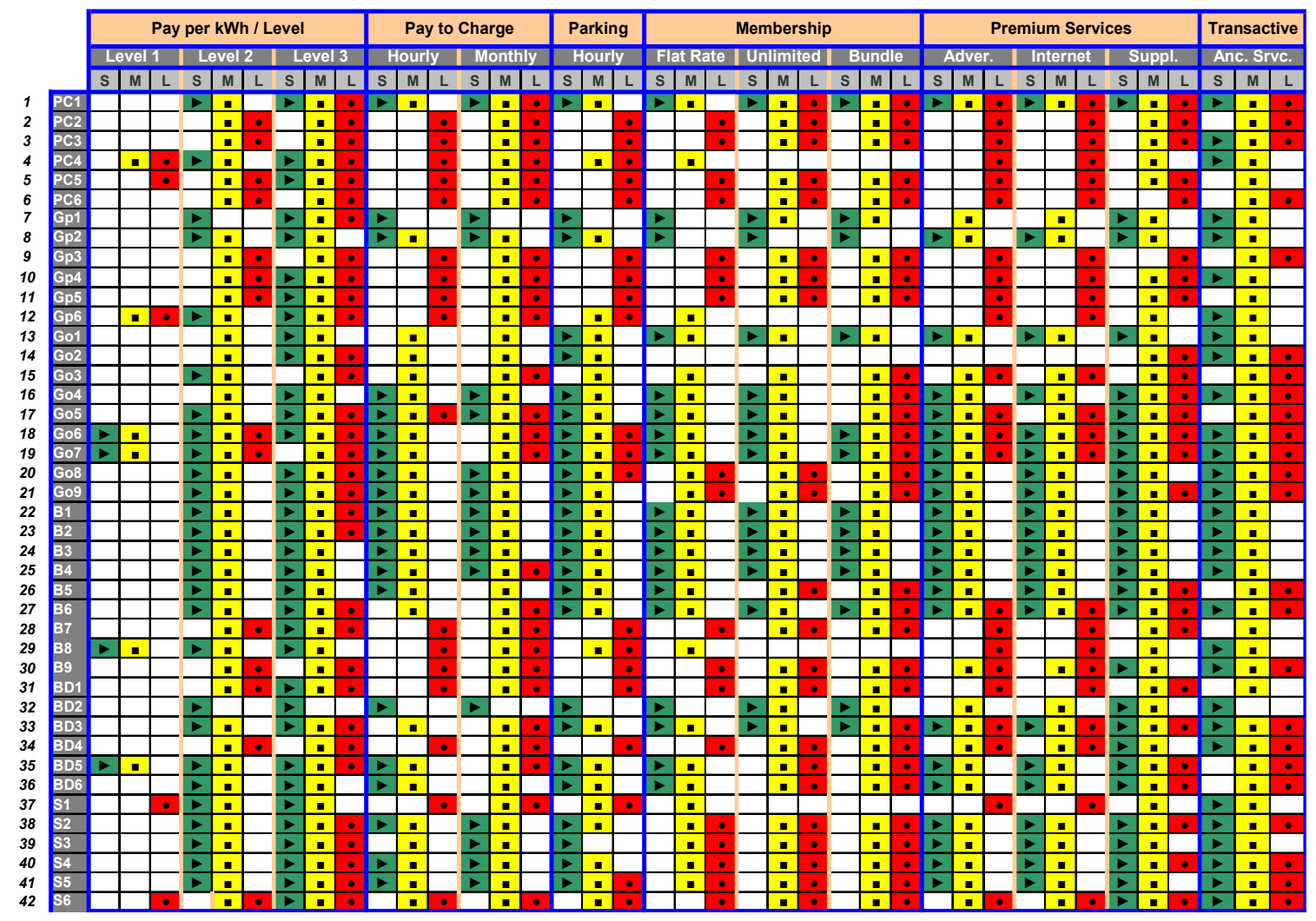

To illustrate how this type of matrix can be used to compare various models under each of the key ownership structures, an example is provided below. As previously 
mentioned, each of the color-coded data points on the chart allow us to see how each model relates to components on the TRM. Red, yellow, and green correspond to short-, medium-, and long-term planning horizons. Using the chart, we can also easily compare this to other models and see how they relate to key points on the roadmap in short (1-3 year), medium (4-6 year), and long-term (7-10 year) planning horizons.

So, how can we interpret this information with regard to specific business models? To illustrate this, we will walk through an example regarding the first business model, which involves the use for investor-owned Level 1 charging. First, with regard to Problem Characteristic 4 (PC4)--Requirements for Consumer Energy Management and Tracking - one issue for consumers will be to understand and control how and when charging occurs. They may also want better abilities to keep track of green energy use, understand energy costs, energy footprint, and control overall energy use. These issues are addressed by Gap 6 (Gp6) and Solution 1 (S1)—Need for Energy Tracking and Management Systems. Since Level 1 charging uses smaller amounts of energy over longer amounts of time than other charging methods, the need for sophisticated energy management and tracking tools is likely to not be immediately significant as consumers first start using charging systems, but in the medium- to long-term, this could become increasingly important. For PC5-Requirements of EV-to-Grid systems - this is also unlikely to be an immediately significant issue for Level 1 charging, due again to the relatively small amounts of energy used over long amounts of time and the difficulty of coordinating each routine consumer level charging use across existing utility systems. In the long-term, as smart grid technologies and EVs become more prevalent, it is possible 
these factors might become important, particular with regard to 1-way systems. For Go6 and Go7--EV Adoption Forecasts and Charging Use Models-as well as the related factors of S6 and B8-Development of Standard EV Charging Technologies and Difficulties of Forecasting Adoption and Charging Use--it is hard to know initial EV charger use for Level 1 systems, but it is expected to play a significant role in the early use of EVs, as home charging will be more widely available than public charging alternatives. Additional Business Development studies and Solutions such as BD5 and S6-EV \& Charging Forecast Tools and Grid Interface Standards Development—will make it easier to understand how and in what ways charging technologies can be used in the future. So, by examining each of the factors mentioned on this comparison table, we can get a better idea of which factors are most important from a short-, medium-, and long-term perspective regarding this business model.

So, how do these factors mentioned above relate to the business environment for investor owned Level 1 charging business models? A basic explanation is that Level 1 charging is a low level of vehicle charging that can be done at home or at a public charging station with relatively minor investment. Basic EV charging can be performed with standard $120 \mathrm{~V}$ outlets. Generally, such charging will occur at residential locations, and often occurring overnight, slowly charge for about 6-10 hours. However, in the Investor-Owned (S1) ownership structure, this could be used in a commercial setting, such as long-term parking. Different rates and conditions may apply versus the residential case, which also typically assumes standardized electricity rates, such as those of a Utility-Owned (S2) ownership structure. Level 2 and Level 3 are faster methods of 
charging, but they use greater amount of power to do so and require much greater infrastructure investment. Therefore, they are more complex and expensive both for the vendor and consumer. With regard to the roadmap, Level 1 does not require very many gaps to be filled in the short-term, like significant additional charging infrastructure or standards to be developed. Level 2 and Level 3 require a deployment of a bit more advanced infrastructure and there are some competing standards in use as well. So, the more difficult, time-intensive, and capital-intensive systems are likely to take longer and cost more. Additional details related to each of these business models are described in Appendix G.

Another way to analyze the differences between the models is to look at them graphically. The following chart compares the most prevalent roadmap elements for this ownership structure. 
Figure 7.24: Business Model vs. TRM Comparison Chart - Investor-Owned

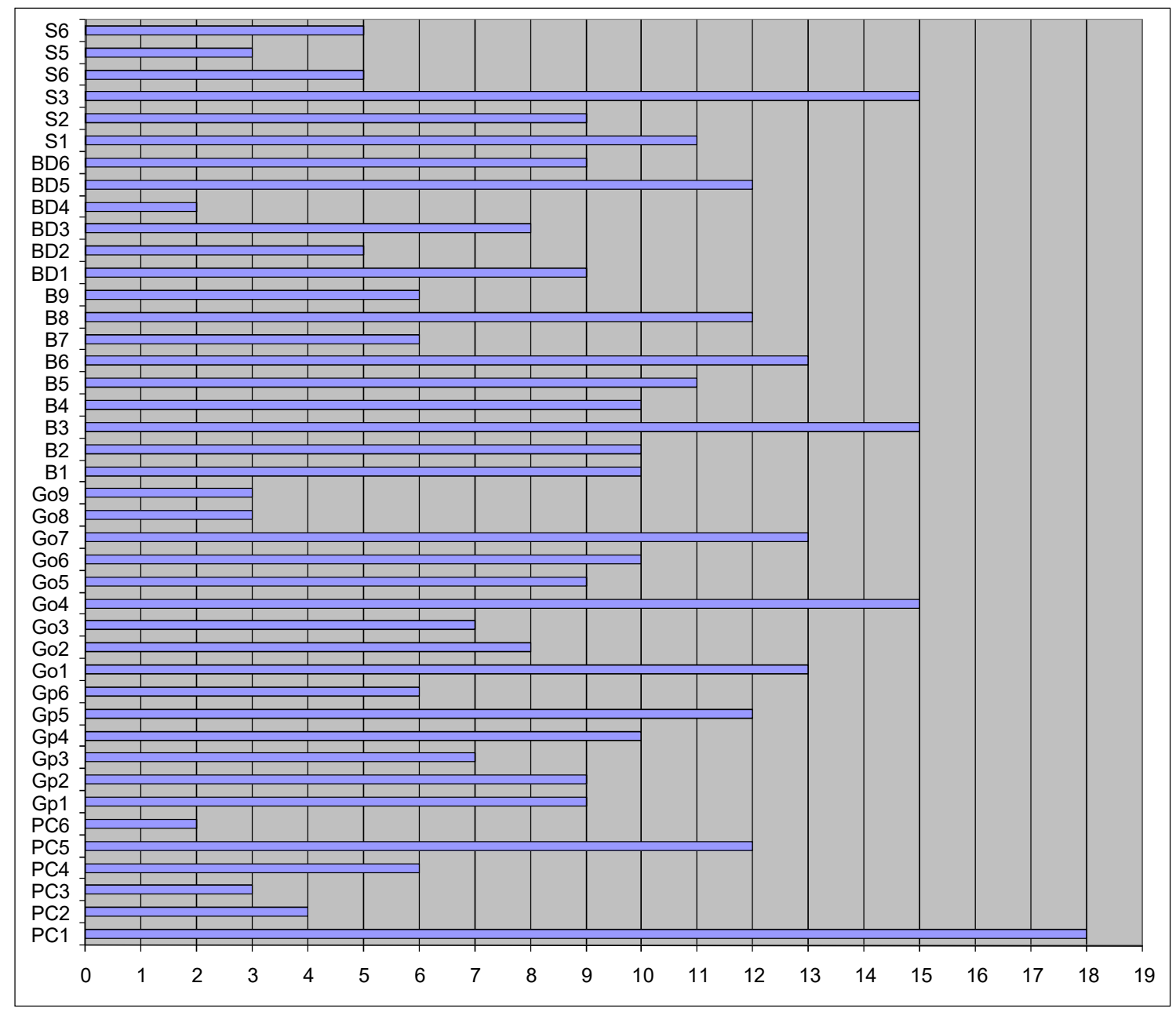

The next matrix below compares how each of business models for Utility-Owned business structures relates to the elements of the roadmap. It further shows which roadmap elements are most important during short, medium, and long-term time horizons. 
Figure 7.25: Business Model vs. TRM Comparison Table - Utility-Owned

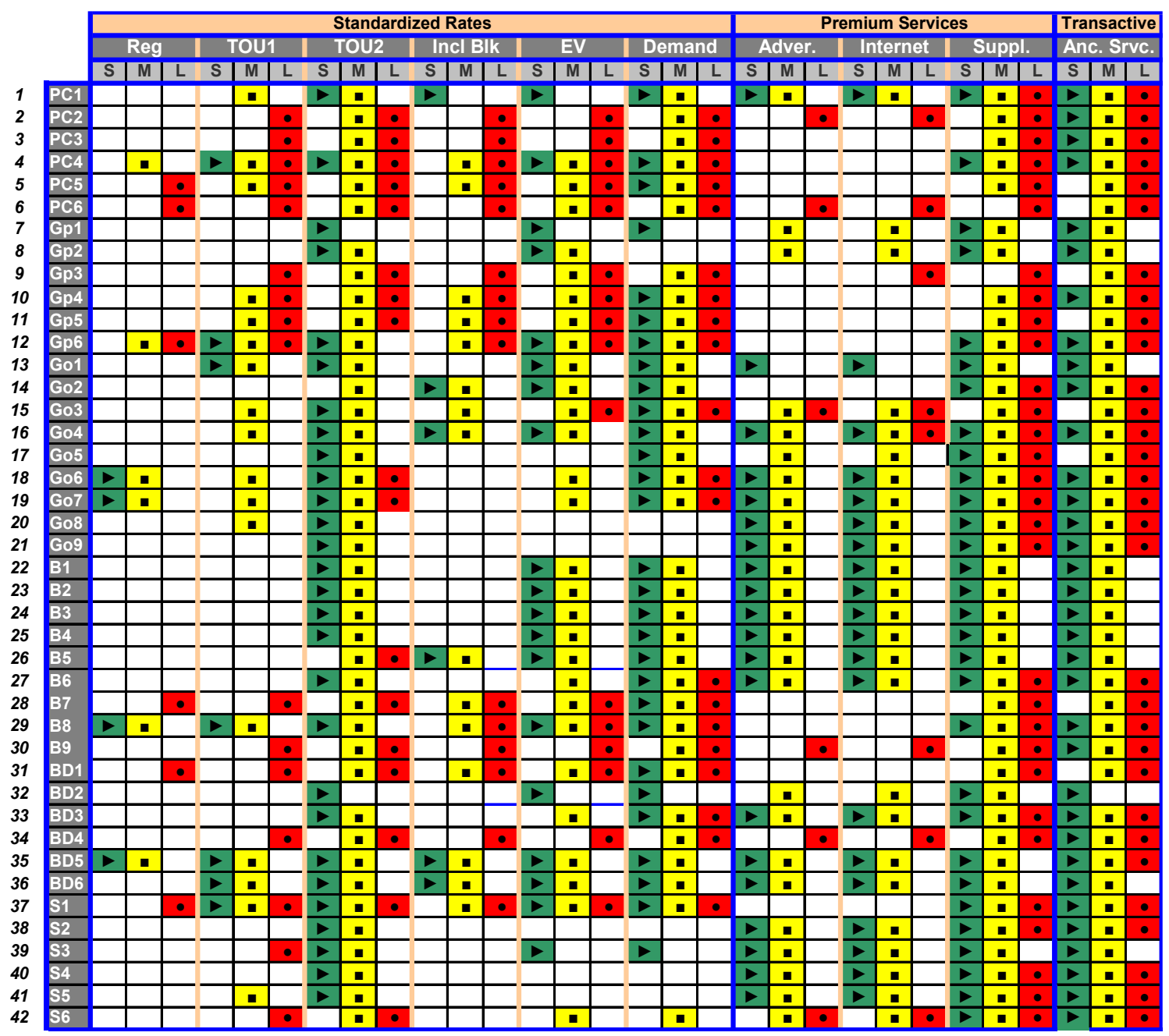

Another way to examine the differences between the models is to look at them graphically. The following chart compares the most prevalent roadmap elements for this ownership structure. 
Figure 7.26: Business Model vs. TRM Comparison Chart - Utility-Owned

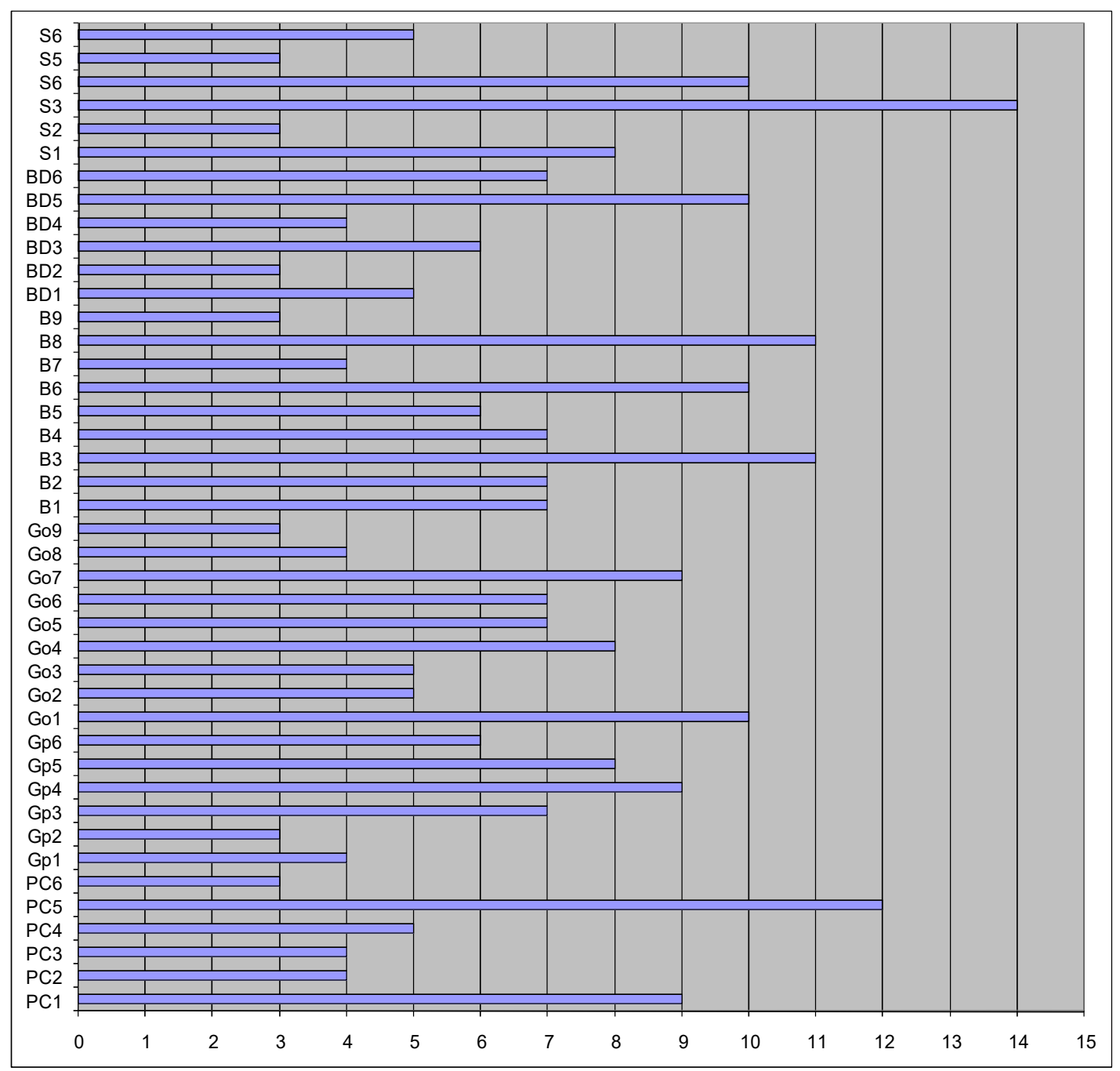

To see a comparison of how each model relates to the elements of the roadmap, a series of comparison charts were created. These show which roadmap elements are most important during short, medium, and long-term time horizons. The matrix below compares Aggregator-Owned business models. 
Figure 7.27: Business Model vs. TRM Comparison Table - Aggregator Owned

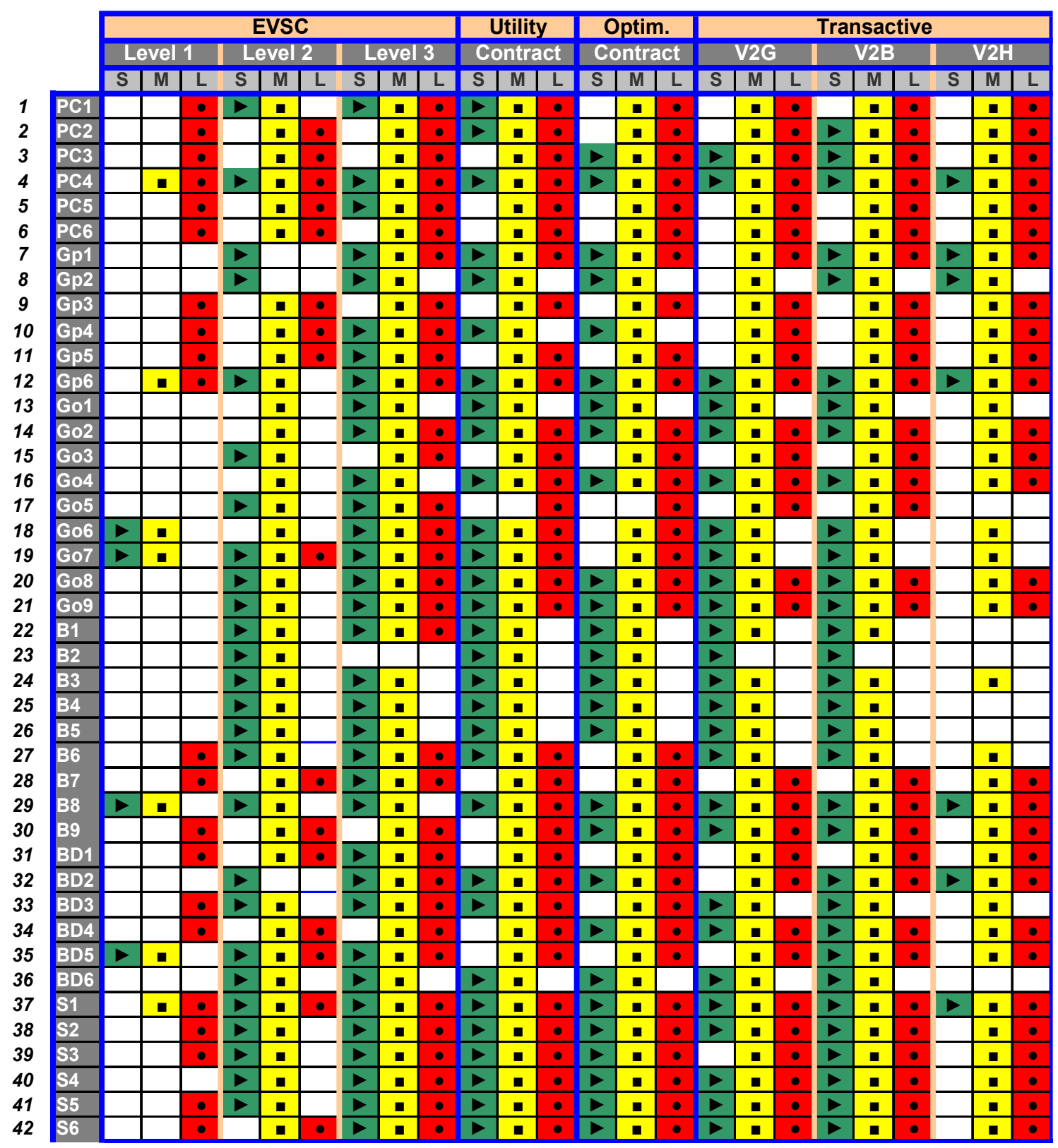

Another way to examine the differences between the models is to look at them graphically. The following chart compares the most prevalent roadmap elements for this ownership structure. 
Figure 7.28: Business Model vs. TRM Comparison Chart - Aggregator-Owned

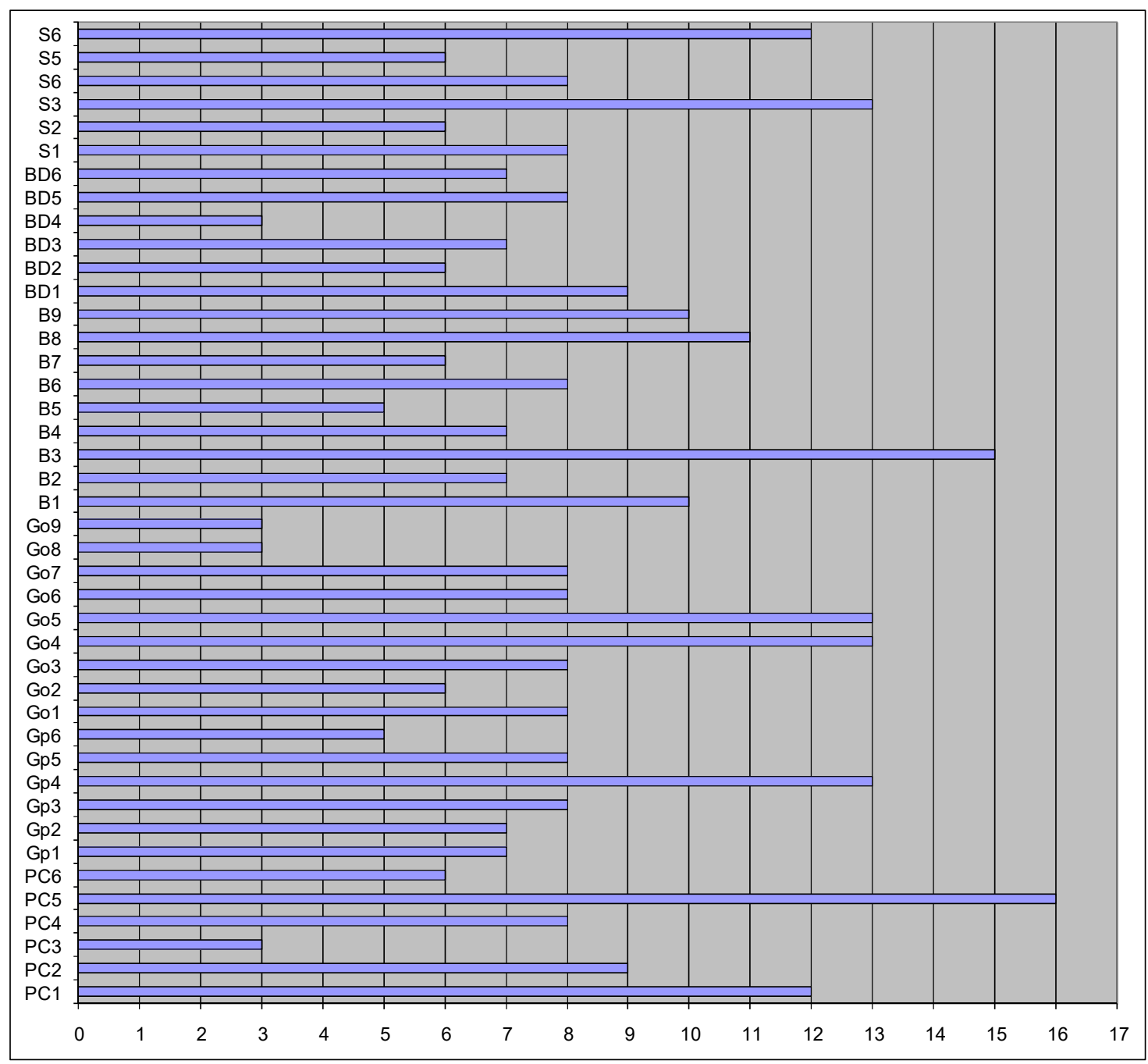

This shows the most prevalent factors for Aggregator-Owned structures. The next chart then shows this information for all three ownership structures. 
Figure 7.29: Business Model vs. TRM Comparison Chart - Overall

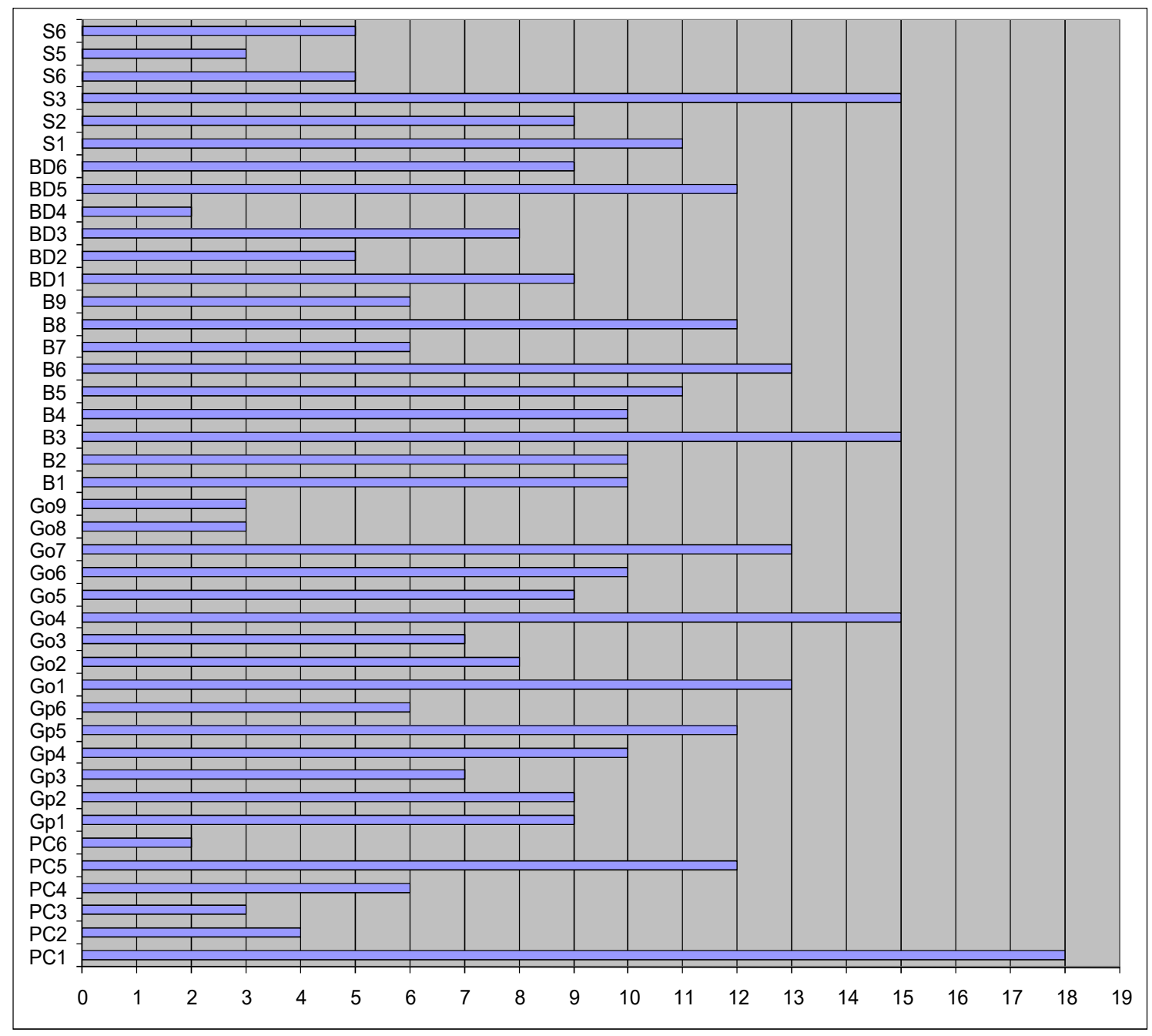

Finally, after showing all of the individual charts listing the relative prevalence of roadmap elements, a stacked bar chart was created to show how all the models compare side by side. This chart is provided below. 
Figure 7.30: Business Model vs. TRM Comparison Chart - S1, S2, S3 -InvestorOwned, Utility-Owned, and Aggregator-Owned

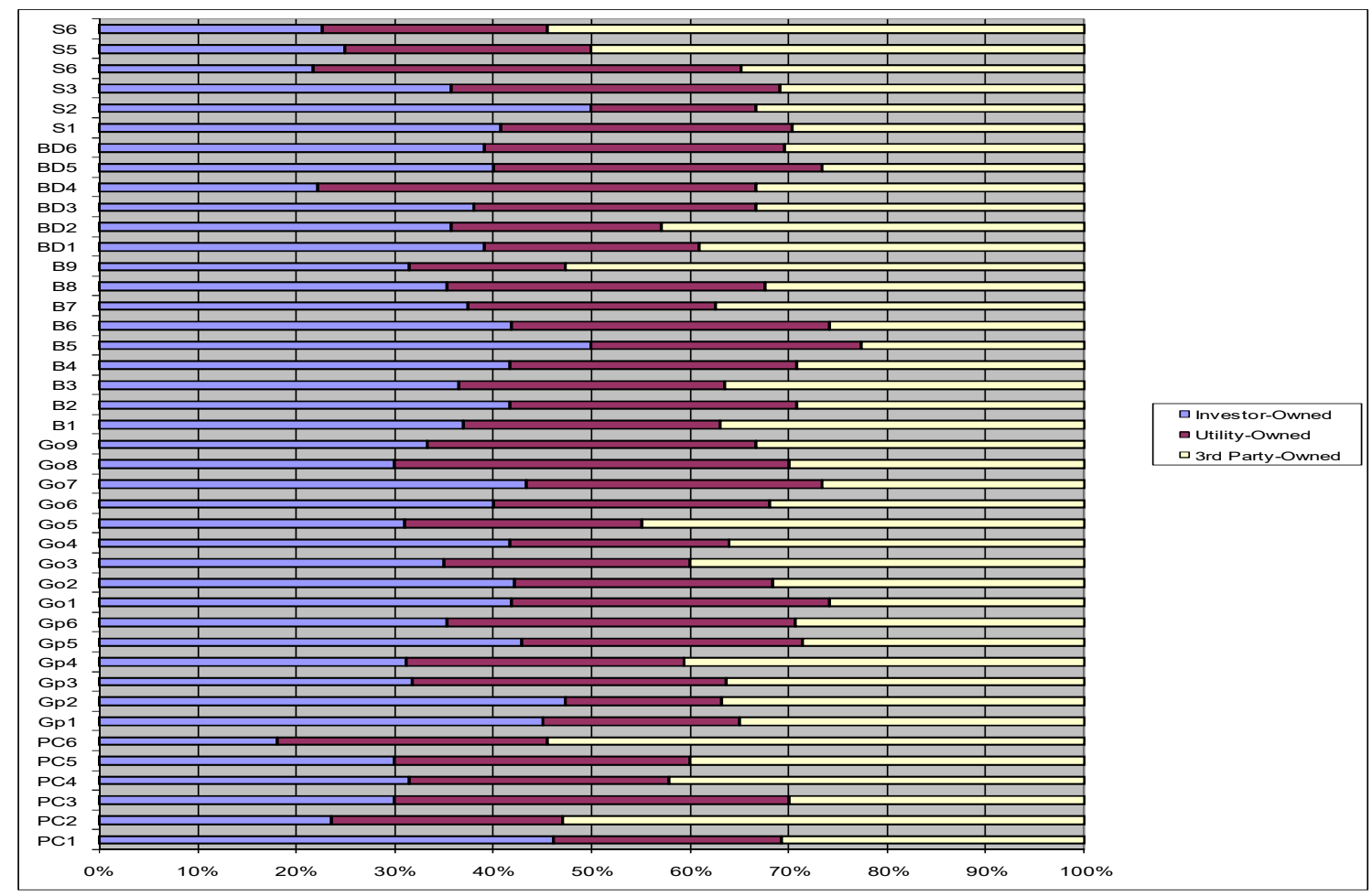

The information provided in this section provides a number of important insights.

First, it enables a unique form of analysis, which permits the mapping of businesses model factors onto technology roadmap factors, allowing a better understanding of exactly how a variety of business models fit onto specific industry roadmaps at different points in time. This allows a comparison of a vast number of factors over an immense set of possible business model permutations which would not be possible through any other form of analysis. While it is difficult to draw just a few simple conclusions from such a data set, one strength of the unique methodological approach used here is that it can provide a resource that enables stakeholders to pore over the data from different angles 
and derive their own conclusions based on the specific set of options they wish to explore.

The approach used here provides an important contribution the state of knowledge in the field, both in the form of theory and practice. The overwhelming majority of this research was hands-on, workshop-based, and lends itself easily to implementation practical results from the study. It also illustrates an important theoretical basis point described at the beginning of the study, which is that not only do the most successful roadmaps unify "technology push" and "market pull" perspectives, but this research has shown a way in which there can also be a policy push-dynamic at play, and a role for business models to play as a means for implementing successful combinations of these factors [33]. More information is provided about this in section 1.2.5. The next section now provides some additional information about research outcomes and conclusions to this study.

\subsection{Validity Analysis}

After collecting data and analyzing results, they were analyzed for validity. This was done by consulting again with the experts used in the study and conducting a number of tests. These tests followed the guidelines mentioned in previous sections of this chapter. Experts were contacted to review the instruments used for the Business Concept Development workshop and Industry analysis workshops. The results of these validity tests are show on the tables below. 
The table summarizes validity results for roadmaps and business model specifications developed in this study

Figure 7.31: Validity - Roadmaps and Business Model Specifications

\begin{tabular}{|c|c|c|c|c|c|c|}
\hline Output & Area & Title & $\begin{array}{c}\text { Experience } \\
\text { (yrs) }\end{array}$ & $\begin{array}{c}\text { Accuracy } \\
(1-5)\end{array}$ & $\begin{array}{c}\text { Relevance } \\
(1-5)\end{array}$ & Comments \\
\hline \multirow{4}{*}{$\begin{array}{l}\text { Overall } \\
\text { Roadmap }\end{array}$} & Indus & President & 25 & 5 & 4 & \multirow{4}{*}{$\begin{array}{l}\text { Seems accurate, but hard to } \\
\text { determine relevance. Fix typos }\end{array}$} \\
\hline & Indus & President & 25 & 5 & 4 & \\
\hline & Gov, Indus & Chairman & 35 & 4 & 5 & \\
\hline & & & & 4.67 & 4.33 & \\
\hline \multirow{3}{*}{$\begin{array}{c}\text { Business and } \\
\text { Government } \\
\text { Roadmap }\end{array}$} & Indus & CEO & 25 & 5 & 4 & \multirow{3}{*}{$\begin{array}{l}\text { Codes hard to follow, but looks } \\
\text { interesting. The key will be how to } \\
\text { apply it. }\end{array}$} \\
\hline & Gov, Indus & Chairman & 35 & 5 & 5 & \\
\hline & & & & 5.00 & 4.50 & \\
\hline \multirow{3}{*}{$\begin{array}{c}\text { Consumer and } \\
\text { Market } \\
\text { Roadmap }\end{array}$} & Gov, Indus & Chairman & 35 & 5 & 4 & \multirow{3}{*}{ Fix typos. } \\
\hline & Indus & CEO & 25 & 4 & 4 & \\
\hline & & & & 4.50 & 4.00 & \\
\hline \multirow{3}{*}{$\begin{array}{l}\text { Business Model } \\
\text { Specifications }\end{array}$} & Indus & Vice President & 10 & 5 & 4 & \multirow{3}{*}{$\begin{array}{l}\text { Seems accurate, but hard to } \\
\text { determine relevance. Fix typos }\end{array}$} \\
\hline & Gov, Indus & Chairman & 35 & 4 & 5 & \\
\hline & & & & 4.50 & 4.50 & \\
\hline
\end{tabular}

Expert from relevant disciplines were asked to provide input on the Accuracy and Relevance the roadmaps and business models analysis produced in this study. The general background areas for these experts included: Utility Executives and Analysts, Policy Analysts, EV/V2G Business and Technology Experts, Regulatory and Policy Experts

familiar with the electric vehicle and vehicle charging industry. Descriptions of the experts' disciplinary area, title, and experience are provided in the summary table.

Each instrument was scored on a 1 to 5 scale, with 1 indicating a poor score and 5 indicating a very good score. All the instruments in the table above received average scores of at least 4 out of 5 for both Accuracy and Relevance. They were also invited to 
provide open-ended comments. These comments were then considered and used to determine the overall accuracy and relevance of the final results. 


\section{CHAPTER 8: Research Outcomes, Conclusions, and Recommendations}

The main outcome of this research is the development of a process to help integrate technology roadmapping with business modeling, as well as regulatory and policy planning, and to thus enable better understanding of opportunities for emerging technologies in emerging environments. This process is expected to be especially important for dealing with highly regulated industries, such as the utility sector, which has historically had one of the lowest rates of research and development investment of any major technology-based industry, only $0.25 \%$ of revenue [23]. There are many reasons for this, including common regulatory structures, and various justifications for such regulatory structures, as discussed in previous sections. However, the result of this investment pattern has clearly been a slow, careful deployment of technology, which has focused on durable, well-understood devices and systems that have often been deployed and operated for decades at a time. While this may have had some favorable effect of protecting utility ratepayers from investing in risky or uncertain new technologies, it has also caused the industry to remain one that is still largely analog and manual in an age where many if not most other technologies are becoming digital and automated. To develop and successfully deploy critical new energy-related technology in the 21 st century, at a time of increasing concern and urgency over rising energy costs and environmental damage caused by current technology, careful planning will be required. New methods which gracefully integrate technology, business, regulatory, and policy considerations into a holistic planning approach may prove extremely useful. Creating a framework to assist with such efforts is a primary aim of this research. 
This research also focuses on the emerging smart grid industry, since smart grid technologies appear to have great potential to drive future innovation in the electric utility sector. This framework could be applied to many other emerging technology and industry environments as well, but new tools are needed to tailor the development process to a variety of unique requirements. This research offers one such set of tools and processes to achieve this goal.

A number of key conclusions have been described in different sections of this study and can now be summarized, along with recommendations for next steps. Contributions the research makes to the existing body of knowledge in this field are described in the next section, followed by limitations and assumptions. As noted in Chapter 7, there appears to be consensus that development of EV charging hardware and software standards (RD3) was extremely important from technology, business, and regulatory perspectives. Improved DC quick chargers (O3) were also important from a technology perspective, and development of clear, consistent standards would help enable these efforts, removing a key barrier to more wide-spread deployment. Creation of support systems and warranty services for advanced batteries (O2) was very important from technology, business, and market perspectives. There was consensus that regional planning visions on charger deployment should be developed that could help integrate with existing plans to reach environmental goals and emissions targets. There was a divergence of views on the development of partnership structures $(\operatorname{Pn} 2)$ as well as incentives and financing for electric vehicle charging (Pn3). These were seen as 
important from the Business and Regulatory perspective, but less so from the Market perspective. From a Technology perspective, payments systems / transactive energy interfaces (T4) were seen as extremely important and also considered quite significant from the point of view of potential Barriers. Other important issues from this perspective included barriers caused by the lack of a clear vision for the role of electric vehicles in regional renewable energy integration plans, and the lack of standardized business model frameworks. This were seen as important from a business and regulatory point of view, but less so from a market-oriented point of view. Therefore, the recommendations for next steps based on this data would be to focus on hardware/software standards (RD3), support systems and battery warranties (O2), quick charger development (O3), and deployment plans (BM2). Once these standards are developed and deployment plans are implemented, partnerships (Pn2) and incentives (Pn3) would then make sense to explore. The research then looks at overall a series of technology roadmaps that incorporate those issues and related challenges over an approximately 10 year horizon and looked at specific alternatives, such as various business model options, which could be used to address specific challenges at different points in that timeline.

Several types of roadmaps were created to examine different aspects of this research. First, an overall roadmap was created that shows the combined effect of business, consumer, regulatory, and market factors over the entire 10-year time span of the roadmap. The roadmap shows many key elements that relate to ownership structure and primary profit mechanism for stakeholders involved in implementing aspects of the roadmap. These mechanisms included: Direct fees for vehicle charging and/or parking 
fees; membership fees and fees for other bundled and premium services, such as internet access or auxiliary vehicle power hook-up fees; advertiser fees or fees for consumers to opt-out of advertisements; ancillary service fees, which provide essential services to utilities, such as voltage and frequency regulation; or energy efficiency optimization contracts and energy aggregation contracts, which allow a network operator to manage and optimize energy use over a grid or micro-grid. The roadmap was then broken into two parts. Section A shows a Business and Regulatory focused version of the roadmap. Section B shows Consumer and Market focused version of the roadmap. Options for financing and distribution methods related to each business model were then considered under the discussion of business models and in Appendix F, where each of the business model specifications is described. Analysis was then done on what business models may be used to implement various aspects of the roadmaps that have been developed. To summarize the main business model challenges, expert input was gathered to create a taxonomy of business models appropriate for the issues discussed in the roadmap construction process. The models were divided into Investor-Owned structures, UtilityOwned structures and Aggregator-Owned structures. This research provides tools to help stakeholders interested in exploring details about each of the 31 business model variations to quickly sort through large amounts of information related to each of the industry options most relevant to them. This allows them to determine appropriate paths to achieve their goals. Due to the large amount of data in this emerging industry, this is an important resource, and a significant practical contribution of this research. Additional contributions are described in the next section. 


\subsection{Contributions}

This research is intended to help improve the processes for envisioning and planning the introduction of emerging technologies into industries like the electrical utility sector. Historically, this industry has been slow to embrace modern information and communication technologies, due to a variety of factors, including relatively durable regulatory structures that have long been common in many parts of the world, as well as a difficulty creating products that have appropriate business models to meet regulatory and policy needs. A key goal of this research is to better integrate technology development with regulatory, policy, and business model development, to increase the likelihood of successful innovation. Within the utility industry, introduction of technologies related to grid modernization, or smart grid, have a particularly strong relevance to this research. However, development of a method that is useful in that area is also expected to have implications for improvements in many other industries, which have a variety of regulatory structures. This research performed a case study on the development of an integrated technology roadmapping process for electric vehicle charging. Specific analysis of details of that case are provided in Chapter 7 and summarized in the previous section. In addition to specific practical recommendations regarding the case study, this research provides a number of other important contributions to several fields of knowledge.

This research reviewed and analyzed many literature streams. It examined the current state of knowledge regarding smart grid technology and the emerging smart grid 
industry. In the process, it also examined the history of the U.S. electrical utility industry, as well as some of the relevant literature on utility economics. Integrated Resource Planning is another literature stream that was examined in the process of understanding how technology has been developed and deployed in this sector. Literature on energy policy and regulation was examined, as well as specific analysis regarding the policy landscape that has developed for the Pacific Northwest region of the U.S. Closely tied to policy and regulatory issues, new frameworks, such as transactive energy structures were explored, and this in turn was specifically related to electric vehicle charging and vehicle-to-grid technology specifically. The technology roadmapping literature was also examined as a unifying concept for envisioning the technology development and deployment over time. Efforts specifically related to "smart grid roadmaps" were examined, and it was determined that few if any of the previous efforts in that literature stream would resemble those used in the technology roadmapping literature. Therefore, this research fills a gap by providing a technology roadmap on electric vehicle charging.

Furthermore, this research ties together important technology adoption concepts regarding "technology push" and "market pull" and offers several new concepts relevant to regulated industries, like electrical utilities. In addition to technology roadmaps balancing the technology push and market pull perspectives, it is proposed that regulated industries also have a significant "regulatory and policy push / pull" force that mediates between the technology push and market pull perspectives. Regulation can, for instance, distort market conditions, as well as place constraints on technology. Business models-- 
which attempt to find a practical combination to solve the problem of competing technology, market, regulatory and policy forces--are affected by these simultaneous dynamics. This concept is summarized in section 1.2.5, which discusses balancing planning perspectives in regulated industries.

This research also examined relevant literature related to business models and tied it in to technology development business concept development, and analysis of industry forces. A set of general categories and characteristics were developed regarding the forces affecting the industry. A taxonomy of 31 business models were then develop and coded so that they could be easily distinguished and compared. These ideas were then connected to the technology roadmapping and prioritization process. Analytical tools were provided to show how specific roadmap elements over short-, medium-, and longterm planning horizons related to each business model. This provides an important resource for comparing elements of existing business models on the roadmap and helping stakeholders who wish to better understand this complex area. By providing a systematic framework for categorizing and comparing models as they relate to the roadmaps, it provides an excellent platform for adding further detail about models or as well as providing possible insights on the development of new models. More about this is addressed in the final section on limitations and further work. 


\subsection{Assumptions Limitations and Future Work}

There are a number of important assumptions for the selection of expert panels for judgment quantification. These include the following:

1. All experts are assumed to be knowledgeable and be able to give independent judgments in their areas of expertise.

2. Biases of experts are expected to balance within panels of experts.

This study is designed to develop a process for improving technology planning by integrating technology roadmapping and prioritization, business modeling, and regulatory and policy analysis. The following limitations should be considered:

1. The research case study is limited to specific smart grid technologies, such as emerging vehicle-to-grid technologies that are current being experimented with in demonstration projects in Oregon and the Pacific Northwest. While future studies may indicate that the findings of this research are applicable to other technologies and other regions, the current case study has not considered other technologies or regional contexts.

2. The outputs of this research rely on the subjective judgments of the experts. Limited knowledge and biases might affect the validity of the model.

This research offers a number of potential areas for future work. First, additional details could be added regarding any specific technologies, business models, or other roadmap elements analyzed in this study. Many of the topics studied are complex and 
additional research could be done on one of these areas alone. Business models, for example, could be developed in further detail, or additional models could be developed. This study provides an organized framework for categorizing and comparing roadmap elements. The more that people continue to build upon that framework, the more valuable it becomes. The method could also be applied to other smart grid or utilityrelated technologies. This could provide important insights both about specific emerging technologies and help understand how they might impact other similar technologies that may soon be developed or deployed. It could also be applied to other regulated industries outside smart grid and the utility sector. It is expected to be generally applicable to other regulated industries, but case studies are needed to demonstrate this. It could also be compared to other roadmapping techniques and analytical methods. It would be valuable to see if industry practitioners are able to use the method to achieve improved results over other methods. 


\section{REFERENCES}

[1] EEI, "Industry Data: Statistical Highlights," Edison Electric Institute 2017.

[2] EIA, "Revenue of the U.S. electric power industry from 1970 to 2015 (in billion U.S. dollars)," Energy Information Administration 2016.

[3] D. J. Hammerstrom, J. M. Gephart, and R. W. A. Pacific Northwest National Laboratory, "Smart Technology Brings Power to the People," Power Engineering International, 14(10):45-46, vol. 14, 2006.

[4] G. Rouse and J. Kelly, "Electricity Reliability: Problems Progress and Policy Solutions," Galvin Electricity Initiative2011.

[5] C. Hussler, M. Tang, and F. Picard, "Taking the Ivory from the Tower to Coat the Economic World: Regional Strategies to make Science Useful," Technovation, vol. 30, pp. 508-518, 2010.

[6] P. Fox-Penner, "Fix Utilities Before they Need a Rescue," Harvard Business Review, vol. 87, 2009.

[7] C. L. Stimmel. (2015). Big data analytics strategies for the smart grid. Available: http://dx.doi.org/10.1201/b17228

[8] J. Jenkins, J. Bauman, and J. Bissonette, "Renewable Energy Standard " Powering Oregon's Future 2007.

[9] EPRI, "Smart Grid Demonstration Two-Year Update," Electric Power Research Institute 2010.

[10] B. Shively and J. Ferrare, Understanding today's electricity business. Laporte, CO: Enerdynamics, 2010.

[11] P. S. Fox-Penner, Smart Power: Climate change, the smart grid, and the future of electric utilities. Washington: Island Press, 2010.

[12] DOE, Energy Independence and Security Act of 2007 (EISA). Washington, D.C.: US GPO: Superintendent of Documents, 2007.

[13] D. Warkentin-Glenn, Electric Power Industry in Nontechnical Language. Tulsa, OK: PennWell Corporation, 2006. 
[14] P. Fox-Penner, Smart Power: Climate Change, the Smart Grid, and the Future of Electric Utilities: Island Press, 2010.

[15] EPRI, "The Green Grid: Energy Savings and Carbon Emissions Reductions Enabled by a Smart Grid," Electric Power Research Institute (EPRI) 2009.

[16] R. J. Procter, "Smart Grid Inventory: A Report to the Oregon Public Utility Commission," Public Utility Commission of Oregon, Salem, OR 2011.

[17] T. L. Friedman, Hot, Flat, and Crowded: Why we Need a Green Revolution -And How it Can Renew America. New York: Farrar, Straus and Giroux, 2008.

[18] EPRI, "Estimating the Costs and Benefts of the Smart Grid: A Preliminary Estimate of the Investment Requirements and the Resultant Benefts of a Fully Functioning Smart Grid," Electric Power Research Institute (EPRI), Palo Alto, CA 2011.

[19] S. M. Amin and B. F. Wollenberg, "Toward a Smart Grid," IEEE Power \& Energy, vol. 4, p. 66, 2006.

[20] C. Cramer, Thomas Edison. San Diego, CA: Greenhaven Press, 2001.

[21] M. Filippini, "Are Municipal Electricity Distribution Utilities Natural Monopolies?," Annals of Public and Cooperative Economics, vol. 69, p. 157, 1998.

[22] S. Insull and W. E. Keily, Central Station Electric Service: Its Commercial Development and Economic Significance. Chicago, 1915.

[23] NSF, "Funds for Industrial R\&D as a Percent of Net Sales of Companies Performing Industrial R\&D in the United States," National Science Foundation (NSF), Washington, DC 2010.

[24] L. Fox, Enron: The Rise and Fall. Hoboken, N.J.: Wiley, 2003.

[25] J. Casazza, Understanding Electric Power Systems: An Overview of the Technology, the Marketplace, and Government Regulation: John Wiley \& Sons, 2010.

[26] S. Coll, The Deal of the Century: The Break Up of AT\&T. New York: Atheneum, 1986. 
[27] C. H. Willyard and C. W. McClees, "Motorola's Technology Roadmap Process," Research Management, pp. 13-19, 1987.

[28] S. T. Walsh, "Roadmapping a Disruptive Technology: A Case Study," Technological Forecasting and Social Change, vol. 71, pp. 161-185, 2004.

[29] O. H. Bray and M. L. Garcia, Technology Roadmapping: The Integration of Strategic and Technology Planning for Competitiveness. Portland, OR: PICMET (Portland International Conference on Management of Engineering and Technology), 1997.

[30] R. Phaal, C. Farrukh, and D. Probert, T-Plan: The Fast-Start to Technology Roadmapping - Planning your Route to Success. Cambridge: University of Cambridge, Institute for Manufacturing, 2001.

[31] R. Phaal, C. J. P. Farrukh, and D. R. Probert, "Technology Roadmapping - A Planning Framework for Evolution and Revolution," Technological Forecasting and Social Change., vol. 71, p. 5, 2004.

[32] C. Holmes and M. Ferrill, "The application of Operation and Technology Roadmapping to aid Singaporean SMEs identify and select emerging technologies," Technological Forecasting and Social Change, vol. 72, pp. 349357, 2005.

[33] A. Nauda and D. L. Hall, "Strategic technology planning--developing roadmaps for competitive advantage," in Portland International Conference on Management of Engineering and Technology, Portland, OR, 1991, pp. 745-748.

[34] J. A. Schumpeter and R. Opie, The Theory of Economic Development: An Inquiry into Profits, Capital, Credit, Interest, and the Business Cycle. Cambridge, MA: Harvard University Press, 1934.

[35] R. Coombs, P. Saviotti, and V. Walsh, Economics and Technological Change. Totowa, N.J.: Rowman \& Littlefield, 1987.

[36] A. Smith and F. Kern, "The transitions storyline in Dutch environmental policy," Environmental Politics, vol. 18, 2009.

[37] CAISO, "Smart Grid Roadmap and Architecture," California Independent System Operator 2010. 
[38] J. Houck and W. Rickerson, "The Sustainable Energy Utility (SEU) Model for Energy Service Delivery," The Bulletin of Science, Technology \& Society, vol. 29, pp. 95-107, 2009.

[39] A. J. O'Donnell, Soul of the Grid: A Cultural Biography of the California Independent System Operator. New York: Universe, 2003.

[40] M. Rawson and J. Sugar, "Distributed Generation and Cogeneration Policy Roadmap for California," California Energy Commission, Sacramento, CA 2007.

[41] A. Chuang. (2011). California Utility Vision and Roadmap for the Smart Grid of 2020: Final Project Report. Available:

http://bibpurl.oclc.org/web/45441http://www.energy.ca.gov/2011publications/CE C-500-2011-034/CEC-500-2011-034.pdf

[42] CEC. (2010). CERTS Smart Grid Demonstration with Renewable Energy Integration. Available: http://www.energy.ca.gov/2010publications/CEC-5002010-FS/CEC-500-2010-FS-005.PDF

[43] ISSGC, "Illinois Statewide Smart Grid Collaborative: Collaborative Report," Illinois Statewide Smart Grid Collaborative 2010.

[44] ISGI, "Illinois Smart Grid Initiative: Summary of Smart Grid Bnefits and Issues," Illinois Smart Grid Initiative (ISGI) 2008.

[45] M. Olken, "A Smart Grid Partnership: International Efforts in Korea and Illinois," IEEE Power and Energy Magazine, vol. 9, pp. 4-6, 2012.

[46] Staff Recommendation to Use Oregon Electricity Regulators Assistance Project Funds from the American Recovery and Reinvestment Act of 2009 to Develop Commission Smart Grid Objectives for 2010-2014, OPUC Order No. 11-172, 2011.

[47] A. Brown and R. Satler, "Smart Grid Issues in State Law and Regulation," Galvin Electricity Initiative 2010.

[48] FERC, "Assessment of Demand Response \& Advanced Metering: Docket AD062-000," Federal Energy Regulatory Commission, Washington, D.C. 2008. 
[49] R. W. Galvin, K. E. Yeager, and J. Stuller, Perfect Power: How the Microgrid Revolution Will Unleash Cleaner, Greener, and More Abundant Energy. New York: McGraw-Hill, 2009.

[50] NIST, "NIST Framework and Roadmap for Smart Grid Interoperability Standards, Release 1.0," National Institute of Standards and Technology, Office of the National Coordinator for Smart Grid Interoperability, Gaithersburg, MD2010 2010.

[51] Xcel, "Xcel Energy Smart Grid: A White Paper," Xcel Energy, Boulder, CO 2010.

[52] D. James, "Xcel Energy's Smart Grid," Proceeding of the Solar Conference, vol. 5, pp. 2859-2869, 2008.

[53] PSPI, "The Pecan Street Project: Working Group Recommendations," Pecan Street Project, Inc. (PSPI), Austin, TX2010.

[54] C. A. Smith, "The Pecan Street Project: Developing the Electric Utility System of the Future," University of Texas, Austin, TX, 2009.

[55] B. McCracken, K. Rábago, and M. E. Webber, Pecan Street Project Smart Grids and Austin's Energy Future. Austin, TX: University of Texas at Austin: Environmental Science Institute, 2010.

[56] CMU, "Smart Grid Maturity Model: Model Definition: A Framework for Smart Grid Transformation," Carnegie Mellon University (CMU), Fort Belvoir, VA 2010.

[57] W. S. Humphrey, Managing the Software Process. Reading, MA: AddisonWesley, 1989.

[58] J. R. Persse, Implementing the Capability Maturity Model. New York: John Wiley \& Sons, 2001.

[59] Public Utilities Regulatory Policy Act of 1978: Report to Accompany S. 2114, 1978.

[60] T. L. Saaty. Hierarchies, Reciprocal Matrices and Ratio Scales. Available: http://catalog.hathitrust.org/api/volumes/oclc/3763277.html 
[61] T. U. Daim, M. Amer, and R. Brenden, "Technology Roadmapping for Wind Energy: Case of the Pacific Northwest," Journal of Cleaner Production, vol. 20, pp. 27-37, 2012.

[62] T. Daim, D. Kocaoglu, N. Gerdsri, and I. Kockan, "Technology Development Envelope Approach for the Adoption of Future Powertrain Technologies: A Case Study on Ford Otosan Roadmapping Model," Journal of Transportation Systems Engineering and Information Technology, vol. 11, pp. 58-69, 2012.

[63] J. G. Bruce, A Hundred Years of Development of Electric Traction: Electric Railway Society, 1985.

[64] H. Lund and W. Kempton, "Integration of Renewable Energy into the Transport and Electricity Sectors through V2G," Energy Policy Energy Policy, vol. 36, pp. 3578-3587, 2008.

[65] J. Voelcker, "June Plug-In Electric Car Sales: Volt Stays Strong, Leaf Low," Green Car Reports2012.

[66] USDOE, "One Million Electric Vehicles By 2015: February Status Report," ed, 2011.

[67] Pike, "Annual Plug-in Electric Vehicle Sales to Cross the One Million Mark by 2015," Pike Research, Boulder Colorado2011.

[68] B. Halvorson, "Ten Percent Electric Vehicles By 2020? No Sweat, Utility CEO Says," Green Car Reports2011.

[69] I. S. Thukral, I. J. R. Von Ehr, S. Walsh, A. J. Groen, P. Van Der Sijde, and K. Akmaliah Adham, "Entrepreneurship, Emerging Technologies, Emerging Markets," International Small Business Journal, vol. 26, pp. 101-116, 2008.

[70] L. Karwoski-Magee and D. Ruben, "The Charrette: An Interdisciplinary Academic Tool," Design Principles and Practices: An International Journal, vol. 4, p. 11, 2010.

[71] NPCC, "Northwest Wind Integration Action Plan," NPCC (Northwest Power and Conservation Council), Portland, OR 2007.

[72] K. Dragoon, "Lowest Cost Balancing Resources," ed. Portland: NPCC (Northwest Power and Conservation Council), 2011. 
[73] B. M. Nickell, "Wind Dispatchability and Storage - Interconnected Grid Perspective," EERE (Energy Efficiency \& Renewable Energy Department) 2009.

[74] USDOT, "National Transportation Statistics 2012," United States Department of Transportation Bureau of Transportation Statistics, Washington, DC 2012.

[75] J. Lorio. (2012) 2011 Auto Sales. Automobile.

[76] C. Paine, J. Deeter, D. Devlin, T. M. Titus, and R. D. Titus, Who Killed the Electric Car? Culver City, CA: Sony Pictures, 2006.

[77] M. Ehsani, Y. Gao, and A. Emadi, Modern Electric, Hybrid Electric, and FuelCell Vehicles: Fundamentals, Theory, and Design. Boca Raton: CRC Press, 2010.

[78] EUC, European Green Cars Initiative: Towards an Electric Future? Luxembourg: European Union Commission (EUC): Directorate-General for Research (DGR), 2010.

[79] P. Stenquist, "How Green Are Electric Cars? Depends on Where You Plug In," in New York Times, ed. New York City, NY: New York Times, 2012.

[80] UCS, "State of Charge: Electric Vehicles' Global Warming Emissions and FuelCost Savings Across the United States," Union of Concerned Scientists (UCS), Cambridge, MA 2012.

[81] USEPA, "National Emissions Inventory Trends Report: Average annual emissions, all criteria pollutants," United States Environmental Protection Agency, Washington, DC 2006.

[82] G. Mom, The Electric Vehicle: Technology and Expectations in the Automobile Age. Baltimore: Johns Hopkins University Press, 2004.

[83] D. A. Kirsch, The Electric Vehicle and the Burden of History. New Brunswick, NJ Rutgers University Press, 2000.

[84] M. Shnayerson, The Car that Could: The Inside Story of GM's Revolutionary Electric Vehicle. New York, NY Random House, 1996.

[85] S. Fletcher, Bottled Lightning: Superbatteries, Electric Cars, and the New Lithium Economy. New York Hill and Wang, 2011.

[86] TMC, "Worldwide Sales of TMC Hybrids Top 4 Million Units," ed: Toyota Motors Corporation (TMC), 2012. 
[87] HMC, "Cumulative Worldwide Sales of Honda Hybrid Vehicles Reaches 1 Million Units," ed: Honda Motor Company (HMC), 2012.

[88] Pike, "Electric Vehicle Market Forecasts - Global Forecasts for Light-Duty Hybrid, Plug-in Hybrid, and Battery Electric Vehicles: 2011-2017," Pike Research2011.

[89] L. Edsall, Chevrolet Volt: Charging into the Future. Minneapolis: MBI Publishing Company, 2010.

[90] J. Erjavec, Hybrid, Electric and Fuel-cell Vehicles. Clifton Park, NJ Delmar Cengage Learning, 2013.

[91] L. Putnam, "From Home to Work, the Average Commute is 26.4 Minutes," US Department of Transportation - Bureau of Transportation Statistics 2003.

[92] USDOT, "Opinions on Cell Phone Use on Airplanes, Congestion, and Telecommuting - 2006 and 2007 Omnibus Household Survey," United States Department of Transportation - Bureau of Transportation, Statistics, Washington, DC 20082008.

[93] N. Ireson. (2010) 2011 Chevrolet Volt Gets 93 MPGe EV Rating, 60 MPG Combined. Green Car Reports. Available: http://www.greencarreports.com/news/1051889 2011-chevrolet-volt-gets-93mpge-ev-rating-60-mpg-combined

[94] N. Bunkley, "Nissan Says Its Electric Leaf Gets Equivalent of 99 MPG," in The New York Times, ed. New York 2010.

[95] E. Evarts. (2011) Leaf, Volt tests show electric cars cost less per mile to operate.

[96] J. Voelcker, "September Plug-In Electric Car Sales Surge, As Tesla Sells 200," ed: Green Car Reports, 2012.

[97] HybridCars and B. Associates, "September 2012 Dashboard," ed: HybridCars, 2012.

[98] J. Cole. (2017) August 2017 Plug-In Electric Vehicle Sales Report Card. Insid EVs. Available: https://insideevs.com/august-2017-plug-in-electric-vehicle-salesreport-card/ 
[99] J. Cole. (2016) December 2016 Plug-In Electric Vehicle Sales Report Card. Insid EVs. Available: https://insideevs.com/december-2016-plug-electric-vehicle-salesreport-card/

[100] J. Cole. (2015) December 2015 Plug-In Electric Vehicle Sales Report Card. Insid EVs. Available: https://insideevs.com/december-2015-plug-electric-vehicle-salesreport-card/

[101] J. Cole. (2014) December 2014 Plug-In Electric Vehicle Sales Report Card. Insid EVs. Available: https://insideevs.com/december-2014-plug-electric-vehicle-salesreport-card/

[102] CBS, "New USGS Number Puts Japan Quake at 4th Largest - U.S. Geological Survey Upgrades Deadly Japan Earthquake to 9.0 After Japan's Meteorological Agency Did Same," in CBS News, ed, 2011.

[103] A. Garcia, "Car sales set another U.S. record," CNN Money, 2017.

[104] D. Scutt, "2016 was a record-breaking year for global car sales, and it was almost entirely driven by China," Business Insider, 2016.

[105] J. Reed and J. Soble, "Electric and Hybrid: Sales Feed off Hype and Subsidy," in Financial Times, ed, 2010.

[106] C. Squatriglia. (2011) Where Will We Plug In? Wired.

[107] Pike, "Electric Vehicle Charging Equipment - Level 1 and Level 2, DC Fast Charging, and Wireless EVSE: Global Market Analysis and Forecasts," Pike Research2012.

[108] Aerovironment, "Zero to 80 Percent in 15 minutes: New Benchmark for EV Fastcharging," 2010.

[109] ECOtality, "ECOtality Introduces Blink - The First Smart, Interactive, Iconic EV Chargers and Network," San Francisco2010.

[110] C. Cleveland and C. Morris, Dictionary of Energy. Amsterdam; London: Elsevier, 2005.

[111] A. Markel, T. Mai, and M. Kintner-Meyer, Transportation Electrification Load Development for a Renewable Future Golden, CO: National Renewable Energy Laboratory, 2010. 
[112] J. Tomic and W. Kempton, "Using Fleets of Electric-Drive Vehicles for Grid Support," Journal of Power Sources, vol. 168, p. 459, 2007.

[113] W. Kempton, F. Marra, P. Anderson, and Rodrigo Garcia-Valle, "Business Models and Control and Management Architecture for EV Electrical Grid Integration," IEEE Innovative Smart Grid Technologies Europe, 2012.

[114] S. Letendre, P. Denholm, and P. Lilienthal, "Electric and Hybrid Vehicles: New Load or New Resource?," Public Utilities Fortnightly, 2006.

[115] M. Kintner-Meyer, K. Schneider, and R. Pratt, "Impacts Assessment of Plug-in Hybrid Vehicles on Electric Utilities and Regional US Power Grids: Part 1: Technical Analysis," Journal of EUEC, vol. 1, 2007.

[116] M. Scott, M. Kintner-Meyer, D. Elliott, and W. Warwick, "Economic Assessment and Impacts Assessment of Plug-In Hybrid Vehicles on Electric Utilities And Regional U.S. Power Grids," Journal of EUEC, vol. 1, 2007.

[117] ODOE. (2007). Available: www.oregon.gov/ENERGY/RENEW/.../Oregon_RPS_Summary_Oct2007.pdf

[118] AWEA, "U.S. Wind Industry Second Quarter 2017 Market Report," American Wind Energy Association2017.

[119] BPA, "Pumped Storage Evaluation," Bonneville Power Administration 2009.

[120] R. N. Kostoff, "Systematic Acceleration of Radical Discovery and Innovation in Science and Technology," Technological Forecasting and Social Change, vol. 73, p. 923, 2006.

[121] M. Rinne, "Technology Roadmaps: Infrastructure for Innovation," Technological Forecasting and Social Change, vol. 71, p. 67, 2004.

[122] E. Lopez-Ortega, T. Concepcion, and S. Viloria, "Strategic Planning, Technology Roadmaps and Technology Intelligence: An Integrated Approach," presented at the PICMET (Portland Internation Conference for Management of Engineering \& Technology), Portland, Oregon, 2006.

[123] S. K. Kassicieh, S. T. Walsh, J. C. Cummings, P. J. M. Whorter, A. D. Romig, and W. D. Williams, "Factors Differentiating the Commercialization of 
Disruptive and Sustaining Technologies," IEEE transactions on engineering management /, vol. 49, p. 375, 2002.

[124] R. N. Kostoff, R. Boylan, and G. R. Simons, "Disruptive Technology Roadmaps," Technological Forecasting and Social Change, vol. 71, p. 141, 2004.

[125] S. T. Walsh, "Roadmapping a Disruptive Technology: A Case Study - The Emerging Microsystems and Top-Down Nanosystems Industry," Technological Forecasting and Social Change, vol. 71, p. 161, 2004.

[126] S. T. Walsh and J. D. Linton, "Infrastructure for Emergent Industries Based on Discontinuous Innovations," Engineering Management Journal - Rolla, vol. 12, pp. 23-32, 2000.

[127] R. Zurcher and R. N. Kostoff, "Modeling Technology Roadmaps," The Journal of Technology Transfer, vol. 22, p. 73, 1997.

[128] B. A. Vojak and F. A. Chambers, "Roadmapping Disruptive Technical Threats and Opportunities in Complex, Technology-Based Subsystems: The SAILS Methodology," Technological Forecasting and Social Change, vol. 71, p. 121, 2004.

[129] J. L. Bower and C. M. Christensen, Disruptive Technologies: Catching the Wave. Boston, MA: Harvard Business School Publications, 1995.

[130] N. Gerdsri, "An Activity Guide for Technology Roadmapping," Technology Analysis and Strategic Management, vol. 22, pp. 229-242, 2010.

[131] M. Amer and T. U. Daim, "Application of Technology Roadmaps for Renewable Energy Sector," Technological Forecasting \& Social Change, vol. 77, pp. 1355$1370,2010$.

[132] H. Abe, T. Ashiki, A. Suzuki, F. Jinno, and H. Sakuma, "Integrating Business Modeling and Roadmapping Methods - The Innovation Support Technology (IST) Approach," Technological Forecasting and Social Change, vol. 76, pp. 8090, 2009.

[133] D. Fenwick, T. U. Daim, and N. Gerdsri, "Value Driven Technology Road Mapping (VTRM) Process Integrating Decision Making and Marketing Tools: 
Case of Internet Security Technologies," Technological Forecasting and Social Change, vol. 76, pp. 1055-1077, 2009.

[134] A. M. Lamb, T. U. Daim, and S. Leavengood, "Wood Pellet Technology Roadmap," IEEE Transactions on Sustainable Energy, vol. 3, pp. 218-230, 2012.

[135] I. J. Petrick and A. E. Echols, "Technology Roadmapping in Review: A Tool for Making Sustainable New Product Development Decisions," Technological Forecasting and Social Change, vol. 71, p. 81, 2004.

[136] S. T. Walsh, R. L. Boylan, C. McDermott, and A. Paulson, "The Semiconductor Silicon Industry Roadmap: Epochs Driven by the Dynamics between Disruptive Technologies and Core Competencies," Technological Forecasting and Social Change, vol. 72, pp. 213-236, 2005.

[137] S. Lee, S. Kang, and Y. Park, "Technology Roadmapping for R\&D Planning: The Case of the Korean Parts and Materials Industry," Technovation, vol. 27, pp. 433445, 2007.

[138] Y. Kajikawa, O. Usui, K. Hakata, Y. Yasunaga, and K. Matsushima, "Structure of Knowledge in the Science and Technology Roadmaps," Technological Forecasting Social Change Technological Forecasting and Social Change, vol. 75, pp. 1-11, 2008.

[139] R. W. Galvin, "A Practitioner's Update to Roadmapping: From Sustainable to Disruptive Technologies," Technological Forecasting and Social Change, vol. 71, pp. 91-103, 2004.

[140] G. L. Huffman, C. C. Lee, S. Rolander, and J. T. White, "A Summary of the EPA's Fuel Cell Program Dealing with the Environmental Life Cycle Assessment," Energy Sources, Part B: Economics, Planning and Policy, vol. 1, pp. 67-74, 2006.

[141] S. Lee and Y. Park, "Customization of Technology Roadmaps According to Roadmapping Purposes: Overall Process and Detailed Modules," Technological Forecasting and Social Change, vol. 72, p. 567, 2005.

[142] N. Gerdsri, "An Analytical Approach on Building a Technology Development Envelope (TDE) for Roadmapping of Emerging Technologies," 2005. 
[143] N. Gerdsri and D. F. Kocaoglu, "Applying the Analytic Hierarchy Process (AHP) to Build a Strategic Framework for Technology Roadmapping," Mathematical and Computer Modelling, vol. 46, pp. 1071-1080, 2007.

[144] N. Gerdsri, R. S. Vatananan, and S. Dansamasatid, "Dealing with the Dynamics of Technology Roadmapping Implementation: A Case Study," Technological Forecasting and Social Change, vol. 76, pp. 50-60, 2009.

[145] R. Phaal, C. Farrukh, and D. Probert, "Customizing Roadmapping," Research Technology Management, vol. 47, p. 26, 2004.

[146] T. Daim and T. Oliver, "Implementing Technology Roadmapping Process: A Case Study of a Government Agency," Technology Forecasting \& Social Change, vol. 75, pp. 687-720, 2008.

[147] K. R. Cowan and T. U. Daim, "Comparative Technological Roadmapping for Renewable Energy," Technology in Society, vol. 31, pp. 333-341, 2009.

[148] T. Daim, T. Oliver, I. Iskin, and J. Kim, "Technology Roadmapping: An Efficient Tool for Driving Regional Technological Changes," in Sustainable Systems and Energy Management at the Regional Level, ed, 2012.

[149] R. Phaal, N. T. M. H. Shehabuddeen, and P. Assakul, "Technology Roadmapping: Charting the Route Ahead for UK Road Transport," in Engineering Management Conference, 2002. IEMC '02. 2002 IEEE International, 2002, pp. 794-798 vol.2.

[150] R. Phaal, C. Farrukh, R. Mitchell, and D. Probert, "Starting-Up Roadmapping Fast," IEEE Engineering Management Review, vol. 31, pp. 54-60, 2003.

[151] O. Saritas and M. A. Oner, "Systemic Analysis of UK Foresight Results - Joint Application of Integrated Management Model and Roadmapping," Technological Forecasting and Social Change, vol. 71, p. 27, 2004.

[152] M. Dissel, R. Phaal, C. Farrukh, and D. Probert, "Value Roadmapping: A Structured Approach for Early Stage Technology Investment Decisions," presented at the PICMET 2006: Technology Management for the Global Future, Istanbul, Turkey, 2006. 
[153] R. Phaal, E. O'Sullivan, M. Routley, S. Ford, and D. Probert, "A Framework for Mapping Industrial Emergence," Technological Forecasting \& Social Change, vol. 78, pp. 217-230, 2011.

[154] R. Phaal and G. Muller, "An Architectural Framework for Roadmapping: Towards Visual Strategy," Technological Forecasting and Social Change, vol. 76, pp. 39-49, 2009.

[155] V. Thorn, F. Hunt, R. Mitchell, D. Probert, and R. Phaal, "Internal Technology Valuation: Real World Issues," International Journal of Technology Management, vol. 53, pp. 149-160.

[156] H. Martin and T. U. Daim, "Technology Roadmap Development Process (TRDP) for the Service Sector: A Conceptual Framework," Technology in Society, vol. 34, pp. 94-105.

[157] G. Hamel, Leading the Revolution. Boston, MA: Harvard Business School Press, 2000 .

[158] A. J. Slywotzky, Value Migration: How to Think Several Moves ahead of the Competition. Boston, MA: Harvard Business School Press, 1996.

[159] A. J. Slywotzky, The Art of Profitability. New York, NY: Warner Business Books, 2002.

[160] H. W. Chesbrough, Open Innovation: The New Imperative for Creating and Profiting from Technology. Boston, Mass.: Harvard Business School Press, 2003.

[161] M. E. Porter, On Competition. Boston, MA: Harvard Business School Pub., 2008.

[162] M. E. Porter, The Five Competitive Forces that Shape Strategy. Boston, MA: Harvard Business School Publishing, 2008.

[163] H. Abe, T. Hirabayashi, F. Ishida, Y. Oku, M. Kado, and H. Sakuma, "Value Creation Framework of Business Modeling Methods for R\&D Outputs," presented at the PICMET (Portland International Conference for Management of Engineering and Technology), 2005.

[164] H. Abe, T. Hirabayashi, M. Kado, and H. Sakuma, "A New Framework of Business Modeling Methods for R\&D Outputs: Valuation and Communication Tools for Engineers, Managers, and Investors," presented at the PICMET 
(Portland International Conference for Management of Engineering and Technology), 2004.

[165] Y. Yasunaga, M. Watanabe, and M. Korenaga, "Application of Technology Roadmaps to Governmental Innovation Policy for Promoting Technology Convergence," Technological Forecasting and Social Change, vol. 76, pp. 61-79, 2009.

[166] Y. Zhou, "A Policy Dimension Required for Technology Roadmapping: Learning from the Development of Emerging Wind Energy Industry in China," presented at the PICMET 2011 Portland, OR, 2011.

[167] W. Spencer and T. Seidel, "National Technology Roadmaps: The U.S. Semiconductor Experience " in 4th International Conference on Solid-State and Integrated Circuit Technology, 1995.

[168] A. Diebold, "Overview of Metrology Requirements Based on the 1994 National Technology Roadmap for Semiconductors," in SEMATECH (IEEE/SEMI 1995 Advanced Semiconductor Manufacturing Conference and Workshop), Austin, TX, 1994.

[169] P. A. Koen, "Technology Maps: Choosing the Right Path," Engineering Management Journal - Rolla, vol. 9, pp. 7-11, 1997.

[170] R. N. Kostoff and R. R. Schaller, "Science and Technology Roadmaps," IEEE Transactions on Engineering Management, vol. 48, pp. 132-143, 2001.

[171] M. G. Kendall and B. B. Smith, "The Problem of Rankings," The Annals of Mathematical Statistics, vol. 10, pp. 275-287, 1989.

[172] H. A. Linstone and M. Turoff, The Delphi Method: Techniques and Applications. Reading, MA: Addison-Wesley Publishing Company, 1975.

[173] K. Brockhoff, "The Performance of Forcasting Groups in Computer Dialogue and Face-to-Face Discussion," in The Delphi Method: Techniques and Applications, H. Linstone and M. Turoff, Eds., ed Reading, MA: Addison- Wesley, 1975, pp. 291-321. 
[174] T. L. Saaty, The Analytic Hierarchy Process: Planning, Priority Setting, Resource Allocation. New York; London: McGraw-Hill International Book Company, 1980.

[175] T. L. Saaty, "Axiomatic Foundation of the Analytic Hierarchy Process," Management Science, vol. 32, pp. 841-855, 1986.

[176] T. L. Saaty, Fundamentals of Decision Making and Priority Theory with the Analytic Hierarchy Process. Pittsburgh, PA: RWS Publications, 2000.

[177] J. L. Salmeron and I. Herrero, "An AHP-Based Methodology to Rank Critical Success Factors of Executive Information Systems," Computer Standards and Interfaces, vol. 28, pp. 1-12, 2005.

[178] E. Geisler, "The Metrics of Technology Evaluation: Where We Stand and Where We Should Go from Here," International Journal of Technology Management, vol. 24, pp. 341-374, 2002.

[179] X. Fang, S. Misra, G. Yue, and D. Yang, "Smart Grid - The New and Improved Power Grid: A Survey," IEEE Communications, 2011.

[180] Pacific Northwest Electric Power Planning and Conservation Act: Report to Accompany S. 885, 1979.

[181] NPCC, Restructuring of the Electric Utility Industry: Implications for the Goals of the Northwest Power Act. Portland, OR: Northwest Power Planning Council (NPCC), 1994.

[182] D. J. Duann, B. Chen, I. National Regulatory Research, and C. National Association of Regulatory Utility, A Survey of Recent State Initiatives on EPACT and FERC Order 636. Columbus, Ohio: National Regulatory Research Institute, 1994.

[183] K. Rose, R. E. Burns, and R. J. Graniere, Research Report: Summary of Key state Issues of FERC orders 888 and 889 . Columbus, $\mathrm{OH}$ : National Regulatory Research Institute, 1997.

[184] K. W. Costello and R. E. Burns, Regional Transmission Organizations and the Coordination of Regional Electricity Markets: A Review of FERC Order 2000. Columbus, Ohio: National Regulatory Research Institute, 2000. 
[185] EEI, A Summary of FERC's Standard Market Design Tariff NOPR. Washington, DC: Edison Electric Institute, 2002.

[186] Energy Policy Act of 2005, 2005.

[187] BPA, What is RTO West? Portland, OR: Bonneville Power Administration, 2000.

[188] M. R. Milligan. (2011). Western Interconnection Energy Imbalance Market:

Status and Prospects. Available: http://purl.fdlp.gov/GPO/gpo16356

[189] ColumbiaGrid, "Intra-Hour Transaction Accelerator Platform: I-Tap," ColumbiaGrid2009.

[190] U. S. Congress, Energy Policy Act of 1992: Public Law 102-486-Oct. 24, 1992. Washington, DC: US Government Printing Office, 1992.

[191] H. Prem and N. Raghavan, "Building a Technology Roadmap in High Performance Computing in the Indian Context," presented at the PICMET 2005: A Unifying Discipline for Melting the Boundaries, Portland, OR, 2005.

[192] C. Wooster, "Encouraging Technology through Legislation: A Study of the Development of Cogeneration Facilities after the Enactment of the Public Utilities Regulatory Policies Act," 1988.

[193] R. Schaller, "Technological Innovation in the Semiconductor Industry: A Case Study of the International Technology Roadmap for Semiconductors (ITRS)," 2004.

[194] L. Karwoski-Magee and D. Ruben, "The Charrette: An Interdisciplinary Academic Tool," Design Principles and Practices: An International Journal, vol. 4, pp. 11-21, 2010.

[195] P. Newman and C. Leverhant, "The Fuzzy Front End - Technology Identification, Staging, and Maturation: Where the Battle is Often Lost Without Firing a Shot," presented at the PICMET, Portland, OR, 2001.

[196] W. Kempton, "Automobiles: Designing the 21 st century fleet," presented at the Seattle V2G Technical Symposium, Seattle, WA, 2005.

[197] R. Wells, R. Phaal, C. Farrukh, and D. Probert, "Technology Roadmapping for a Service Organization," Research technology management., vol. 47, p. 46, 2004. 
[198] A. Nauda and D. Hall, "Strategic Technology Planning - Developing Roadmaps for Competitive Advantage," presented at the PICMET 1991, Portland, OR, 1991.

[199] ODOE, "Summary of Oregon's RPS " Oregon Department of Energy2007.

[200] C. Willyard and C. McClees, "Motorola's Technology Roadmap Process," Research Management, pp. 13-19, 1987.

[201] C. Holmes and M. Ferrill, "The Application of Operation and Technology Roadmapping to Aid Singaporean SMEs Identify and Select Emerging Technologies," Technological Forecasting and Social Change, vol. 72, p. 349, 2005.

[202] R. Phillips, Stakeholder Theory: Impacts and Prospects. Cheltenham: Elgar, 2011.

[203] E. Bardach, A Practical Guide for Policy Analysis: The Eightfold Path to More Effective Problem Solving, 3rd ed. New York, N.Y.: Chatham House Publishers, Seven Bridges Press, 2009.

[204] V. Elmer and A. Leigland, Infrastructure Planning and Finance: A Smart and Sustainable Guide. New York: Routledge, 2013.

[205] F. Ishida, H. Sakuma, H. Abe, and B. Fazekas, "Remodeling Method for Business Models of R\&D Outputs," in PICMET (Portland International Conference for Management of Engineering and Technology), Istanbul, Turkey, 2006, pp. 708714.

[206] R. R. Cooper and P. S. Schindler, Business Research Methods. Boston, Mass.: McGraw-Hill, 2007.

[207] K. E. M. Howe, "Standards for Qualitative (and Quantitative) Research: A Prolegomenon," Educational Researcher Educational Researcher, vol. 19, pp. 29, 1990.

[208] R. W. Scholz and O. Tietje, Embedded Case Study Methods: Integrating Quantitative and Qualitative Knowledge. Thousand Oaks, CA: Sage Publications, 2002.

[209] A. Tashakkori and C. Teddlie, Sage Handbook of Mixed Methods in Social \& Behavioral Research. Los Angeles, CA: SAGE Publications, 2010. 
[210] R. K. Yin, Case Study Research : Design and Methods. Thousand Oaks, CA: Sage, 2013.

[211] T. U. Daim, "Technology Evaluation and Acquisition Strategies and Their Implications in the U.S. Electronics Manufacturing Industry," Doctoral, Systems Science: Engineering \& Technology Management, Portland State University, Portland, OR, 1998.

[212] K. R. Murphy and C. O. Davidshofer, Psychological Testing: Principles and Applications: Prentice Hall, 1990.

[213] D. R. Cooper and W. Emory, Business Research Methods. Chicago: Irwin, 1995. 


\section{APPENDIX A: US Sales of Leading BEVs and PHEVs from 2010 to 2017}

US Sales of Leading BEVs and PHEVs from 2010 to 2017

\begin{tabular}{|c|c|c|c|c|c|c|c|c|}
\hline & Cumulative & $2017(Q 1-3)$ & 2016 & 2015 & 2014 & 2013 & 2012 & 2011 \\
\hline Tesla Model S & 104,771 & 14,700 & 29,421 & 25,700 & 17,300 & 17,650 & & \\
\hline Chevrolet VOLT & 126,658 & 13,895 & 24,339 & 15,393 & 18,805 & 23,094 & 23,461 & 7,671 \\
\hline Nissan LEAF & 113,263 & 9,685 & 14,006 & 17,269 & 30,200 & 22,610 & 9,819 & 9,674 \\
\hline Toyota Prius PHV/Prime* & 52,908 & 13,157 & 2,474 & 4,191 & 13,264 & 12,088 & 7,734 & \\
\hline Tesla Model X & 30,607 & 12,170 & 18,223 & 214 & & & & \\
\hline Chevrolet BOLT & 12,249 & 11,670 & 579 & & & & & \\
\hline Ford C-Max Energi & 35,151 & 5,929 & 7,957 & 5,678 & 8,433 & 7,154 & & \\
\hline Fusion Energi & 46,998 & 6,522 & 15,938 & 6,899 & 11,550 & 6,089 & & \\
\hline BMW i3 & 31,799 & 4,097 & 7,625 & 13,985 & 6,092 & & & \\
\hline
\end{tabular}

Source: Calculated from Green Car Reports [96], HybridCars [97], and InsideEVs [98-101] 


\section{APPENDIX B: Definitions of Smart Grid Technology and Investment Terms}

Definitions of some common Smart Grid technology and investment terms are included here [16]. Some of the definitions in this glossary may overlap. This is due to differences in terminology that are often used for similar products or processes.

\section{Advanced Analysis/Visualization Software:}

Systems installed to analyze grid information or help human operators.

\section{Automated Appliance:}

Appliance that is able to receive, and automatically responds to, a signal (price or operating) from the utility or from an in-premises control system.

\section{Automatic or Automated Meter Infrastructure (AMI):}

(AMI requires digital meters, 2-way communication, all the necessary computing hardware \& software to generate bills, ability to send price \& disconnect signals from utility to meters). It provides for two-way communication between the delivery infrastructure and the end consumer that enables real-time monitoring of individual nodes on the grid by the central office. It includes the smart meters, AMI server(s), Meter Data Management (MDM) system, required software, core AMI transport infrastructure and the required backhaul communications. 


\section{Automated Capacitors:}

Sensors that can monitor and control capacitor banks remotely in order to increase distribution efficiency.

\section{Advanced Demand Response Management System (DRMS):}

DRMS links the utility's back office to its customers. It is used to control distributed DR resources. From an enterprise systems point of view, the DRMS falls into a category of an information management system much like the Meter Data Management System and connects the flow of information to the DR devices to/from the utility.

\section{Automated Distribution:}

Distribution automation (DA) involves the integration of SCADA systems, advanced distribution sensors, advanced IED's and advanced two-way communication systems to optimize system performance. In a dense urban network it will also include network transformers and network protectors. The SCADA system collects and reports voltage levels, current demand, MVA, VAR flow, equipment state, operational state, and event logging, among others, allowing operators to remotely control capacitor banks, breakers and voltage regulation. Substation automation, when combined with automated switches, Reclosers, and capacitors, will enable full Smart Grid functionality. This means automating switches on the distribution system to allow automatic reconfiguration, automating protection systems and adapting them to facilitate reconfiguration and integration of DER, integrating power-electronic based controllers and other technologies 
to improve reliability and system performance, and optimizing system performance through voltage and VAR control to reduce losses, improve power quality.

\section{Automated Distribution Feeders (ADF):}

Implementing feeder automation that is virtually a simple extension of the substation automation by covering the feeders. ADF is usually implemented either based on a centralized approach or a distributed approach. Normally a distributed approach is simple and flexible. It can be implemented in a small scale but can only provide limited ADF functions. Instead, a centralized approach is capable of providing complete ADF functions but requires large scale implementation. Distribution Feeder Automation is the monitoring and control of devices located out on the feeders themselves: Line Reclosers, Load Break Switches, Sectionalizers, Capacitor Banks, and Line Regulators.

\section{Automatic Feeder Switching:}

Automated Feeder Switching is the monitoring and control of electrically operable switches located outside the substation fence. Automated feeder switching usually involves remote control from a centralized location (I.e., control center). It is used to detect feeder faults, determine the fault location (between 2 switches), Isolate the faulted section of the feeder (between 2 feeder switches), and restore service to portions of the feeder Automated regulators Equipment involved in feeder automation may include Feeder level switches/reclosers with Intelligent Electronic Devices (IEDs), communications such as RF, cellular, WiMAX or fiber connection; communications 
server; software algorithms; communications surveys, field integration of communications, configuration, and integration and commissioning may also be provided.

\section{Automation with Supervisory and Advisory Control:}

This refers to automation that includes both hardware and software. Power System Optimization Software or Supervisory Control allows the operator to apply objectives and constraints to achieve an optimal power system operation.

\section{Automated Relays:}

These are relays that are better able to protect the system from the widespread effects of fast disturbances. Communications between all digital devices on the distribution system including to feeders for AMI and distributed smart circuits No single technology is optimal for all applications. Among the communications media now being used for AMI applications are cellular networks, licensed and unlicensed radio and power line communications. In addition to the media, the type of network is also an important part of communications design. Networks used for Smart Grid applications include fixed wireless, mesh networks, and a combination of the two, fiber optics, Optical Ground Wire Cables, Microwave, Remote Radio Monitoring, Wi-Fi, and Internet networks are also under investigation. Communication architectures remain diverse for integrating residential devices with the grid. Approaches used include using the meter as a gateway to the home, Internet or other communication channels, radio frequency (RF) networks communicating in both licensed and unlicensed radio bands, mesh networks incorporate 
multi-hop technology where each node in the network can communicate with any other node, star networks utilize a central tower that can communicate with a large number of end devices over a wide area, and power line carrier networks.

\section{Communications Infrastructure to Support Transmission Lines and Substations:}

Substations in the future will require wide-area network interfaces to receive and respond to data from an extensive array of transmission line sensors, dynamic-thermal circuit ratings, and strategically placed phasor measurement units. The smart substation must be able to integrate variable power flows from renewable energy systems in real time, and maintain a historical record or have access to a historical record of equipment performance. Combined with real-time monitoring of equipment, the smart substation will facilitate reliability-centered and predictive maintenance. Some of the various applications include: Core Substation Infrastructure for IT; Communications Infrastructure to Support Transmission Lines \& Substations.

\section{Controllable/Regulating Inverters:}

Inverters that can be coordinated or managed collectively to provide grid support.

\section{Continuity Grid Sensors:}

Helps enable communication with the central distribution points to improve outage detection. 


\section{Customer Display Device or Portal:}

Devices or portals through which energy and related information can be communicated to and from utilities or third party energy service providers.

\section{Data Management:}

Data management covers all aspects of collecting, analyzing, storing, and providing data to users and applications, including the issues of data identification, validation, accuracy, updating, time-tagging, consistency, etc.

\section{Direct Load Control Devices:}

A radio-controlled device on an appliance that allows the utility to directly control its use.

\section{Distribution Line Automation Equipment (DLAE):}

DLAE refers to one or more technologies involved in automating at least some part of distribution line operations. Technologies may include at least some of the following-(1) remote sensing and reporting line switch position; (2) video monitoring to visually confirm line switch position; and/or (3) remote actuate/toggle line switches.

\section{Distribution Management System Integration:}

Technologies may include at least some of the following: (1) remote sensing and reporting line switch position; (2) video monitoring to visually confirm line switch position; and/or (3) remote actuate/toggle line switches. One definition of distribution automation is -A set of intelligent sensors, processors, and communication technologies 
that enables an electric utility to remotely monitor and coordinate its distribution assets, and operate these assets in an optimal manner with or without manual intervention.

\section{Enterprise Front and Back-Office Systems and their Integration:}

These are primarily IT-based systems that may include managing utility operations, demand response, connection to customer systems, power usage recording, customer billing.

\section{Enterprise-wide view of system via intelligent one-line diagram:}

Electrical power system analysis software that simulates a wide range of backup, control, and other scenarios.

EVSE (Electric Vehicle Service Equipment, i.e. chargers):

A Level I or Level II component that is used charge an electric car. FACTS devices and HVDC terminals Flexible AC transmission (FACTS) devices can be used for power flow control, loop flow control, load sharing among parallel corridors, voltage regulation, enhancement of transient stability, and mitigation of system oscillations. FACTS devices include the thyristor controlled series capacitor (TCSC), thyristor controlled phase angle regulator (TCPAR), static condenser (STATCON), and the unified power flow controller (UPFC). 


\section{Fault Current Limiter:}

A fault current limiter is a device that uses superconductors to instantaneously limit or reduce unanticipated electrical surges that may occur on utility distribution and transmission networks.

\section{High Temperature Superconductor (HTS) Cable:}

These could be used for capacity or applications such as Very Low Impedance (VLI) to control impedance and power flow.

\section{High Voltage Line Temperature and Weather Condition Sensors:}

Provide real-time temperature and weather conditions for to improve the efficiency of high voltage distribution lines and allow more accurate dispatch of current in times of significant demand with reduced chance of outages due to line sag.

Home Area Networks (HAN) (including Building Energy Management Systems (BEMS) for commercial and industrial applications):

Whether a HAN or a BEMS it refers to a computer-based system that assists in managing energy use. It will be programmable and ideally has the ability to automatically respond to price signals in one or more ways.

\section{Improved interfaces and decision support:}

Improved interfaces and decision support will enable grid operators and managers to make more accurate and timely decisions at all levels of the grid, including the consumer 
level, while enabling more advanced operator training. Improved interfaces will better relay and display real-time data to facilitate: Data reduction; Visualization; Speed of comprehension; Decision support; System operator training. Integrated volt-VAR control help provide the distribution grid with constant voltage levels. Most enhanced voltage regulators also provide a means to monitor the line voltage

\section{Intelligent Electronic Devices (IEDs):}

These devices encompass a wide array of microprocessor based controllers of power system equipment, such as circuit breakers, transformers and capacitor banks. IEDs receive data from sensors and power equipment, and can issue control commands, such as tripping circuit breakers if they sense voltage, current, or frequency anomalies, or raise/lower voltage levels in order to maintain the desired level. Common types of IEDs include protective relaying devices, load tap changer controllers, circuit breaker controllers, capacitor bank switches, recloser controllers, voltage regulators, network protectors, relays etc.

\section{Meter Data Management System (MDMS):}

A meter data management system (MDMS) collects and translates meter data into information that can be used by the various utility applications such as billing, outage management, GIS and smart metering. The MDMS helps utilities meet the challenges of processing and managing large quantities of meter data. 


\section{Micro-processor Based Protective Relays:}

These are substitutes for electromechanical and solid-state relays. They have benefits in performance (sensitivity and speed), reliability (security, selectivity, and dependability), availability, efficiency, economics, safety, compatibility, and capabilities of microprocessor multifunction protective relaying technology over the previous existing technologies.

Phasor Data Concentrators (PDC or PDCs):

A PDC forms a node in a system where phasor data from a number of PMUs or PDCs are correlated and fed out as a single stream to other applications

Phasor Measurement Units (PMU or PMUs):

These are high-speed sensors distributed throughout a network that can be used to monitor power quality and in some cases respond automatically to them.

Power Factor Management System (metering, power factor correction):

Power factor is the percentage of electricity that is being used to do useful work, and it is expressed as a ratio; the higher the ratio, the greater the efficiency. Power factor management involves advanced metering that more accurately measures true power factor. Automating 'power factor correction' is aimed at reducing costly energy loss which can help reduce overall system costs. 


\section{Power Quality Monitor:}

A device that monitors power quality within the distribution system.

\section{Reclosers:}

Centrally monitor and report circuit status (i.e. either open or closed), centrally monitor and report actions performed on the recloser, Transmit commands to the recloser.

\section{Redistribution Management System:}

Communication networking of distribution can provide enhanced line voltage monitoring (e.g., on-demand and scheduled voltage level reports, remote control of voltage level settings, and event-based reporting of regulator problems).

\section{SCADA Communications Network (SCADA):}

Supervisory Control and Data Acquisition generally refers to a system that collects data from various sensors at a factory, plant or in other remote locations and then sends this data to a central computer that then manages and controls the data.

\section{Sensing and Measuring Technologies:}

Sensing and measurement technologies enhance power system measurements and information to evaluate the health of equipment, support advanced protective relaying, enable consumer choice and help relieve congestion. Examples include: Smart meters, Ubiquitous system operating parameters, Asset condition monitors, Wide-area 
monitoring systems (WAMS), Advanced system protection, and Dynamic rating of transmission lines.

\section{Smart Grid Maturity Model:}

That model is actually a framework that is designed to help a utility self-assess its current smart grid status, prioritize its smart grid related actions, measure its smart grid progress, and assist in linking smart grid to other of the utility's planning efforts. San Diego Gas \& Electric (S, D, and G\&E) is one utility that has used this tool as part of its work developing its Smart Grid Plan which was recently submitted to the California Public Utilities Commission (CPUC).

\section{Software Applications:}

Software applications cover the programs, algorithms, calculations, data analysis, and other software that provides additional capabilities to distribution and transmission automation. These software applications can be in electronic equipment, in control center systems, in laptops, in handhelds, or in any other computer-based system.

\section{Substation Automation:}

This involves a suite of hardware and software applications. For example, some of the technologies/functions involved include automatic supervision of interlocks, local and global alarms, detection fault location - useful for distribution systems, disturbance diagnostics, automation with supervisory and advisory control, complex logic for device protection and coordination, automatic generation of switching sequences, enterprise- 
wide view of system via intelligent one-line diagram, etc. Applications and data of interest may include remote access to IED/relay configuration ports, waveforms, event data, diagnostic information, video for security or equipment-status assessment, metering, switching, volt/VAR management, and others for maintaining uninterrupted power services to the end users

\section{Substation Transformer Monitors:}

Number of substation transformers with monitoring devices that measure station transformer loading, operating temperature, oil condition, or parameters that affect capability.

\section{Synchrophasors:}

Equipment that measures conditions on power lines - like power flows, voltage and some more exotic characteristics of electricity, like frequency and phase angle - and reports the information back to a computer at a grid control center.

\section{Transmission Line Monitors:}

Number of monitoring devices that can measure transmission line loading, operating temperature, ground clearance, or other parameters that would affect capability.

\section{Web-based information portals:}

A web-based site through which a customer is able to access information, such as, their own consumption and the price(s) they face. 


\section{APPENDIX C: Human Subjects Waiver Request}

I. Project Title and Prospectus

The title of this project is titled: "Technology Planning for Emerging Business Model, Policy and Regulatory Integration - The Case of Smart Electric Vehicle Charging in Regional Utilities Systems.” The basic research question guiding this research is: How can an integrated planning process be created to address technology development, emerging business models, policy, and regulatory issues for smart electric vehicle charging systems to meet the needs of the regional utility systems in the Pacific Northwest. Methods used will include literature review and expert judgment to perform an initial assessment of the technology, analysis of the industry, and develop the business concept to be explored. Technology roadmapping and prioritization procedures will then be used to map out the key goals for this industry and critical paths needed to accomplish them.

\section{Exemption Claim for Waiver of Review}

I am requesting a waiver of review per exemption two. I will be interviewing people who have experience in the fields of smart grid, energy policy, technology entrepreneurship, and technology development throughout the course of this proposal. Even though their identities may become public knowledge if the article is published in a journal, they will not be put at risk as defined in 2(2). As a Ph.D. student in Engineering \& Technology Management 
Department with an adequate background in this topic, I would not initiate questions to get inappropriate information. I will not put the careers of others or myself in jeopardy at risk by asking questions pertaining to classified information. Therefore, I request a waiver of review.

\section{Subject Recruitment}

I will collect the data from an expert panel of about $12-16$ people which will be identified according to their expertise in the fields of smart grid, energy policy, and technology entrepreneurship. Those people should have managers or senior analysts with at least 5 years of experience in their fields. Ages will vary from about 25-65. The expert panel will include both female and male experts and all ethnicities. The criteria for recruitment are wide open and not limited to complicated requirements. Those who do not have experience in areas related to this study will not be included in the expert panel.

IV. Informed Consent

I will only be contacting "adult" subjects. I will be the only person approaching participants for their voluntarily participation. The following consent form and privacy act release form will be used with all of the subjects (see Appendix) to obtain their consent. If the subject is contacted via telephone or email, then the consent form will be faxed or mailed to them ahead of the data gathering process.

\section{First Person Scenario}


I received a notification from Kelly, who described a new research study entitled: Technology Planning for Emerging Business and Regulatory Integration

- The Case of Smart Electric Vehicle Charging in Regional Utilities Systems. After I heard the explanation about what Kelly wanted from me, I agreed to provide the initial data he requested over email or web-based judgment quantification and to schedule a time when I could meet to participate in a technology roadmapping workshop at Portland State University or any other place that works for us. Kelly will fax the consent form to me before sending the instrument. Kelly said that he will contact me if he needs more information to support the research. We can discuss any unresolved questions over the phone or meet face to face.

\section{Potential Risks and Safeguards}

While participating in this study, the respondents may not want to reveal some potential experiences because it is embarrassing to them or they are uncomfortable revealing certain information on-the-record. If they say something inadvertently regarding experiences of this type, I will be cognizant of its potential to embarrass them and make sure to verify with them if they want that particular piece of information included in the research or if they wish it to be an off-the-record comment. Following each data gathering cycle, I will summarize the information gathered and e-mail it to the respondent to verify the accuracy and intent of the comments to avoid further problems. It is also possible that participants will encounter experts of different viewpoints. Possible risks, 
discomforts, and inconveniences include the fact that disagreements may occur and some people may feel uncomfortable expressing these disagreements. Some participants may also experience discomfort if certain participants tend to dominate conversations and make it difficult for everyone to express their views. To safeguard against these discomforts, the researcher will act as a moderator for the group workshop. The research is experienced in many similar types of group processes and interactions. Therefore, the researcher will use this experience to facilitate conversations that encourage all participants to express their views and ensure that the interactions are as comfortable and respectful as possible. Participants may not receive any direct benefit from taking part in this study, but the study may help to increase knowledge which may help others in the future.

\section{Potential Benefits}

Subjects will not receive any direct benefit. This project seeks to illicit the subjects' opinions on how to enhance the finding of this paper and research and to potentially codify these opinions within the proposed framework. Therefore, subjects can take pride in realizing that their opinions might be utilized to improve the quality of this research.

\section{Records and Distributions}

Subjects will not be confidential or anonymous. Information provided by the subjects will be kept on my personal laptop computer to which only I will have the access. However, the name of the interviewee will not be exposed in the paper unless it is necessary. 
IX. Attachments

(A) Sample Data Gathering Instrument

(B) Consent Form

(C) Privacy Act Release Form 
APPENDIX C1: Human Subjects Waiver Request - Sample Instruments

\section{$\underline{\text { Human Subjects (Attachment A) - Sample Data Gathering Instruments }}$}

Part I - Example of Business Concept Development

1. Stakeholder-Objective Matrix

Stakeholder (S) /

Customer (C) / Provider

What they Support

What they Resist

(P) 


\section{Business Sub Model Matrix}

\begin{tabular}{|l|l|}
\hline \multicolumn{1}{|c|}{ Sub Model } & Sub Model Features \\
\hline Who? & Structure of Market? \\
Stakeholders? & Target Customers? \\
What do they support? & \\
What do they oppose? & \\
Customers? & \\
\hline Markets? & \\
Segments? & \\
\hline What? & Products? \\
\hline Value Proposition? & Customer Utilities? \\
What do stakeholders have now? & Competitiveness? \\
\hline What do stakeholders want? & \\
\hline How? & Profit Model? \\
Value Delivery? & Ownership Structure? \\
\hline Profit \& Revenues? & Manufacturing? \\
\hline Segments? & Distribution Channel? \\
\hline & \\
\hline & \\
\hline
\end{tabular}


B. Business Model Development Summary: What is the basic opportunity and why is it valuable? (IRP, Policy Analysis, ISRM)

Value Proposition

A. Ask: What? Products?

Capabilities?

Competitive Advantage?

B. Ask: Where?

C. Ask: Why? Why is this important? (See Perspectives in next section for more detail)

4. Perspectives Overview: Priority Issues in next 1 to 10 years (Based on S-Plan elements)

\begin{tabular}{|c|c|c|c|}
\hline A. Technical Capabilities & B. Policy Goals & C. Reguktory & D. Market \\
\hline $1 \mathrm{Yeay}$ & 1 Iogus. & 1 Yeay & $1 \mathrm{Feay}$ \\
\hline $2-4$ Years & $2-4$ Years & $2-4$ Years & $2-4$ Years \\
\hline 5.10 Years & 5-10 Years & 5-10 Years & 5-10 Years \\
\hline
\end{tabular}


5. Business Model Development Overview
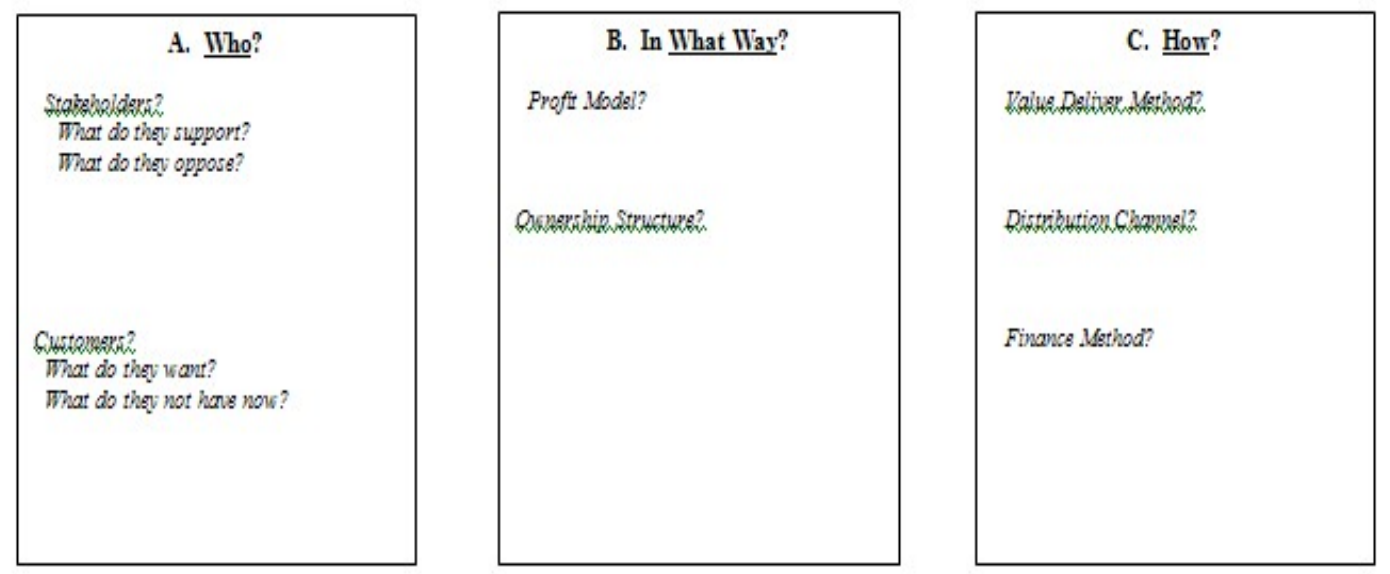

6. Synthesis: By answering the above questions, it should be possible to determine (at least tentatively):

- What is the "as is" situation or opportunity to be explored?

- What is the "to be" vision?

- What are the business goals over time (i.e. $10 \mathrm{X}$ growth in 10 years...)

- What are the key gap areas or needs?

\section{Part II - Example of Industry Analysis}

1. Identification of viable business concept: Opportunity finding is particularly important in regulated industries, like utilities, where new option may become available due to evolving of regulation, policy, and technological capabilities (5 Forces).

Porter's Five Forces is a well-known tool for industry analysis. In regulated industries, barriers are particularly important to consider and the modified version of this tool that is used here emphasizes this need.

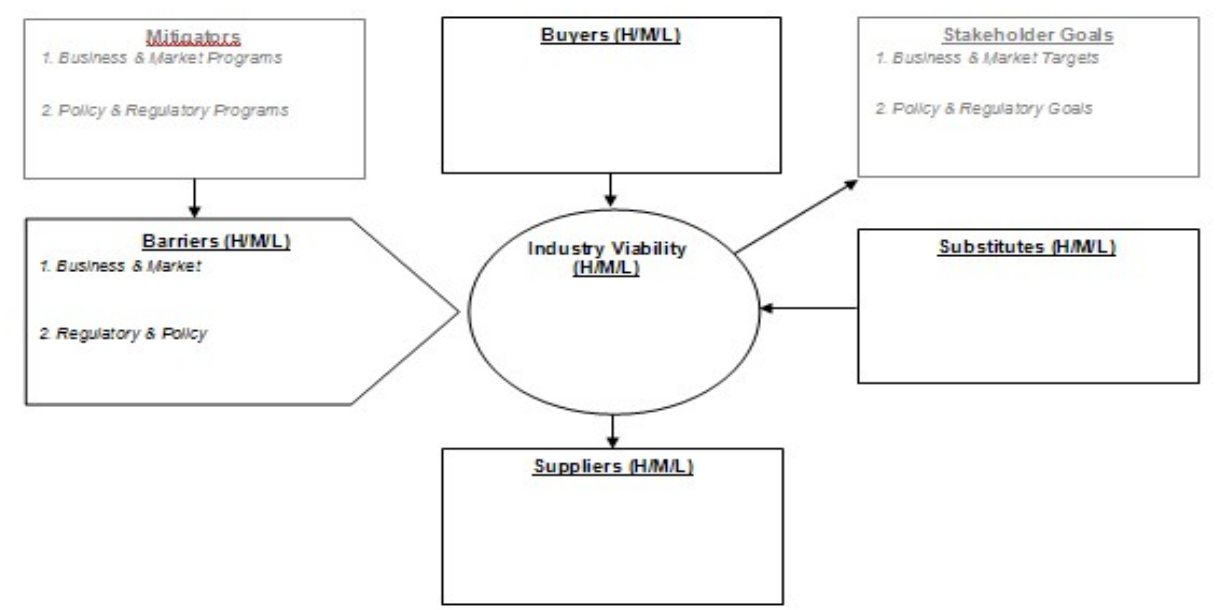


2. Business to Stakeholder Alternatives Matrix: The following matrix is a tool to determine the type of business to customer relationship that is envisioned.

\begin{tabular}{|l|l|l|l|}
\hline & & B to B & B to G \\
\hline Susiness \\
Stakeholder & & & \\
\hline Product/Services & & & \\
\hline Operations System & & & \\
\hline Profit Model & & & \\
\hline Growth Model & & & \\
\hline
\end{tabular}

3. Industry Factor Alternatives: This tool is used to examine the effect of the potential factors that may impact an industry with respect to various dimensions of competition and overall industry viability.

\begin{tabular}{|c|c|c|c|c|}
\hline & & 2015 & 2020 & 2025 \\
\hline \multirow[t]{2}{*}{ Regulatory/Policy } & $\begin{array}{l}\text { New Policy / } \\
\text { Existing Regulatory } \\
\text { Structure }\end{array}$ & & & \\
\hline & $\begin{array}{l}\text { New Regulatory } \\
\text { Structure / } \\
\text { Existing Policy }\end{array}$ & & & \\
\hline \multirow[t]{2}{*}{ Market / Product } & $\begin{array}{l}\text { New Product / } \\
\text { Existing Market }\end{array}$ & & & \\
\hline & \begin{tabular}{|l} 
New Market / \\
Existing Product
\end{tabular} & & & \\
\hline \multirow[t]{2}{*}{ Technology / Function } & Technological Factor & & & \\
\hline & Functional Factor & & & \\
\hline
\end{tabular}


4. Static and Dynamic Business Models: This tool is used to examine core business areas and which, if any, have the potential to grow or shrink given current conditions and practices, or which areas have the potential to sustain long-term growth.

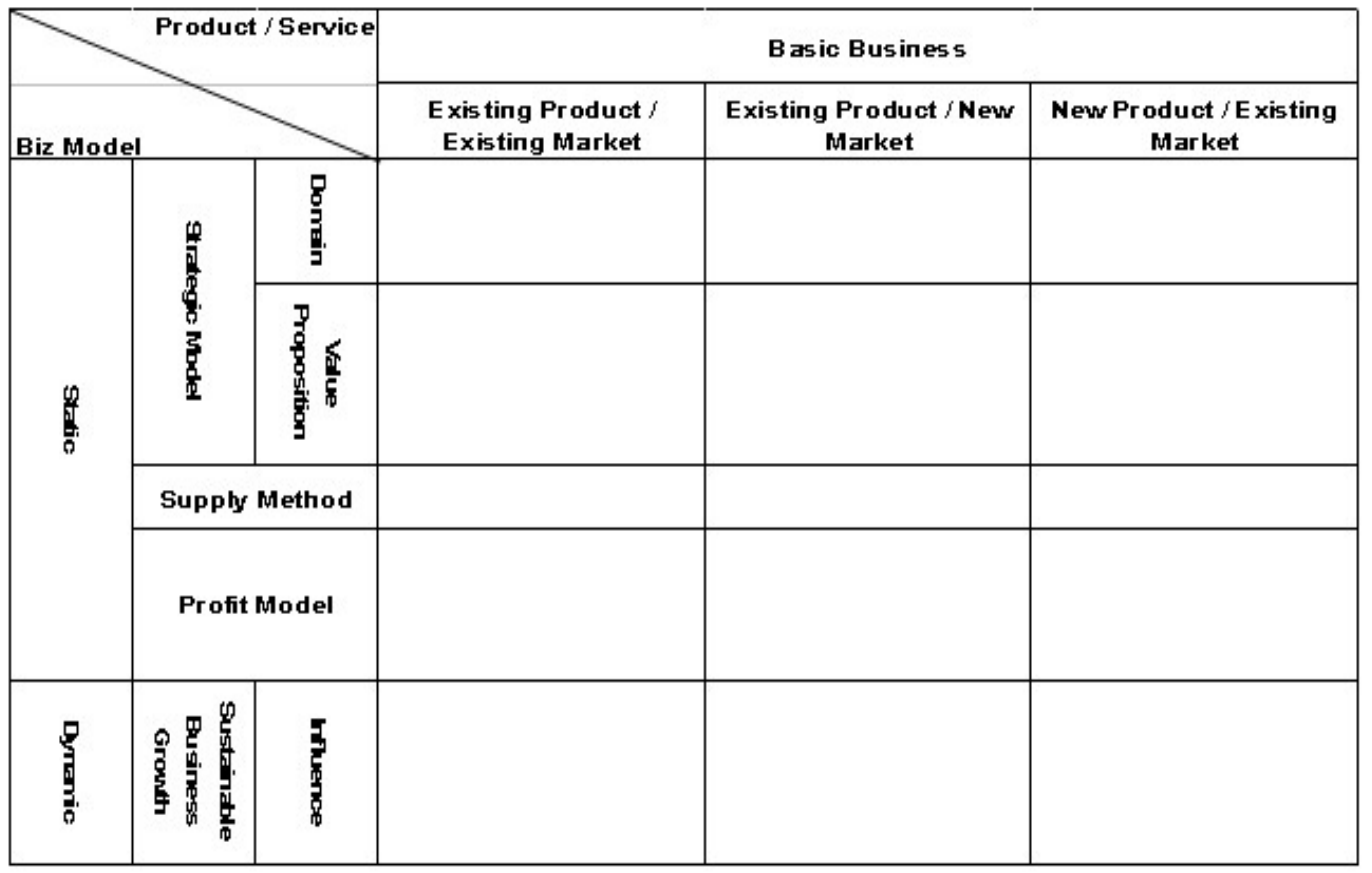


Part III - Example of Technology Roadmap Construction \& Prioritization

\section{Grouped Drivers}

\section{A. Market and Business}

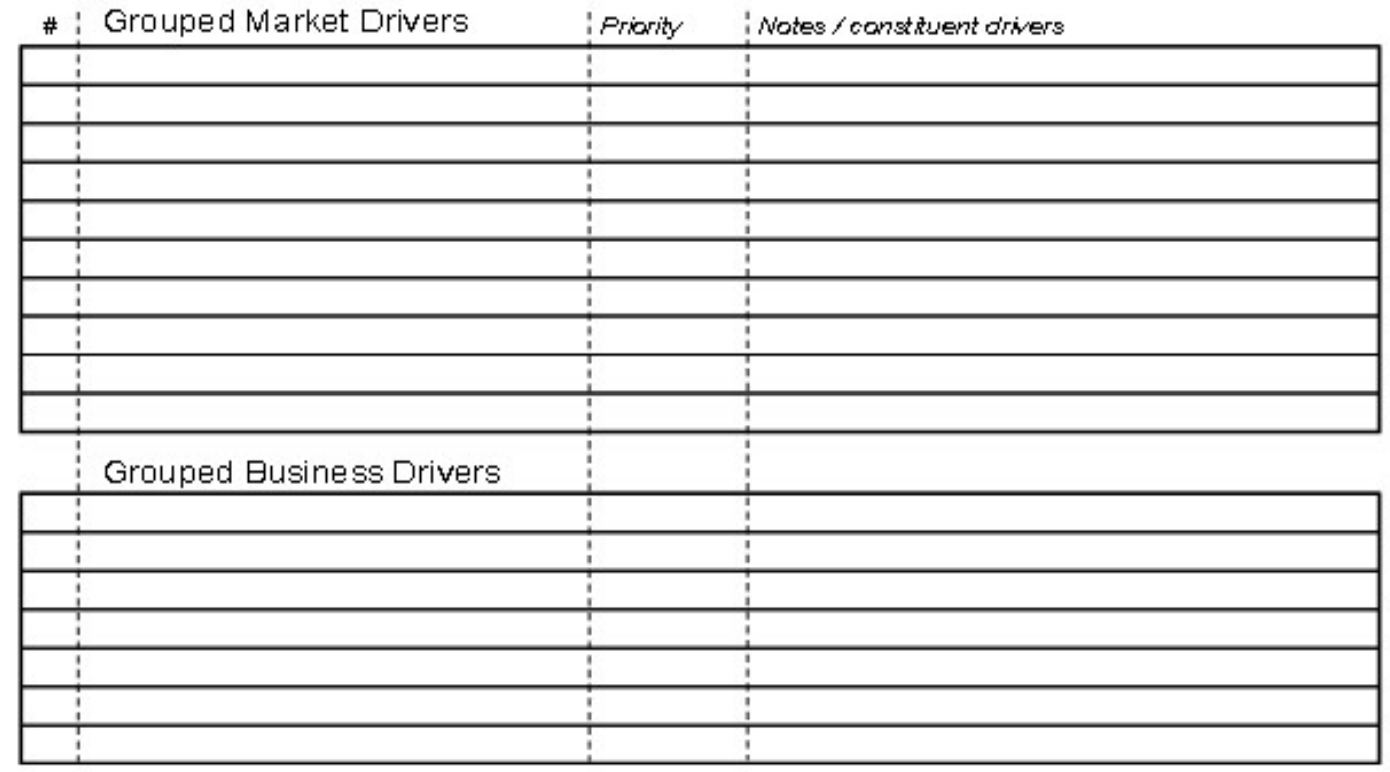

\section{B. Policy and Regulatory Drivers}

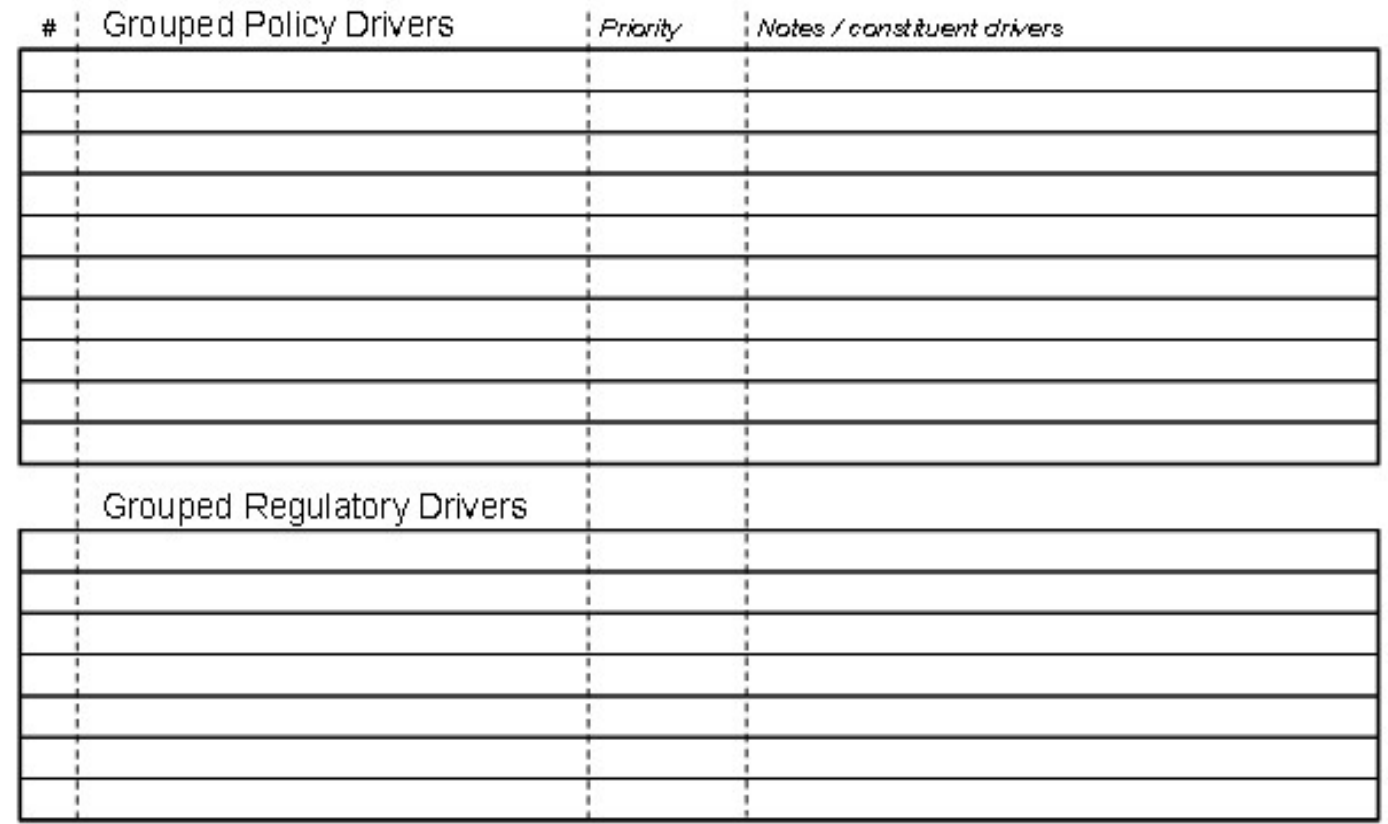




\section{Market-Product Grid}

Column Priority: $\quad 1-10,1-10,1-10,1-10,1-10,1-10,1-10,1-10,1-10,1-10,1-10,1-10$

Business, Market, Regulatory \& Policy Drivers

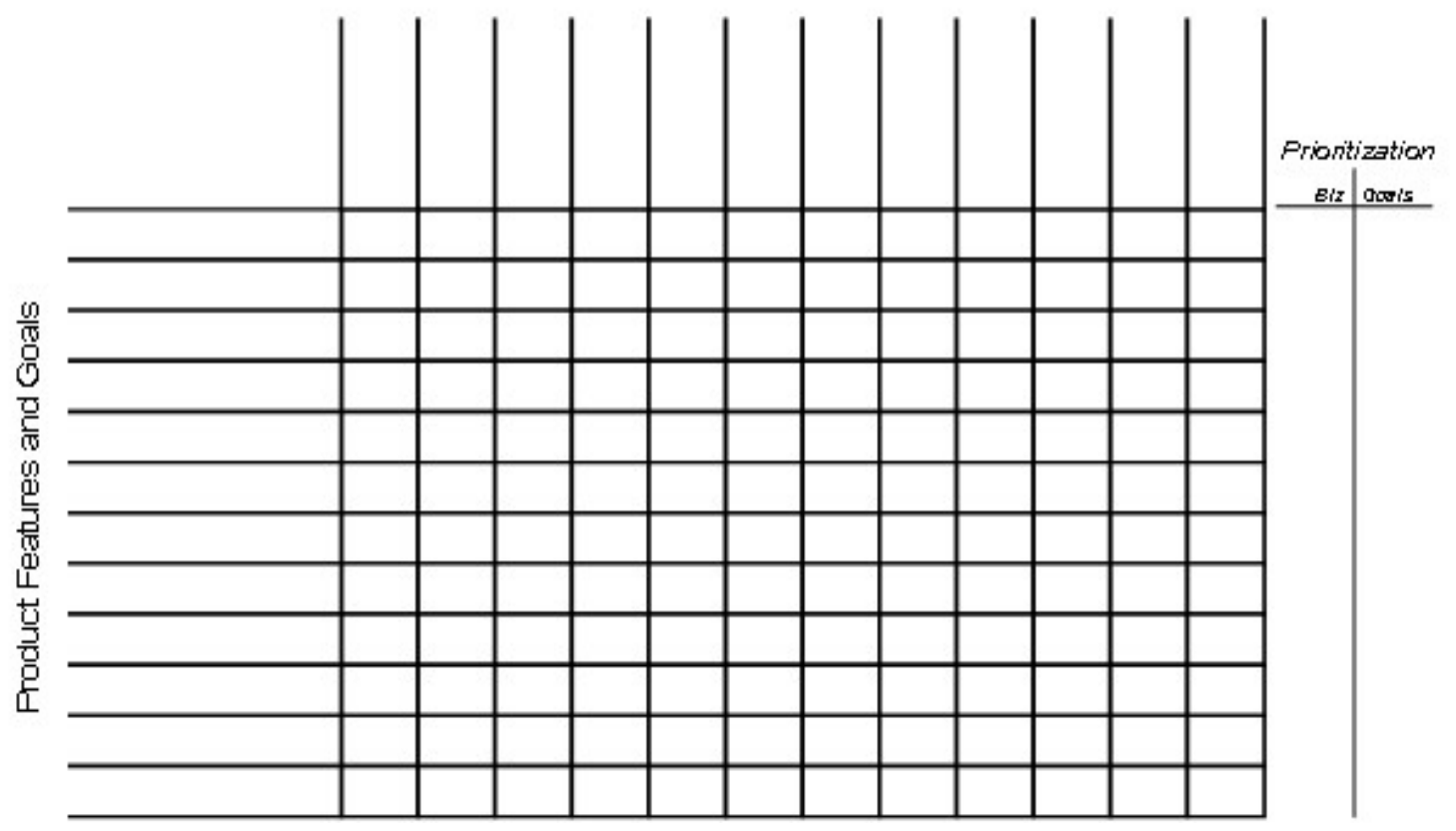


3. Product-Technology Grid

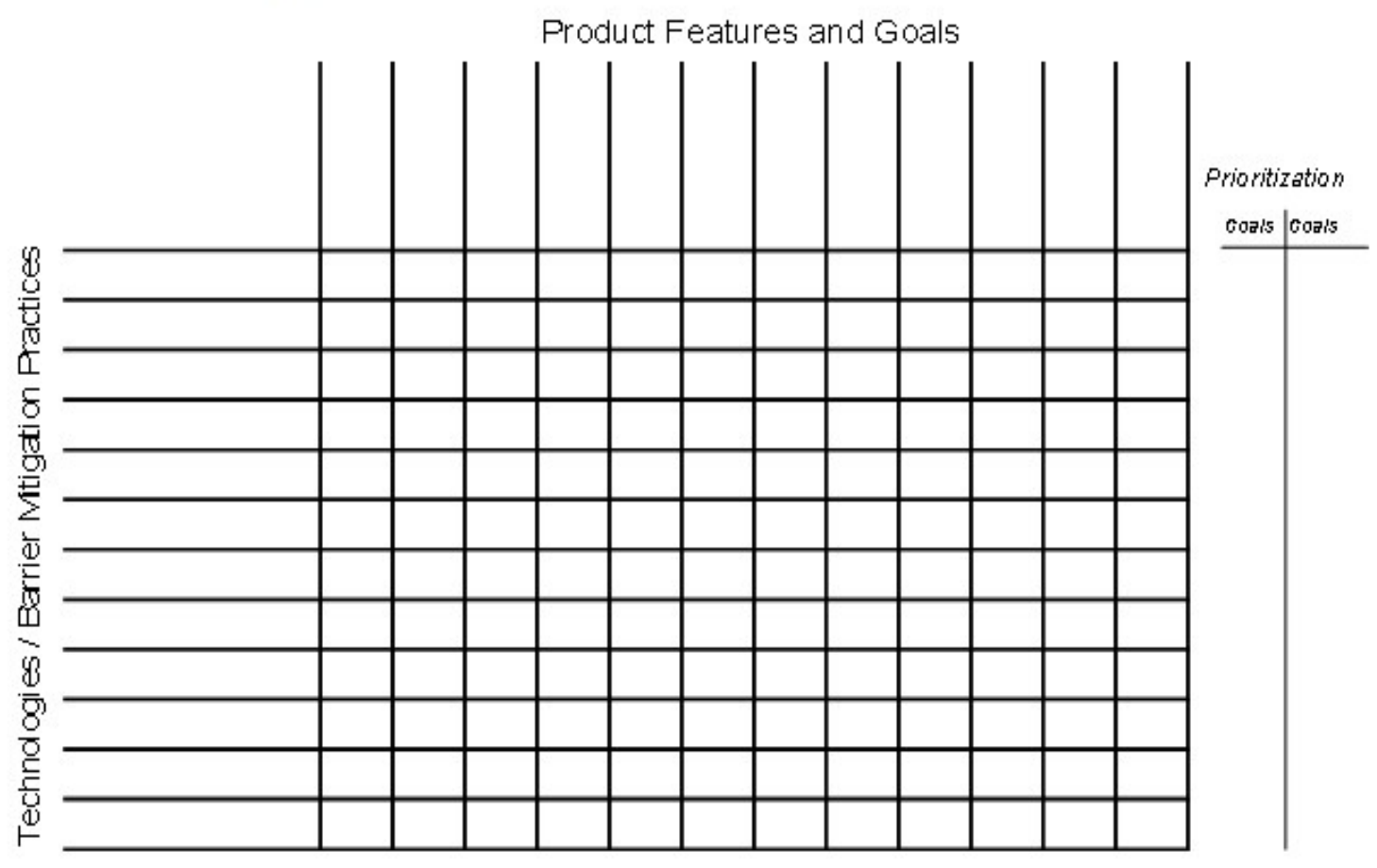

4. Technology-Barrier Grid

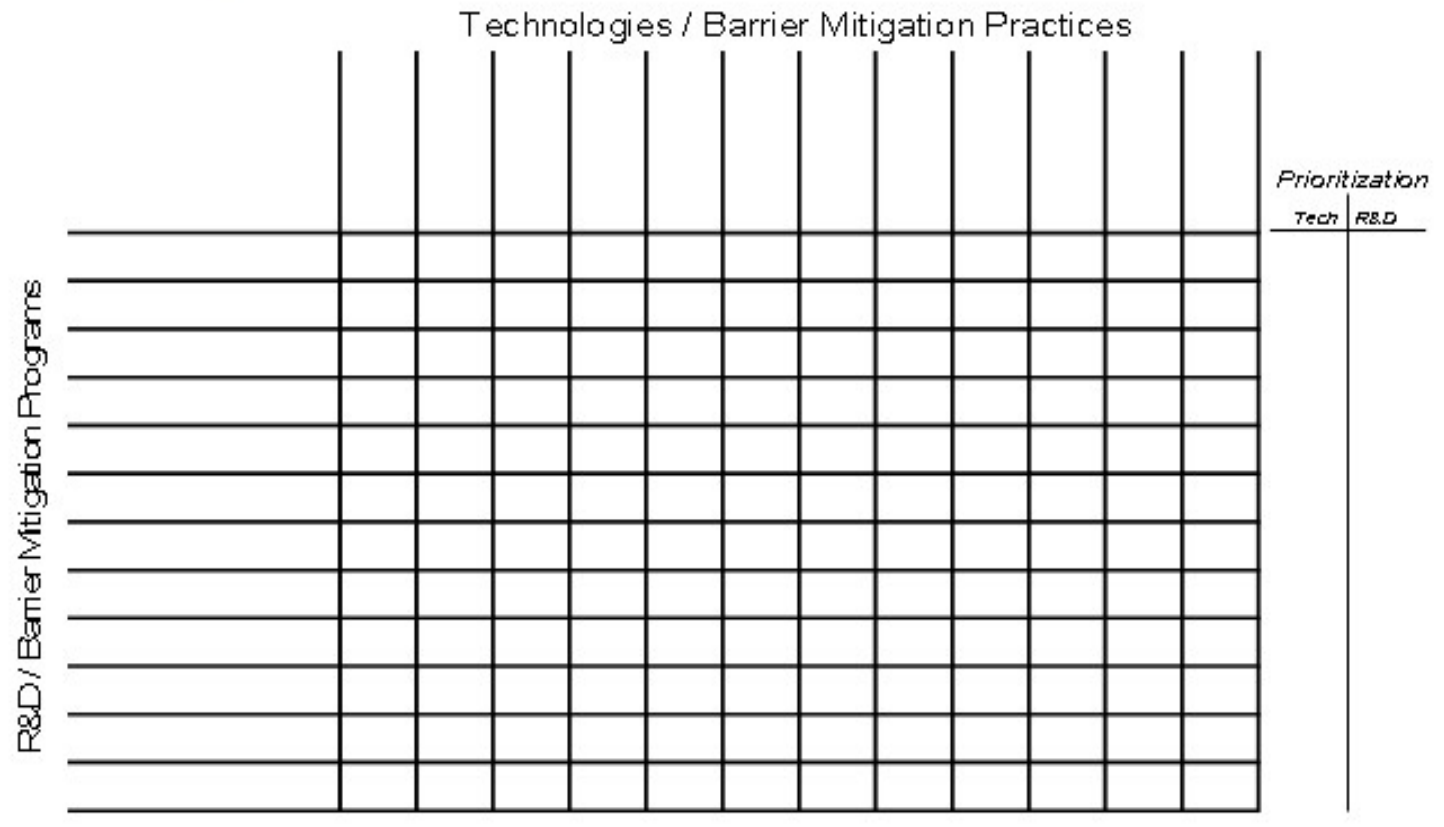


5. Technology Roadmap Layout

\section{Sample Regional Model: EVSC}
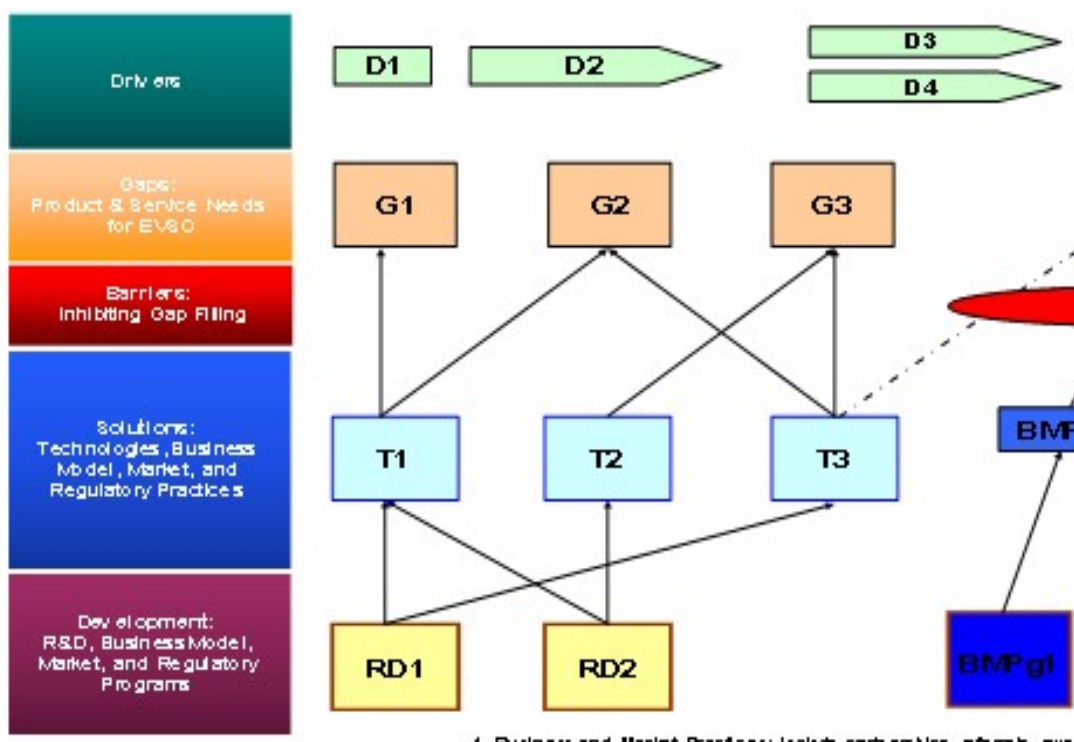

D5

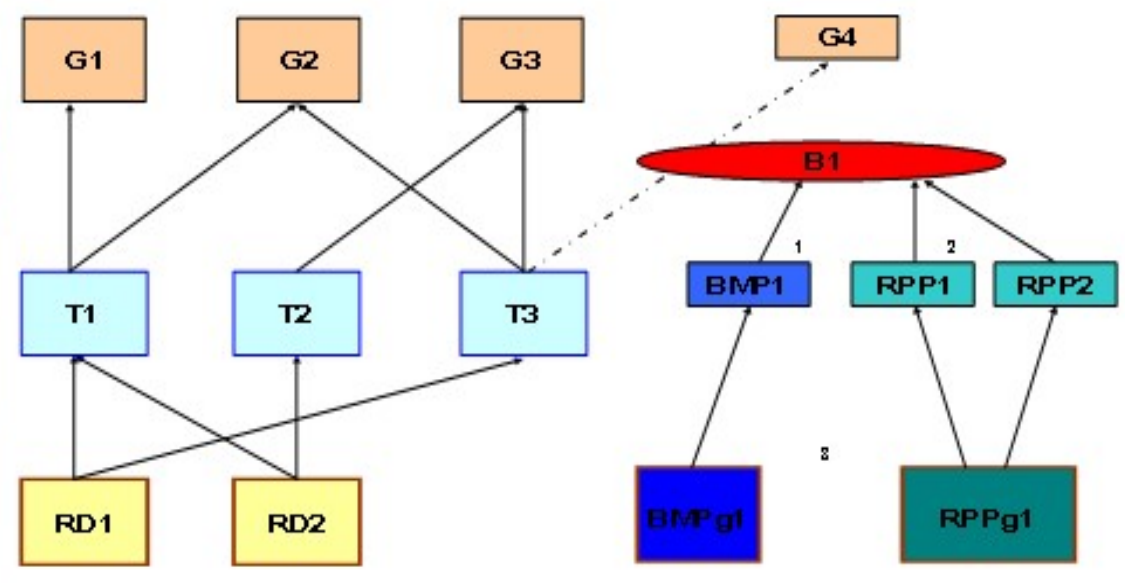

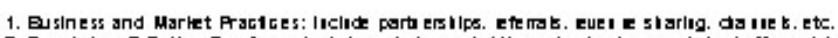

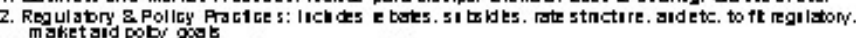

3. Program s a $E$ colediols of o ie or more polteles.

\section{Part IV. Example of Outcome Analysis}

1. Deliverables: Prioritized requirements to meet desired outcomes

2. Paths and Dependencies: Action steps over time with prioritized requirements 


\title{
APPENDIX C2: Human Subjects Waiver Request - Consent Form
}

\author{
$\underline{\text { Human Subjects (Attachment B) - Consent Form }}$
}

\section{Technology Planning for Aligning Emerging Business Models and Regulatory Structures - The Case of Electric Vehicle Charging and the Smart Grid}

You are invited to participate in a research study conducted by Kelly Cowan from Portland State University, Engineering and Technology Management Department. The researcher hopes to learn how an integrated planning process be created to address technology development, emerging business models, policy, and regulatory issues for smart electric vehicle charging systems to meet the needs of the regional utility systems in the Pacific Northwest. This project is being conducted in partial fulfillment for the requirements of a Ph.D. degree under supervision by Dr. Tugrul Daim. You were selected as a possible participant because you have experience in one or more of the fields that the researcher is examining for the study.

If you decide to participate, you will be asked to provide information about your knowledge of smart grid, energy policy, technology entrepreneurship, and technology development.. You may not receive any direct benefit from taking part in this study, but the study may help to increase knowledge that may help others in the future.

Your name and responses will not be confidential and may be included in a published journal article. Your participation is voluntary. You do not have to take part in this study and it will not affect anything in your career or life. You may also withdraw from this study at any time without affecting your career or life. 
If you have concerns or problems about your participation in this study or your rights as a research subject, please contact the Human Subjects Research Review committee, Office of Research Strategic Partnerships, 1600 SW Fourth Avenue, Suite 620, Portland, OR, 97201, (503) 725 3423. If you have any questions about the study itself, contact Kelly at 105 SW Curry Street, Portland, OR, 97239, (971) 2120936.

Your signature indicates that you have read and understand the above information and agree to take part in this study. Please understand that you may withdraw your consent at any time without penalty, and that by signing, you are not waiving any legal claims, rights or remedies. The researcher will provide you with a copy of this form for your records.

Signature:

Date: 


\title{
APPENDIX C3: Human Subjects Waiver Request - Release Form
}

\section{$\underline{\text { Human Subjects (Attachment C) - Privacy Act Release Form }}$}

\author{
Portland State University \\ Department of Engineering \& Technology Management
}

\section{Privacy Act Release Form}

I have been invited to participate in a research study conducted by Kelly Cowan, who is currently a student at Portland State University. I have been made aware that the research study will involve questions that I will be asked to answer. I understand that participation in the research study is voluntary and that if I choose to participate, my responses may be published as part of the final report. I also understand that my name may also be published. Therefore, I authorize Kelly Cowan to disclose my name and any responses I provide in responding to his questions. I understand that authorizing the disclosure of this personal information is voluntary and that $\mathrm{I}$ can revoke this authorization by providing written notice of the same to Kelly Cowan. I further understand that any disclosure or publication of this information carries with it the potential for an unauthorized further disclosure of this information by third parties and that such further disclosure may not be protected under applicable laws.

Signature:

Printed Name:

Date: 


\title{
APPENDIX D: Research Approach
}

Technology Planning for Aligning Emerging Business Models and Regulatory Structures - The Case of Electric Vehicle Charging and the Smart Grid

\author{
Kelly Cowan
}

\section{Dissertation Committee}

\author{
Tugrul U. Daim (Chair) \\ Jisun Kim \\ Steven Walsh \\ Alan Yeakley (Graduate Representative) \\ Department of Engineering \& Technology Management \\ Maseeh College of Engineering and Computer Science \\ 蛋 Portland $\underset{\text { UNIVERSITY }}{\text { State }}$
}




\section{APPENDIX D1: Research Approach - Summary RESEARCH APPROACH (PART 1): \\ D1. Summary of Research Approach}

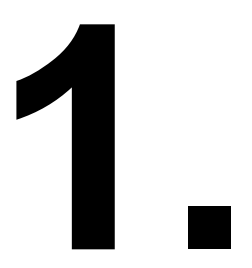

1. SUMMARY OF APPROACH (PART 1)

2. COVER LETTER (PART 2)

3. WORKSHOP REQUIREMENTS (PART 3) 


\section{D1. Summary of Research Approach}

The phases of this research process are summarized below. The Research Schema in the next section provides additional details about what each of the research phases entails. Prior to beginning formal data collection, each instrument will be pre-tested by an informal advisory group, as mentioned in the Phase 0 agenda for pre-testing. Then, pre-selected experts will be sent a cover letter and consent form to secure their participation in the study.

The experts may be asked to participate in up to three workshops, which will have a duration of approximately 2 hours for the first two workshops and about 4 hours for the final workshop. The first two workshops will be online forums with 6 to 9 experts in business, technology, or policy aspects of the field. All data collection forms will be emailed to experts ahead of time and the time in the workshop time will be spent clarifying the results of the responses and determining if consensus can be achieved regarding these results. The third workshop is expected to be an in-person forum involving experts from both of the previous workshops. Depending on expert background and willingness to participate they may be asked to attend one or both of the first two workshops, as well as the third. Workshop participants will include Utility Industry Executives, Policy Analysts, Electric Vehicle Technology Experts, Business Owners and Managers in the Electric Vehicle and Vehicle Charging industries, and experts in the emerging field of Vehicle-to-Grid. The workshops will focus on the following 
topics: (1) Business Concept Development, including future technology and business model development; (2) Industry Analysis, including regulatory, policy, and business development; and (3) Technology Roadmap Development, including prioritization and desirability rating of objectives and barriers.

When the first three workshops are completed, the results will be analyzed and tested for validity and consistency. This analysis will then be used to synthesize final results, such as the prioritized requirements needed to overcome key barriers and meet the outcomes that experts consider most desirable. A prioritized set of action steps needed over time to achieve these results will be discussed and final conclusions will be made regarding the current research and any next steps. 


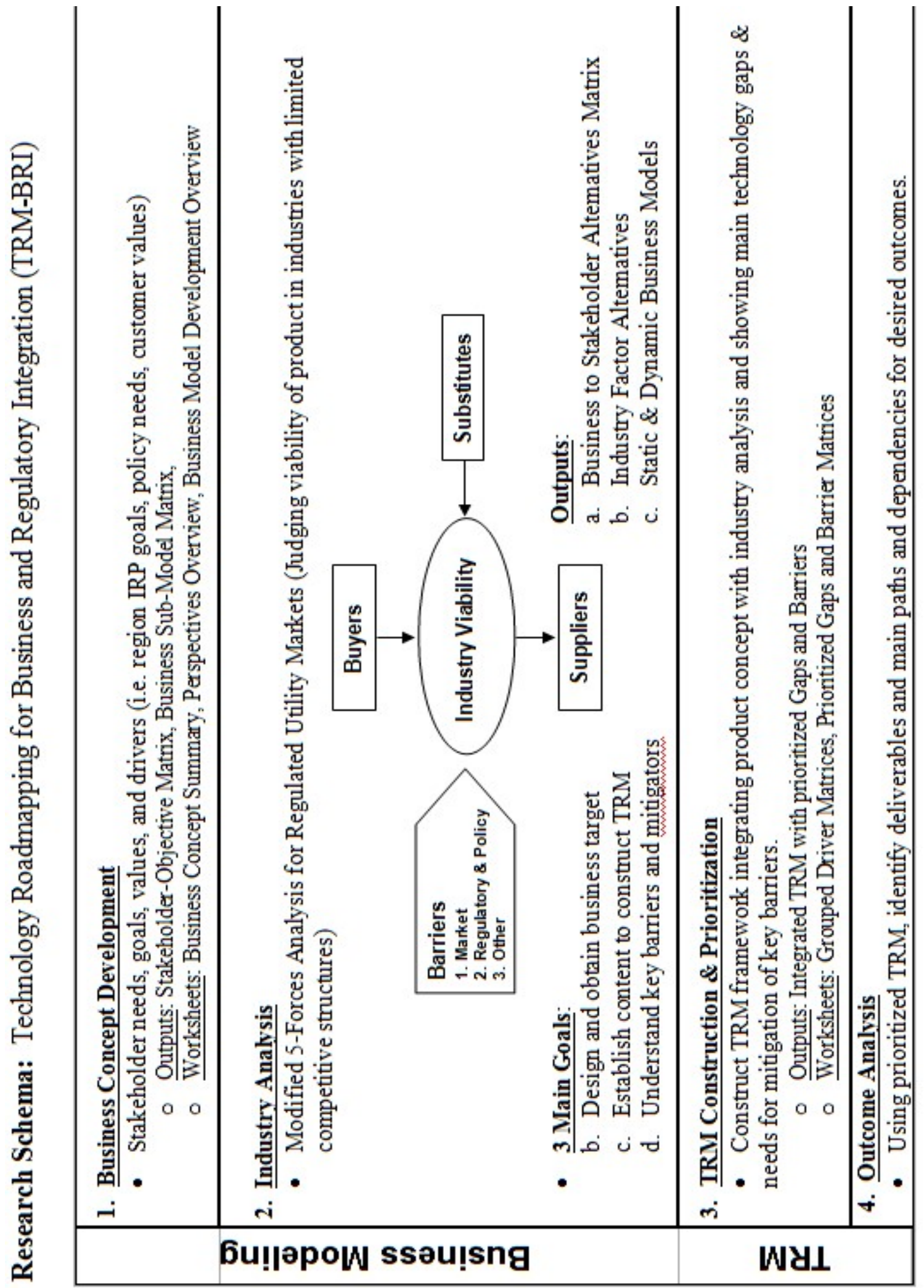




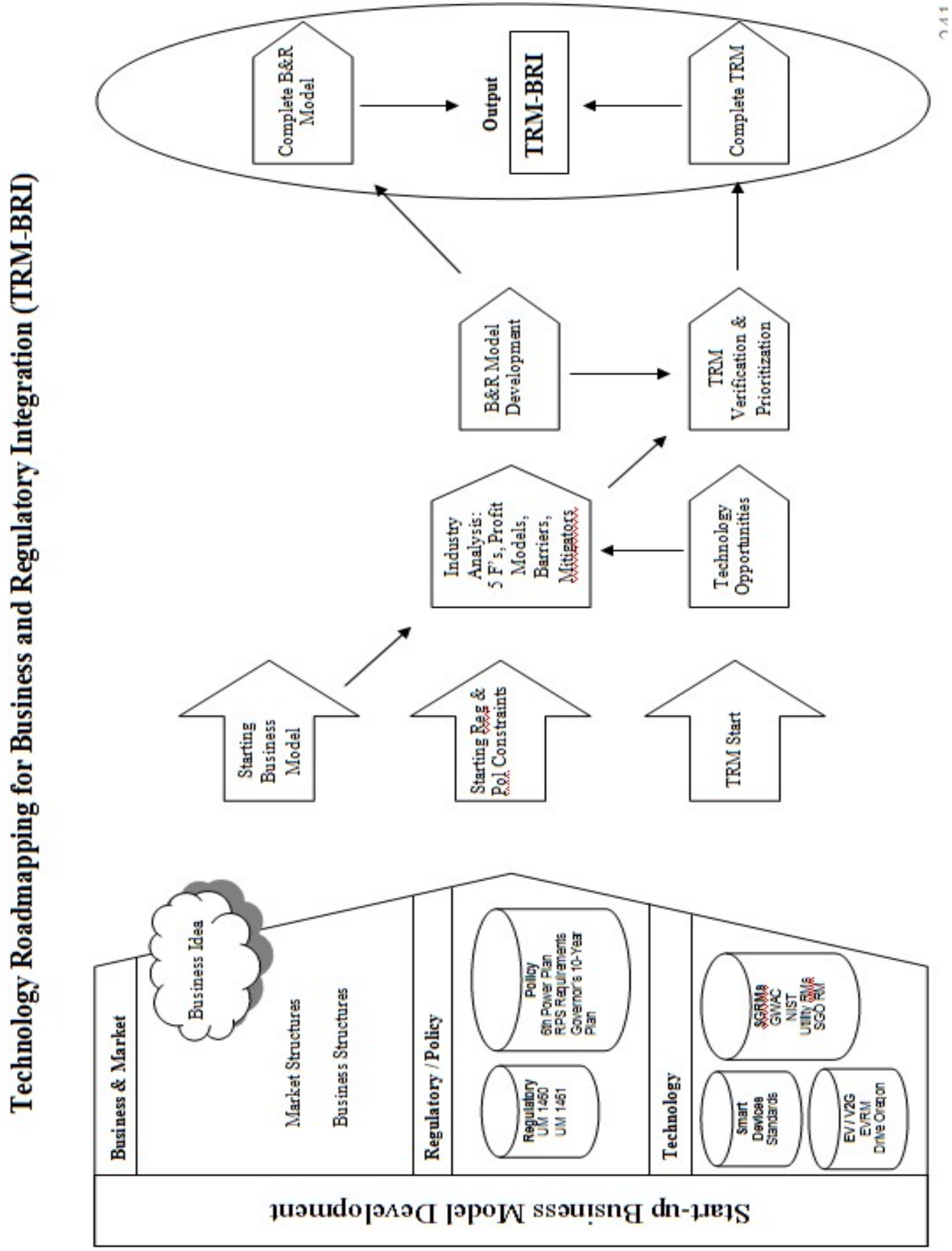


APPENDIX D2: Research Approach - Cover Letter

RESEARCH APPROACH (PART 2):

D2. Cover Letter

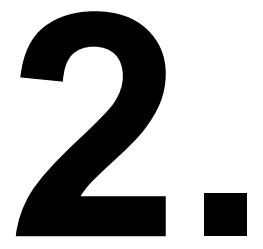




\section{D2. Cover Letter}

\section{Technology Planning for Aligning Emerging Business Models and Regulatory Structures: The Case of Smart Electric Vehicle Charging and Smart Grid}

Dear Industry, Technology, or Policy Expert,

My name is Kelly Cowan, and I am a Ph.D. Candidate in the Department of Engineering and Technology Management at Portland State University. I am beginning a study to develop a regional technology roadmap on the smart grid sector. I am looking specifically at the case of electric vehicle charging and the effects on regional utility systems. The study will consider how technology development needs can be integrated with emerging business models, as well as policy and regulatory considerations. I would like to invite you to participate. You are being asked to take part because you are considered an expert in one or more of the areas mentioned above and your professional experience and feedback will help to better understand the evolving smart grid sector. This study is being conducted in partial fulfillment of the requirements for a doctoral degree in Technology Management, under the supervision of Dr. Tugrul Daim, Associate Professor, Engineering and Technology Management Department, Portland State University .

As part of the study, I am interested in your expert judgment in order to create plausible roadmaps for the development of the electric vehicle charging industry in the Pacific Northwest. You may be asked to identify, prioritize, and 
rate the desirability of regional objectives, business objectives and barriers in the proposed technology roadmap, as well as to provide suggestions for future action items. I hope that your expert judgment will help us to better understand the potential for electric vehicle charging systems in the region.

If you decide to participate, you will be asked to take part in up to 3 workshops, for a duration of approximately 2 hours each. The first two workshops will be online forums with 6 to 9 experts in business, technology, or policy aspects of the field. All data collection forms will be emailed to you ahead of time and the time in the workshop time will be spent clarifying the results of the responses and determining if consensus can be achieved regarding these results. The third workshop is expected to be an in-person forum involving experts from both of the previous workshops. Depending on your background and willingness to participate you may be asked to attend one or both of the first two workshops, as well as the third. Workshop participants will include Utility Industry Executives, Policy Analysts, Electric Vehicle Technology Experts, Business Owners and Managers in the Electric Vehicle and Vehicle Charging industries, and experts in the emerging field of Vehicleto-Grid. The workshops will focus on the following topics: (1) Business Concept Development, including future technology and business model development; (2) Industry Analysis, including regulatory, policy, and business development; and (3) Technology Roadmap Development, including prioritization and desirability rating of objectives and barriers. There will a follow-up surveys 
after the workshops and questionnaire will take approximately 10-15 minutes to complete.

Risks are minimal for involvement in this study. The research instrument has been approved by a rigorous and federally compliant Internal Review Board (IRB) at Portland State University. No personally identifiable data, and will be reported unless permission is given.

There are two benefits for participating in the study. At the conclusion of the research, a copy of the report will be provided to you at no cost. And most importantly, it is hoped that through your participation as an expert, policy makers, researchers and industry professionals will learn more about the factors leading successful development of the electric vehicle charging industry in the region.

All data obtained from participants will be kept confidential and will only be reported in the aggregate format (by reporting only combined results and never reporting individual ones). All questionnaires will be concealed, and no one other than then primary investigator and assistant researchers will have access to them. Any information that is obtained in connection with this study and that can be linked to you or identify you will be kept confidential. After completion of this research, this information will be deleted by the primary investigator. 
Participation in this research study is completely voluntary. You have the right to withdraw at any time or refuse to participate entirely and it will not affect your relationship with the investigator or Portland State University.

If you have questions regarding this study, you may contact Kelly Cowan, at 971-212-0936, kcowan@pdx.edu. If you have concerns or problems about your participation in this study or your rights as a research subject, please contact the Human Subjects Research Review Committee, Research and Strategic Partnerships, Market Center Building, 6th Floor, 1600 SW 4th Ave, Portland, OR 97201, (503) 725-4288 / 1-877-480-4400.

Sincerely,

Kelly

Cowan

Ph.D.

Candidate

Department of Engineering \& Technology

Management Portland State University 
APPENDIX D3: Research Approach - Workshop Requirements List RESEARCH APPROACH (PART 3):

D3. List of Workshop Requirements

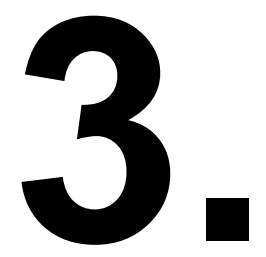




\section{D3. List of Workshop Requirements}

0. (Phase 0: Instrument Pre-Testing)

1. Phase 1: Business Concept Development
a. Stakeholder-Objective Matrix
b. Business Sub-Models
c. Business Summary,
d. Stakeholder Perspectives
e. Business Model Overview

2. Phase 2: Industry Analysis
a. Modified 5-Forces Model
b. Business Stakeholder Alternatives Matrix
c. Industry Factor Alternatives Matrix
d. Static \& Dynamic Business Models

3. Phase 3: Roadmap Construction \& Prioritization
a. Grouped Drivers
b. Impact Matrices
c. Initial TRM and Prioritization

4. Phase 4: Analysis \& Synthesis
a. Integrated TRM
b. Analysis of Alternatives and Priorities 
APPENDIX D3-0: Research Approach - Workshop Requirements (Pre-Testing) RESEARCH APPROACH (PART 3):

\section{D3-0. Pre-Testing of Instruments}

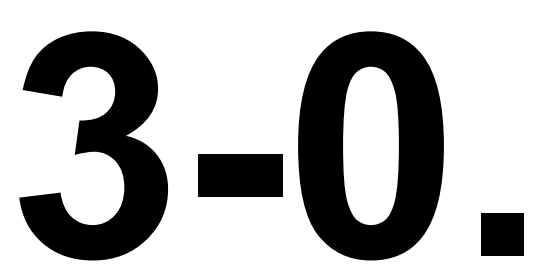




\section{D3-0. Pre-Testing of Instruments}

\section{Portland State \\ University \\ Portland, OR \\ Pre-Testing of Instruments Agenda}

Purpose of Phase 0 Workshop: Pre-Testing of Instruments

- An advisory group of students and/or professionals knowledge about the energy industry will be used to test the data collection instruments that will be used for this study before they are given to the final experts.

- They will examine the instruments that are emailed to them and provide feedback.

- They will be asked to rate the relevance of each question, the ease of answering it, and its importance on a 5 point Likert scale.

- If any clarification is needed, the researcher will meet with advisory group members individually.

\section{Pre-Testing Tool}

- The following pre-testing tool will be used to establish content and construct validity.

\begin{tabular}{|c|c|c|c|}
\hline Intention of Instrument & $\begin{array}{l}\text { Relevance / } \\
\text { Importance }\end{array}$ & \begin{tabular}{|l} 
Ease of \\
Responding \\
to this \\
instrument \\
\end{tabular} & Comments \\
\hline $\begin{array}{l}\text { 1. < Instrument Text or } \\
\text { Summary }>\text { The importance or } \\
\text { relevance of this instrument } \\
\text { is... } \\
<\text { Intention of the Instrument> } \\
\text { This instrument is intended to } \\
\text { get information on... }\end{array}$ & $\begin{array}{l}\text { Rate on a scale } \\
\text { of } 1 \text { to } 5 \text {, with } 5 \\
\text { being high }\end{array}$ & $\begin{array}{l}\text { Rate on a } \\
\text { scale of } 1 \text { to } 5 \text {, } \\
\text { with } 5 \text { being } \\
\text { high }\end{array}$ & \\
\hline
\end{tabular}




\section{D3-0. Pre-Testing of Instruments}

\section{Directions for Expert Input}

Thank you again for contributing your expert judgment to this research.

Please refer to the set of directions below for filling out this data collection form.

Phase 0 of this research involves the pre-testing of data collection instruments.

Prior to beginning formal data collection, each instrument will be pre-tested by an informal advisory group, as mentioned in the Phase 0 agenda for pre-testing. The advisory group will consist of students and professionals who are knowledgeable about the energy industry will be used to test the data collection instruments that will be used for this study before they are given to the final experts. They will examine the instruments that are emailed to them and provide feedback. They will be asked to rate the relevance of each question or collection instrument, the ease of responding to it, and its importance on a 5 point Likert scale. If any clarification is needed, the researcher will meet with advisory group members individually. Then, pre-selected experts will be sent a cover letter and consent form to secure their participation in the study.

\section{Background on Instrument Testing}

For the proposed research, validity will be addressed through a variety of procedures, including, but not limited to the following. An advisory group will be recruited for pre-testing of data collection instruments. The people selected for the advisory group will preferably have experience in the energy sector, or will have knowledge from similar work or research in related areas. The advisory group will be asked to fill out the initial draft data collection instruments and provide feedback to help 
refine it. The goal of this testing process is to ensure relevance, verify logic and flow structure, and eliminate as many ambiguities as possible.

Following a suggestion from Daim's study of the electronics manufacturing sector [1], a data collection instrument test tool will be used to help experts review the data

collection instruments and assess relevance, as well as ease of use in answering questions [2,3]. A 5-point Likert scale will be used to rate relevance and ease of answering question, with a 1 indicating low values and a 5 indicating high values. The overall goal is to verify content and construct validity.

\section{Instrument Testing References}

[1] T. U. Daim, "Technology Evaluation and Acquisition Strategies and Their Implications in the U.S. Electronics Manufacturing Industry," Doctoral, Systems Science: Engineering \& Technology Management, Portland State University, Portland, OR, 1998.

[2] K. R. Murphy and C. O. Davidshofer, Psychological Testing: Principles and Applications: Prentice Hall, 1990.

[3] D. R. Cooper and W. Emory, Business Research Methods. Chicago: Irwin, 1995. 
APPENDIX D3-1: Research Approach - Workshop Requirements (Business Concept Development)

\section{RESEARCH APPROACH (PART 3):}

\section{D3-1. Business Concept Development}

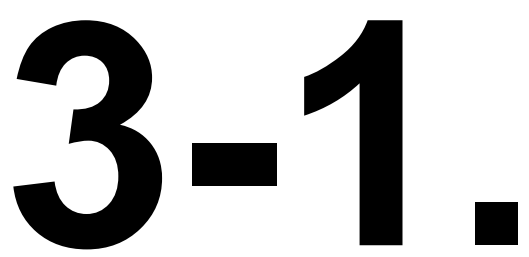




\section{D3-1. Business Concept Development}

\section{Portland State}

University

Portland, OR

\section{Business Concept Development Agenda}

Purpose of Phase 1 Workshop: Developing the Business Concept

- Identify and describe stakeholder needs, goals, values, and drivers (i.e. regional IRP goals, policy needs, customer values, etc.)

- Prior to this online forum, the data entry form for the workshop will be distributed to the participants by email and completed forms will be returned to the investigator.

- The goal of the online forum will be to facilitate consensus regarding the results of provided on the forms.

9:00 AM Introduction and Overview

9:15 AM Discuss use of Business Concept Development and tools and review of initial results

9:30 AM Achieving consensus and use of Delphi rounds

- Completion of first round

10:00 AM Assessment of consensus and need for additional rounds

- Additional Delphi processes as needed

10:45 AM Adjournment and Closing Comments 


\section{D3-1. Business Concept Development}

\section{D3-1a. Stakeholder-Objective Matrix}

\section{Directions for Expert Input}

Thank you again for contributing your expert judgment to this research.

Please refer to the set of directions below for filling out this data collection form.

Part a of the Business Concept Development process is using a tool called a Stakeholder-Objective Matrix [1][2]. This tool has been used in various types of research,to understand the actors affecting the decision making environment. In this research, it is used to better understand the environment in which a particular technology-based industry is developing by better understanding the stakeholders who current exist in areas related to that industry [3]. In this case, the industry/business opportunity in question is the development of electric vehicle smart charging systems specifically in the Pacific Northwest (OR, WA, ID, and MT). While this topic ultimately may have much more widespread appeal and impact than just this region, it is being examined first in a limited regional context to keep the issues manageable and develop a research design which can then be extended to other areas.

To fill in the data on the Stakeholder-Objective Matrix, answer the questions at the top of each column. Below are a few clarifications and suggested steps to make this process easier. Keep this focus question in mind as you are filling out the matrix:

\section{With regard to the development of electric vehicle charging technologies and smart grid in the Pacific Northwest:}

1. Who are the current stakeholders customers, providers, agencies, or other key 
players who will have a role in the setting up necessary processes and infrastructures, providing products and services, using products and services, as well as administering, monitoring, or involved with other aspects of the process. Also, who might be the beneficiaries or losers related to the focus question? Stakeholders come in many categories, but for the purposes of this study, remember to include, at a minimum, stakeholders who represent the following perspectives: Technology (R\&D), Business and Industry, and Policy / Regulatory. Listing the key stakeholders is probably the most time consuming step and should probably be done first. Then move on to the question in column 2.

2. What do the stakeholders defined in the previous step generally support? What are their goals? How will this affect the issue in the focus question? Try to keep answer relatively brief. You can answer in either short phrases or sentences. But, please try to be as clear, specific, and concise as possible.

3. Similarly, what do the stakeholders defined in the previous step generally oppose? What are their goals? How will this affect the issue in the focus question?

\section{Background - Stakeholder Objective Analysis}

An important step in understanding the technology, business, regulatory, and policy landscapes for emerging smart grid appliances, like electric vehicle smart charging systems, is to examine key opportunities that are arising in this area and see if these opportunities can be developed into viable business concepts and business plans. A number of steps are necessary in order to identify and analyze such opportunities. 
It is first important to thoroughly define a complete set of stakeholders who may support or oppose a particular business opportunity. Unlike many traditional business opportunities that have been studied outside the utility industry, the unique regulatory structures that exist for companies in Oregon and the Pacific Northwest mean that there are many significant stakeholders who are not direct customers for the product under consideration [3]. For analyzing stakeholders and their values, common tools are outcome matrices, and stakeholder-objective matrices [1] [2].

The stakeholder-objective matrix shown here shows the key stakeholders and the main objectives they both support and oppose. To handle the potential for expert disagreement, the Delphi Method will be used. Delphi is a structured communication method using an expert panel [4]. Questions are asked over a series of two or more rounds, or iterative sessions. Experts have the opportunity to revise their answers each round as a result of the information they observe from other experts. The goal is to get the experts opinions to converge on a general consensus, which is deemed to be more accurate than individual opinions.

In the case of this research, experts will first be asked to log in to their online accounts and enter their judgments individually. The primary investigator will examine all the results and summarize them, attempting to eliminate any redundancies and clarifying any confusion prior to an online meeting with all experts. When all the experts get together for their online meeting, a second round will be conducted. The experts will be asked if the summary fairly represents their view on the complete list of stakeholders for the issue and all the main points they support or oppose. If a majority of experts does not agree, then additional rounds will be conducted until a majority agreement is reached. It is not anticipated that more than 3 rounds will be needed, because experts 
are likely to be able to identify key stakeholders quickly and with a fairly high degree of accuracy. Also, this information will primarily be used to start future conversations, so if additional stakeholders are identified through future discussions, they can always be added back into the initial matrix

\section{References - Stakeholder Objective Analysis}

[1] E. Bardach, A Practical Guide for Policy Analysis: The Eightfold Path to More Effective Problem Solving, 3rd ed. New York, N.Y.: Chatham House Publishers, Seven Bridges Press, 2009.

[2] V. Elmer and A. Leigland, Infrastructure Planning and Finance: A Smart and Sustainable Guide. New York: Routledge, 2013.

[3] R. Phillips, Stakeholder Theory: Impacts and Prospects. Cheltenham: Elgar, 2011.

[4] H. A. Linstone and M. Turoff, The Delphi Method: Techniques and Applications. Reading, MA: Addison-Wesley Publishing Company, 1975. 


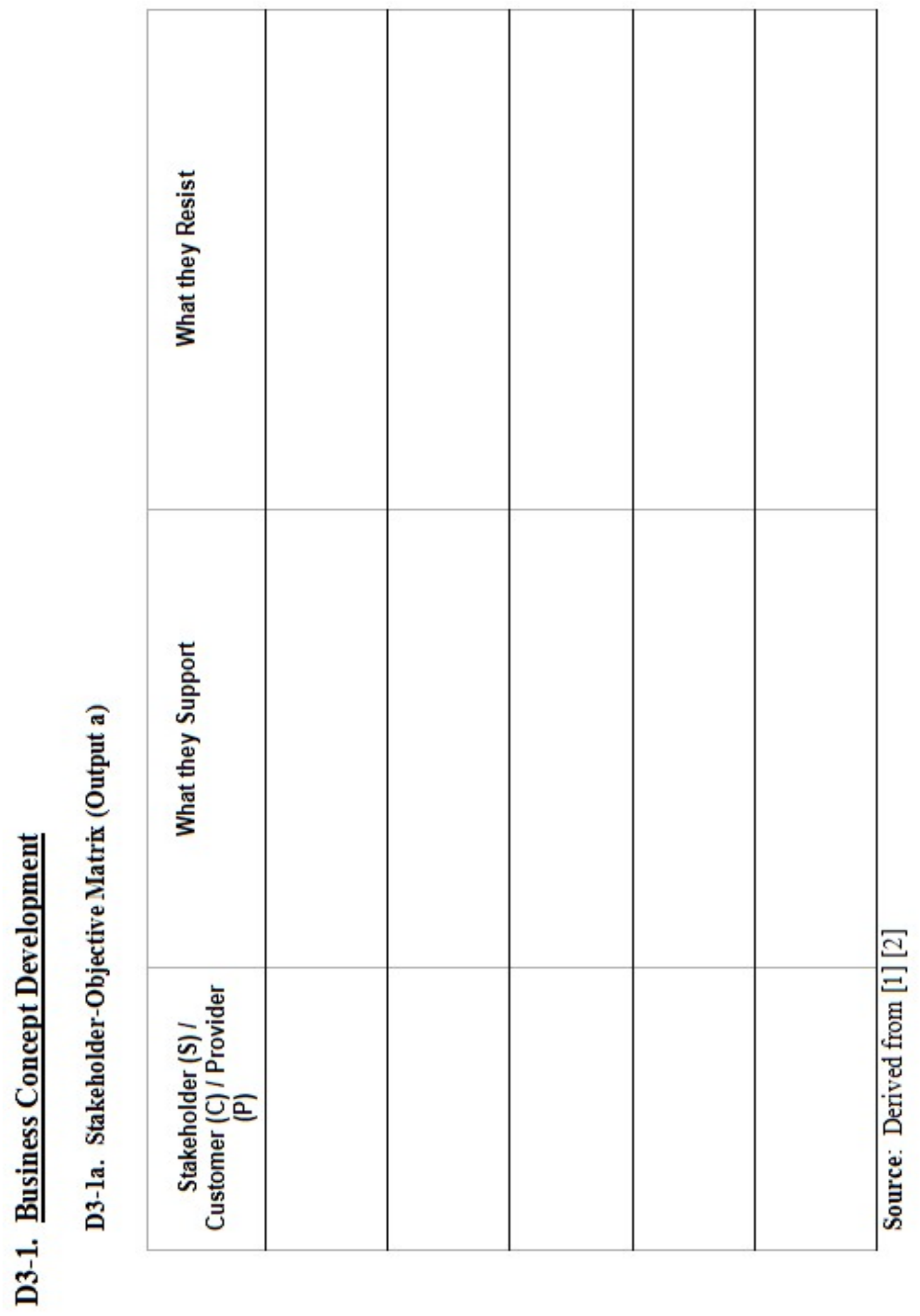




\section{D3-1. Business Concept Development}

\section{D3-1b Business Sub-Model Matrix}

\section{Directions for Expert Input}

Please refer to the set of directions below for filling out this data collection form.

Part $b$ of the Business Concept Development process is using a tool called a Business Sub-Model Matrix. This tool has been used in business research around the world, but particularly in Japan. Its purpose is to better understand a business opportunity in the context of its environment. It looks at a particular business opportunity and begins by asking the questions, who, what, how, and the profits or revenue that can be expected. It then goes into additional detail about the market structure, products, competitiveness, finance, and distribution methods involved with the business opportunity. There is a partial overlap with the Stakeholder-Objective Matrix on the first couple of question. Please use this as an opportunity to summarize in just a few words the names of the stakeholders you identified in the previous section, and a word or two describing the issues important to them. You can feel free to take as much space as you like in filling out the electronic form. Also, if you feel you cannot adequately summarize all your thoughts about stakeholders in just a few words, it is ok to just say "See Stakeholder-Matrix," referring back to the previous information you entered in that matrix. Like all of the data collection forms in this study, please fill in your responses with regard to the case of the development of electric vehicle smart charging systems in the Pacific Northwest (OR, WA, ID, and MT). While this topic ultimately may have much more widespread appeal and impact than just this region, it is being examined first in a limited regional context to keep the issues manageable and develop a research design which can then be extended to other areas. 
To complete the Business Sub-Model Matrix, you just need to answer the questions in each column from top to bottom. However, unlike the previous data collection form, please try to keep the responses limited to a shorter responses, such as a word or phrase. The idea is summarize complex concepts. In some cases, as you answer a question in one of the columns, there may be a corresponding question in the next column that becomes easier to answer. For examples, as you describe "Markets" in column one, you may then want to enter data in column two regarding "Market Structures." So, while you generally should work from top to bottom in each column, feel free to jump over to the next question and answer questions if you think that makes sense. Also, below are a few clarifications and suggested steps to make this process easier. Like the previous data collection forms, keep this focus question in mind as you are filling out the matrix:

\section{With regard to the development of electric vehicle charging technologies and smart grid in the Pacific Northwest:}

1. Who are the current stakeholders? This is the key question in the first column of the first row of this matrix. As mentioned above, there is a partial overlap between this question and the questions on the Stakeholder-Objective Matrix. Please use this as an opportunity to summarize in just a few words the names of the stakeholders you identified in the previous section, and a word or two describing the issues important to them. You can feel free to take as much space as you like in filling out the electronic form. Also, if you feel you cannot adequately summarize all your thoughts about stakeholders in just a few words, it is ok to just say "See Stakeholder-Matrix," referring back to the previous 
information you entered in that matrix. As you are summarizing your thoughts regarding stakeholders, use this as an opportunity to think about whether these stakeholders related to Customers, Markets, or Market Segments.

2. What is the Value Proposition? This is the key question in the first column of the second row of this matrix. To help answer this, the follow up questions in this column prompt you to consider, what do stakeholders have now, and what might they want instead in the future. In the second column of row two, consider how a value proposition could be expressed in terms of a product or a service. What is provided by the value proposition that value or customer utility (i.e usefulness) to the person using it or other stakeholders? Lastly, what type of competitiveness do you think would exist in terms of this value proposition? Is it currently a crowed field or a niche market? Will it be easy or hard to maintain competitive advantage?

3. How is Value Deliver accomplished? This is the key question in the first column of the third row of this matrix. Describe the key activities that generate value (eg. Sales of equipment, rentals, services, etc.) After considering the value delivery model, how is financing acquired for setting up the enterprise? Will Manufacturing be needed? If so, is it external or internal? What distribution channels will be used for the value delivery?

4. Revenue and Profitability: Where should the focus be in terms of generating revenue and creating profitability? This is the key question in the first column of the fourth row of this matrix. What Customers, Market, and Segments are expected to provide the most profit and revenue? Also, what type of profit model is being considered? Do you think a business or businesses of this type 
are generally going to be for-profit or non-profit? What kind of ownership structure are they likely to have? Are they likely to be individually owned companies, partnerships, large business, small businesses, private companies, public companies, or some combination of these elements?

\section{Background - Business Sub-Model Analysis}

Using the list of stakeholders from the stakeholder-objective matrix, business sub-model analysis can begin to define the characteristics that affect the ability of stakeholders to operate in a particular industry opportunity space. While the stakeholder-objective matrix defined details about what the stakeholders support or oppose, the business sub-model simply lists the key stakeholders and provides an opportunity to elaborate on values and motivations of each stakeholder and how these factors are likely to relate to business behaviors in the industry. For electric vehicle smart charging, it is important to examine the details of how business concepts and business plans can be implemented as business models. A number of steps are necessary in order to identify and analyze such opportunities.

After an opportunity is recognized, such as through literature, consultation with experts, or other means, a business modeling process can be performed to further define and assess the potential opportunity. A model is then defined describing the opportunity both in it current state, the "as is" model, and what is desired in the future, the "to be" model [1] [2] [3]. However, prior to creating this model, a preliminary submodel is created to assess initial ideas. A series of basic questions are answered as shown below to begin defining an opportunity that may later be developed into a complete business model. The questions have been modified to make them relevant for 
creating an integrated smart grid roadmap, which may have a number of stakeholders who are not necessarily direct customers.

The goal of the business sub-model in this research is to describe the key values and motivations of each stakeholder and how these factors are likely to relate to business behaviors in the industry. To handle the potential for expert disagreement, the Delphi Method will be used. Delphi is a structured communication method using an expert panel [4]. Questions are asked over a series of two or more rounds, or iterative sessions. Experts have the opportunity to revise their answers each round as a result of the information they observe from other experts. The goal is to get the experts opinions to converge on a general consensus, which is deemed to be more accurate than individual opinions. In the case of this research, experts will first be asked to log in to their online accounts and enter their judgments individually. The primary investigator will examine all the results and summarize them, attempting to eliminate any redundancies and clarifying any confusion prior to an online meeting with all experts. When all the experts get together for their online meeting, a second round will be conducted. The experts will be asked if the summary fairly represents their view on the complete list of stakeholders for the issue and all the main points they support or oppose. If a majority of experts does not agree, then additional rounds will be conducted until a majority agreement is reached. It is not anticipated that more than 3 rounds will be needed.

\section{References - Business Sub-Model Analysis}

[1] H. Abe, et al., "Integrating Business Modeling and Roadmapping Methods - The Innovation Support Technology (IST) Approach," Technological Forecasting and Social Change, vol. 76, pp. 80-90, 2009. 
[2] H. Abe, et al., "Value Creation Framework of Business Modeling Methods for R\&D Outputs," presented at the PICMET (Portland International Conference for Management of Engineering and Technology), 2005.

[3] H. Abe, et al., "A New Framework of Business Modeling Methods for R\&D Outputs: Valuation and Communication Tools for Engineers, Managers, and Investors," presented at the PICMET (Portland International Conference for Management of Engineering and Technology), 2004.

[4] H. A. Linstone and M. Turoff, The Delphi Method: Techniques and Applications. Reading, MA: Addison-Wesley Publishing Company, 1975. 


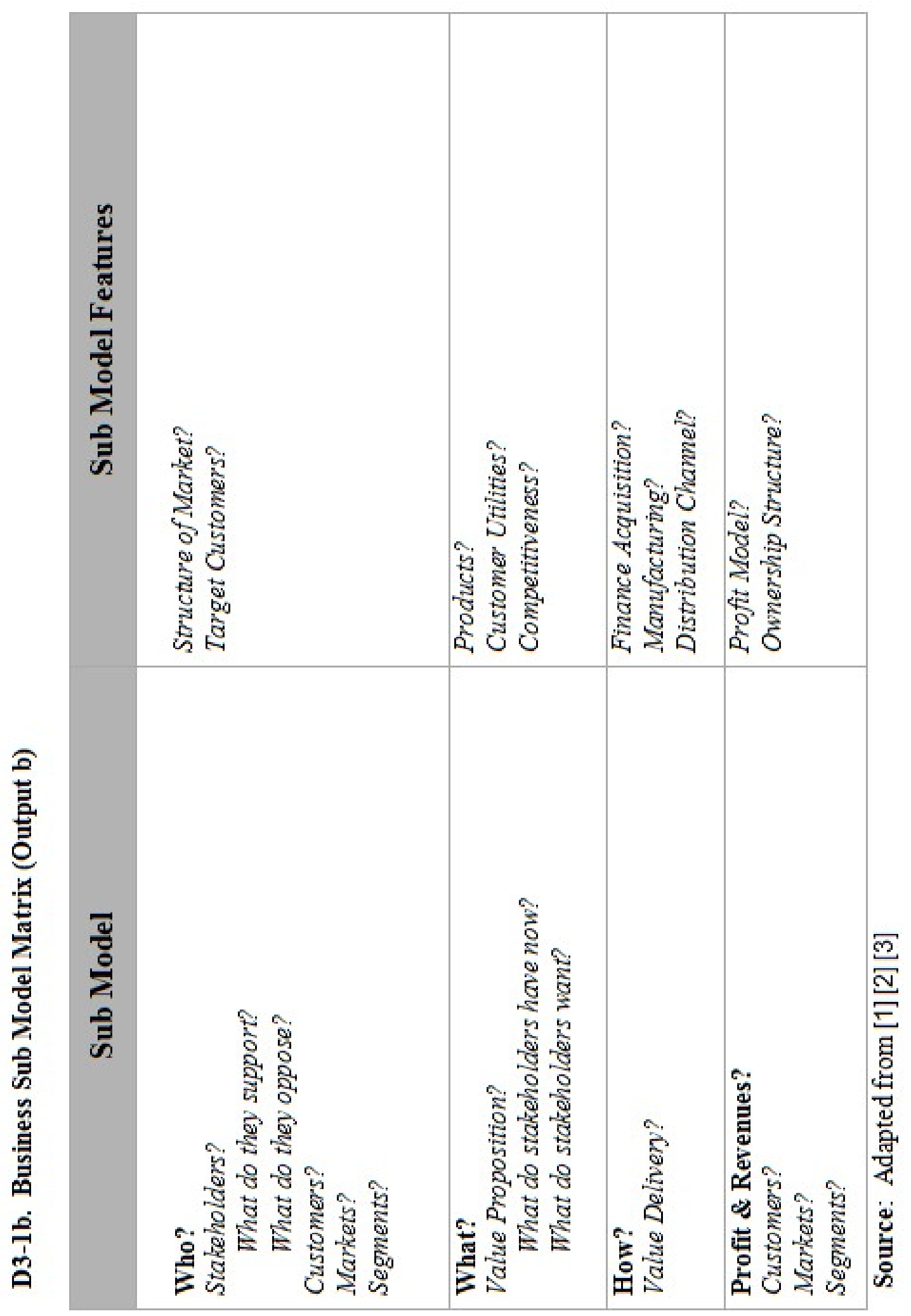




\section{D3-1. Business Concept Development}

\section{D3-1c. Opportunities Recognition Matrix D3-1d. Perspective Recognition Matrix}

\section{Directions for Expert Input}

Please refer to the set of directions below for filling out this data collection form.

Part $C$ and Part $D$ of the Business Concept Development process using tools called the Opportunities Recognition Matrix and the Perspectives Recognition Matrix. You can feel free to take as much space as you like in filling out the electronic form. Also, if you feel you cannot adequately summarize all your thoughts about stakeholders in just a few words, it is ok to just say "See Stakeholder-Matrix," referring back to the previous information you entered in that matrix. Like all of the data collection forms in this study, please fill in your responses with regard to the case of the development of electric vehicle smart charging systems in the Pacific Northwest (OR, WA, ID, and MT). While this topic ultimately may have much more widespread appeal and impact than just this region, it is being examined first in a limited regional context to keep the issues manageable and develop a research design which can then be extended to other areas.

To complete the Opportunities \& Perspectives Recognition Matrix, you just need to answer the questions in each column from top to bottom. However, unlike the previous data collection form, please try to keep the responses limited to a shorter responses, such as a word or phrase. The idea is summarize complex concepts. In some cases, as you answer a question in one of the columns, there may be a corresponding question in the next column that becomes easier to answer. For examples, as you describe "Markets" in column one, you may then want to enter data in 
column two regarding "Market Structures." So, while you generally should work from top to bottom in each column, feel free to jump over to the next question and answer questions if you think that makes sense. Also, below are a few clarifications and suggested steps to make this process easier. Like the previous data collection forms, keep this focus question in mind as you are filling out the matrix:

\section{With regard to the development of electric vehicle charging technologies and smart grid in the Pacific Northwest:}

1. Opportunity Recognition. This is the key question in the first column of the first row of this matrix. You can feel free to take as much space as you like in filling out the electronic form. Also, if you feel you cannot adequately summarize all your thoughts about stakeholders in just a few words, it is ok to just say "See Stakeholder-Matrix," referring back to the previous information you entered in that matrix. As you are summarizing your thoughts regarding stakeholders, use this as an opportunity to think about whether these stakeholder related to Customers, Markets, or Market Segments.

2. Perspectives Recognition. This is the key question in the first column of the second row of this matrix. To help answer this, the follow up questions in this column prompt you to consider, what do stakeholders have now, and what might they want instead in the future. In the second column of row two, consider how a value proposition could be expressed in terms of a product or a service. What is provided by the value proposition that value or customer utility (i.e. usefulness) to the person using it or other stakeholders? Lastly, what type of competitiveness do you think would exist for this value proposition? Is it currently a crowed field or a niche market? Will it be easy or hard to maintain competitive advantage? 


\section{Background - Opportunity \& Perspective Recognition}

A number of steps are required in order to define a business model. However, before proceeding, it is important to define what is meant by a business model. In creating the framework for this research, we referred mainly to Hamel [1], Slywotzky [2] [3] and Chesbrough [4]. Slywotzky's definition is perhaps most clear and succinct. A business model is described as:

"The totality of how a company selects its customers, defines and differentiates its offerings, defines the tasks it will perform itself and those it will outsource, configures its resources, goes to market, creates utility for customers, and captures profit. It is the entire system for delivering utility to customers and earning a profit from that activity."

Understanding appropriate business models for emerging technologies, such as electric vehicle-to-grid smart charging appliances, is critically important, since much of the new technology is in a nascent state and the direction of development can depend strongly upon perceived business opportunities. This can likewise be affected by perspectives regarding the market, regulatory and policy goals, and the rate at which technical capabilities are developing. Therefore, the next step in this process is to examine each of these key perspectives and to have experts determine what that they consider to be the highest priority issues in these areas during the following time periods: 1 year; 2 to 4 years; and 5 to 10 years. This also begins a process which will later be used for technology road (T-Plan) and strategic landscape scanning (S-Plan). known as the T-Plan was developed in early 2000 [5] [6] as well as policy issues previously discussed in stakeholder analysis [7] [8]. 
To handle the potential for expert disagreement, the Delphi Method will be used. Delphi is a structured communication method using an expert panel [9]. Questions are asked over a series of two or more rounds, or iterative sessions. Experts have the opportunity to revise their answers each round as a result of the information they observe from other experts. The goal is to get the experts opinions to converge on a general consensus, which is deemed to be more accurate than individual opinions. In the case of this research, experts will first be asked to log in to their online accounts and enter their judgments individually. The primary investigator will examine all the results and summarize them, attempting to eliminate any redundancies and clarifying any confusion prior to an online meeting with all experts. When all the experts get together for their online meeting, a second round will be conducted. The experts will be asked if the summary fairly represents their view on the complete list of stakeholders for the issue and all the main points they support or oppose. If a majority of experts does not agree, then additional rounds will be conducted until a majority agreement is reached. It is not anticipated that more than 3 rounds will be needed.

\section{References - Opportunity and Perspective Recognition}

[1] G. Hamel, Leading the Revolution. Boston, MA: Harvard Business School Press, 2000 .

[2] A. J. Slywotzky, Value Migration: How to Think Several Moves ahead of the Competition. Boston, MA: Harvard Business School Press, 1996.

[3] A. J. Slywotzky, The Art of Profitability. New York, NY: Warner Business Books, 2002.

[4] H. W. Chesbrough, Open Innovation: The New Imperative for Creating and Profiting from Technology. Boston, MA: Harvard Business School Press, 
2003.

[5] R. Phaal, et al., T-Plan: The Fast-Start to Technology Roadmapping - Planning your Route to Success. Cambridge: University of Cambridge, Institute for Manufacturing, 2001.

[6] R. Phaal, et al., "Customizing Roadmapping," Research Technology Management, vol. 47, p. 26, 2004.

[7] E. Bardach, A Practical Guide for Policy Analysis: The Eightfold Path to More Effective Problem Solving, 3rd ed. New York, N.Y.: Chatham House Publishers, Seven Bridges Press, 2009.

[8] V. Elmer and A. Leigland, Infrastructure Planning and Finance: A Smart and Sustainable Guide. New York: Routledge, 2013.

[9] H. A. Linstone and M. Turoff, The Delphi Method: Techniques and Applications. Reading, MA: Addison-Wesley Publishing Company, 1975. 


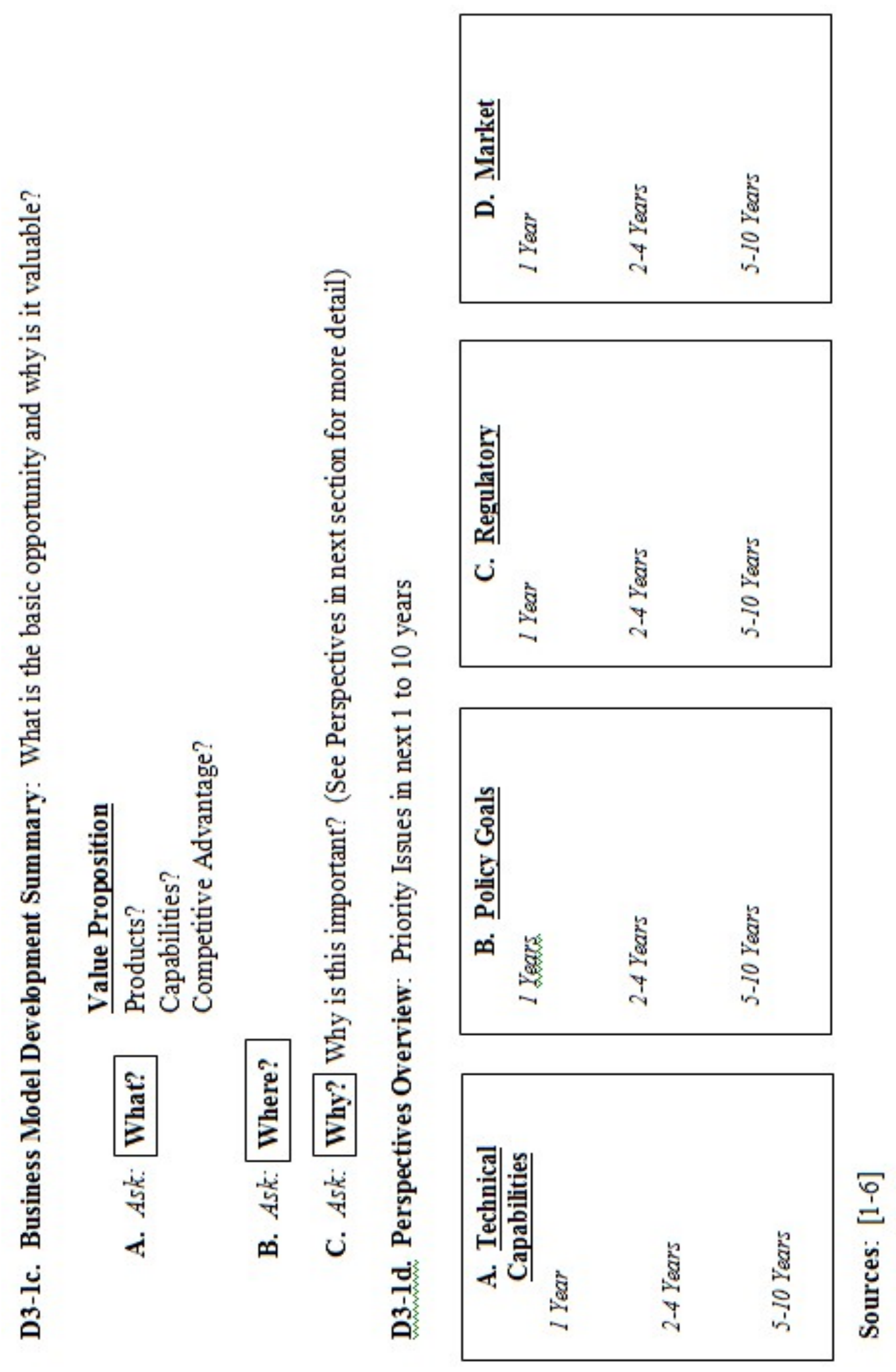




\section{D3-1. Business Concept Development}

\section{D3-1e. Business Model Development Overview D3-1f. "As is" and "To be" Visions}

\section{Directions for Expert Input}

Please refer to the set of directions below for filling out this data collection form.

Part $\mathrm{E}$ and Part $\mathrm{F}$ of the Business Concept Development process uses tools called the Business Model Development Overview and the "As is" and "To be" Visions. You can feel free to take as much space as you like in filling out the electronic form. Like all of the data collection forms in this study, please fill in your responses with regard to the case of the development of electric vehicle smart charging systems in the Pacific Northwest (OR, WA, ID, and MT). While this topic ultimately may have much more widespread appeal and impact than just this region, it is being examined first in a limited regional context to keep the issues manageable and develop a research design which can then be extended to other areas.

To complete the Business Structure and Goals Summary, you just need to answer the questions in each column from top to bottom. However, unlike the previous data collection form, please try to keep the responses limited to a shorter responses, such as a word or phrase. The idea is summarize complex concepts. In some cases, as you answer a question in one of the columns, there may be a corresponding question in the next column that becomes easier to answer. For examples, as you describe "Markets" in column one, you may then want to enter data in column two regarding "Market Structures." So, while you generally should work from top to bottom in each column, feel free to jump over to the next question and answer questions if you think that 
makes sense. Also, below are a few clarifications and suggested steps to make this process easier. Like the previous data collection forms, keep this focus question in mind as you are filling out the matrix:

\section{With regard to the development of electric vehicle charging technologies and smart grid in the Pacific Northwest:}

1. Who are the current stakeholders? You can feel free to take as much space as you like in filling out the electronic form. Also, if you feel you cannot adequately summarize all your thoughts about stakeholders in just a few words, it is ok to just say "See Stakeholder-Matrix," referring back to the previous information you entered in that matrix. As you are summarizing your thoughts regarding stakeholders, use this as an opportunity to think about whether these stakeholders related to Customers, Markets, or Market Segments.

2. In what way? This is the key question in the first column of the second row of this matrix. To help answer this, the follow up questions in this column prompt you to consider, what do stakeholders have now, and what might they want instead in the future. In the second column of row two, consider how a value proposition could be expressed in terms of a product or a service. What is provided by the value proposition that value or customer utility (i.e. usefulness) to the person using it or other stakeholders? Lastly, what type of competitiveness do you think would exist in terms of this value proposition? Is it currently a crowed field or a niche market? Will it be easy or hard to maintain competitive advantage? 
3. How? This is the key question in the first column of the third row of this matrix. Describe the key activities that generate value (eg. Sales of equipment, rentals, services, etc.) After considering the value delivery model, how is financing acquired for setting up the enterprise? Will Manufacturing be needed? If so, is it external or internal? What distribution channels will be used for the value delivery?

4. Business Concept Synthesis. Where should the focus be in terms of generating revenue and creating profitability? This is the key question in the first column of the fourth row of this matrix. What Customers, Market, and Segments are expected to provide the most profit and revenue? Also, what type of profit model is being considered? Do you think a business or businesses of this type are generally going to be for-profit or non-profit? What kind of ownership structure are they likely to have? Are they likely to be individually owned companies, partnerships, large business, small businesses, private companies, public companies, or some combination of these elements?

\section{Background - Business Model Development and "As is" vs. "To be" Visions}

This step in the Business Concept Development process uses tools called the Business Model Development Overview and the "As is" and "To be" Visions. The objective of these tools is to provide more details about the necessary business structure and goals. By answering the types of questions presented on the instruments, it should be possible to determine the following, at least tentatively: What is the "as is" situation or 
opportunity to be explored? ; What is the "to be" vision?; What are the business goals over time (i.e. 10X growth in 10 years...); What are the key gap areas or needs?

After an opportunity is recognized, such as through literature, consultation with experts, or other means, a business modeling process can be performed to further define and assess the potential opportunity. A model is then defined describing the opportunity both in it current state, the "as is" model, and what is desired in the future, the "to be" model [1] [2] [3]. A series of basic questions are answered as shown below to begin defining an opportunity that may later be developed into a complete business model [4]. The questions have been modified to make them relevant for creating an integrated smart grid roadmap, which may have a number of stakeholders who are not necessarily direct customers.

To handle the potential for expert disagreement, the Delphi Method will be used. Delphi is a structured communication method using an expert panel [5]. Questions are asked over a series of two or more rounds, or iterative sessions. Experts have the opportunity to revise their answers each round as a result of the information they observe from other experts. The goal is to get the experts opinions to converge on a general consensus, which is deemed to be more accurate than individual opinions. In the case of this research, experts will first be asked to log in to their online accounts and enter their judgments individually. The primary investigator will examine all the results and summarize them, attempting to eliminate any redundancies and clarifying any confusion prior to an online meeting with all experts. When all the experts get together for their online meeting, a second round will be conducted. The experts will be asked if the summary fairly represents their view on the complete list of stakeholders for the issue and all the main points they support or oppose. If a majority of experts does not 
agree, then additional rounds will be conducted until a majority agreement is reached. It is not anticipated that more than 3 rounds will be needed, because experts are likely to be able to identify key stakeholders quickly and with a fairly high degree of accuracy. Also, this information will primarily be used to start future conversations, so if additional stakeholders are identified through future discussions, they can always be added back into the initial matrix

\section{References - Business Model Development and "As is" vs. "To be" Visions}

[1] H. Abe, et al., "Integrating Business Modeling and Roadmapping Methods - The Innovation Support Technology (IST) Approach," Technological Forecasting and Social Change, vol. 76, pp. 80-90, 2009.

[2] H. Abe, et al., "Value Creation Framework of Business Modeling Methods for R\&D Outputs," presented at the PICMET (Portland International Conference for Management of Engineering and Technology), 2005.

[3] H. Abe, et al., "A New Framework of Business Modeling Methods for R\&D Outputs: Valuation and Communication Tools for Engineers, Managers, and Investors," presented at the PICMET (Portland International Conference for Management of Engineering and Technology), 2004.

[4] F. Ishida, et al., "Remodeling Method for Business Models of R\&D Outputs," in PICMET (Portland International Conference for Management of Engineering and Technology), Istanbul, Turkey, 2006, pp. 708-714.

[5] H. A. Linstone and M. Turoff, The Delphi Method: Techniques and Applications. Reading, MA: Addison-Wesley Publishing Company, 1975. 


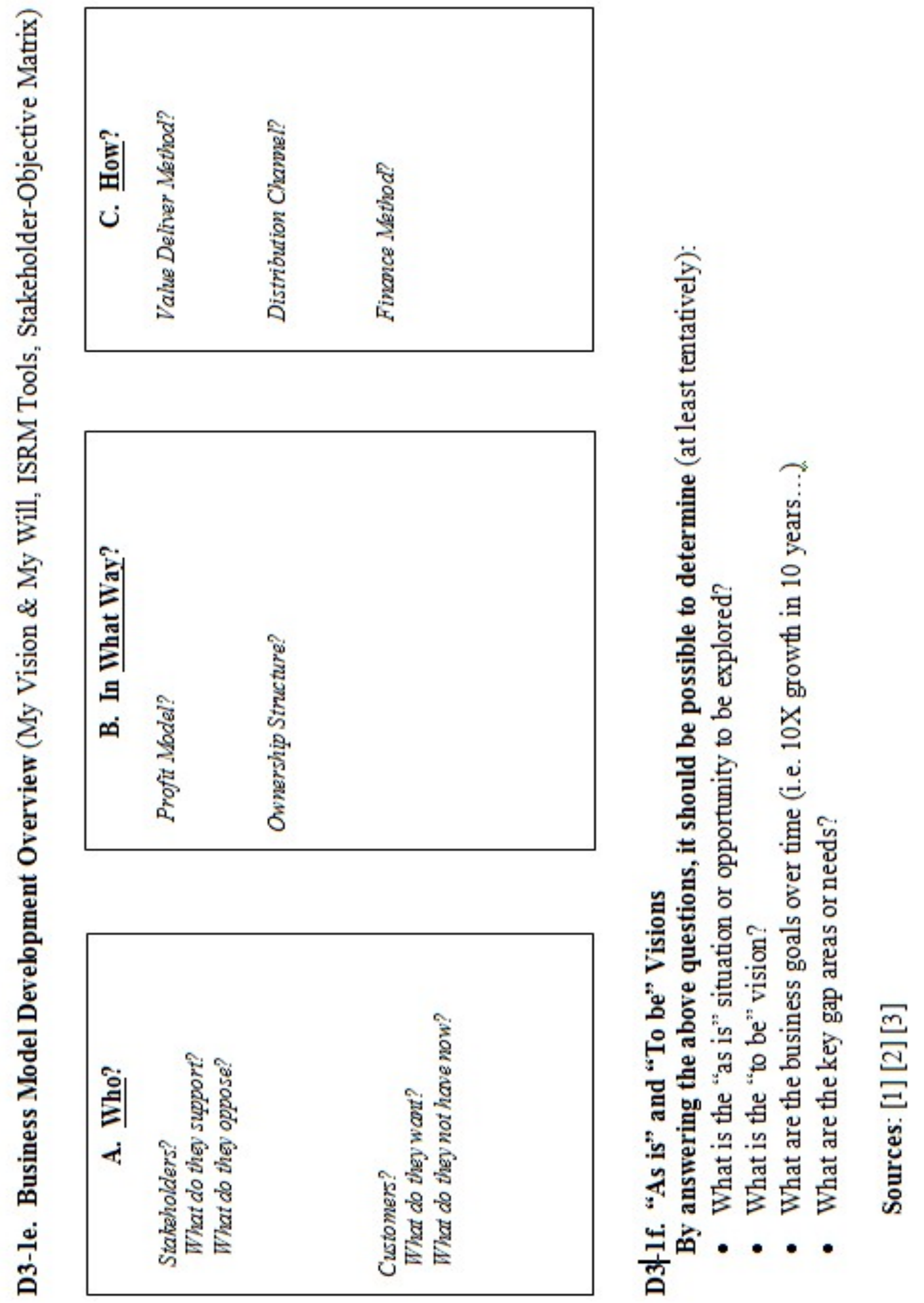


APPENDIX D3-2: Research Approach - Workshop Requirements (Industry Analysis Considerations)

\section{RESEARCH APPROACH (Part3):}

D3-2. Industry Analysis

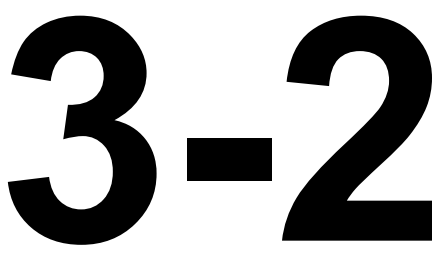




\section{D3-2. Industry Analysis}

\section{Portland State \\ University \\ Portland, OR \\ Industry Analysis Agenda}

Purpose of Phase 2 Workshop: Industry Analysis

- Judging viability of product in industries with regulated competitive structures

- Goals: (a) Design and obtain business target; (b) Establish content to construct TRM; (c) Understand key barriers and mitigators

- Prior to this online forum, the data entry form for the workshop will be distributed to the participants by email and completed forms will be returned to the investigator.

- The goal of the online forum will be to facilitate consensus regarding the results of provided on the forms.

9:00 AM Introduction and Overview

9:15 AM Discuss use of Industry Analysis and tools and review of initial results

9:30 AM Achieving consensus and use of Delphi rounds

- Competion of first round

10:00 AM Assessment of consensus and need for additional rounds

- Additional Delphi processes as needed

10:45 AM Adjournment and Closing Comments 


\section{D3-2. Industry Analysis}

\section{D3-2a. Identification of Viable Business Concept}

\section{D3-2a1. Porters Five Forces (Regulated Industries) D3-2a2. Identification of Barriers and Mitigators}

\section{Directions for Expert Input}

Please refer to the set of directions below for filling out this data collection form.

Part a of the Porter's Five Forces (1) and the Identification of Barriers and Mitigators (2) process uses tools called a Porter's Five Forces and the Identification of Barriers and Mitigators. This tool has been used in business research around the world, but particularly in Japan. Its purpose is to better understand a business opportunity in the context of its environment. You can feel free to take as much space as you like in filling out the electronic form. Also, if you feel you cannot adequately summarize all your thoughts about stakeholders in just a few words, it is ok to just say "See StakeholderMatrix," referring back to the previous information you entered in that matrix. Like all of the data collection forms in this study, please fill in your responses with regard to the case of the development of electric vehicle smart charging systems in the Pacific Northwest (OR, WA, ID, and MT). While this topic ultimately may have much more widespread appeal and impact than just this region, it is being examined first in a limited regional context to keep the issues manageable and develop a research design which can then be extended to other areas.

To complete this section on Porter's Five Forces and the Identification of Barriers 
and Mitigators, you just need to answer the questions in each column from top to bottom. However, unlike the previous data collection form, please try to keep the responses limited to a shorter responses, such as a word or phrase. The idea is summarize complex concepts. In some cases, as you answer a question in one of the columns, there may be a corresponding question in the next column that becomes easier to answer. Like the previous data collection forms, keep this focus question in mind as you are filling out the matrix:

\section{With regard to the development of electric vehicle charging technologies and smart grid in the Pacific Northwest:}

1. Porter's Five Forces (modified for regulated utility industries). This is a wellknown tool for industry analysis. In regulated industries, barriers are particularly important to consider and the modified version of this tool that is used here emphasizes this need. Opportunity finding is particularly important in regulated industries, like utilities, where new option may become available due to evolving of regulation, policy, and technological capabilities (5 Forces). As you are summarizing your thoughts regarding stakeholders, use this as an opportunity to think about whether these stakeholder related to Customers, Markets, or Market Segments.

2. Barriers and Mitigators. This is a key factor that differs from markets that are not formally regulated. While barriers to entry exist in other markets, in formally regulated markets, barriers can also take the form of specific regulatory constraints. To an extent, regulation is a part of all business environments. However, in markets with a formal regulation process, the amount of control and 
oversight exerted over businesses can include setting of regulated rates of return, approval of plans, and oversight of operational functions. New business models and technology products seeking to operate in such an environment or to function along side large incumbent business who operate within regulated structures must be aware of significant barriers that can exist with regard to how they can do business. Thus, in order to know it is possible to operate in a way that takes advantage of a new opportunity or value proposition in a regulated market, methods must be found to either avoid or mitigate any regulatory barriers that exist. What is provided by the value proposition that value or customer utility (i.e usefulness) to the person using it or other stakeholders? Lastly, what type of competitiveness do you think would exist in terms of this value proposition? Is it currently a crowed field or a niche market? Will it be easy or hard to maintain competitive advantage?

3. Stakeholder Goals This is a crucial concept for analysis in regulated industries. Stakeholder goals are often different than in traditional competitive industries. As you are summarizing your thoughts regarding stakeholders, use this as an opportunity to think about Regulatory and Policy Goals and Business and Market Targets that may provide unique drivers constraints in this particular industry.

\section{Background - Analysis of Business Concept}

Industry analysis is a critical step in this research process. A widely used tool for analyzing industry conditions is Porter's Five Forces [1] [2]. However, this tool needs to be modified to focus particular attention on the effect of barriers that exist within regulated industries, such as utilities, which generally have been structured as regulated 
monopolies [3]. While, in most cases, regulated monopoly structures are not expected to be fundamentally changed in these industries, it is important to understand how changes in technology, policy, and limited market restructuring may lead to the creation of new opportunities. Therefore, the goal of this phase of industry analysis is to understand what factors can mitigate existing barriers and how appropriate business targets can be designed and incorporated into roadmaps.

The tool identifies five forces based on industrial organization economics that indicate the overall attractiveness or profitability of an industry based on its intensity of competition. The tool is valuable for most industries with competitive structures. The forces examined include the internal market issues of: (1) bargaining power of buyers; bargaining power of suppliers; (3), the viability of substitutes for the product or service in question (4), and the external market issue of new entrants to market. In the case of pure monopolies, there would be almost no threat of new entrants, so Porter's Five Forces would be of limited value. However, many utility systems function as regulated monopolies in limited service territories. In these cases, the five forces model is relevant and can produce some valuable insights. This is especially true, as many utility systems have considered various types of restructuring, creating de-regulated or partially deregulated systems that have increased the competitive elements within the industry. Typically, barriers to entry are still extremely high for utilities, even in the absence of traditional monopoly structures, since the investments for utility infrastructure are very capital intensive. So, a starting assumption for analysis in this industry is that is very important to understand the size and types of barriers that exist. Barriers can be further sub-divided into both the typical business \& market barriers (1) and regulatory \& policy barriers (2). So, the industry analysis portion of this research makes use of this modified structure for the five forces model. 
To handle the potential for expert disagreement, the Delphi Method will be used. Delphi is a structured communication method using an expert panel [4]. Questions are asked over a series of two or more rounds, or iterative sessions. Experts have the opportunity to revise their answers each round as a result of the information they observe from other experts. The goal is to get the experts opinions to converge on a general consensus, which is deemed to be more accurate than individual opinions. In the case of this research, experts will first be asked to log in to their online accounts and enter their judgments individually. The primary investigator will examine all the results and summarize them, attempting to eliminate any redundancies and clarifying any confusion prior to an online meeting with all experts. When all the experts get together for their online meeting, a second round will be conducted. The experts will be asked if the summary fairly represents their view on the complete list of stakeholders for the issue and all the main points they support or oppose. If a majority of experts does not agree, then additional rounds will be conducted until a majority agreement is reached. It is not anticipated that more than 3 rounds will be needed.

\section{References - Analysis of Business Concept}

[1] M. E. Porter, On Competition. Boston, MA: Harvard Business School Pub., 2008.

[2] M. E. Porter, The Five Competitive Forces that Shape Strategy. Boston, MA: Harvard Business School Publishing, 2008.

[3] M. Filippini, "Are Municipal Electricity Distribution Utilities Natural Monopolies?," Annals of Public and Cooperative Economics, vol. 69, p. 157, 1998.

[4] H. A. Linstone and M. Turoff, The Delphi Method: Techniques and Applications. Reading, MA: Addison-Wesley Publishing Company, 1975. 


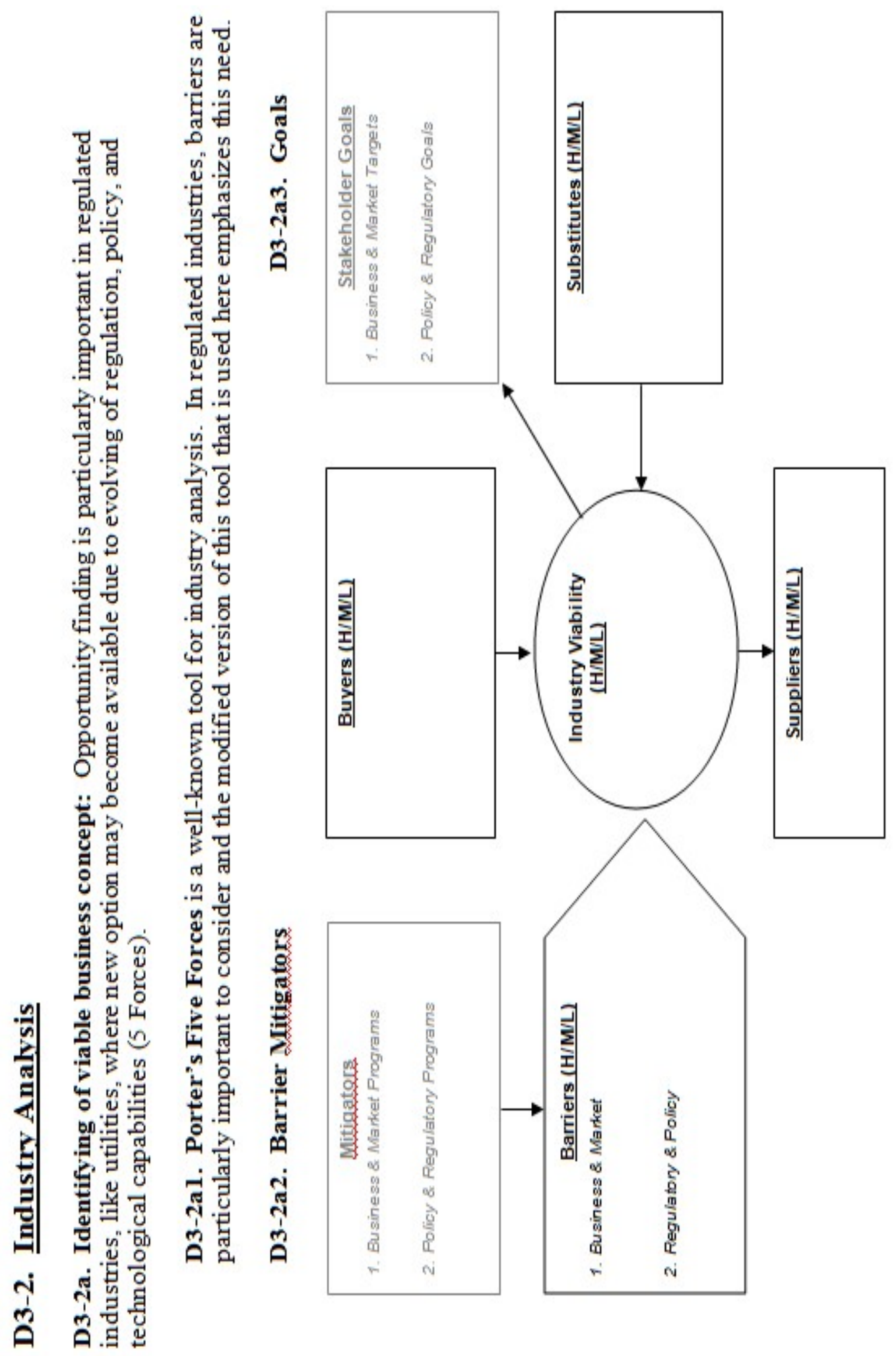




\section{D3-2. Industry Analysis}

\section{D3-2b. Business Stakeholder Alternatives Matrix}

\section{Directions for Expert Input}

Please refer to the set of directions below for filling out this data collection form.

Part $b$ of the Industry Analysis process is using a tool called a Business Stakeholder Alternatives Matrix. You can feel free to take as much space as you like in filling out the electronic form. Also, if you feel you cannot adequately summarize all your thoughts about stakeholders in just a few words, it is ok to just say "See StakeholderMatrix," referring back to the previous information you entered in that matrix. Like all of the data collection forms in this study, please fill in your responses with regard to the case of the development of electric vehicle smart charging systems in the Pacific Northwest (OR, WA, ID, and MT). While this topic ultimately may have much more widespread appeal and impact than just this region, it is being examined first in a limited regional context to keep the issues manageable and develop a research design which can then be extended to other areas.

To complete the Business Stakeholder Alternatives Matrix, you just need to answer the questions in each column from top to bottom. However, unlike the previous data collection form, please try to keep the responses limited to a shorter responses, such as a word or phrase. The idea is summarize complex concepts. In some cases, as you answer a question in one of the columns, there may be a corresponding question in the next column that becomes easier to answer. For examples, as you describe "Markets" in column one, you may then want to enter data in column two regarding 
"Market Structures." So, while you generally should work from top to bottom in each column, feel free to jump over to the next question and answer questions if you think that makes sense. Also, below are a few clarifications and suggested steps to make this process easier. Like the previous data collection forms, keep this focus question in mind as you are filling out the matrix:

\section{With regard to the development of electric vehicle charging technologies and smart grid in the Pacific Northwest:}

1. $\mathbf{B 2 B} / \mathbf{C} / \mathbf{G}$ ? This is the key question in the first column of the first row of this matrix. You can feel free to take as much space as you like in filling out the electronic form. Also, if you feel you cannot adequately summarize all your thoughts about stakeholders in just a few words, it is ok to just say "See Stakeholder-Matrix," referring back to the previous information you entered in that matrix. As you are summarizing your thoughts regarding stakeholders, use this as an opportunity to think about whether these stakeholderS related to Customers, Markets, or Market Segments.

2. Customers / Stakeholders? This is the key question in the first column of the second row of this matrix. To help answer this, the follow up questions in this column prompt you to consider, what do stakeholders have now, and what might they want instead in the future. In the second column of row two, consider how a value proposition could be expressed in terms of a product or a service. What is provided by the value proposition that value or customer utility (i.e usefulness) to the person using it or other stakeholders? Lastly, what type of competitiveness do you think would exist in terms of this value proposition? Is it currently a 
crowed field or a niche market? Will it be easy or hard to maintain competitive advantage?

3. Products / Services? This is the key question in the first column of the third row of this matrix. Describe the key activities that generate value (e.g. Sales of equipment, rentals, services, etc.) After considering the value delivery model, how is financing acquired for setting up the enterprise? Will Manufacturing be needed? If so, is it external or internal? What distribution channels will be used for the value delivery?

4. Operations System? Where should the focus be in terms of generating revenue and creating profitability? This is the key question in the first column of the fourth row of this matrix. What Customers, Market, and Segments are expected to provide the most profit and revenue? Also, what type of profit model is being considered? Do you think a business or businesses of this type are generally going to be for-profit or non-profit? What kind of ownership structure are they likely to have? Are they likely to be individually owned companies, partnerships, large business, small businesses, private companies, public companies, or some combination of these elements?

5. Profit Model? This is the key question in the first column of the first row of this matrix. You can feel free to take as much space as you like in filling out the electronic form. Also, if you feel you cannot adequately summarize all your thoughts about stakeholders in just a few words, it is ok to just say "See Stakeholder-Matrix," referring back to the previous information you entered in that matrix. 
6. Growth Model? This is the key question in the first column of the third row of this matrix. Describe the key activities that generate value (eg. Sales of equipment, rentals, services, etc.) After considering the value delivery model, how is financing acquired for setting up the enterprise? Will Manufacturing be needed? If so, is it external or internal? What distribution channels will be used for the value delivery?

\section{Background - Business Stakeholder Alternatives}

The industry analysis produces three main outcomes: (1) Designing and Obtaining a business target; (2) Establishing content to construct a technology roadmap integrating the business / market and regulatory / policy issues identified in the industry analysis; and (3) to understand the key barriers that exist and how they can be mitigated. In situations where clear business opportunities already exist, a technology roadmap makes it easier to identify and understand the nature of such opportunities. However, in many cases, opportunities and strategies for capturing them are just being identified. In some cases, business models have not yet been developed to accommodate evolving regulatory and policy structures.

To better analyze and define the basis for various business models that are possible in the emerging smart grid industry, a Business Stakeholder Alternatives matrix will be used [1] [2] [3]. Business opportunities can be examined in terms of both "as is" and "to be" conditions. By looking at gaps between these two conditions, different scenarios or alternative approaches can be envisioned for achieving the desired objective [4]. Therefore, this matrix is one tool that is helpful in determining the type of business to customer relationship that is envisioned. 
To handle the potential for expert disagreement, the Delphi Method will be used. Delphi is a structured communication method using an expert panel [5]. Questions are asked over a series of two or more rounds, or iterative sessions. Experts have the opportunity to revise their answers each round as a result of the information they observe from other experts. The goal is to get the experts opinions to converge on a general consensus, which is deemed to be more accurate than individual opinions. In the case of this research, experts will first be asked to log in to their online accounts and enter their judgments individually. The primary investigator will examine all the results and summarize them, attempting to eliminate any redundancies and clarifying any confusion prior to an online meeting with all experts. When all the experts get together for their online meeting, a second round will be conducted. The experts will be asked if the summary fairly represents their view on the complete list of stakeholders for the issue and all the main points they support or oppose. If a majority of experts does not agree, then additional rounds will be conducted until a majority agreement is reached. It is not anticipated that more than 3 rounds will be needed.

\section{References - Business Stakeholder Alternatives}

[1] H. Abe, et al., "Integrating Business Modeling and Roadmapping Methods - The Innovation Support Technology (IST) Approach," Technological Forecasting and Social Change, vol. 76, pp. 80-90, 2009.

[2] H. Abe, et al., "Value Creation Framework of Business Modeling Methods for R\&D Outputs," presented at the PICMET (Portland International Conference for Management of Engineering and Technology), 2005.

[3] H. Abe, et al., "A New Framework of Business Modeling Methods for R\&D Outputs: Valuation and Communication Tools for Engineers, Managers, and Investors," presented at the PICMET (Portland International Conference for Management of Engineering and Technology), 2004. 
[4] F. Ishida, et al., "Remodeling Method for Business Models of R\&D Outputs," in PICMET (Portland International Conference for Management of Engineering and Technology), Istanbul, Turkey, 2006, pp. 708-714.

[5] H. A. Linstone and M. Turoff, The Delphi Method: Techniques and Applications. Reading, MA: Addison-Wesley Publishing Company, 1975. 


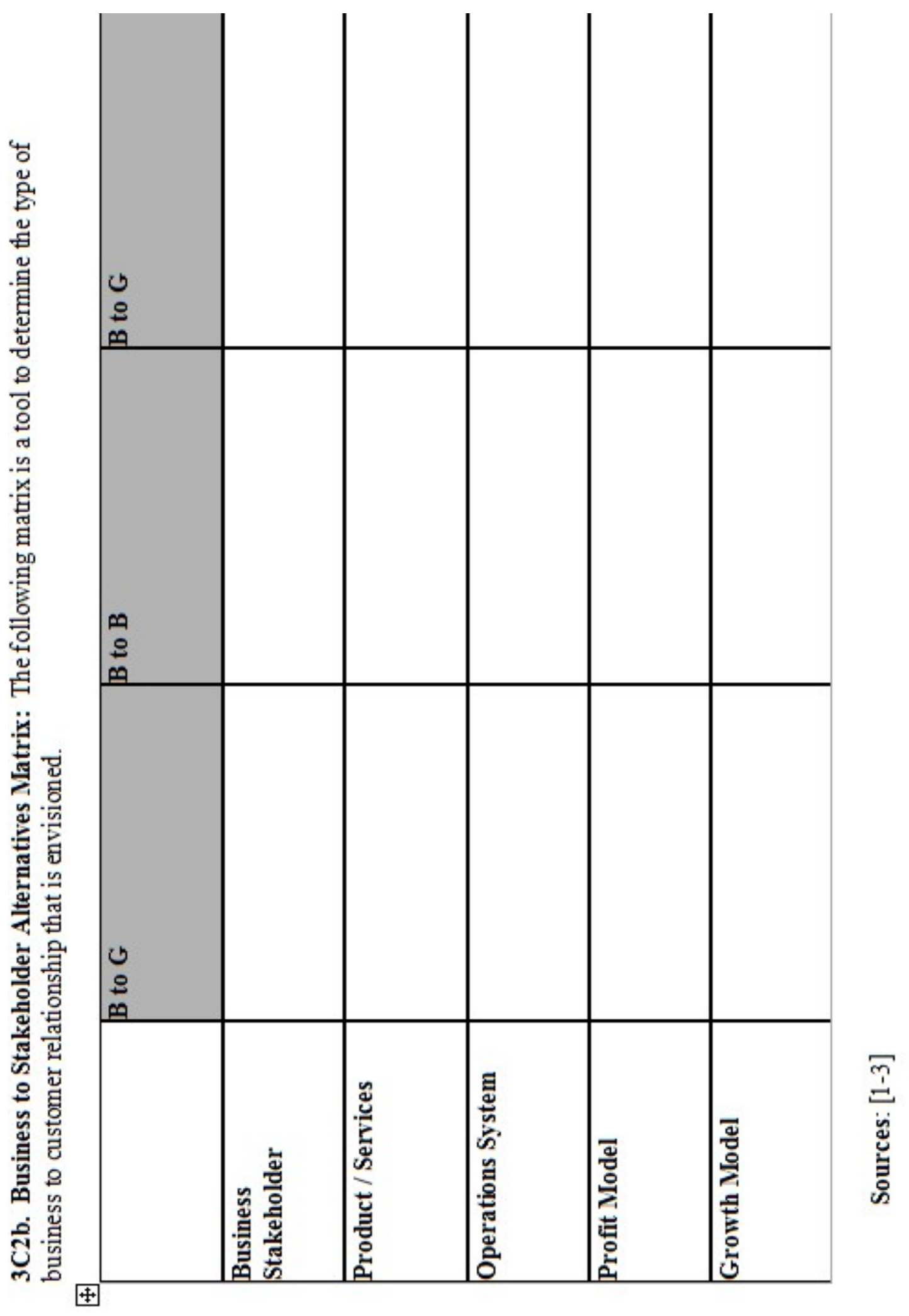




\section{D3-2. Industry Analysis}

\section{D3-2c. Industry Factor Alternatives}

\section{Directions for Expert Input}

Please refer to the set of directions below for filling out this data collection form.

Part c of the Industry Analysis process a tool called Industry Factor Alternatives. This tool has been used in business research around the world to better understand a business opportunity in the context of its environment. You can feel free to take as much space as you like in filling out the electronic form. Also, if you feel you cannot adequately summarize all your thoughts about stakeholders in just a few words, it is ok to just say "See Stakeholder-Matrix," referring back to the previous information you entered in that matrix. Like all of the data collection forms in this study, please fill in your responses with regard to the case of the development of electric vehicle smart charging systems in the Pacific Northwest (OR, WA, ID, and MT). While this topic ultimately may have much more widespread appeal and impact than just this region, it is being examined first in a limited regional context to keep the issues manageable and develop a research design which can then be extended to other areas.

To complete the Industry Factor Alternatives, you just need to answer the questions in each column from top to bottom. For each topic in each column, consider the sub-topics in the next column of the same row. Also, for all topics in the row, consider how the issues regarding these topics will change over the following years: 2015, 2020, and 2025. Like the previous data collection forms, keep this focus question in mind as you are filling out the matrix: 


\section{With regard to the development of electric vehicle charging technologies and smart grid in the Pacific Northwest:}

1. Regulatory / Policy. This is the topic of the first column of the first row of this matrix. This topic consists of two categories: New Policy / Existing Regulatory Structure (1); and New Regulatory Structure / Existing Policy (2). Please use this as an opportunity to summarize in just a few words the names of the stakeholders you identified in the previous section, and a word or two describing the issues important to them. You can feel free to take as much space as you like in filling out the electronic form. As you are summarizing your thoughts regarding stakeholders, use this as an opportunity to think about whether these stakeholders related to Customers, Markets, or Market Segments.

2. Market / Product. This is the topic of the first column of the first row of this matrix. This topic consists of two categories: New Product / Existing Market (1); and New Market / Existing Product (2). In the second column of row two, consider how a value proposition could be expressed in terms of a product or a service. What is provided by the value proposition that value or customer utility (i.e usefulness) to the person using it or other stakeholders? Lastly, what type of competitiveness do you think would exist in terms of this value proposition? Is it currently a crowed field or a niche market? Will it be easy or hard to maintain competitive advantage?

3. Technology / Function. This is the topic of the first column of the first row of this matrix. This topic consists of two categories: Technological Factor (1); and 
Functional Factor (2). After considering the value delivery model, how is financing acquired for setting up the enterprise? Will Manufacturing be needed? If so, is it external or internal? What distribution channels will be used for the value delivery?

\section{Background - Industry Factor Alternatives}

It is important in business modeling tool to consider how various factors may be able to change the basis of competition over time. The Industry Factor Alternatives matrix provides a way of analyzing this. This offers a useful tool for examining potential factors that may impact an industry with respect to emerging dimensions of competition and overall industry viability. This tool has been used in business research to better understand a business opportunity in the context of its environment. The tool asks experts to consider how the issues regarding these topics will change over the following years: 2015,2020 , and 2025 .

Understanding appropriate business models for emerging technologies, such as electric vehicle-to-grid smart charging appliances, is critically important, since much of the new technology is in a nascent state and the direction of development can depend strongly upon perceived business opportunities. To better analyze the industry factors

and alternatives that affect possible business models in the emerging smart grid industry, a Industry Factor Alternatives matrix will be used [1] [2] [3]. This matrix is one tool that is helpful in analyzing how different industry factor alternatives change over time. 
To handle the potential for expert disagreement, the Delphi Method will be used. Delphi is a structured communication method using an expert panel [4]. Questions are asked over a series of two or more rounds, or iterative sessions. Experts have the opportunity to revise their answers each round as a result of the information they observe from other experts. The goal is to get the experts opinions to converge on a general consensus, which is deemed to be more accurate than individual opinions. In the case of this research, experts will first be asked to log in to their online accounts and enter their judgments individually. The primary investigator will examine all the results and summarize them, attempting to eliminate any redundancies and clarifying any confusion prior to an online meeting with all experts. When all the experts get together for their online meeting, a second round will be conducted. The experts will be asked if the summary fairly represents their view on the complete list of stakeholders for the issue and all the main points they support or oppose. If a majority of experts does not agree, then additional rounds will be conducted until a majority agreement is reached. It is not anticipated that more than 3 rounds will be needed.

\section{References - Industry Factor Alternatives}

[1] H. Abe, et al., "Integrating Business Modeling and Roadmapping Methods - The Innovation Support Technology (IST) Approach," Technological Forecasting and Social Change, vol. 76, pp. 80-90, 2009.

[2] H. Abe, et al., "Value Creation Framework of Business Modeling Methods for R\&D Outputs," presented at the PICMET (Portland International Conference for Management of Engineering and Technology), 2005.

[3] H. Abe, et al., "A New Framework of Business Modeling Methods for R\&D Outputs: Valuation and Communication Tools for Engineers, Managers, and Investors," presented at the PICMET (Portland International Conference for Management of Engineering and Technology), 2004. 
[4] H. A. Linstone and M. Turoff, The Delphi Method: Techniques and Applications. Reading, MA: Addison-Wesley Publishing Company, 1975. 


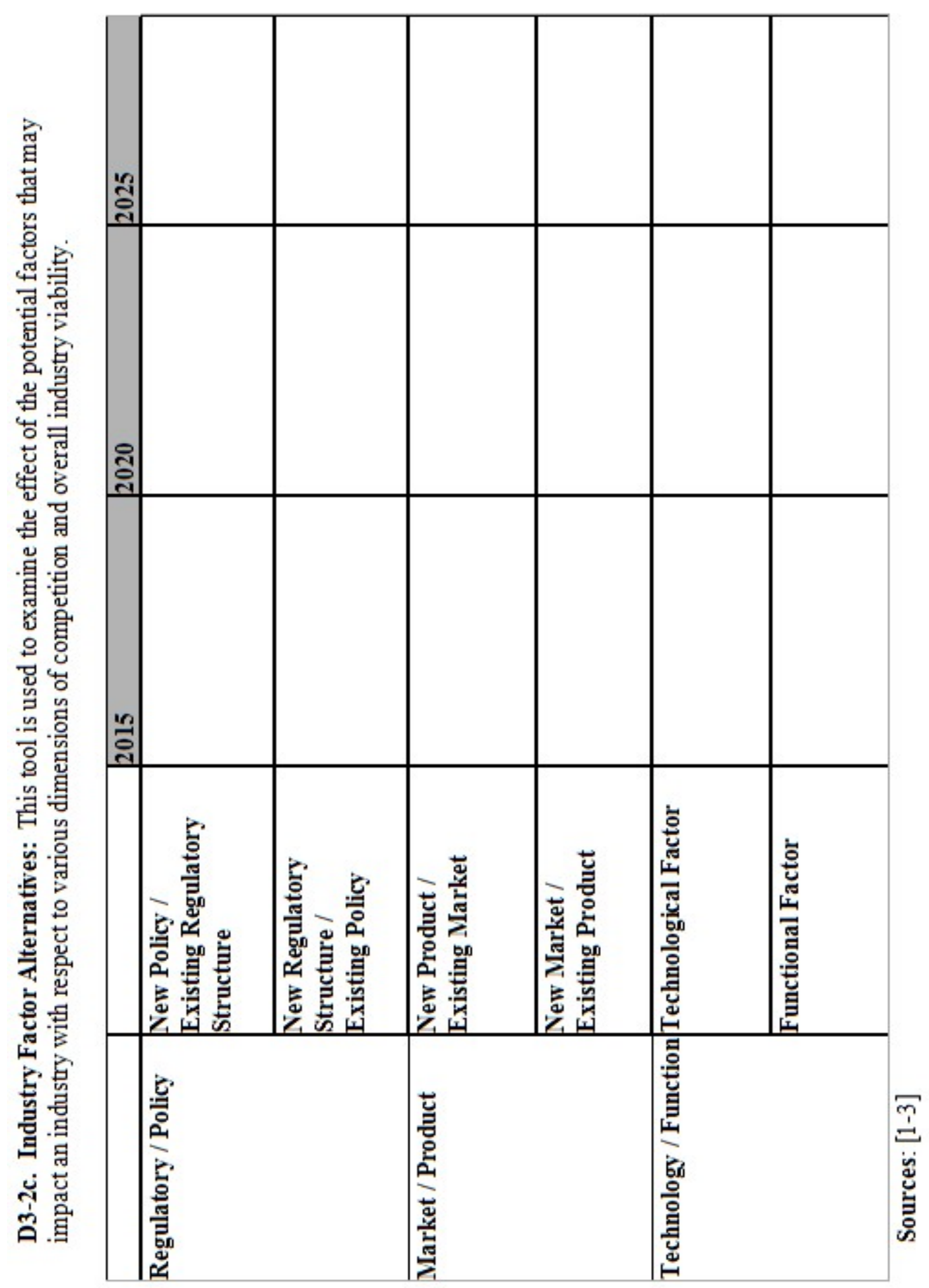




\section{D3-2. Industry Analysis}

\section{D3-2d. Static and Dynamic Business Models Matrix}

\section{Directions for Expert Input}

Please refer to the set of directions below for filling out this data collection form.

Part d of the Industry Analysis process uses a tool called the Static and Dynamic Business Models Matrix. Its purpose is to better understand a business opportunity in the context of its environment. You can feel free to take as much space as you like in filling out the electronic form. Also, if you feel you cannot adequately summarize all your thoughts about stakeholders in just a few words, it is ok to just say "See StakeholderMatrix," referring back to the previous information you entered in that matrix. Like all of the data collection forms in this study, please fill in your responses with regard to the case of the development of electric vehicle smart charging systems in the Pacific Northwest (OR, WA, ID, and MT). While this topic ultimately may have much more widespread appeal and impact than just this region, it is being examined first in a limited regional context to keep the issues manageable and develop a research design which can then be extended to other areas.

To complete the Static and Dynamic Business Models Matrix, you just need to answer the questions in each column from top to bottom. However, unlike the previous data collection form, please try to keep the responses limited to a shorter responses, such as a word or phrase. The idea is summarize complex concepts. In some cases, as you answer a question in one of the columns, there may be a corresponding question in the next column that becomes easier to answer. For examples, as you describe 
"Markets" in column one, you may then want to enter data in column two regarding "Market Structures." So, while you generally should work from top to bottom in each column, feel free to jump over to the next question and answer questions if you think that makes sense. Also, below are a few clarifications and suggested steps to make this process easier. Like the previous data collection forms, keep this focus question in mind as you are filling out the matrix:

\section{With regard to the development of electric vehicle charging technologies and smart grid in the Pacific Northwest:}

1. Product / Service. This is the first topic in first column of the first row of this matrix. Business Model is the second topic in the first column of the first row. The other two main divisions in the first column are Static and Dynamic. The following issues are address with regard to Static Business model elements: Strategic Model (1); Domain (2); Value Proposition (3); Supply Method (4); Profit Model (5). The following issues are address with regard to Dynamic Business model elements: Sustainable Business Growth (1); and Influence (2). Additional description is being added for each of these topics. Think about how these topics relate to Customers, Markets, or Market Segments.

2. Basic Business. This is the topic of the second column of the second row of this matrix. Basic Business Model can be divided into several alternatives based on possible business channels. In this case a different business channel is described in three different columns these channels. Although many alternatives are possible, the basic alternatives are usually B2B, B2C, and B2G. However, other combinations and arrangements can exist. In the second column of row 
two, consider how a value proposition could be expressed in terms of a product or a service. What is provided by the value proposition that value or customer utility (i.e usefulness) to the person using it or other stakeholders? Lastly, what type of competitiveness do you think would exist in terms of this value proposition.

\title{
Background - Static and Dynamic Business Models
}

\begin{abstract}
A final Industry Analysis method used for understanding business modeling is the Static vs. Dynamic Business Model Matrix [1] [2] [3]. The matrix examines core business areas and which, if any, have the potential to grow or shrink given current conditions and practices, or which areas have the potential to sustain long-term growth. Much of the information on the Static \& Dynamic Business Model Matrix is just a summary of information presented on previous matrices, but it is then categorized according to the areas that contribute to long-term stable growth versus more variable growth. A variety of pros and cons related to each of the basic business models have already been used with previous Industry Analysis tools, but this tool allows a final comparison of some of those similarities and differences, as well as a few new insights about risks and rewards associated with each.
\end{abstract}

To handle the potential for expert disagreement, the Delphi Method will be used. Delphi is a structured communication method using an expert panel [4]. Questions are asked over a series of two or more rounds, or iterative sessions. Experts have the opportunity to revise their answers each round as a result of the information they observe from other experts. The goal is to get the experts opinions to converge on a 
general consensus, which is deemed to be more accurate than individual opinions. In the case of this research, experts will first be asked to log in to their online accounts and enter their judgments individually. The primary investigator will examine all the results and summarize them, attempting to eliminate any redundancies and clarifying any confusion prior to an online meeting with all experts. When all the experts get together for their online meeting, a second round will be conducted. The experts will be asked if the summary fairly represents their view on the complete list of stakeholders for the issue and all the main points they support or oppose. If a majority of experts does not agree, then additional rounds will be conducted until a majority agreement is reached. It is not anticipated that more than 3 rounds will be needed.

\section{References - Static and Dynamic Business Models}

[1] H. Abe, et al., "Integrating Business Modeling and Roadmapping Methods - The Innovation Support Technology (IST) Approach," Technological Forecasting and Social Change, vol. 76, pp. 80-90, 2009.

[2] H. Abe, et al., "Value Creation Framework of Business Modeling Methods for R\&D Outputs," presented at the PICMET (Portland International Conference for Management of Engineering and Technology), 2005.

[3] H. Abe, et al., "A New Framework of Business Modeling Methods for R\&D Outputs: Valuation and Communication Tools for Engineers, Managers, and Investors," presented at the PICMET (Portland International Conference for Management of Engineering and Technology), 2004.

[4] H. A. Linstone and M. Turoff, The Delphi Method: Techniques and Applications. Reading, MA: Addison-Wesley Publishing Company, 1975. 


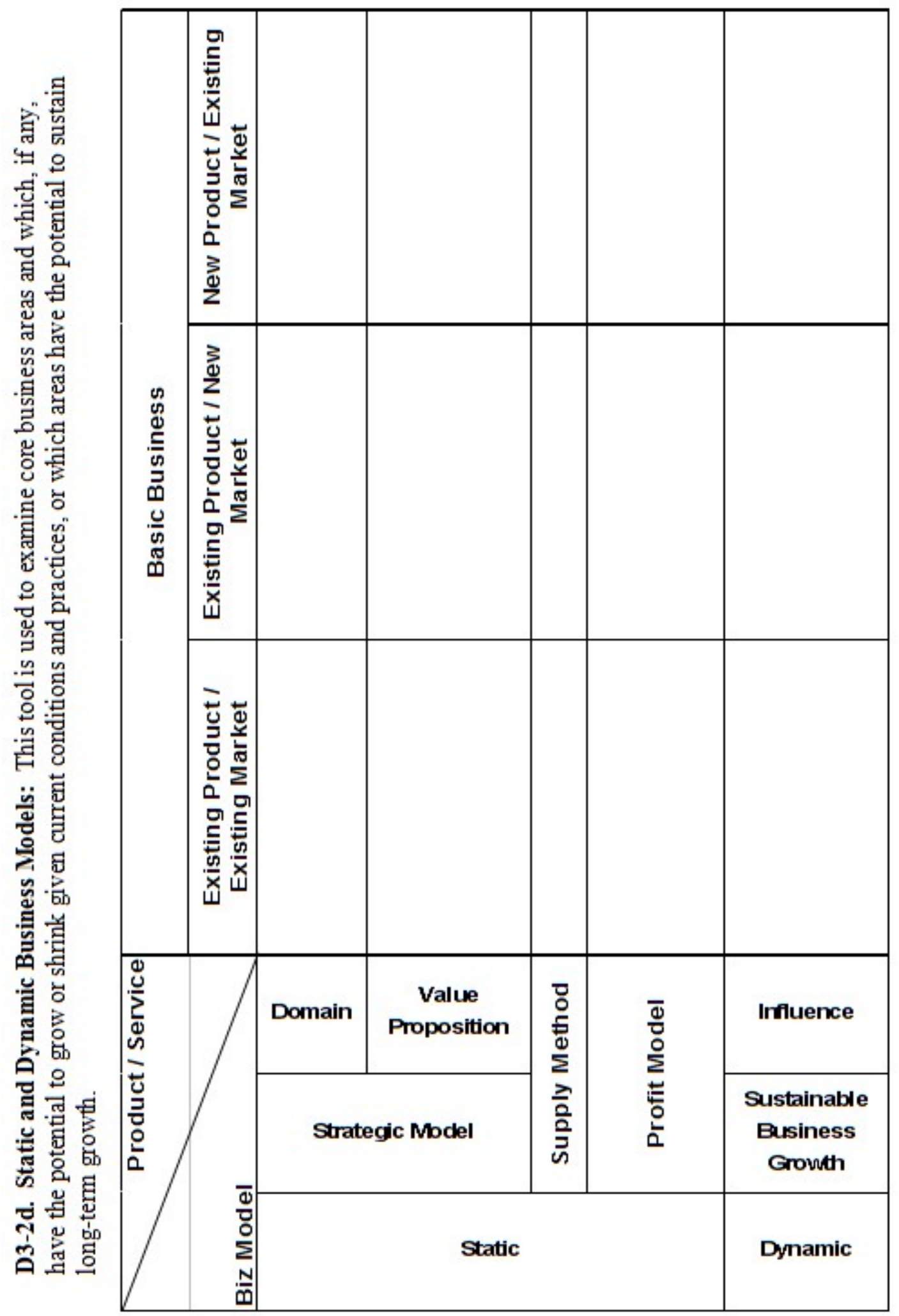


APPENDIX D3-3: Research Approach - Workshop Requirements (Roadmapping \& Prioritization)

RESEARCH APPROACH (PART 3-3):

D3-3. Roadmap Construction \& Prioritization

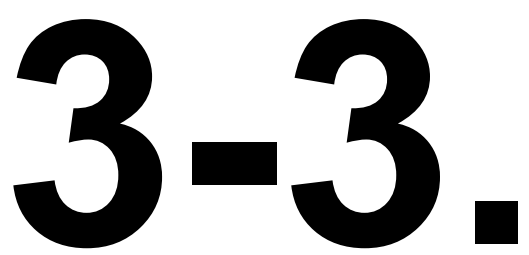




\section{D3-3. Roadmap Construction \& Prioritization}

\section{Portland State \\ University \\ Portland, OR \\ Roadmap Construction \& Prioritization Agenda}

Purpose of Phase 3 Workshop: Roadmap Construction and Prioritization

- Construct Technology Roadmap framework integrating product concept with industry analysis and showing main technology gaps \& needs for mitigation of key barriers

- Prior to this online forum, the data entry form for the workshop will be distributed to the participants by email and completed forms will be returned to the investigator.

- The goal of the online forum will be to facilitate consensus regarding the results of provided on the forms.

9:00 AM Introduction and Overview

9:15 AM Discuss use of Technology Roadmap and tools and review of initial results

9:30 AM Achieving consensus and use of Delphi rounds

- Competion of first round

10:00 AM Assessment of consensus and need for additional rounds

- Additional Delphi processes as needed

10:45 AM Adjournment and Closing Comments 


\section{D3-3. Technology Roadmap Construction \& Prioritization}

\section{D3-3a. Grouped Drivers}

\section{Directions for Expert Input}

Please refer to the set of directions below for filling out this data collection form.

Part A of the Technology Roadmap Construction and Prioritization consists of identifying Grouped Drivers. You can feel free to take as much space as you like in filling out the electronic form. Also, if you feel you cannot adequately summarize all your thoughts about stakeholders in just a few words, it is ok to just say "See StakeholderMatrix," referring back to the previous information you entered in that matrix. Like all of the data collection forms in this study, please fill in your responses with regard to the case of the development of electric vehicle smart charging systems in the Pacific Northwest (OR, WA, ID, and MT). While this topic ultimately may have much more widespread appeal and impact than just this region, it is being examined first in a limited regional context to keep the issues manageable and develop a research design which can then be extended to other areas.

To complete the Grouped Drivers Table, you just need to answer the questions in each column from top to bottom. However, unlike the previous data collection form, please try to keep the responses limited to a shorter responses, such as a word or phrase. The idea is summarize complex concepts. In some cases, as you answer a question in one of the columns, there may be a corresponding question in the next column that becomes easier to answer. For examples, as you describe "Markets" in 
column one, you may then want to enter data in column two regarding "Market Structures." So, while you generally should work from top to bottom in each column, feel free to jump over to the next question and answer questions if you think that makes sense. Also, below are a few clarifications and suggested steps to make this process easier. Like the previous data collection forms, keep this focus question in mind as you are filling out the matrix:

\section{With regard to the development of electric vehicle charging technologies and smart grid in the Pacific Northwest:}

1. Market and Business. This is the key question in the first column of the first row of this matrix. As mentioned above, there is a partial overlap between this question and the questions on the Stakeholder-Objective Matrix. Please use this as an opportunity to summarize in just a few words the names of the stakeholders you identified in the previous section, and a word or two describing the issues important to them. You can feel free to take as much space as you like in filling out the electronic form. Also, if you feel you cannot adequately summarize all your thoughts about stakeholders in just a few words, it is ok to just say "See Stakeholder-Matrix," referring back to the previous information you entered in that matrix. As you are summarizing your thoughts regarding stakeholders, use this as an opportunity to think about whether these stakeholder related to Customers, Markets, or Market Segments.

2. Policy and Regulatory. This is the key question in the first column of the second row of this matrix. To help answer this, the follow up questions in this column prompt you to consider, what do stakeholders have now, and what might they 
want instead in the future. In the second column of row two, consider how a value proposition could be expressed in terms of a product or a service. What is provided by the value proposition that value or customer utility (i.e usefulness) to the person using it or other stakeholders? Lastly, what type of competitiveness do you think would exist in terms of this value proposition? Is it currently a crowed field or a niche market? Will it be easy or hard to maintain competitive advantage?

\section{Background - Roadmap Construction and Prioritization}

The goal of this research phase is to construct a roadmap based on information obtained through the Industry Analysis and Business Concept Development processes. This information will be used to begin constructing the roadmap and prioritizing key factors. In the first step, stakeholder information will be translated into drivers of value production for products and services on a technology roadmap. Product and service performance factors necessary to satisfy these drivers will then be identified. Current products and services that meet existing performance requirements will be identified, along with any gaps or deficiencies in being able to meet these requirements. The initial

process uses a Grouped Driver tool to provide a means of grouping data related to market and business drivers [1] [2] [3]. Expert are also asked to rate the general priority level of each of these drivers based on their views of it overall future impact on the market.

To handle the potential for expert disagreement, the Delphi Method will be used. Delphi is a structured communication method using an expert panel [4]. Questions are 
asked over a series of two or more rounds, or iterative sessions. Experts have the opportunity to revise their answers each round as a result of the information they observe from other experts. The goal is to get the experts opinions to converge on a general consensus, which is deemed to be more accurate than individual opinions. In the case of this research, experts will first be asked to log in to their online accounts and enter their judgments individually. The primary investigator will examine all the results and summarize them, attempting to eliminate any redundancies and clarifying any confusion prior to an online meeting with all experts. When all the experts get together for their online meeting, a second round will be conducted. The experts will be asked if the summary fairly represents their view on the complete list of stakeholders for the issue and all the main points they support or oppose. If a majority of experts does not

agree, then additional rounds will be conducted until a majority agreement is reached. It is not anticipated that more than 3 rounds will be needed.

\section{References - Roadmap Construction and Prioritization}

[1] R. Phaal, et al., T-Plan: The Fast-Start to Technology Roadmapping - Planning your Route to Success. Cambridge: University of Cambridge, Institute for Manufacturing, 2001.

[2] R. Phaal, et al., "Customizing Roadmapping," Research Technology Management, vol. 47, p. 26, 2004.

[3] R. Phaal, et al., "Starting-Up Roadmapping Fast," IEEE Engineering Management Review, vol. 31, pp. 54-60, 2003.

[4] H. A. Linstone and M. Turoff, The Delphi Method: Techniques and Applications. Reading, MA: Addison-Wesley Publishing Company, 1975. 


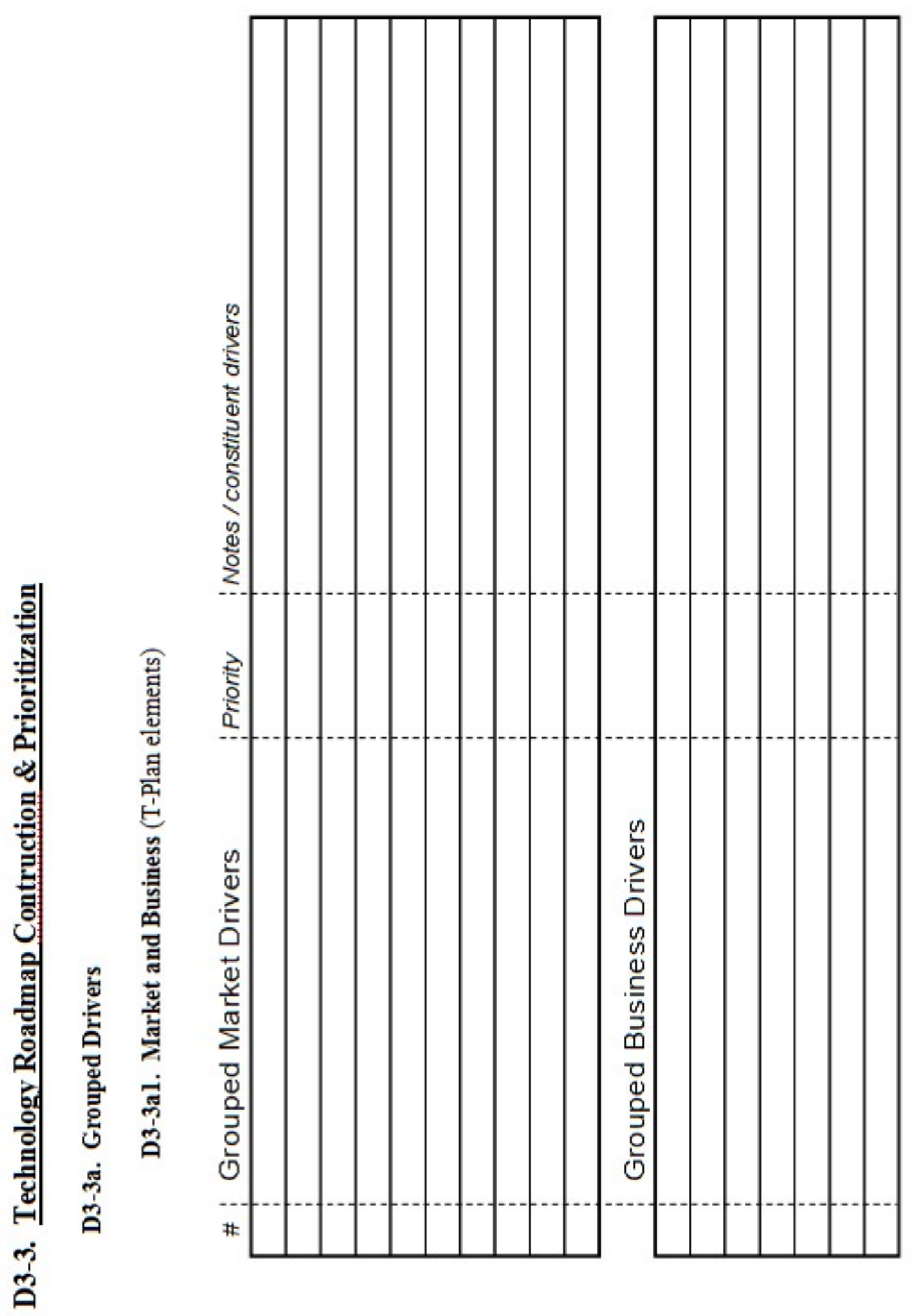




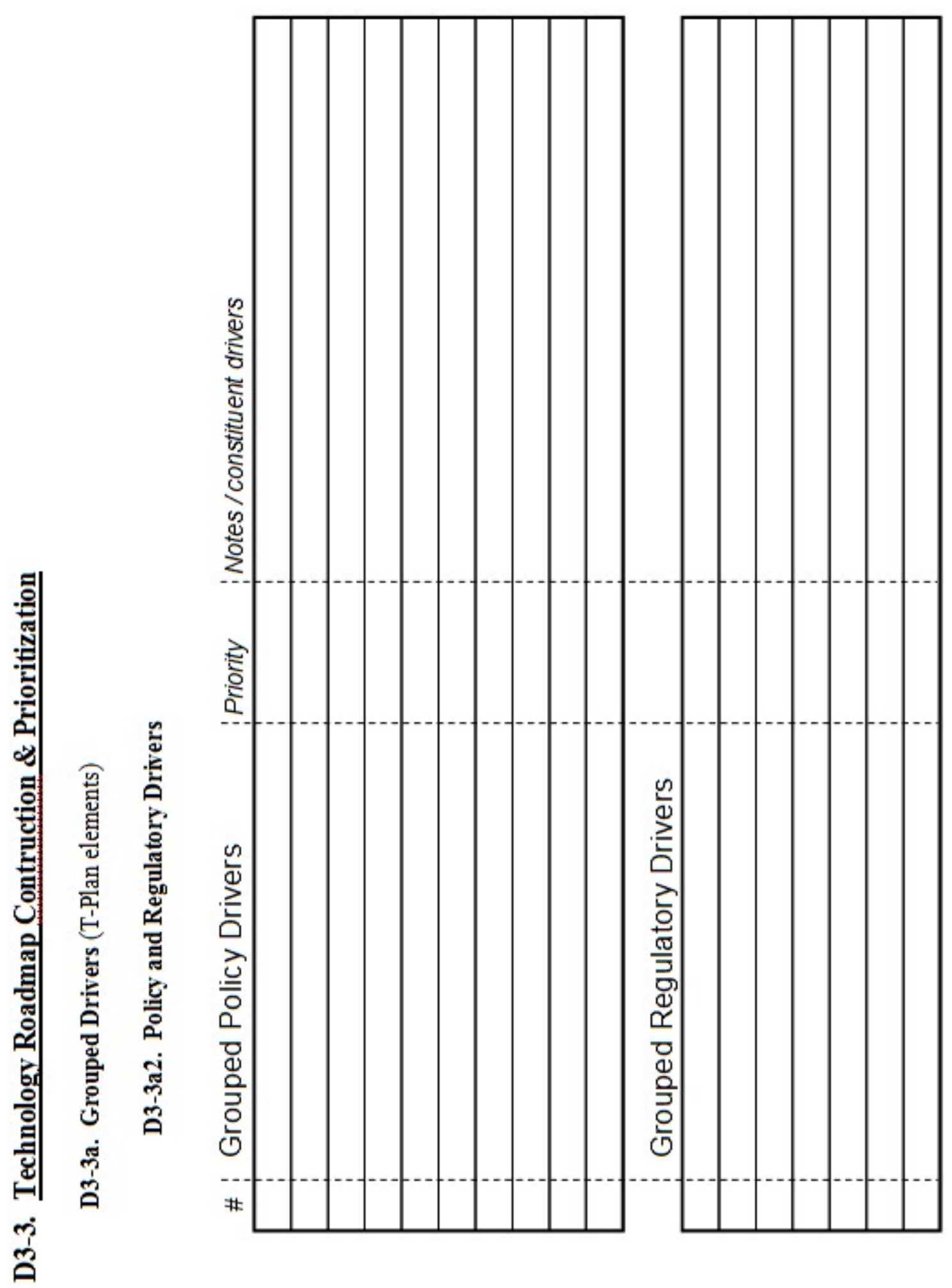




\section{D3-3. Technology Roadmap Construction \& Prioritization}

D3-3b. Prioritization Grids

D3-3b1. Markets-Products Grid

D3-3b2. Product-Technology Grid

D3-3b3. Technology-Barrier Grid

\section{Directions for Expert Input}

Please refer to the set of directions below for filling out this data collection form.

Part b1 through b3 of the Technology Roadmap Construction and Prioritization process Analysis Grids for Markets, Products, Technologies, and Barriers. You can feel free to take as much space as you like in filling out the electronic form. Also, if you feel you cannot adequately summarize all your thoughts about stakeholders in just a few words, it is ok to just say "See Stakeholder-Matrix," referring back to the previous information you entered in that matrix. Like all of the data collection forms in this study, please fill in your responses with regard to the case of the development of electric vehicle smart charging systems in the Pacific Northwest (OR, WA, ID, and MT). While this topic ultimately may have much more widespread appeal and impact than just this region, it is being examined first in a limited regional context to keep the issues manageable and develop a research design which can then be extended to other areas.

To complete the Analysis Grids for Markets, Products, Technologies, and Barriers, you just need to answer the questions in each column from top to bottom. 
However, unlike the previous data collection form, please try to keep the responses limited to a shorter responses, such as a word or phrase. The idea is summarize complex concepts. In some cases, as you answer a question in one of the columns, there may be a corresponding question in the next column that becomes easier to answer. For examples, as you describe "Markets" in column one, you may then want to enter data in column two regarding "Market Structures." So, while you generally should work from top to bottom in each column, feel free to jump over to the next question and answer questions if you think that makes sense. Also, below are a few clarifications and suggested steps to make this process easier. Like the previous data collection forms, keep this focus question in mind as you are filling out the matrix:

\section{With regard to the development of electric vehicle charging technologies and smart grid in the Pacific Northwest:}

1. Market. This is the key question in the first column of the first row of this matrix. As mentioned above, there is a partial overlap between this question and the questions on the Stakeholder-Objective Matrix. Please use this as an opportunity to summarize in just a few words the names of the stakeholders you identified in the previous section, and a word or two describing the issues important to them. You can feel free to take as much space as you like in filling out the electronic form. Also, if you feel you cannot adequately summarize all your thoughts about stakeholders in just a few words, it is ok to just say "See Stakeholder-Matrix," referring back to the previous information you entered in that matrix. As you are summarizing your thoughts regarding stakeholders, use this as an opportunity to think about whether these stakeholders are related to specific Customers, 
Markets, or Market Segments.

2. Product. This is the key question in the first column of the second row of this matrix. To help answer this, the follow up questions in this column prompt you to consider, what do stakeholders have now, and what might they want instead in the future. In the second column of row two, consider how a value proposition could be expressed in terms of a product or a service. What is provided by the value proposition that value or customer utility (i.e usefulness) to the person using it or other stakeholders? Lastly, what type of competitiveness do you think would exist in terms of this value proposition? Is it currently a crowed field or a niche market? Will it be easy or hard to maintain competitive advantage?

3. Technologies. This is the key question in the first column of the third row of this matrix. Describe the key activities that generate value (eg. Sales of equipment, rentals, services, etc.) After considering the value delivery model, how is financing acquired for setting up the enterprise? Will Manufacturing be needed? If so, is it external or internal? What distribution channels will be used for the value delivery?

4. Barriers. Where should the focus be in terms of generating revenue and creating profitability? This is the key question in the first column of the fourth row of this matrix. What Customers, Market, and Segments are expected to provide the most profit and revenue? Also, what type of profit model is being considered? Do you think a business or businesses of this type are generally going to be for-profit or non-profit? What kind of ownership structure are they likely to have? Are they likely to be individually owned companies, partnerships, large business, small businesses, private companies, public companies, or some 
combination of these elements?

\section{Background - Prioritization Grids}

This phase of the roadmapping process takes the information gathered from the grouped drivers that were previously identified and then attempts to match business and market, as well as regulatory and policy drivers to specific product features and performance goals desired by customers and other potential stakeholders for a particular

product. A series of prioritization grid are created using the following procedure. For each row, or feature, on the matrix a score is determined as follows: 1 to 3 check marks are used $(1$ check $=$ low, 2 checks $=$ medium, 3 checks $=$ high $)$, or one to three "X's" can be assigned ( $1 X=-1$ impact, $2 X^{\prime} s=-2$ impact, $3 X^{\prime} s=-3$ impact) [1] [2] [3]. For each column, a driver priority score of 1 to 10 is used, with 1 being a low high priority and 10 being a very high priority. Overall scores are then determined by multiplying each set of row and column scores and then adding up these scores for each category of drivers, such as the business and market, or regulatory and policy drivers shown below, and then normalizing the scores out of 10 . These scores are then shown on the right hand side of the matrix under the heading "Prioritization." Additional score columns can be added if needed.

To handle the potential for expert disagreement, the Delphi Method will be used. Delphi is a structured communication method using an expert panel [4]. Questions are asked over a series of two or more rounds, or iterative sessions. Experts have the opportunity to revise their answers each round as a result of the information they observe from other experts. The goal is to get the experts opinions to converge on a general consensus, which is deemed to be more accurate than individual opinions. In 
the case of this research, experts will first be asked to log in to their online accounts and enter their judgments individually. The primary investigator will examine all the results and summarize them, attempting to eliminate any redundancies and clarifying any confusion prior to an online meeting with all experts. When all the experts get together for their online meeting, a second round will be conducted. The experts will be asked if the summary fairly represents their view on the complete list of stakeholders for the issue and all the main points they support or oppose. If a majority of experts does not agree, then additional rounds will be conducted until a majority agreement is reached. It is not anticipated that more than 3 rounds will be needed.

\section{References - Prioritization Grids}

[1] R. Phaal, et al., T-Plan: The Fast-Start to Technology Roadmapping - Planning your Route to Success. Cambridge: University of Cambridge, Institute for Manufacturing, 2001.

[2] R. Phaal, et al., "Customizing Roadmapping," Research Technology Management, vol. 47, p. 26, 2004.

[3] R. Phaal, et al., "Starting-Up Roadmapping Fast," IEEE Engineering Management Review, vol. 31, pp. 54-60, 2003.

[4] H. A. Linstone and M. Turoff, The Delphi Method: Techniques and Applications. Reading, MA: Addison-Wesley Publishing Company, 1975. 


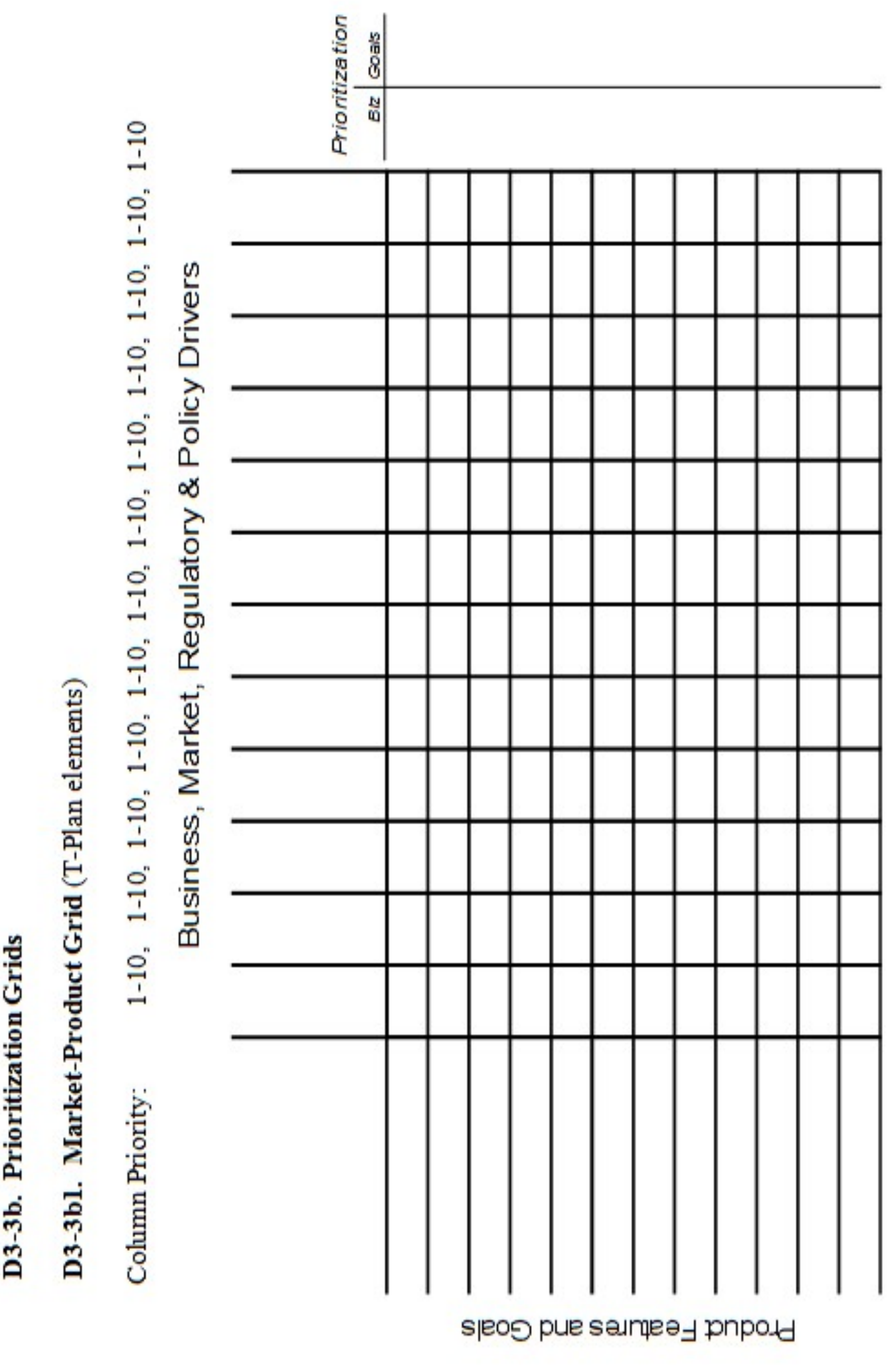




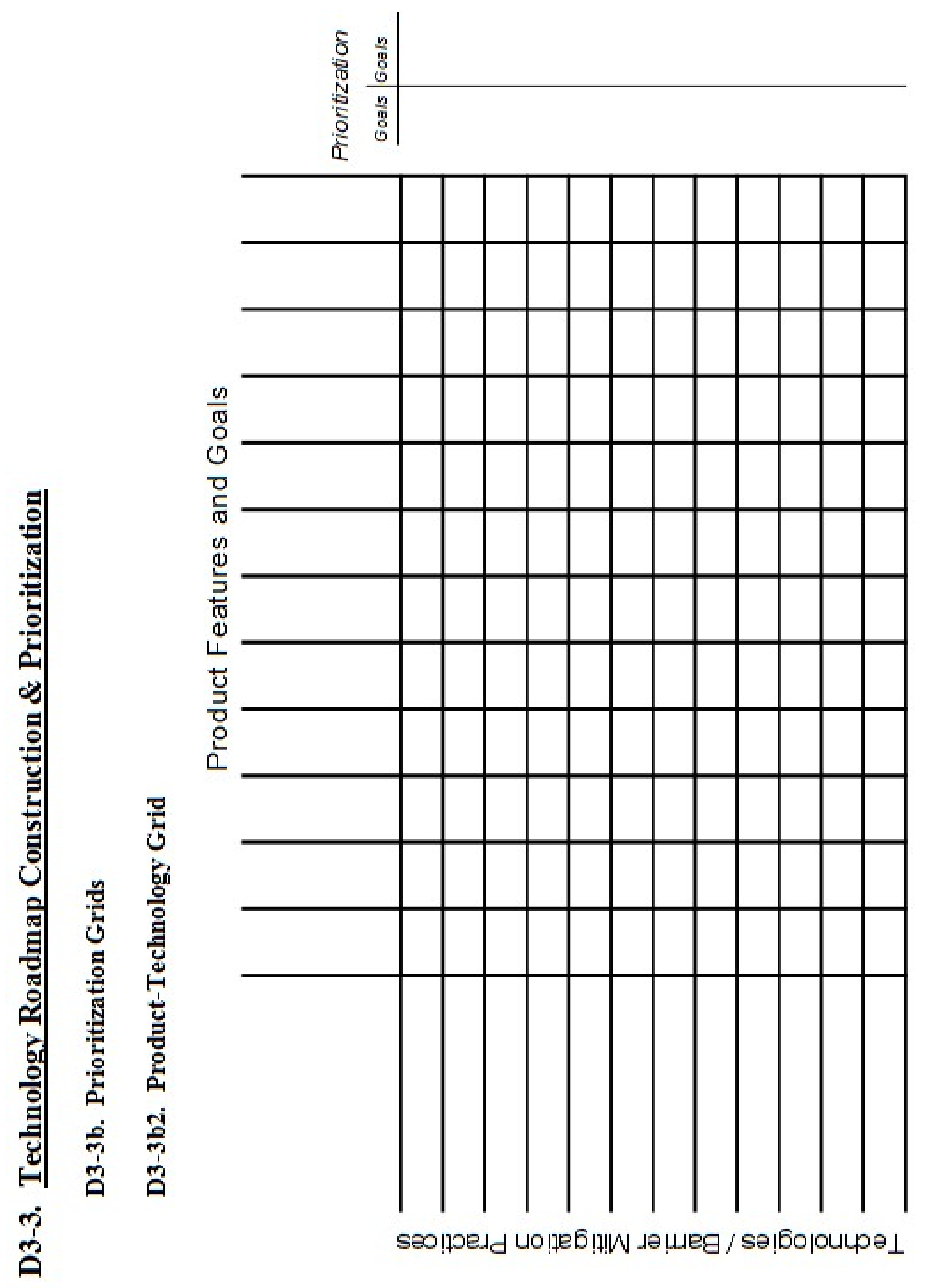




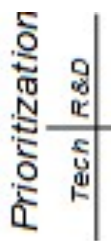

힐

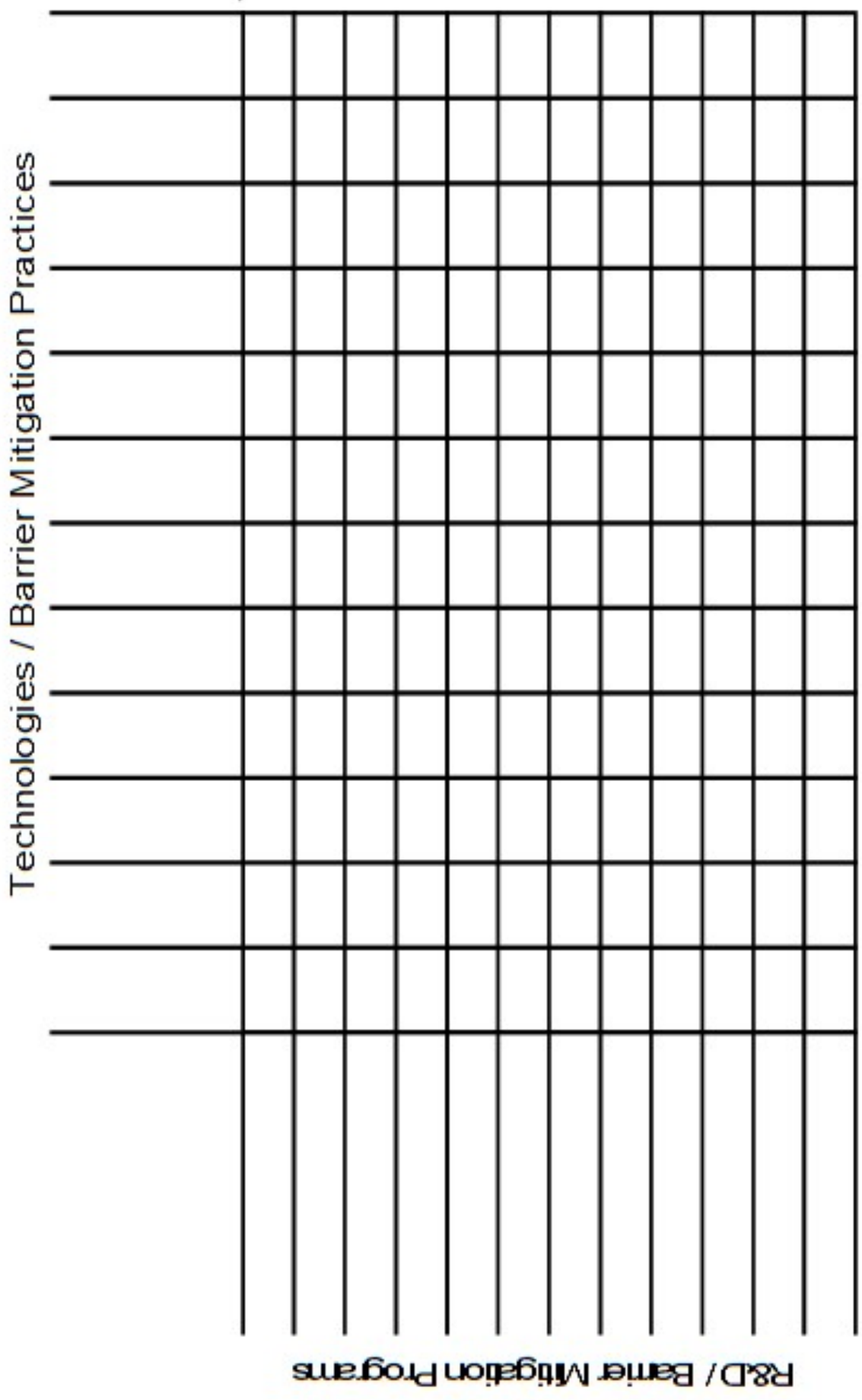




\section{D3-3. Technology Roadmap Construction \& Prioritization}

\section{D3-3c. Technology Roadmap Layout}

\section{Directions for Expert Input}

Please refer to the set of directions below for filling out this data collection form.

Part C of the Technology Roadmap Construction and Prioritization process consists of determining the Technology Roadmap Layout. Please fill in your responses with regard to the case of the development of electric vehicle smart charging systems in the Pacific Northwest (OR, WA, ID, and MT). While this topic ultimately may have much more widespread appeal and impact than just this region, it is being examined first in a limited regional context to keep the issues manageable and develop a research design which can then be extended to other areas.

To construct the Technology Roadmap Layout, you just need to follow the process described below. However, unlike the previous data collection form, please try to keep the responses limited to a shorter responses, such as a word or phrase. The idea is summarize complex concepts. In some cases, as you answer a question in one of the columns, there may be a corresponding question in the next column that becomes easier to answer. For examples, as you describe "Markets" in column one, you may then want to enter data in column two regarding "Market Structures." So, while you generally should work from top to bottom in each column, feel free to jump over to the next question and answer questions if you think that makes sense. Also, below are a few clarifications and suggested steps to make this process easier. Like the previous data 
collection forms, keep this focus question in mind as you are filling out the matrix:

\section{With regard to the development of electric vehicle charging technologies and smart grid in the Pacific Northwest:}

1. Technology Roadmap Layout. The technology roadmap construction and prioritization differs from other section of this research in that it is a group activity and thus is not started individually prior to meeting as a group. Guidelines and process descriptions will be provided during the workshop. Some of these are currently available, but others are still under development. More detail on this will be provided in future iterations of this document.

2. Outcome Analysis. As mentioned for technology roadmap construction and prioritization, this process differs from other section of this research in that it is a group activity and thus is not started individually prior to meeting as a group. Guidelines and process descriptions will be provided during the workshop. Some of these are currently available, but others are still under development. More detail on this will be provided in future iterations of this document.

\section{Background - Technology Roadmap Construction}

Roadmapping is a term used in many industries, but it is not always interpreted in the same way. For the purposes of this research, the technology roadmapping process pioneered by Motorola in the 1980's is the main concept that will be extended [1]. Second generation roadmaps for disruptive technologies were developed by [2]. The concept was further refined in the 1990's [3] and a standard approach, known as the T- 
Plan was developed in early 2000 [4-5]. In addition, a process known as an S-Plan was developed to provide an overview of the strategic landscape for a potential technology product. Such roadmaps are useful for identifying key technologies and gaps that exist in a strategic and technology planning processes [6].

Roadmaps show key possibilities for relationships between technologies and products over time. Most successful roadmaps attempt to integrate the perspectives of "technology push" and the "market pull [7]." In the case of the development of smart grid roadmaps, integration of these perspectives is critical. While the Shumpeterian view that essential change within an industry depends strongly on the type and quality of technology developed in that new industry [8], it also must meet important and well defined market needs, as described by Schmookler [9]. Additionally, the history of strong regulation in the electric utility industry requires an understanding of the policy and regulatory perspectives. As the industry looks at possible regulatory restructuring, the development of new market structures and business models will also be key perspectives to incorporate. Therefore, this research will develop a roadmapping process that specifically considers business and market needs, regulatory and policy issues, and technology development needs. The application of roadmapping to smart grid related industries also need to consider regional implications associated with region spanning utility systems [10-14].

After previous research phases that began the data collection and prioritization processes, a roadmap model incorporating all the data that has been collected can be constructed. The sample model proposed here is just an example. Experts will be free to modify and restructure it as needed. However, the general outline of the sample models offers a number of interesting advantages over current roadmapping models. 
Technology development often occurs to meet multiple market and stakeholder needs and often must function in complex policy and regulatory landscapes. This is especially true in the case of technologies used by in public utility industries. It is difficult to visualize which technologies need to be developed to meet key stakeholder needs, because barriers often exist that would prevent those technologies from perform an intended function. By putting barriers directly on a roadmap, it becomes easier to visualize whether technology development is needed to meet specific goals, or if it could already meet those goals in the absence of barriers. Furthermore, in emerging industries, market structures and business models are often not well defined in the initial stages. By analyzing the need for business model and market development, significant insight may be gained regarding future progress in an industry. In addition, examining how such business model and market development may affect industry barriers could provide suggestions about the type and direction of technology development that needs to occur. Therefore, this roadmap design aims to integrate technology, business, regulatory, and policy issues into a single process that gives a powerful visual representation of the development priorities and pathways. A final stage of outcome analysis is then performed to examine the key learnings from the roadmapping in more detail and make a step-by-step action plan.

To handle the potential for expert disagreement, the Delphi Method will be used. Delphi is a structured communication method using an expert panel [172]. Questions are asked over a series of two or more rounds, or iterative sessions. Experts have the opportunity to revise their answers each round as a result of the information they observe from other experts. The goal is to get the experts opinions to converge on a general consensus, which is deemed to be more accurate than individual opinions. In the case of this research, experts will first be asked to log in to their online accounts and 
enter their judgments individually. The primary investigator will examine all the results and summarize them, attempting to eliminate any redundancies and clarifying any confusion prior to an online meeting with all experts. When all the experts get together for their online meeting, a second round will be conducted. The experts will be asked if the summary fairly represents their view on the complete list of stakeholders for the issue and all the main points they support or oppose. If a majority of experts does not agree, then additional rounds will be conducted until a majority agreement is reached. It is possible that many rounded will be needed to complete this process.

\section{References - Technology Roadmap Construction}

[1] C. H. Willyard and C. W. McClees, "Motorola's Technology Roadmap Process," Research Management, pp. 13-19, 1987.

[2] S. T. Walsh, "Roadmapping a Disruptive Technology: A Case Study," Technological Forecasting and Social Change, vol. 71, pp. 161-185, 2004.

[3] O. H. Bray and M. L. Garcia, Technology Roadmapping: The Integration of Strategic and Technology Planning for Competitiveness. Portland, OR: PICMET (Portland International Conference on Management of Engineering and Technology), 1997.

[4] R. Phaal, et al., T-Plan: The Fast-Start to Technology Roadmapping - Planning your Route to Success. Cambridge: University of Cambridge, Institute for Manufacturing, 2001.

[5] R. Phaal, et al., "Technology Roadmapping - A Planning Framework for Evolution and Revolution," Technological Forecasting and Social Change., vol. 71, p. 5, 2004.

[6] C. Holmes and M. Ferrill, "The application of Operation and Technology Roadmapping to aid Singaporean SMEs identify and select emerging technologies," Technological Forecasting and Social Change, vol. 72, pp. 349$357,2005$. 
[7] A. Nauda and D. L. Hall, "Strategic technology planning--developing roadmaps for competitive advantage," in Portland International Conference on

Management of Engineering and Technology, Portland, OR, 1991, pp. 745-748.

[8] J. A. Schumpeter and R. Opie, The Theory of Economic Development: An Inquiry into Profits, Capital, Credit, Interest, and the Business Cycle. Cambridge, MA: Harvard University Press, 1934.

[9] R. Coombs, et al., Economics and Technological Change. Totowa, N.J.: Rowman \& Littlefield, 1987.

[10] T. Daim and T. Oliver, "Implementing Technology Roadmapping Process: A Case Study of a Government Agency," Technology Forecasting \& Social Change, vol. 75, pp. 687-720, 2008.

[11] K. R. Cowan and T. Daim, "Comparative Technological Roadmapping for Renewable Energy," Technology in Society, vol. 31, pp. 333-341, 2009.

[12] T. U. Daim, et al., "Technology Roadmapping for Wind Energy: Case of the Pacific Northwest," Journal of Cleaner Production, vol. 20, pp. 27-37, 2012.

[13] T. Daim, et al., "Technology Roadmapping: An Efficient Tool for Driving Regional Technological Changes," in Sustainable Systems and Energy Management at the Regional Level, 2012.

[14] T. Daim, et al., "Technology Development Envelope Approach for the Adoption of Future Powertrain Technologies: A Case Study on Ford Otosan Roadmapping Model," Journal of Transportation Systems Engineering and Information Technology, vol. 11, pp. 58-69, 2012. 


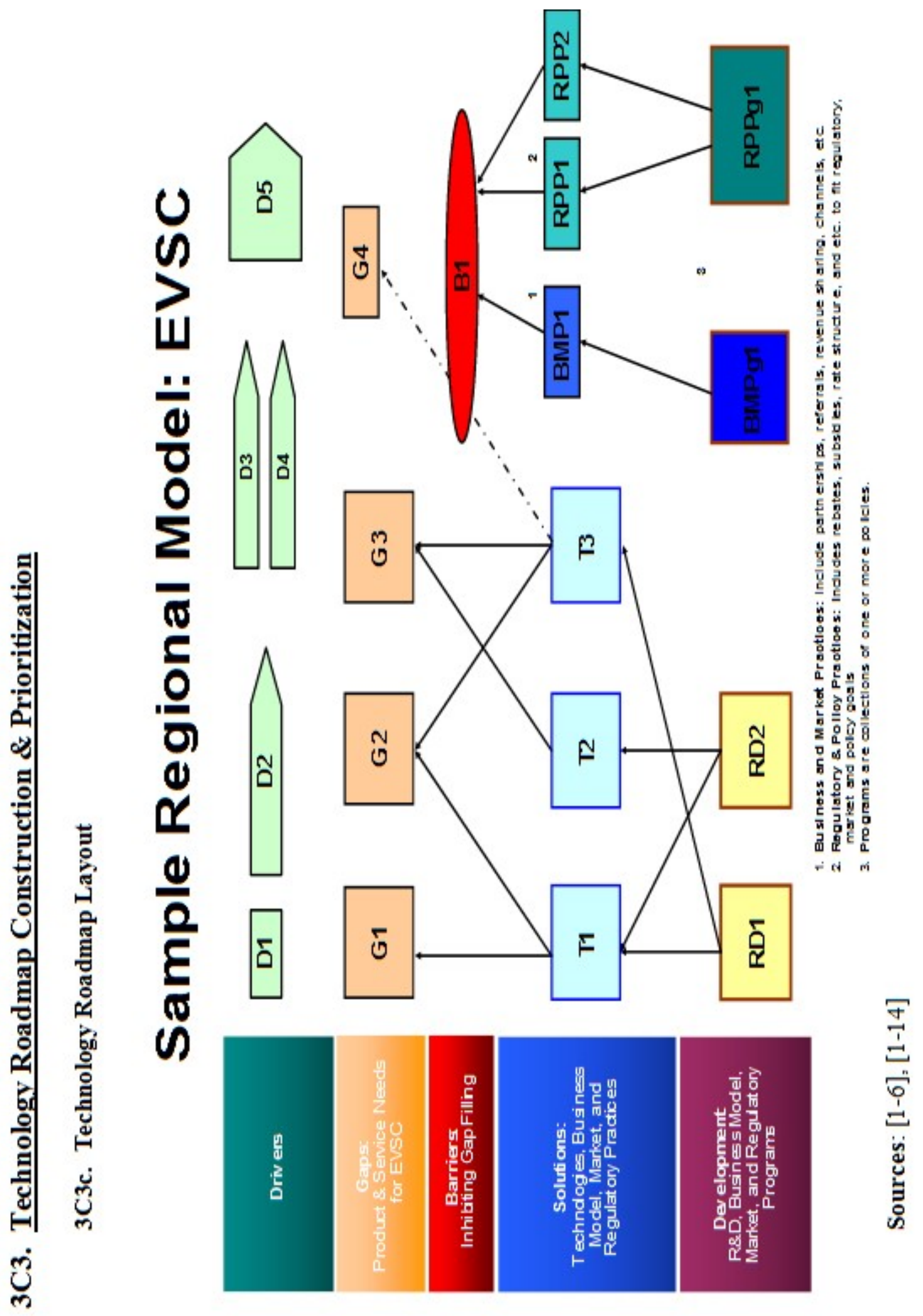


APPENDIX D3-4: Research Approach - Workshop Requirements (Analysis \& Synthesis)

\section{RESEARCH APPROACH (PART 3-4):}

D3-4. Analysis \& Synthesis

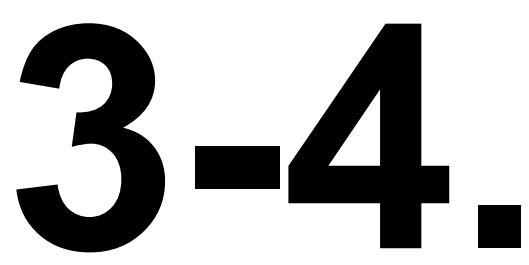




\section{D3-4. Analysis \& Synthesis}

\section{Portland State \\ University \\ Portland, OR \\ Analysis and Synthesis Process Outline}

Purpose of Phase 4 Workshop: Analysis and Synthesis

- Using prioritized Technology Roadmap, identify deliverables and main paths and dependencies for desired outcomes.

- After consensus is achieved on roadmap in prior research phase, this phase will be conducted by the research asynchronously.

- However, as needed, experts will be consulted to clarify remaining issues

\section{Deliverables}

- Prioritized requirements to meet desired outcomes

- Paths and Dependencies: Action steps over time with prioritized requirements

\section{Validity}

- Content Validity: Research instruments will be tested and reviewed by expert advisory group to confirm no ambiguity or confusion

- Construct Validity: Expert panel will rate relevance, importance and ease of answering questions

- Criteria Validity:After the study, experts will rate how well final results match roadmapping needs and expectations

- K-means clustering will be used for determining most significant barriers

\section{Consistency}

- Delphi method used for resolving inconsistencies in expert judgment during study

- After study, consistency of judgments analyzed with a combination of appropirate statistical tests, including the K-S test, Chi Square, and Krippendorf's alpha

\section{Analysis and Conclusion}

- Synthesis of results, conclusions, contributions 


\section{D3-4. Analysis of Data \& Synthesis of Results}

\section{Background - Analysis and Results}

When three main research phases are completed, results will be analyzed and summarized. The main paths to desired outcomes will be identified and the factor dependencies exist in order to achieve these outcomes. Using prioritized Technology Roadmap, deliverables will be identified, along and main paths and dependencies for desired outcomes. After consensus is achieved on roadmap in prior research phase, this phase will be conducted by the research asynchronously. Experts will be consulted to clarify remaining issues. Deliverables include prioritized requirements to meet desired outcomes. Paths and dependencies are action steps over time with prioritized requirements.

Several types of validity tests [1] will be conducted, which will be described in greated detail in Chapter 6. Content validity will be established by testing research instruments, which will be reviewed by expert advisory group to minimize ambiguity and confusion in the data collection process. Construct validity will be established using an expert panel that will rate the relevance, importance and ease of responding to each instrument. Criteria validity will be established after the study by asking experts to rate how well they feel the final results match roadmapping needs and expectations they have. K-means clustering will be used for determining most significant barriers [2]. Consistency will be established primarily by using the Delphi Method used for resolving inconsistencies in expert judgments during study [3]. 
After consensus is achieved on roadmap in prior research phase, this phase will be conducted by the research asynchronously. Experts will be consulted to clarify remaining issues. Deliverables include prioritized requirements to meet desired outcomes. Paths and dependencies are action steps over time with prioritized requirements. After the study, consistency of judgments analyzed with Krippendorf's alpha [4] [5], the standard statistical test in social science research for loosely structured textual content data. It works with small sample sizes like the expert groups recruited for this study. Final analysis and conclusions will then be done drawing upon a variety of qualitative research techniques [6] [7] [8], including case study analysis [9]. Then final results, limitations, and contributions will be determined.

\section{References - Analysis of Results}

[1] R. R. Cooper and P. S. Schindler, Business Research Methods. Boston, Mass.: McGraw-Hill, 2007.

[2] R. Xu and W. D. C., Clustering. Oxford: Wiley, 2009.

[3] H. A. Linstone and M. Turoff, The Delphi Method: Techniques and Applications. Reading, MA: Addison-Wesley Publishing Company, 1975.

[4] A. F. Hayes and K. Krippendorff, "Answering the Call for a Standard Reliability Measure for Coding Data," Communication Methods and Measures, vol. 1, pp. 77-89, 2007.

[5] J. F. Hair, Multivariate Data Analysis: A Global Perspective. Upper Saddle River, NJ: Pearson Education, 2009.

[6] K. E. M. Howe, "Standards for Qualitative (and Quantitative) Research: A Prolegomenon," Educational Researcher Educational Researcher, vol. 19, pp. 29, 1990.

[7] R. W. Scholz and O. Tietje, Embedded Case Study Methods: Integrating Quantitative and Qualitative Knowledge. Thousand Oaks, CA: Sage Publications, 2002. 
[8] A. Tashakkori and C. Teddlie, Sage Handbook of Mixed Methods in Social \& Behavioral Research. Los Angeles, CA: SAGE Publications, 2010.

[9] R. K. Yin, Case Study Research : Design and Methods. Thousand Oaks, CA: Sage, 2013. 


\section{APPENDIX E1: Market Drivers}

\begin{tabular}{|c|c|c|}
\hline$\#$ & Market Drivers & Description \\
\hline DM1 & $\begin{array}{l}\text { Energy Management, Emissions, and } \\
\text { Sustainability }\end{array}$ & $\begin{array}{l}\text { This driver represents the need expressed by green consumers } \\
\text { who drive EVs for understanding the carbon footprint produced } \\
\text { by their vehicle, through "upstream emissions," such as when } \\
\text { they use electricity generated by power plants burning coal or } \\
\text { natural gas. Environmentally conscious consumers have } \\
\text { expressed an interest in better understanding how their carbon } \\
\text { footprint varies due to EV charging under from different } \\
\text { sources, as well as the how the costs of those different sources } \\
\text { affects their power bill. Technology available with some vehicle } \\
\text { charging systems or after market software applications meets } \\
\text { some of these needs. However, this driver represents the need } \\
\text { for further development of products, services, and standards for } \\
\text { better understanding this issue. Linked to DM4 }\end{array}$ \\
\hline DM2 & $\begin{array}{l}\text { Improved Electric Vehicle } \\
\text { Batteries Performance }\end{array}$ & $\begin{array}{l}\text { This driver represents the need to improve cost versus } \\
\text { performance ratios for electric vehicle batteries. The primary } \\
\text { challenge for electric vehicle batteries is to improve their } \\
\text { storage capacity while also reducing costs. The main reason for } \\
\text { increasing energy storage capacity is to allow vehicles to travel } \\
\text { longer distances without having to recharge. Another way to } \\
\text { achieve long range travel is to increase the speed at which } \\
\text { batteries can recharge. So, if a quick charging battery can be } \\
\text { made inexpensively, it may be another way to drive down costs. } \\
\text { Another closely linked battery performance issue is the service } \\
\text { life, or number of charge cycles that a battery can perform } \\
\text { before it wears out. While battery cost, storage capacity, vehicle } \\
\text { range, charging speed, and service life are different issues, they } \\
\text { are closely linked, as a change in any one of them can strongly } \\
\text { affect the others. So, for an electric vehicle battery to be } \\
\text { considered an improvement over existing batteries, it need to } \\
\text { achieve an optimal mix of these characteristics. }\end{array}$ \\
\hline DM3 & Reduce Vehicle Cost & $\begin{array}{l}\text { This driver represents the need for low a low cost vehicle which } \\
\text { provides transportation at a low total cost of ownership. The } \\
\text { upfront purchase cost of an automobile is generally the most } \\
\text { expensive part of of the total cost for owning such a vehicle, } \\
\text { followed by operations and maintenance costs. For electric } \\
\text { vehicles, it has been noted that the purchase costs are currently } \\
\text { much higher than internal combustion vehilces, primarily due to } \\
\text { high battery costs. However, the operational costs of using } \\
\text { electricity instead of gasoline is much lower, owing to the } \\
\text { higher efficiency of electric motors. Maintenance costs are } \\
\text { generally lower as well. So, in looking to reduce electric vehicle } \\
\text { costs, the most meaningful comparison is total cost of } \\
\text { ownership. }\end{array}$ \\
\hline DM4 & Consumer EV Incentives & $\begin{array}{l}\text { Consumers purchasing EV can receive incentives, often in the } \\
\text { form of tax credits to help offset the high initial cost of } \\
\text { purchasing an EV. There are also subsidies available for some } \\
\text { forms of electric vehicle charging stations for home use. In } \\
\text { addition, rate structures setting either standard EV rates or time }\end{array}$ \\
\hline
\end{tabular}




\begin{tabular}{|l|l|l|}
\hline & $\begin{array}{l}\text { of use rates are critical for managing total charging costs. } \\
\text { Linked to DM 3 }\end{array}$ \\
\hline
\end{tabular}




\section{APPENDIX E2: Business Drivers}

\begin{tabular}{|c|c|c|}
\hline$\#$ & Market Drivers & Description \\
\hline DB1 & $\begin{array}{c}\text { Transactive Energy Product / } \\
\text { Service Development }\end{array}$ & $\begin{array}{l}\text { This driver represents the need for transactive energy product } \\
\text { and service development. As described in DR3, from a } \\
\text { regulatory perspective, transactive energy systems are evolving } \\
\text { methods of electricity supply and demand management which } \\
\text { can treat each use of electricity on a grid system as if it were } \\
\text { discrete financial transaction. }\end{array}$ \\
\hline DB2 & $\begin{array}{l}\text { Development of Export Market } \\
\text { for EV Charging Products and } \\
\text { Services }\end{array}$ & $\begin{array}{l}\text { This driver represents the need for development of electric } \\
\text { vehicle charging products and services which can be tested in } \\
\text { relatively small markets, like Oregon, but then exported to other } \\
\text { regions of the country and the world. }\end{array}$ \\
\hline DB3 & $\begin{array}{l}\text { Reducing Utility Peak Costs } \\
\text { (Demand Response, Ancillary } \\
\text { services) }\end{array}$ & $\begin{array}{l}\text { This driver represents a key business need, which is the } \\
\text { development of systems for reducing peak utility costs, through } \\
\text { technologies such as demand response. Products or services } \\
\text { which can perform this function may work by managing the } \\
\text { supply and demand of ancillary services for utility customers. } \\
\text { These services could be provided by electric vehicle charging } \\
\text { sytems. One way to provide this is with the transactive energy } \\
\text { systems mentioned in DB1 and DR3. }\end{array}$ \\
\hline DB4 & $\begin{array}{l}\text { Need for Grid Support Services } \\
\text { to Enhance Stability }\end{array}$ & $\begin{array}{l}\text { This driver represents the need for development of systems } \\
\text { improving the stability of power grid operations. Smart grid } \\
\text { technologies often offer many possible ways to increase grid } \\
\text { stability, including the management of ancillary services, which } \\
\text { could be provided through electric vehicle charging systems. } \\
\text { Linked to DB1 and DR3. }\end{array}$ \\
\hline DB5 & $\begin{array}{l}\text { Business Finance Mechanisms to } \\
\text { Promote Adoption and } \\
\text { Investment }\end{array}$ & $\begin{array}{l}\text { This driver represents the need for development of appropriate } \\
\text { financial mechanisms to promote the adoption of electric } \\
\text { vehicle charging technology and infrastructure investment. } \\
\text { Some of these investments are considerable, such as grid-wide } \\
\text { charging infrastructure, so specific methods of promoting such } \\
\text { investments are needed to make viable business case for these } \\
\text { investments. }\end{array}$ \\
\hline
\end{tabular}




\section{APPENDIX E3: Regulatory Drivers}

\begin{tabular}{|c|c|c|}
\hline \# & Regulatory Drivers & Description \\
\hline DR1 & $\begin{array}{l}\text { Zero Emissions Vehicle Sales } \\
\text { Mandate (ZEV / PZEV) }\end{array}$ & $\begin{array}{l}\text { This driver represents the need requirement for the sale of } \\
\text { ZEVs/PZEVs as mentioned from a market perspective in DM2. } \\
\text { Linked to DP6 ZEV sales requirement in CA and other states. } \\
\text { Linked to DP1, DP4, DP5, DM2. }\end{array}$ \\
\hline DR2 & $\begin{array}{l}\text { Regulation \& Legislation on EV } \\
\text { charging rates and processes }\end{array}$ & $\begin{array}{l}\text { This driver represents regulatory and legislative mandates which } \\
\text { have specified either specific rates that can be charged for } \\
\text { certain types of electric vehicle charging, rate plans or general } \\
\text { structures which are allowed, or other rules or standards } \\
\text { governing the process of how EV charging is allowed to be } \\
\text { performed. }\end{array}$ \\
\hline DR3 & $\begin{array}{c}\text { Transactive Energy Standards } \\
\text { Development }\end{array}$ & $\begin{array}{l}\text { This driver represents the need for development of transactive } \\
\text { energy systems, which are evolving methods of electricity } \\
\text { supply and demand management which can treat each use of } \\
\text { electricity on a grid system as if it were discrete financial } \\
\text { transaction. }\end{array}$ \\
\hline DR4 & $\begin{array}{c}\text { Charging Hardware / Software } \\
\text { Standardization }\end{array}$ & $\begin{array}{l}\text { This driver represents the need to continue the development of } \\
\text { hardware and software standards used for electric vehicle } \\
\text { charging. }\end{array}$ \\
\hline DR5 & $\begin{array}{l}\text { Plans for Grid Modernization and } \\
\text { Stability }\end{array}$ & $\begin{array}{l}\text { This driver represents the need to integrate plans for the } \\
\text { development of electric vehicle charging infrastructure with } \\
\text { existing or future plans to invest in grid modernization } \\
\text { technology and enhance grid stability. In theory, such plans can } \\
\text { be synchronized, but often it is unclear how EV infrastructure } \\
\text { plans relate to other grid modernization plans. }\end{array}$ \\
\hline
\end{tabular}




\section{APPENDIX E4: Policy Drivers}

\begin{tabular}{|c|c|c|}
\hline \# & Regulatory Drivers & Description \\
\hline DP1 & Reducing Vehicle Emissions & $\begin{array}{l}\text { This driver represents the need for reducing vehicle emissions. } \\
\text { It is linked market factors like the ZEV mandate in DM2. The } \\
\text { mandate defines emission both regarding the toxicity of } \\
\text { pollutants emits that can be harmful to health and contribute to } \\
\text { climate change. }\end{array}$ \\
\hline DP2 & $\begin{array}{l}\text { Vehicle Energy Efficiency } \\
\text { Policies }\end{array}$ & $\begin{array}{l}\text { This driver represents the need for policies to promote } \\
\text { improvement of vehicle energy efficiency. Linked to DM } 3 .\end{array}$ \\
\hline DP3 & $\begin{array}{l}\text { State and Regional Energy } \\
\text { Resource Planning Goals }\end{array}$ & $\begin{array}{l}\text { This driver represents the need for state and regional energy } \\
\text { resource planning goals, such as integrated resource planning, } \\
\text { or the type of regional planning done in the Pacific Northwest } \\
\text { by the Northwest Power and Conservation Council. }\end{array}$ \\
\hline DP4 & $\begin{array}{l}\text { State and Regional Emissions } \\
\text { Policies or Plans }\end{array}$ & $\begin{array}{l}\text { This driver represents the need for state and regional emissions } \\
\text { planning goals. }\end{array}$ \\
\hline DP5 & $\begin{array}{c}\text { Electric Vehicle Adoption Goals } \\
\text { or Plans }\end{array}$ & $\begin{array}{l}\text { This driver represents the electric vehicle adoption goals or } \\
\text { plans that are often set by governments at the national, state, or } \\
\text { regional level. Adoption plans may not exist at all of these } \\
\text { levels, but in areas where they do exist, they may contribute to } \\
\text { meeting energy resource planning goals and emissions goals. } \\
\text { Linked to DP } 3 \text { and DP4. }\end{array}$ \\
\hline DP6 & Renewable Portfolio Standard & $\begin{array}{l}\text { This driver represents the Renewable Portfolio Standard } \\
\text { requirements which have been put in place by over } 30 \text { states } \\
\text { across the US. An RPS requires a certain amount of energy } \\
\text { production, typically limited to electricity generation, to be } \\
\text { produced from specific sources of renewable energy by } \\
\text { specified dates. }\end{array}$ \\
\hline DP7 & Business EV Charger Incentives & $\begin{array}{l}\text { This driver represents the need to encourage and/or incentivize } \\
\text { businesses to install and operate EV charging stations. }\end{array}$ \\
\hline DP8 & $\begin{array}{l}\text { Renewable Energy Integration } \\
\text { Needs }\end{array}$ & $\begin{array}{l}\text { This driver represents the need for the integrate sources of } \\
\text { renewable energy onto the power grid. The highest need for } \\
\text { such integration occurs in states which have adopted an RPS. } \\
\text { Linked to DP6. }\end{array}$ \\
\hline DP9 & $\begin{array}{l}\text { Charging Infrastructure Upgrades } \\
\text { and Investment Needs }\end{array}$ & $\begin{array}{l}\text { This driver represents the need to for investment and upgrades } \\
\text { in electric vehicle charging infrastructures on local, state, } \\
\text { regional, and national levels. }\end{array}$ \\
\hline
\end{tabular}




\section{APPENDIX F1: Roadmapping - Problem Characteristics}

\begin{tabular}{|c|c|c|}
\hline$\#$ & Problem Characteristic & Description \\
\hline PC1 & $\begin{array}{l}\text { Deployment requirements for } \\
\text { improved charging equipment } \\
\text { infrastructure }\end{array}$ & $\begin{array}{l}\text { This problem characteristic represents the need for deployment } \\
\text { of improved charging infrastructure and equipment. } \\
\text { Deployment plans are needed for implementation of } \\
\text { infrastructure improvements in both urban and rural areas in } \\
\text { ways which could support electric vehicle charger development, } \\
\text { as well as fit with existing goals for modernization and } \\
\text { improvement of grid reliability. }\end{array}$ \\
\hline PC2 & $\begin{array}{l}\text { Transactive energy service } \\
\text { standards development and grid } \\
\text { interface processes }\end{array}$ & $\begin{array}{l}\text { This problem characteristic represents the need for } \\
\text { standardization of Transactive Energy service/product } \\
\text { development and grid interface processes. Currently, the } \\
\text { National Association of Regulatory Utility Commissioners } \\
\text { (NARUC) has a Business and Regulatory Assistance Project } \\
\text { which helps with the standardization of some of these processes. } \\
\text { Therefore, the starting point for this would be to tap into those } \\
\text { resources and customize them specifically with respect to } \\
\text { specific transactive energy products. }\end{array}$ \\
\hline PC3 & $\begin{array}{l}\text { Renewable energy integration } \\
\text { service and product requirements }\end{array}$ & $\begin{array}{l}\text { This problem characteristic represents the need to understand } \\
\text { the potential connection between electric vehicle charger } \\
\text { development and enabling of renewable energy integration } \\
\text { service / product development. }\end{array}$ \\
\hline PC4 & $\begin{array}{l}\text { Requirements for consumer } \\
\text { energy management and tracking } \\
\text { products and services }\end{array}$ & $\begin{array}{l}\text { This problem characteristic represents the need to develop } \\
\text { consumer energy management and tracking products. These } \\
\text { products would be targeted at environmentally conscious "green } \\
\text { energy consumers," who would use the product to manage Time } \\
\text { of Use (TOU) energy products, as well as better remote } \\
\text { management and energy usage control. }\end{array}$ \\
\hline PC5 & $\begin{array}{l}\text { Requirements for standardized 1- } \\
\text { way EV-grid systems }\end{array}$ & $\begin{array}{l}\text { This problem characteristic represents the need for development } \\
\text { of standardized } 1 \text {-way EV-grid systems. This is also called } \\
\text { electric vehicle smart charging or V2G/2. }\end{array}$ \\
\hline PC6 & $\begin{array}{l}\text { Requirements for standardized 2- } \\
\text { way EV-grid systems }\end{array}$ & $\begin{array}{l}\text { This problem characteristic represents the need for development } \\
\text { of standardized 2-way EV-grid systems. Examples of this are } \\
\text { electric vehicle to grid (V2G), vehicle to business (V2B), and } \\
\text { vehicle to home (V2H) systems. }\end{array}$ \\
\hline
\end{tabular}




\section{APPENDIX F2: Roadmapping - Gaps}

\begin{tabular}{|c|c|c|}
\hline \# & Gap & Description \\
\hline Gp1 & Reducing Charging Station Costs & $\begin{array}{l}\text { This gap represents the need for reducing charging station costs, } \\
\text { including reduction in initial capital costs and improvements in } \\
\text { operating efficiencies. }\end{array}$ \\
\hline Gp2 & $\begin{array}{l}\text { Simplifying Charging Station } \\
\text { Installation }\end{array}$ & $\begin{array}{l}\text { This gap represents the need for simplifying charging station } \\
\text { installation costs, reducing both labor and capital costs and } \\
\text { improving reliability. }\end{array}$ \\
\hline Gp3 & $\begin{array}{l}\text { Need for 2-way Grid to Vehicle } \\
\text { Charger Communication }\end{array}$ & $\begin{array}{l}\text { This gap represents the need for development of improved } \\
\text { systems for 2-way Vehicle-to-Grid Charger Communication, } \\
\text { such as Vehilce-to-Grid (V2G), Vehicle-to-Building (V2B), and } \\
\text { Vehicle-to-Home (V2H) systems. Examples of this include } \\
\text { efforts to develop lower cost SCADA systems, which are } \\
\text { currently used for remote monitoring and control of utility } \\
\text { systems. }\end{array}$ \\
\hline Gp4 & $\begin{array}{l}\text { Need for 1-way Grid to Vehicle } \\
\text { Charger Communication } \\
\text { development. }\end{array}$ & $\begin{array}{l}\text { This gap represents the need to continue the development of 1- } \\
\text { way vehicle to grid charger communication used for electric } \\
\text { vehicle charging, such as EVSC HW / SW process } \\
\text { standardization. }\end{array}$ \\
\hline Gp5 & $\begin{array}{l}\text { Need for Charging HW and SW } \\
\text { Standards Development for } \\
\text { Battery Secondary Use }\end{array}$ & $\begin{array}{l}\text { This gap represents the need to continue the development of } \\
\text { hardware and software standards used for electric vehicle } \\
\text { charging, including standards development to deal with battery } \\
\text { secondary use and warranty issues. }\end{array}$ \\
\hline Gp6 & $\begin{array}{l}\text { Need for Consumer Energy Mgt } \\
\text { \& Tracking Products and } \\
\text { Services }\end{array}$ & $\begin{array}{l}\text { This gap represents the need to continue the development of } \\
\text { consumer energy management and tracking product and service } \\
\text { development needs for electric vehicle charging. This may take } \\
\text { the form of an interface known as a carbon footprint dashboard. }\end{array}$ \\
\hline
\end{tabular}




\section{APPENDIX F3: Roadmapping - Goals}

\begin{tabular}{|c|c|c|}
\hline \# & Goal & $\begin{array}{r}\text { Description } \\
\end{array}$ \\
\hline Go1 & $\begin{array}{l}\text { Charging Rates and Process } \\
\text { Restructuring }\end{array}$ & $\begin{array}{l}\text { This goal represents the need the restructing of rates and } \\
\text { processes related to electric vehicle charging. One potential } \\
\text { problem for vehicle charging stations, and in particular for } \\
\text { quick charge stations, is that they can require a very large, } \\
\text { sudden energy use. Usage patterns of this were often limited in } \\
\text { the past to heavy industrial customers and were not commonly } \\
\text { addressed on many parts of the residential and urban grids. } \\
\text { Very high "demand charges" were often used to discourage } \\
\text { these large, sudden loads. However, such loads are likely to be } \\
\text { needed to enable rapid electric vehicle charging and } \\
\text { infrastructure can be developed to help reduce the impact of } \\
\text { these load patterns. Therefore, a restructuring of rates and } \\
\text { processes for electricity distribution needs to be considered to } \\
\text { enable the development of future charging stations. }\end{array}$ \\
\hline Go2 & $\begin{array}{c}\text { Integration of Charging } \\
\text { Infrastructure Plan with State and } \\
\text { Regional Energy Plans } \\
\end{array}$ & $\begin{array}{l}\text { This goal comes from the need for charging infrastructure } \\
\text { improvement and grid support, as well the creation of integrated } \\
\text { systems to coordinate state and regional energy planning. }\end{array}$ \\
\hline Go3 & $\begin{array}{l}\text { Rural Charging Infrastructure } \\
\text { Improvement Plan }\end{array}$ & $\begin{array}{l}\text { This goal involves the need for improving rural electrical } \\
\text { distribution infrastructure, increasing access to 3-Phase power, } \\
\text { and upgrading systems that could be used to provide future } \\
\text { electric vehicle charging infrastructure. }\end{array}$ \\
\hline Go4 & $\begin{array}{l}\text { Urban Charging Infrastructure } \\
\text { Improvement \& Accessibility } \\
\text { Plans }\end{array}$ & $\begin{array}{l}\text { This goal represents the need for a plan to improve urban } \\
\text { electric vehicle charging infrastructure, as well as system } \\
\text { accessibility for different types of customers who may lack } \\
\text { private, off-street parking for vehicle charging and need } \\
\text { neighborhood-level and multi-family access points for vehicle } \\
\text { charging options. }\end{array}$ \\
\hline Go5 & $\begin{array}{c}\text { Deployment Plan for Public } \\
\text { Charging Network for Long } \\
\text { Range EV Travel Needs }\end{array}$ & $\begin{array}{l}\text { This goal represents the need to develop a deployment plan for } \\
\text { public charging network that would be adequate to enable long } \\
\text { distance travel by electric vehicles. }\end{array}$ \\
\hline Go6 & $\begin{array}{l}\text { Integrated EV Adoption Forecast } \\
\text { \& Energy Strategy } \\
\end{array}$ & $\begin{array}{l}\text { This goal is aimed at the development of long term forecasts for } \\
\text { electric vehicle use and vehicle charging behavior. }\end{array}$ \\
\hline Go7 & $\begin{array}{l}\text { Develop Improved EV Charging } \\
\text { Use Models }\end{array}$ & $\begin{array}{l}\text { This goal is based on the need for the development of better use } \\
\text { models for EV charging and the integration of those models into } \\
\text { planning processes. }\end{array}$ \\
\hline Go8 & $\begin{array}{c}\text { Transactive Energy } \\
\text { Demonstration Projects for } \\
\text { Renewable Energy Integration } \\
\text { and Grid Support } \\
\end{array}$ & $\begin{array}{l}\text { This goal is based on the need for the development of } \\
\text { transactive energy demonstration projects for renewable energy } \\
\text { integration and grid support. }\end{array}$ \\
\hline Go9 & $\begin{array}{c}\text { Develop Partnership Models and } \\
\text { Ownership Structures for } \\
\text { Emerging EV Charging Business } \\
\text { Models } \\
\end{array}$ & $\begin{array}{l}\text { This goal is based on the need for the development of } \\
\text { partnership models and ownership structures for emerging ev } \\
\text { charging business models. }\end{array}$ \\
\hline
\end{tabular}




\section{APPENDIX F4: Roadmapping - Barriers}

\begin{tabular}{|c|c|c|}
\hline \# & Barrier & Description \\
\hline B1 & $\begin{array}{l}\text { Low Penetration of Public } \\
\text { Charging Stations }\end{array}$ & $\begin{array}{l}\text { This barrier represents the low current penetration of public } \\
\text { charging stations and lack of consistent deployment by key } \\
\text { players in the industry. The case of ECOtality is one prominent } \\
\text { example of a company that was given a large number of } \\
\text { contracts to install public charging stations and then failed to } \\
\text { live up to those promises due to a variety of financial problems. } \\
\text { This created a significant public relations problem in the minds } \\
\text { of many customers, so overcoming the images like this will be a } \\
\text { key challenge to address. }\end{array}$ \\
\hline B2 & $\begin{array}{c}\text { Loss of Trust in Product / Service } \\
\text { Reliability }\end{array}$ & $\begin{array}{l}\text { This barrier represents a loss of trust in product / service } \\
\text { reliability, based on poor experiences some customers initially } \\
\text { had with early generations of charging stations. Blink is an } \\
\text { example of a company that gained such a poor reputation for } \\
\text { reliability that customers began referring to it as being "on the } \\
\text { blink," meaning it was likely to be out of service. So, } \\
\text { overcoming initial perceptions many customers formed about } \\
\text { charging station products and services being unreliable will be a } \\
\text { key challenge to address. }\end{array}$ \\
\hline B3 & $\begin{array}{l}\text { Non-Standardized Payment / } \\
\text { Access Methods }\end{array}$ & $\begin{array}{l}\text { This barrier represents the current state in which there is non- } \\
\text { standardized pricing, payment, and access methods in the } \\
\text { electric vehicle charging industry. This can create substantial } \\
\text { confusion and detract from the usability of emerging products } \\
\text { and services. Determining how and in which ways to overcome } \\
\text { these barriers will be an important challenge. }\end{array}$ \\
\hline B4 & $\begin{array}{l}\text { Difficulty Finding Charging } \\
\text { Stations / Signage }\end{array}$ & $\begin{array}{l}\text { This barrier represents the current industry condition in which it } \\
\text { it may often be difficult to find charging stations and even to } \\
\text { identify common signage to help guide users to locate and use } \\
\text { charging stations. Improvements both in the deployment and } \\
\text { availability of charging stations as well as development of better } \\
\text { way to label and location these stations is a significant future } \\
\text { concern. }\end{array}$ \\
\hline B5 & Ease of Use of Charging Stations & $\begin{array}{l}\text { This barrier represents the need for development electric vehicle } \\
\text { charging hardware and software interfaces that consider ease of } \\
\text { use factors. Lack of clear, standard, and easy to use systems } \\
\text { could present a significant barrier to adoption. }\end{array}$ \\
\hline B6 & $\begin{array}{l}\text { High EV Charger Investment } \\
\text { Costs and Lack of Financial } \\
\text { Planning Tools }\end{array}$ & $\begin{array}{l}\text { This barrier represents the high initial costs for Electric Vehicle } \\
\text { Supply Equipment (or EVSE, which is common industry term } \\
\text { for electric vehicle chargers) have could present significant } \\
\text { barriers to entry for the charging industry. Coupled with this } \\
\text { has been a lack of financing tools, methods, and options which } \\
\text { could provide clearer and easier ways to incentive EVSE } \\
\text { investment. }\end{array}$ \\
\hline B7 & $\begin{array}{c}\text { Battery Warranty and Secondary } \\
\text { Use Issues }\end{array}$ & $\begin{array}{l}\text { This barrier deals with the issue that electric vehicle batteries } \\
\text { are rated for a certain number of charge cycles over their service } \\
\text { lifetime and warranties are generally provided to guarantee that } \\
\text { the batteries will last a minimum amount of time under normal, } \\
\text { primary usage conditions. However, as electric vehicle } \\
\text { charging system develop the ability to allow vehicles to interact }\end{array}$ \\
\hline
\end{tabular}




\begin{tabular}{|c|c|c|}
\hline & & $\begin{array}{l}\text { with the grid and possibly act as both a source of energy supply } \\
\text { and demand, this creates the option of using batteries for } \\
\text { secondary purposes, such as grid storage or voltage regulation, } \\
\text { which was not originally intended when vehicle warranties were } \\
\text { created. The ability for electric vehicles to perform secondary } \\
\text { energy functions has the potential to outpace standards set when } \\
\text { initial warranties were developed. Therefore, this barrier } \\
\text { represents the need for a reexamination electric vehicle battery } \\
\text { warranties with regard to the growing vehicle-to-grid } \\
\text { capabilities and how the use of these functions may or may not } \\
\text { affect the longevity of battery systems. }\end{array}$ \\
\hline B8 & $\begin{array}{l}\text { Difficulty Forecasting EV } \\
\text { Adoption \& Charging Use }\end{array}$ & $\begin{array}{l}\text { This barrier represents the general difficulty of forecasting the } \\
\text { adoption of electric vehicles and closely related question of how } \\
\text { vehicle charging is likely to impact the grid, given different } \\
\text { levels of vehicle adoption on various portions of the grid. } \\
\text { Therefore, developing better forecasts will be needed to address } \\
\text { uncertainties regarding both the number and type of electric } \\
\text { vehicles that are adopted, as well as the charging behavior that } \\
\text { occurs. }\end{array}$ \\
\hline B9 & $\begin{array}{c}\text { Transactive Energy } \\
\text { Measurement, Verification, and } \\
\text { Grid Interface Process }\end{array}$ & $\begin{array}{l}\text { This barrier represents the need for development of transactive } \\
\text { energy measurement and verification processes, as well as grid } \\
\text { interface process better manage how energy transactions are } \\
\text { handled on the grid. }\end{array}$ \\
\hline
\end{tabular}




\section{APPENDIX F5: Roadmapping - Business Development}

\begin{tabular}{|c|c|c|}
\hline$\#$ & $\begin{array}{c}\text { Business Development } \\
\text { Factor }\end{array}$ & Description \\
\hline BD1 & $\begin{array}{l}\text { Battery and EV Charging } \\
\text { Development Partnerships with } \\
\text { Design for Secondary Uses }\end{array}$ & $\begin{array}{l}\text { This business development factor represents the need for battery } \\
\text { and EV charging development partnerships with design for } \\
\text { secondary uses. This includes joint development to address } \\
\text { issues related to use of EV battery for energy storage and grid } \\
\text { functions, which go beyond the original functions for which } \\
\text { early EV battery were designed for and provided with warranty } \\
\text { protection from vehicle manufacturers. }\end{array}$ \\
\hline BD2 & $\begin{array}{l}\text { Financial Tools for EV Charger } \\
\text { and Infrastructure Investment }\end{array}$ & $\begin{array}{l}\text { This business development factor represents the need for } \\
\text { financial tools to help with the planning of investments for EV } \\
\text { chargers and related infrastructure deployment. This business } \\
\text { development factor attempts to address high initial costs for } \\
\text { EVSE and the lack of financing tools, methods, and options } \\
\text { which could provide clearer and easier ways to incentive EVSE } \\
\text { investment. }\end{array}$ \\
\hline BD3 & $\begin{array}{c}\text { Standardization of Payment } \\
\text { Systems and Access Methods for } \\
\text { Charging Stations }\end{array}$ & $\begin{array}{l}\text { This business development factor represents the need for } \\
\text { standardization of payment systems, as well as access methods } \\
\text { for charging stations. Non-standardized pricing, payment, and } \\
\text { access methods in the electric vehicle charging industry can } \\
\text { create significant confusion and detract from the usability of } \\
\text { emerging products and services. This business development } \\
\text { factor deals with ways to overcome these barriers. }\end{array}$ \\
\hline BD4 & $\begin{array}{c}\text { Transactive Energy Business } \\
\text { Process Development and Use } \\
\text { Modeling }\end{array}$ & $\begin{array}{l}\text { This business development factor represents the need for } \\
\text { development of transactive energy business processes and the } \\
\text { creation of better models for EV charger use. }\end{array}$ \\
\hline BD5 & $\begin{array}{c}\text { EV Adoption and Charging Use } \\
\text { Forecast Tools }\end{array}$ & $\begin{array}{l}\text { This business development factor represents regulatory and } \\
\text { legislative mandates which have specified either specific rates } \\
\text { that can be charged for certain types of electric vehicle } \\
\text { charging, rate plans or general structures which are allowed, or } \\
\text { other rules or standards governing the process of how EV } \\
\text { charging is allowed to be performed. }\end{array}$ \\
\hline BD6 & $\begin{array}{l}\text { Transactive Energy Business } \\
\text { Process Development and Use } \\
\text { Modeling }\end{array}$ & $\begin{array}{l}\text { This business development factor represents the need to } \\
\text { continue the development of transactive energy business process } \\
\text { development and use modeling. It included efforts for customer } \\
\text { outreach \& education initiatives to restore trust after early } \\
\text { generation technology and service problems. }\end{array}$ \\
\hline
\end{tabular}




\section{APPENDIX F6: Roadmapping - Solutions}

\begin{tabular}{|c|c|c|}
\hline \# & Solutions & Description \\
\hline S1 & $\begin{array}{l}\text { Consumer EV Energy } \\
\text { Management System }\end{array}$ & $\begin{array}{l}\text { This solution addresses the need for consumer EV energy } \\
\text { management system. It attempts to solve problems related to } \\
\text { consumer energy management and tracking needs. These } \\
\text { systems would be targeted at environmentally conscious } \\
\text { consumers, who would use the product to manage Time of Use } \\
\text { energy products, as well as better remote management and } \\
\text { energy usage control. }\end{array}$ \\
\hline S2 & $\begin{array}{c}\text { Standardized Business } \\
\text { Partnership Models for EV } \\
\text { Charging and Transactive Energy } \\
\text { Systems } \\
\end{array}$ & $\begin{array}{l}\text { This solution addresses the need for consumer standardized } \\
\text { business partnership models for EV charging and transactive } \\
\text { energy systems. }\end{array}$ \\
\hline S3 & $\begin{array}{l}\text { Investment Vision for EV } \\
\text { Charger Deployment }\end{array}$ & $\begin{array}{l}\text { This solution addresses the need for an investment vision on EV } \\
\text { charger deployment. It attempts to solve problems related to } \\
\text { lack of clear planning on future deployment of such systems, } \\
\text { including public versus private efforts. }\end{array}$ \\
\hline S4 & $\begin{array}{c}\text { Business Ownership Structures } \\
\text { and Vision }\end{array}$ & $\begin{array}{l}\text { This solution addresses the need to develop clear planning } \\
\text { visions regarding business ownership structures for EV } \\
\text { charging. }\end{array}$ \\
\hline S5 & $\begin{array}{c}\text { Standardized Transactive Energy } \\
\text { Grid Interface Process } \\
\text { Requirements } \\
\end{array}$ & $\begin{array}{l}\text { This solution addresses the need for development of transactive } \\
\text { energy grid interface process requirements, including clear } \\
\text { requirements and standards. }\end{array}$ \\
\hline S6 & EV-Grid Interface Technology & $\begin{array}{l}\text { This solution addresses the need for development of EV-grid } \\
\text { interface technology. This includes } \mathrm{V} 2 \mathrm{G} / \mathrm{B} / \mathrm{H} \text { and EVSC } \\
\text { systems. It attempts to solve problems related lack of clarity on } \\
\text { how such systems would be constructed and operated. }\end{array}$ \\
\hline
\end{tabular}




\section{APPENDIX F7: Roadmapping - Outputs}

\begin{tabular}{|c|l|l|}
\hline$\#$ & \multicolumn{1}{|c|}{ Output } & \multicolumn{1}{c|}{ Description } \\
\hline $\mathbf{O 1}$ & $\begin{array}{l}\text { Development of products, and/or } \\
\text { services for emissions tracking, } \\
\text { energy management, and } \\
\text { sustainability awareness for } \\
\text { green consumers. }\end{array}$ & $\begin{array}{l}\text { This output represents the need for development of products, } \\
\text { and/or services for emissions tracking, energy management. } \\
\text { This can also help with issues like sustainability awareness for } \\
\text { green consumers. }\end{array}$ \\
\hline $\mathbf{O 2}$ & $\begin{array}{l}\text { Development of improved } \\
\text { batteries for faster charging, high } \\
\text { capacity, longer lifecycle, } \\
\text { partnering on issues like battery } \\
\text { secondary use \& warranty issues }\end{array}$ & $\begin{array}{l}\text { This output represents the need for development of improved } \\
\text { batteries for faster charging, high capacity, longer lifecycle. It } \\
\text { can include partnering with industry on issues like battery } \\
\text { secondary use and warranty issues. }\end{array}$ \\
\hline $\mathbf{O 3}$ & $\begin{array}{l}\text { Improved EV chargers: Reducing } \\
\text { capital cost, improving speed, } \\
\text { efficiency, simplicity of } \\
\text { installation }\end{array}$ & $\begin{array}{l}\text { This output represents the need for development of improved } \\
\text { EV chargers. Such improvements include the need for reducing } \\
\text { capital cost, improving speed, efficiency, simplicity of } \\
\text { installation. }\end{array}$ \\
\hline $\begin{array}{l}\text { Improved charger tools and } \\
\text { systems, ease of finding/use, } \\
\text { outreach and education, TE } \\
\text { capability and quantification of } \\
\text { benefits }\end{array}$ & $\begin{array}{l}\text { This output represents the need to continue the development of } \\
\text { improved charger tools and systems. Such improvements } \\
\text { include improving the ease of use and ease of finding charging } \\
\text { stations, as well as outreach and education. Transactive Energy } \\
\text { capabilities are another element that can provide value in future } \\
\text { advance generation EV chargers, as well as the ability to } \\
\text { quantify the benefits of using such systems. }\end{array}$ \\
\hline
\end{tabular}




\section{APPENDIX F8: Roadmapping - Market Development}

\begin{tabular}{|c|l|l|}
\hline$\#$ & \multicolumn{1}{|c|}{$\begin{array}{c}\text { Market Development } \\
\text { Element }\end{array}$} & \multicolumn{1}{c|}{ Description } \\
\hline DM1 & $\begin{array}{l}\text { Energy management / emission } \\
\text { \& sustainability }\end{array}$ & $\begin{array}{l}\text { This market development element represents the need for } \\
\text { development of products, and/or services for emissions tracking, } \\
\text { energy management. This can also help with issues like } \\
\text { sustainability awareness for green consumers. }\end{array}$ \\
\hline DM2 & $\begin{array}{l}\text { Development of improved } \\
\text { batteries for faster charging, high } \\
\text { capacity, longer lifecycle, } \\
\text { partnering on issues like battery } \\
\text { secondary use \& warranty issues }\end{array}$ & $\begin{array}{l}\text { This market development element represents the need for } \\
\text { development of improved batteries for faster charging, high } \\
\text { capacity, and longer lifecycle. It can include partnering with } \\
\text { industry on issues like battery secondary use and warranty } \\
\text { issues. }\end{array}$ \\
\hline $\begin{array}{l}\text { Improved EV chargers: Reducing } \\
\text { capital cost, improving speed, } \\
\text { efficiency, simplicity of } \\
\text { installation }\end{array}$ & $\begin{array}{l}\text { This market development element represents the need for } \\
\text { development of improved EV chargers. Such improvements } \\
\text { include the need for reducing capital cost, improving speed, } \\
\text { efficiency, simplicity of installation. }\end{array}$ \\
\hline $\begin{array}{l}\text { Improved charger tools and } \\
\text { systems, ease of finding/use, } \\
\text { outreach and education, TE } \\
\text { capability and quantification of } \\
\text { benefits }\end{array}$ & $\begin{array}{l}\text { This market development element represents the need to } \\
\text { continue the development of improved charger tools and } \\
\text { systems. Such improvements include improving the ease of use } \\
\text { and ease of finding charging stations, as well as outreach and } \\
\text { education. transactive energy capabilities are another element } \\
\text { that can provide value in future advance generation EV } \\
\text { chargers, as well as the ability to quantify the benefits of using } \\
\text { such systems. }\end{array}$ \\
\hline
\end{tabular}




\section{APPENDIX F9: Roadmapping - Business Development}

\begin{tabular}{|c|l|l|}
\hline \# & \multicolumn{1}{|c|}{$\begin{array}{c}\text { Business Development } \\
\text { Element }\end{array}$} & \multicolumn{1}{c|}{ Description } \\
\hline DB1 & $\begin{array}{l}\text { Grid interfaces for transactive } \\
\text { energy business development: 1- } \\
\text { way and 2-way VG }\end{array}$ & $\begin{array}{l}\text { This business development element represents the need for } \\
\text { work on grid interfaces for transactive energy businesses } \\
\text { regarding 1-way and 2-way communication for Vehicle-to-Grid } \\
\text { systems. }\end{array}$ \\
\hline DB2 & $\begin{array}{l}\text { Charging infrastructure } \\
\text { requirements, meeting regional } \\
\text { energy and electric vehicle goals, } \\
\text { emissions plans }\end{array}$ & $\begin{array}{l}\text { This business development element represents the need for } \\
\text { work on specification of charging infrastructure requirements } \\
\text { for meeting regional energy and electric vehicle goals, as well } \\
\text { as better integration with emissions plans. }\end{array}$ \\
\hline DB3 & $\begin{array}{l}\text { Business partnership policies, } \\
\text { structures \& guidelines }\end{array}$ & $\begin{array}{l}\text { This business development element represents the need for } \\
\text { work on business partnership policies, structures and guidelines } \\
\text { regarding EV charging. }\end{array}$ \\
\hline DB4 & $\begin{array}{l}\text { Development of standardized } \\
\text { business ownership structures } \\
\text { and models }\end{array}$ & $\begin{array}{l}\text { This business development element represents the need for } \\
\text { work on standardized business ownership structures and models } \\
\text { regarding EV charging. }\end{array}$ \\
\hline DB5 & $\begin{array}{l}\text { Vision for charging infrastructure } \\
\text { deployment }\end{array}$ & $\begin{array}{l}\text { This business development element represents the need for } \\
\text { work on establishment of visions for charging infrastructure } \\
\text { deployment. }\end{array}$ \\
\hline
\end{tabular}




\section{APPENDIX F10: Roadmapping - Research \& Development}

\begin{tabular}{|c|l|l|}
\hline$\#$ & $\begin{array}{c}\text { Research \& Development } \\
\text { Element }\end{array}$ & \multicolumn{1}{c|}{ Description } \\
\hline RD1 & Low Cost Charger Development & $\begin{array}{l}\text { This research and development element represents the need for } \\
\text { low cost EV charger development. This would reduce the initial } \\
\text { capital costs of providing charger systems, which is current a } \\
\text { major barrier. }\end{array}$ \\
\hline RD2 & $\begin{array}{l}\text { Device management, energy } \\
\text { management, and quick charge } \\
\text { capability development }\end{array}$ & $\begin{array}{l}\text { This research and development element represents the need for } \\
\text { developing products for EV chargers that allow sophisticated } \\
\text { device management, energy management, and offer quicker } \\
\text { charging capabilities.. }\end{array}$ \\
\hline RD3 & $\begin{array}{l}\text { EV Charging HW / SW Std } \\
\text { Development }\end{array}$ & $\begin{array}{l}\text { This research and development element represents the need for } \\
\text { EV charging hardware and software standards development. }\end{array}$ \\
\hline
\end{tabular}




\section{APPENDIX F11: Roadmapping - Barrier Mitigator}

\begin{tabular}{|c|l|l|}
\hline$\#$ & Barrier Mitigator Element & \multicolumn{1}{c|}{ Description } \\
\hline BM1 & $\begin{array}{l}\text { Grid interface requirements, } \\
\text { utility regulatory standards } \\
\text { specifications, transactive energy } \\
\text { interfaces, and measurement and } \\
\text { verification processes }\end{array}$ & $\begin{array}{l}\text { This barrier mitigator element represents the need for } \\
\text { development of grid interface requirements, utility regulatory } \\
\text { standards specifications, transactive energy interfaces, as well as } \\
\text { measurement and verification processes regarding the } \\
\text { performance of these systems. }\end{array}$ \\
\hline BM2 & $\begin{array}{l}\text { Regional and state vehicle energy } \\
\text { plan development: Charger use } \\
\text { forecasting, emissions \& } \\
\text { renewable energy integration } \\
\text { planning, and deployment vision }\end{array}$ & $\begin{array}{l}\text { This barrier mitigator element represents the need for } \\
\text { development of regional and state vehicle energy plan } \\
\text { development. This includes charger use forecasting, emissions } \\
\text { and renewable energy integration planning, and a coherent } \\
\text { deployment vision regarding EV charging }\end{array}$ \\
\hline BM3 & $\begin{array}{l}\text { Business partnership policies, } \\
\text { guidelines, and processes }\end{array}$ & $\begin{array}{l}\text { This barrier mitigator element represents the need for } \\
\text { development of business partnership policies, guidelines, and } \\
\text { processes regarding EV charging.. }\end{array}$ \\
\hline BM4 & $\begin{array}{l}\text { Business ownership structure, } \\
\text { terms \& models }\end{array}$ & $\begin{array}{l}\text { This barrier mitigator element represents the need for } \\
\text { development of business ownership structure, terms \& models } \\
\text { regarding EV charging. }\end{array}$ \\
\hline
\end{tabular}




\section{APPENDIX F12: Roadmapping - Plans}

\begin{tabular}{|c|l|l|}
\hline$\#$ & \multicolumn{1}{|c|}{ Plan } & \multicolumn{1}{c|}{ Description } \\
\hline Pn1 & $\begin{array}{l}\text { Charging infrastructure } \\
\text { improvement plan development: } \\
\text { advanced charger hw/sw } \\
\text { interface systems, infrastructure } \\
\text { investment financial tools, } \\
\text { urban/rural and public/private } \\
\text { grid pentration and network for } \\
\text { long range travel. }\end{array}$ & $\begin{array}{l}\text { This plan element represents the need for charging } \\
\text { infrastructure improvement plan development. This includes } \\
\text { advanced charger hw/sw interface systems, infrastructure } \\
\text { investment financial tools, urban/rural and public/private grid } \\
\text { penetration and network issues related to the ability to conduct } \\
\text { long-range travel between networks of charging stations. It also } \\
\text { includes explanations of policies and practices for installing } \\
\text { charging equipment on the grid, interfacing with systems, } \\
\text { performing charging, and planning for future charging } \\
\text { infrastructure investment. }\end{array}$ \\
\hline Pn2 & $\begin{array}{l}\text { Utility, Investor, and Aggregator- } \\
\text { Owned partnership structures, } \\
\text { and operational policies. }\end{array}$ & $\begin{array}{l}\text { This plan element represents the need for development of } \\
\text { utility-, investor-, and aggregator-owned partnership structures, } \\
\text { as well as operational policies. This includes partnership } \\
\text { policies, guidelines, and regulations regarding business } \\
\text { partnership structures, rates, ownership, and operations. }\end{array}$ \\
\hline Pn3 & $\begin{array}{l}\text { Plans to facilitate EV charging } \\
\text { and TE business process } \\
\text { development through regulatory } \\
\text { reform, rate restruc and } \\
\text { incentives }\end{array}$ & $\begin{array}{l}\text { This plan element represents the need for development of plans } \\
\text { to facilitate EV charging and transactive energy business } \\
\text { process development. This includes through regulatory reform } \\
\text { efforts, rate restructuring and the possible use of promotions, } \\
\text { subsidies, credits, and other privileges to encourage EV charger } \\
\text { use and provide grid support. }\end{array}$ \\
\hline
\end{tabular}




\section{APPENDIX F13: Roadmapping - Technologies}

\begin{tabular}{|c|l|l|}
\hline$\#$ & \multicolumn{1}{|c|}{ Technologys } & \multicolumn{1}{c|}{ Description } \\
\hline T1 & $\begin{array}{l}\text { Lower EV Charger Costs } \\
\text { (upfront cost) }\end{array}$ & $\begin{array}{l}\text { This technology element represents the need for developing } \\
\text { lower cost EV chargers. This would reduce the up-front cost of } \\
\text { providing charger systems, which is current a significant issue. }\end{array}$ \\
\hline T2 & $\begin{array}{l}\text { More Efficient EV Charging } \\
\text { Systems (operating cost) }\end{array}$ & $\begin{array}{l}\text { This technology element represents the need for developing } \\
\text { more efficient EV charger systems. This would reduce } \\
\text { operational costs. }\end{array}$ \\
\hline T3 & $\begin{array}{l}\text { Improved metering, energy } \\
\text { management systems }\end{array}$ & $\begin{array}{l}\text { This technology element represents the need for developing } \\
\text { Improved metering, energy management systems for } \\
\text { environmentally conscious consumers. This would be } \\
\text { particularly important for helping environmentally conscious } \\
\text { consumers understand energy use. }\end{array}$ \\
\hline T4 & $\begin{array}{l}\text { Smart EV Charging Payment } \\
\text { System and TE Support Interface }\end{array}$ & $\begin{array}{l}\text { This technology represents the need to develop smart electric } \\
\text { vehicle charging payment systems and transactive energy } \\
\text { support interface for hardware and software used in electric } \\
\text { vehicle charging. }\end{array}$ \\
\hline
\end{tabular}




\section{APPENDIX F14: Roadmapping - Barrier Element}

\begin{tabular}{|c|l|l|}
\hline$\#$ & \multicolumn{1}{|c|}{ Barrier Elements } & \multicolumn{1}{c|}{ Description } \\
\hline Be1 & $\begin{array}{l}\text { Lack of grid interface processes } \\
\text { and utility regulatory standards } \\
\text { for transactive energy. }\end{array}$ & $\begin{array}{l}\text { This barrier element involves the current lack of grid interface } \\
\text { processes and utility regulatory standards regarding transactive } \\
\text { energy systems. This includes development of requirement } \\
\text { regarding grid interfaces and utility regulatory specifications. }\end{array}$ \\
\hline Be2 & $\begin{array}{l}\text { Lack of vision for EVs as part of } \\
\text { emissions planning, grid support, } \\
\text { and renewable energy integration }\end{array}$ & $\begin{array}{l}\text { This barrier element involves the lack of clear of visions } \\
\text { regarding planning for EVs as part of emissions programs, grid } \\
\text { support, and renewable energy integration systems. These } \\
\text { elements could be better integrated into regional vehicle plans, } \\
\text { emissions targets, and specific plans regarding EV charging. }\end{array}$ \\
\hline Be3 & $\begin{array}{l}\text { Lack of partnership \& } \\
\text { generalized business model } \\
\text { frameworks }\end{array}$ & $\begin{array}{l}\text { This barrier element involves the current lack of partnership and } \\
\text { generalized business model frameworks regarding EV charging. } \\
\text { This would include development of business partnership } \\
\text { policies and guidelines and transactive energy frameworks. }\end{array}$ \\
\hline Be4 & $\begin{array}{l}\text { Lack of general frameworks for } \\
\text { ownership terms \& structures }\end{array}$ & $\begin{array}{l}\text { This barrier element represents the lack of general frameworks } \\
\text { for ownership terms and structures need to develop standard } \\
\text { business ownership models for the burgeoning electric vehicle } \\
\text { charging industry. }\end{array}$ \\
\hline
\end{tabular}




\section{APPENDIX G1: Investor-Owned Business Structures}

\begin{tabular}{|c|c|c|}
\hline BM\# & Investor-Owned (S1) & Description \\
\hline \multirow{3}{*}{$\begin{array}{c}\text { Pay per kWh } \\
\text { / Level } \\
\text { (BMS1A) }\end{array}$} & 1. Level 1 Charging (BMS1A-1) & $\begin{array}{l}\text { This business model represents the need expressed for simple, basic } \\
\text { EV charging, generally performed with standard } 120 \mathrm{~V}, 1,500 \mathrm{~W}, 16 \mathrm{~A} \\
\text { outlets. Generally, such charging will occur at residential locations, } \\
\text { and often occurring overnight, slowly charge for about } 6-10 \text { hours. } \\
\text { However, in the Investor-Owned (S1) ownership structure, this could } \\
\text { be used in a commercial setting, such as long-term parking. Different } \\
\text { rates and conditions may like apply versus the residential case, which } \\
\text { also typically assumes standardized electricity rates, such as those of } \\
\text { a Utility-Owned (S2) ownership structure, like a public utility. }\end{array}$ \\
\hline & 2. Level 2 Charging (BMS1A-2) & $\begin{array}{l}\text { This business model would be very similar to the Level } 1 \text { model, but } \\
\text { basic EV charging would be performed with more power } 220 \mathrm{~V} \text {, } \\
6,600 \mathrm{~W}, 32 \mathrm{~A} \text { outlets. Charging can occur at residential or commercial } \\
\text { locations, often occurring over about } 3-4 \text { hours. In the Investor-Owned } \\
\text { (S1) ownership structure, this could be used in settings such as } \\
\text { parking structures, street parking, or retail locations. It is likely that a } \\
\text { premium rate would be applied for each kWh purchased in such } \\
\text { locations. For the purposes of defining the basic business model } \\
\text { types, the assumption for this model is that customer costs would be } \\
\text { based on kWh or electricity provided. However, it is both possible and } \\
\text { likely that additional incentives could be provided, such as discounted } \\
\text { or free charging, if the customer submits a code which shows a certain } \\
\text { minimum purchase has been made at a sponsoring retail location. So, } \\
\text { a variety of cost calculation methods and hybrid fee structures are } \\
\text { possible. }\end{array}$ \\
\hline & 3. Level 3 Charging (BMS1A-3) & $\begin{array}{l}\text { This business model an extremely powerful advancement over Level } 1 \\
\text { and Level } 2 \text { models. EV charging would be performed with more } \\
\text { power } 400-500 \mathrm{~V} \text { DC fast chargers. Many systems are envisioned as } \\
\text { approximately } 50,000 \mathrm{~W} \text { 100-125A charging units. Charging can occur } \\
\text { as quickly as } 20-30 \text { minutes. Due to significant needs for distribution } \\
\text { infrastructure and charging hardware, this model is likely to only be } \\
\text { viable in commercial setting within the immediate future. For the } \\
\text { purposes of this model, rates charged would be based on kWh of } \\
\text { electricity provided. However, it is likely that this model would also } \\
\text { emphasize rapid throughput and would avoid long-term parking that } \\
\text { occupied the charging facilities for too long, preventing other } \\
\text { customers from using them. This model is envisioned as analogous to } \\
\text { a gas station, but with slightly longer charging times than current gas } \\
\text { stations require to fuel vehicles. This model would also be useful at } \\
\text { waypoints on highways and long-distance commuting routes, as it } \\
\text { would enable travelers to quickly charge up and move on to the next } \\
\text { destination. }\end{array}$ \\
\hline \multirow[t]{2}{*}{$\begin{array}{c}\text { Flat Rate per } \\
\text { hour } \\
\text { (BMS1B) }\end{array}$} & 4. Flat hourly rate (BMS1B-1) & $\begin{array}{l}\text { In this business model, rather than using a fee structure based on } \\
\mathrm{kWh} \text { of electricity provided for EV charging, alternative systems based } \\
\text { on flat hourly fees for the number of hours of charging time are used. } \\
\text { This can be differentiated based on the level of charging provided, } \\
\text { such as Level } 1 \text { and } 2 \text {, which may be provided at different hourly } \\
\text { rates. Level } 3 \text { charging is likely to remain a premium service under } \\
\text { most plans and would probably not be provided on a flat hourly fee } \\
\text { basis. However, by paying for a certain number of hours per month at } \\
\text { a flat rate, this may provide a better deal for customers who need a } \\
\text { about } 10 \text { hours per week or less of low-level EV charging. This is } \\
\text { likely to be a better deal for them than if they paid on a per kWh basis. } \\
\text { Such a structure may also be valuable from the point of view of an } \\
\text { Investor-Owned (S1) ownership structure, since it could provide more } \\
\text { consistent, predictable income than a fee per service model. }\end{array}$ \\
\hline & 5. Flat monthly rate (BMS1B-2) & $\begin{array}{l}\text { This business model would have many similarities to the flat hourly } \\
\text { models, but rather than buying only a certain number of hours at a } \\
\text { fixed rate, it may provided a more extensive amount of charging, such } \\
\text { as unlimited Level } 1 \text { and } 2 \text { charging for a customer. It may be useful } \\
\text { for people who frequently need to take their car in and out of parking } \\
\text { spaces and need it to be quickly available for moderately long }\end{array}$ \\
\hline
\end{tabular}




\begin{tabular}{|c|c|c|}
\hline & & $\begin{array}{l}\text { distance trips in a local area. One type of customer this is likely to fit } \\
\text { would may be vehicle fleet owners who operate delivery services } \\
\text { within a metropolitan area. This can be differentiated based on the } \\
\text { level of charging provided, such as Level } 1 \text { and } 2 \text {, which may be } \\
\text { provided at different hourly rates. Level } 3 \text { charging is likely to remain } \\
\text { a premium service under most plans and would probably not be } \\
\text { provided on a flat hourly fee basis. Such a structure may also be } \\
\text { valuable from the point of view of an Investor-Owned (S1) ownership } \\
\text { structure, since it could enable a larger number of transactions more } \\
\text { easily that an hourly model and accommodate higher volume } \\
\text { customers. So, it could potentially lead to long-term business } \\
\text { relationships that could provide more even consistent and predictable } \\
\text { income than an hourly charging model. }\end{array}$ \\
\hline $\begin{array}{l}\text { Pay for } \\
\text { Parking } \\
\text { (BMS1C) }\end{array}$ & $\begin{array}{l}\text { 6. Pay for Parking } \\
\text { Hourly(BMS1C-1) }\end{array}$ & $\begin{array}{l}\text { This business model emphasizes providing premium long-term and } \\
\text { medium term parking space, the value of which is greater than the } \\
\text { cost of electric vehicle charging. Level } 1 \text { and } 2 \text { electric vehicle } \\
\text { charging can be provided as an added convenience for customers } \\
\text { already paying for parking. This model has the expectation of long } \\
\text { duration parking and has the advantage of simplifying billing and } \\
\text { payment systems all under parking charges. }\end{array}$ \\
\hline \multirow{3}{*}{$\begin{array}{l}\text { Membership } \\
\text { (BMS1D) }\end{array}$} & 7. Flat (BMS1D-1) & $\begin{array}{l}\text { This business model represents the need expressed by green } \\
\text { consumers who drive EVs for understanding the carbon footprint } \\
\text { produced by their vehicle, through "upstream emissions," such as } \\
\text { when they use electricity generated by power plants burning coal or } \\
\text { natural gas. }\end{array}$ \\
\hline & 8. Unlimited (BMS1D-2) & $\begin{array}{l}\text { This business model represents the need expressed by green } \\
\text { consumers who drive EVs for understanding the carbon footprint } \\
\text { produced by their vehicle, through "upstream emissions," such as } \\
\text { when they use electricity generated by power plants burning coal or } \\
\text { natural gas. }\end{array}$ \\
\hline & 9. Bundle (BMS1D-3) & $\begin{array}{l}\text { This business model represents the need for a low cost vehicle which } \\
\text { provides transportation at a low total cost of ownership. The upfront } \\
\text { purchase cost of an automobile is generally the most expensive part of } \\
\text { the total cost for owning such a vehicle, followed by operations and } \\
\text { maintenance costs. For electric vehicles, it has been noted that the } \\
\text { purchase costs are currently much higher than internal combustion } \\
\text { vehilces, primarily due to high battery costs. }\end{array}$ \\
\hline \multirow{3}{*}{$\begin{array}{l}\text { Premium } \\
\text { Services } \\
\text { (BMS1E) }\end{array}$} & 10. Advertising (BMS1E-1) & $\begin{array}{l}\text { This business model represents the need expressed by green } \\
\text { consumers who drive EVs for understanding the carbon footprint } \\
\text { produced by their vehicle, through "upstream emissions," such as } \\
\text { when they use electricity generated by power plants burning coal or } \\
\text { natural gas. }\end{array}$ \\
\hline & 11. Internet (BMS1E-2) & $\begin{array}{l}\text { This business model represents the need expressed by green } \\
\text { consumers who drive EVs for understanding the carbon footprint } \\
\text { produced by their vehicle, through "upstream emissions," such as } \\
\text { when they use electricity generated by power plants burning coal or } \\
\text { natural gas. }\end{array}$ \\
\hline & 12. Supplemental (BMS1E-3) & $\begin{array}{l}\text { This business model represents the need for a low cost vehicle which } \\
\text { provides transportation at a low total cost of ownership. The upfront } \\
\text { purchase cost of an automobile is generally the most expensive part of } \\
\text { the total cost for owning such a vehicle, followed by operations and } \\
\text { maintenance costs. For electric vehicles, it has been noted that the } \\
\text { purchase costs are currently much higher than internal combustion } \\
\text { vehicles, primarily due to high battery costs. }\end{array}$ \\
\hline $\begin{array}{c}\text { Transactive } \\
\text { (BMS1F) }\end{array}$ & 13. Ancillary (BMS1F-1) & $\begin{array}{l}\text { This business model represents a 2-Way V2G system where the } \\
\text { customer charges the vehicle based on need and transactive pricing. } \\
\text { The vehicle is also capable of communicating with the grid and selling } \\
\text { back unneeded electricity stored in the vehicles battery, as well as } \\
\text { ancillary services, such as voltage regulation. Software estimating } \\
\text { vehicle usage needs over time is used to optimize vehicle charge } \\
\text { capacity and transactive revenue. }\end{array}$ \\
\hline
\end{tabular}




\section{APPENDIX G2: Utility-Owned Business Structures}

\begin{tabular}{|c|c|c|}
\hline BM\# & Utility-Owned (S2) & Description \\
\hline \multirow{6}{*}{$\begin{array}{c}\text { Standardized } \\
\text { Rates } \\
(\mathrm{BMS} 2 \mathrm{~A})\end{array}$} & 1. Regulated Rates (BMS2A-1) & $\begin{array}{l}\text { This business model represents the need expressed for simple, } \\
\text { basic EV charging, generally performed with standard } 120 \mathrm{~V} \text {, } \\
1,500 \mathrm{~W}, 16 \mathrm{~A} \text { outlets. Generally, such charging will occur at } \\
\text { residential locations, and often occurring overnight, slowly charge for } \\
\text { about } 6-10 \text { hours. However, in the Utility-Owned (S2) ownership } \\
\text { structure, this could be used in a commercial setting as well, such as } \\
\text { long-term parking. This model assumes standardized electricity } \\
\text { rates, such as those paid by residential or business customers to an } \\
\text { entity, such as a public utility. }\end{array}$ \\
\hline & $\begin{array}{l}\text { 2. Time of Rate Program } 1 \text { - Opt in } \\
\text { (BMS2A-2) }\end{array}$ & $\begin{array}{l}\text { This business model represents the need expressed by green } \\
\text { consumers who drive EVs for understanding the carbon footprint } \\
\text { produced by their vehicle, through "upstream emissions," such as } \\
\text { when they use electricity generated by power plants burning coal or } \\
\text { natural gas. }\end{array}$ \\
\hline & $\begin{array}{l}\text { 3. Time of Use Rate Program } 2 \text { - } \\
\text { Mandatory (BMS2A-3) }\end{array}$ & $\begin{array}{l}\text { This business model represents the need for low a low cost vehicle } \\
\text { which provides transportation at a low total cost of ownership. The } \\
\text { upfront purchase cost of an automobile is generally the most } \\
\text { expensive part of the total cost for owning such a vehicle, followed } \\
\text { by operations and maintenance costs. For electric vehicles, it has } \\
\text { been noted that the purchase costs are currently much higher than } \\
\text { internal combustion vehilces, primarily due to high battery costs. }\end{array}$ \\
\hline & 4. Inclined Block Rates (BMS2A-4) & $\begin{array}{l}\text { Consumers purchasing EV can receive incentives, often in the form } \\
\text { of tax credits to help offset the high initial cost of purchasing an EV. } \\
\text { There are also subsidies available for some forms of electric vehicle } \\
\text { charging stations for home use. In addition, rate structures setting } \\
\text { either standard EV rates or time of use rates are critical for } \\
\text { managing total charging costs. Linked to DM } 6\end{array}$ \\
\hline & $\begin{array}{l}\text { 5. Electric Vehicle Specific Rates } \\
\text { (BMS2A-5) }\end{array}$ & $\begin{array}{l}\text { As described in DM 5, consumers purchasing EV can receive } \\
\text { financial incentives, such tax credits to help purchase EVs. Such } \\
\text { mechanisms, as well as favorable lending practices, and leasing } \\
\text { programs are important for encouraging technology adoption and } \\
\text { this driver represents many ideas currently under development. } \\
\text { Linked to DM5 }\end{array}$ \\
\hline & 6. Demand Charges (BMS2A-6) & $\begin{array}{l}\text { This business model represents the need for low a low cost vehicle } \\
\text { which provides transportation at a low total cost of ownership. The } \\
\text { upfront purchase cost of an automobile is generally the most } \\
\text { expensive part of the total cost for owning such a vehicle, followed } \\
\text { by operations and maintenance costs. For electric vehicles, it has } \\
\text { been noted that the purchase costs are currently much higher than } \\
\text { internal combustion vehilces, primarily due to high battery costs. }\end{array}$ \\
\hline \multirow{3}{*}{$\begin{array}{l}\text { Premium } \\
\text { Services } \\
\text { (BMS2B) }\end{array}$} & $\begin{array}{l}\text { 7. Advertising-Based Plans } \\
\text { (BMS2B-1) }\end{array}$ & $\begin{array}{l}\text { Consumers purchasing EV can receive incentives, often in the form } \\
\text { of tax credits to help offset the high initial cost of purchasing an EV. } \\
\text { There are also subsidies available for some forms of electric vehicle } \\
\text { charging stations for home use. In addition, rate structures setting } \\
\text { either standard EV rates or time of use rates are critical for } \\
\text { managing total charging costs. Linked to DM } 6\end{array}$ \\
\hline & 8. Internet-Based Plans (BMS2B-2) & $\begin{array}{l}\text { As described in DM 5, consumers purchasing EV can receive } \\
\text { financial incentives, such tax credits to help purchase EVs. Such } \\
\text { mechanisms, as well as favorable lending practices, and leasing } \\
\text { programs are important for encouraging technology adoption and } \\
\text { this driver represents many ideas currently under development. } \\
\text { Linked to DM5 }\end{array}$ \\
\hline & $\begin{array}{l}\text { 9. Supplement Power Plans } \\
\text { (BMS2B-3) }\end{array}$ & $\begin{array}{l}\text { As described in DM 5, consumers purchasing EV can receive } \\
\text { financial incentives, such tax credits to help purchase EVs. Such } \\
\text { mechanisms, as well as favorable lending practices, and leasing } \\
\text { programs are important for encouraging technology adoption and } \\
\text { this driver represents many ideas currently under development. } \\
\text { Linked to DM5 }\end{array}$ \\
\hline
\end{tabular}




\section{APPENDIX G3: Third Party / Aggregator-Owned Structures}

\begin{tabular}{|c|c|c|}
\hline BM\# & Aggregator-Owned (S3) & Description \\
\hline \multirow{3}{*}{$\begin{array}{l}\text { Electric } \\
\text { Vehicle } \\
\text { Service } \\
\text { Equipment } \\
\text { (BMS3A) }\end{array}$} & 1. Level 1 Charging (BMS3A-1) & $\begin{array}{l}\text { This business model represents the need expressed for simple, } \\
\text { basic EV charging, generally performed with standard } 120 \mathrm{~V}, \\
1,500 \mathrm{~W}, 15 \mathrm{~A} \text { outlets. Generally, such charging will occur at } \\
\text { residential locations, and often occurring overnight, slowly charge } \\
\text { for about } 6-10 \text { hours. However, in the Investor-Owned (S1) } \\
\text { ownership structure, this could be used in a commercial setting, } \\
\text { such as long-term parking. Different rates and conditions may like } \\
\text { apply versus the residential case, which also typically assumes } \\
\text { standardized electricity rates, such as those of a Utility-Owned (S2) } \\
\text { ownership structure, like a public utility. }\end{array}$ \\
\hline & 2. Level 2 Charging (BMS3A-2) & $\begin{array}{l}\text { This business model would be very similar to the Level } 1 \text { model, but } \\
\text { basic EV charging would be performed with more power } 220 \mathrm{~V} \text {, } \\
6,600 \mathrm{~W}, 32 \mathrm{~A} \text { outlets. Charging can occur at residential or } \\
\text { commercial locations, often occurring over about } 3-4 \text { hours. In the } \\
\text { Investor-Owned (S1) ownership structure, this could be used in } \\
\text { settings such as parking structures, street parking, or retail } \\
\text { locations. It is likely that a premium rate would be applied for each } \\
\text { kWh purchased in such locations. For the purposes of defining the } \\
\text { basic business model types, the assumption for this model is that } \\
\text { customer costs would be based on kWh or electricity provided. } \\
\text { However, it is both possible and likely that additional incentives } \\
\text { could be provided, such as discounted or free charging, if the } \\
\text { customer submits a code which shows a certain minimum purchase } \\
\text { has been made at a sponsoring retail location. So, a variety of cost } \\
\text { calculation methods and hybrid fee structures are possible. }\end{array}$ \\
\hline & 3. Level 3 Charging (BMS3A-3) & $\begin{array}{l}\text { This business model an extremely powerful advancement over } \\
\text { Level } 1 \text { and Level } 2 \text { models. EV charging would be performed with } \\
\text { more power } 400-500 V \text { DC fast chargers. Many systems are } \\
\text { envisioned as approximately } 50,000 \mathrm{~W} 100-125 \mathrm{~A} \text { charging units. } \\
\text { Charging can occur as quickly as } 20-30 \text { minutes. Due to significant } \\
\text { needs for distribution infrastructure and charging hardware, this } \\
\text { model is likely to only be viable in commercial setting within the } \\
\text { immediate future. For the purposes of this model, rates charged } \\
\text { would be based on kWh of electricity provided. However, it is likely } \\
\text { that this model would also emphasize rapid throughput and would } \\
\text { avoid long-term parking that occupied the charging facilities for too } \\
\text { long, preventing other customers from using them. This model is } \\
\text { envisioned as analogous to a gas station, but with slightly longer } \\
\text { charging times than current gas stations require to fuel vehicles. } \\
\text { This model would also be useful at waypoints on highways and } \\
\text { long-distance commuting routes, as it would enable travelers to } \\
\text { quickly charge up and move on to the next destination. }\end{array}$ \\
\hline $\begin{array}{l}\text { Utility } \\
\text { Contract } \\
\text { (BMS3B) }\end{array}$ & 4. Utility Contract (BMS3B-1) & $\begin{array}{l}\text { This business model offer a contract to a utility customer that allows } \\
\text { the utility to meet it's mandated capacity reserve requirements. } \\
\text { Traditionally, providing backup capacity to meet system reserve } \\
\text { requirements was provided by back up power plants. Here, } \\
\text { management of electric charging systems and be both a source of } \\
\text { supply and demand. }\end{array}$ \\
\hline $\begin{array}{l}\text { Optimization } \\
\text { Contract } \\
\text { (BMS1C) }\end{array}$ & 5. Optimization Contract (BMS3C-1) & $\begin{array}{l}\text { In this business model, demand aggregation service providers offer } \\
\text { customers (often a utility or large industry customer) a contract that } \\
\text { promises to provide electricity when needed, through dynamic } \\
\text { management of supply and demand within an enterprise and } \\
\text { aggregated across a network of other customers. If customer have } \\
\text { excess supply, this is shifted as needed to other customers who } \\
\text { have demand requirements. Here, management of electric } \\
\text { charging systems and be both a source of supply and demand. }\end{array}$ \\
\hline
\end{tabular}




\begin{tabular}{|c|l|l|}
\hline $\begin{array}{c}\text { Transactive } \\
\text { (BMS3D) }\end{array}$ & 6. Vehicle-to-Grid (BMS3D-1) & $\begin{array}{l}\text { This business model represents a 2-Way V2G system where the } \\
\text { customer charges the vehicle based on need and transactive } \\
\text { pricing. The vehicle is also capable of communicating with the grid } \\
\text { and selling back unneeded electricity stored in the vehicles battery. } \\
\text { Software estimating vehicle usage needs over time is used to } \\
\text { optimize vehicle charge capacity and transactive revenue. }\end{array}$ \\
\hline
\end{tabular}

